A UTILIZATION-FOCUSED PROGRAM EVALUATION OF THE GRADUATE SAFETY PROGRAM AT UNIVERSITY OF CENTRAL MISSOURI

A Dissertation

presented to the

Faculty of the Graduate School

University of Missouri - Columbia

In Partial Fulfillment

of the Requirements for the Degree of

Doctor of Education

By

TAMMY J. ALLEN, B.S., M.S.

Dr. Sandy Hutchinson, Dissertation Supervisor

DECEMBER 2014 
The undersigned, appointed by the dean of the Graduate School, have examined the dissertation entitled

\section{A UTILIZATION-FOCUSED PROGRAM EVALUATION OF THE GRADUATE SAFETY PROGRAM AT UNIVERSITY OF CENTRAL MISSOURI}

Presented by

Tammy J. Allen, a candidate for the degree of doctor of education, and hereby certify that, in their opinion, it is worthy of acceptance

Dr. Sandy Hutchinson, Dissertation Advisor

Dr. Barbara N. Martin

Dr. Doug Thomas

Dr. David Kreiner 


\section{ACKNOWLEDGEMENTS}

I would never have been able to finish my dissertation without the support and guidance of my committee members, support from my family, and help from friends. I would like to express my deepest gratitude to my advisor, Dr. Sandy Hutchinson, for her excellent guidance, caring, and coaching along the journey. I would like to thank Dr. David Kreiner for his assistance through the statistical analysis of the study. I would also like to thank Dr. Martin and Dr. Thomas for guiding my research and their willingness to participate in dissertation committee.

Finally, I would like to thank my husband, Pat Allen. He was always there offering encouragement and assisting with the home front duties to make this journey with me since we are a team. 


\section{TABLE OF CONTENTS}

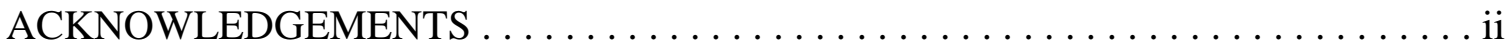

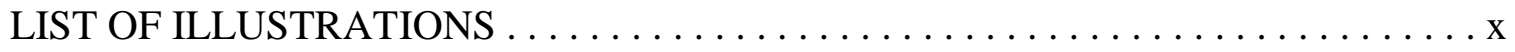

LIST OF TABLES $\ldots \ldots \ldots \ldots \ldots \ldots \ldots \ldots \ldots \ldots \ldots \ldots \ldots \ldots \ldots \ldots \ldots \ldots$

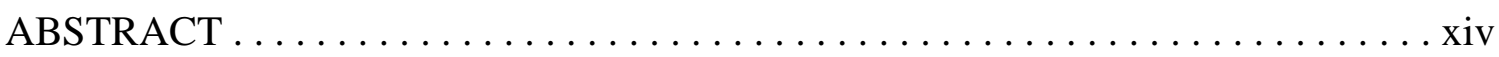

CHAPTER 1: INTRODUCTION TO THE STUDY $\ldots \ldots \ldots \ldots \ldots \ldots \ldots \ldots \ldots$

Background of the Study $\ldots \ldots \ldots \ldots \ldots \ldots \ldots \ldots \ldots \ldots$

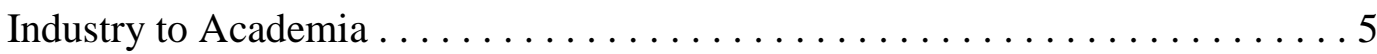

Problem Statement . . . . . . . . . . . . . . . . . . . . 6

Research Purpose $\ldots \ldots \ldots \ldots \ldots \ldots \ldots \ldots \ldots \ldots \ldots \ldots \ldots$

Research Questions ........................... 10

Conceptual Framework Guiding Study . . . . . . . . . . . . . 11

Design and Methods $\ldots \ldots \ldots \ldots \ldots \ldots \ldots \ldots \ldots \ldots \ldots \ldots \ldots \ldots$

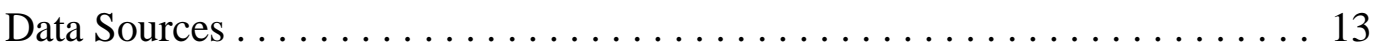

Rationale for Data Sources . . . . . . . . . . . . . . . . 14

Data Collection Methods ......................... 14

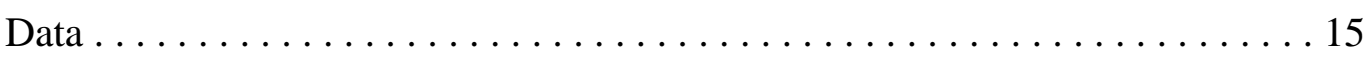

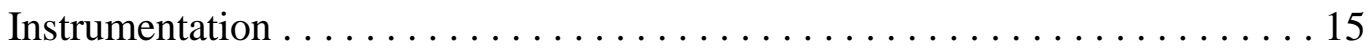

Assumptions . . . . . . . . . . . . . . . . . . 16

Definitions of Key Terms $\ldots \ldots \ldots \ldots \ldots \ldots \ldots \ldots \ldots \ldots \ldots \ldots$

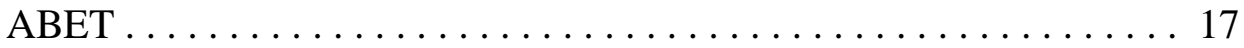

Amer. Conference of Governmental Industrial Hygienists (ACGIH) . 17

American Industrial Hygiene Association (AIHA) . . . . . . . . 18 
American Society of Safety Engineers (ASSE) . . . . . . . . . . . 19

Associate Safety Professional (ASP) . . . . . . . . . . . . . . . . 19

Board of Certified Safety Professionals (BCSP) . . . . . . . . . 20

Centers for Disease Control and Prevention (CDC) . . . . . . . . 21

Certified Industrial Hygienist $(\mathrm{CIH}) \ldots \ldots \ldots \ldots \ldots \ldots \ldots \ldots \ldots \ldots$

Certified Safety Professional $(\mathrm{CSP}) \ldots \ldots \ldots \ldots \ldots \ldots \ldots \ldots \ldots$

Constituent Groups . . . . . . . . . . . . . . . . . . . . 23

Higher Learning Commission $\ldots \ldots \ldots \ldots \ldots \ldots \ldots \ldots \ldots \ldots$

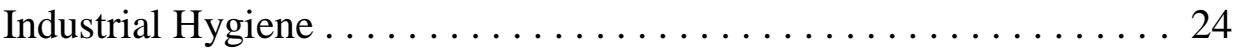

Industrial hygiene code of ethics $\ldots \ldots \ldots \ldots \ldots \ldots \ldots \ldots \ldots$

National Institute for Occupational Safety and Health (NIOSH) . . . . 25

Occupational Exposure Limits $(\mathrm{OEL}) \ldots \ldots \ldots \ldots \ldots \ldots \ldots \ldots$

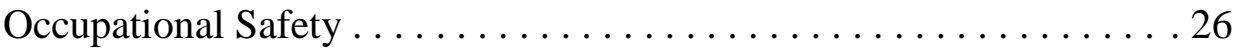

Occupational Safety and Health Act (OSH Act) .......... 26

Occupational Safety and Health Administration (OSHA) . . . . . . . 27

Program Evaluation $\ldots \ldots \ldots \ldots \ldots \ldots \ldots \ldots \ldots \ldots \ldots \ldots$

Recommended Exposure Limits $(\mathrm{REL}) \ldots \ldots \ldots \ldots \ldots \ldots \ldots . \ldots . \ldots 27$

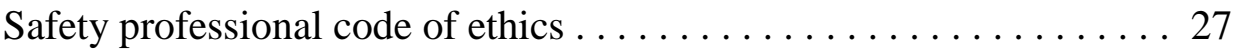

Threshold limit values $(\mathrm{TLV}) \ldots \ldots \ldots \ldots \ldots \ldots \ldots \ldots \ldots$

Utilization-focused program evaluation $\ldots \ldots \ldots \ldots \ldots \ldots \ldots . \ldots 28$

Limitations of the Study . . . . . . . . . . . . . . . . . . . . . . . . 29

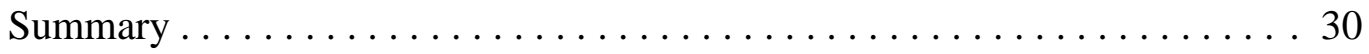


CHAPTER 2: LITERATURE REVIEW $\ldots \ldots \ldots \ldots \ldots \ldots \ldots \ldots \ldots \ldots \ldots$

Program Evaluation $\ldots \ldots \ldots \ldots \ldots \ldots \ldots \ldots \ldots \ldots \ldots \ldots \ldots$

Definition of Program Evaluation $\ldots \ldots \ldots \ldots \ldots \ldots \ldots \ldots \ldots \ldots \ldots \ldots \ldots \ldots$

Utilization-Based Focused Evaluation $\ldots \ldots \ldots \ldots \ldots \ldots \ldots$

University of Central Missouri Program Evaluation . . . . . . . . . . 41

University of Central Missouri’s M. S. Occupational Safety Mgmt. Program

Review of graduate safety degree history $\ldots \ldots \ldots \ldots \ldots \ldots$

Program Evaluations from other Universities and UCM's MS-IH Program

University of Pittsburgh $\ldots \ldots \ldots \ldots \ldots \ldots \ldots \ldots \ldots$

Murray State University $\ldots \ldots \ldots \ldots \ldots \ldots \ldots \ldots \ldots \ldots \ldots \ldots \ldots$

Stevens Institute of Technology $\ldots \ldots \ldots \ldots \ldots \ldots \ldots \ldots \ldots \ldots$

Capella University . . . . . . . . . . . . . . . . 53

UCM-Industrial Hygiene Program $\ldots \ldots \ldots \ldots \ldots \ldots \ldots \ldots$

Graduate degrees in Occupational Safety Management (OSM) . . . . . . . 55

Indiana State University $\ldots \ldots \ldots \ldots \ldots \ldots \ldots \ldots \ldots \ldots \ldots \ldots \ldots \ldots \ldots$

Tulane University $\ldots \ldots \ldots \ldots \ldots \ldots \ldots \ldots \ldots \ldots \ldots \ldots \ldots \ldots \ldots \ldots \ldots$

Oakland University $\ldots \ldots \ldots \ldots \ldots \ldots \ldots \ldots \ldots \ldots \ldots \ldots \ldots \ldots \ldots \ldots$

Keene State College. . . . . . . . . . . . . . . . . . . 56

Columbia Southern University . . . . . . . . . . . . . 56

Murray State University ..................... 56

University of Alabama - Birmingham .............. 57

History of Occupational Safety Management . . . . . . . . . . . 57

Historical Perspective $\ldots \ldots \ldots \ldots \ldots \ldots \ldots \ldots \ldots \ldots \ldots . \ldots . \ldots$ 
Background of Occupational Safety . . . . . . . . . . . . 58

Specific Industry Safety Efforts . . . . . . . . . . . . . . 59

Fire Incidents $\ldots \ldots \ldots \ldots \ldots \ldots \ldots \ldots \ldots \ldots \ldots \ldots \ldots \ldots \ldots \ldots \ldots \ldots$

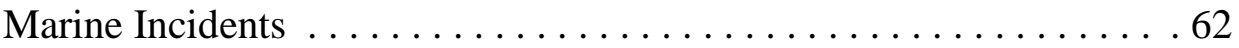

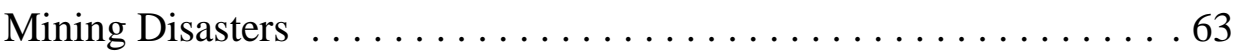

Construction Safety $\ldots \ldots \ldots \ldots \ldots \ldots \ldots \ldots \ldots \ldots \ldots \ldots \ldots \ldots$

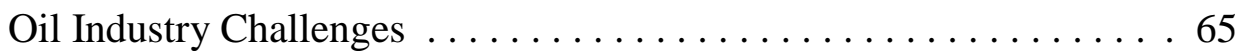

Workplace Injuries $\ldots \ldots \ldots \ldots \ldots \ldots \ldots \ldots \ldots \ldots \ldots \ldots \ldots \ldots \ldots \ldots \ldots$

Establishment of OSHA $\ldots \ldots \ldots \ldots \ldots \ldots \ldots \ldots \ldots \ldots$

OSHA's response to manmade and natural disasters $\ldots \ldots \ldots \ldots \ldots \ldots$

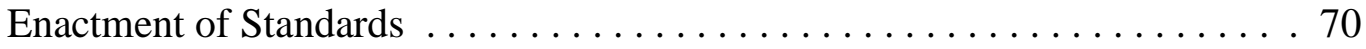

General Hazards $\ldots \ldots \ldots \ldots \ldots \ldots \ldots \ldots \ldots \ldots \ldots \ldots$

Physical Hazards . . . . . . . . . . . . . . . . . . 72

Chemical Hazards . . . . . . . . . . . . . . . . . . . . . . 74

Ergonomic Hazards . . . . . . . . . . . . . . . . . . 76

Biohazards . . . . . . . . . . . . . . . . . . 77

Establishment of OSHA Training Institute/Summits $\ldots \ldots \ldots \ldots \ldots 77$

Establishment of OSHA State Plans . . . . . . . . . . . . . 78

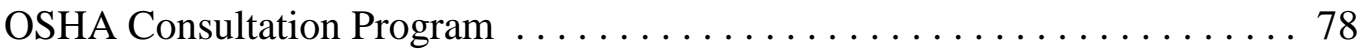

Catastrophic Incidents leading to new standards $\ldots \ldots \ldots \ldots \ldots \ldots$

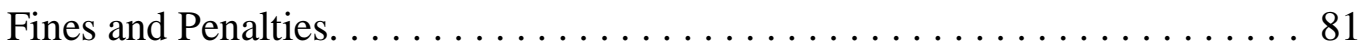

Court Rulings and Executive Orders $\ldots \ldots \ldots \ldots \ldots \ldots \ldots \ldots \ldots \ldots$

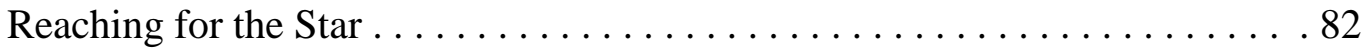




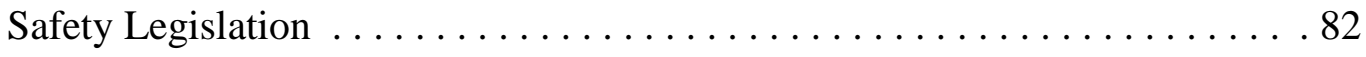

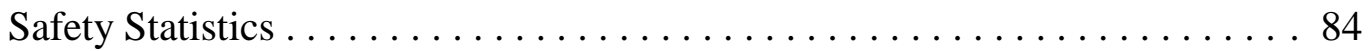

Workers' Compensation .............................. 84

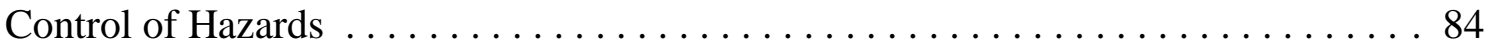

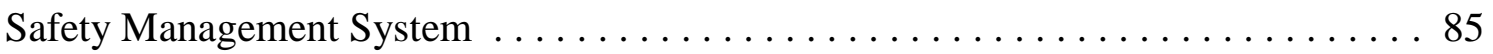

Professional Organizations $\ldots \ldots \ldots \ldots \ldots \ldots \ldots \ldots \ldots \ldots \ldots \ldots \ldots \ldots$

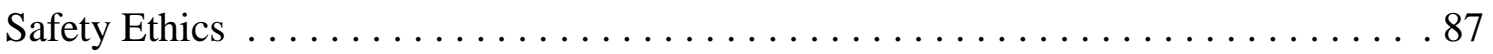

Safety Leadership $\ldots \ldots \ldots \ldots \ldots \ldots \ldots \ldots \ldots \ldots \ldots \ldots \ldots \ldots \ldots$

Preparing Graduates for the Future $\ldots \ldots \ldots \ldots \ldots \ldots \ldots \ldots \ldots \ldots . . \ldots 0$

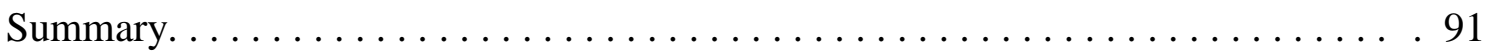

CHAPTER THREE: RESEARCH DESIGN AND METHODOLOGY $\ldots \ldots \ldots . .92$

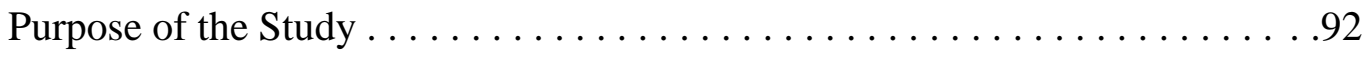

Research Design ...................................93

Population and Representative Sample ...................... 95

Research Questions ..................................96

Sampling Procedures: Design and Methods . . . . . . . . . . . . . . . . 97

Rationale for Quantitative Design ........................... 97

Data Sources $\ldots \ldots \ldots \ldots \ldots \ldots \ldots \ldots \ldots \ldots \ldots \ldots$

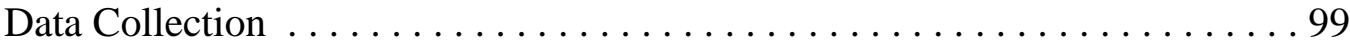

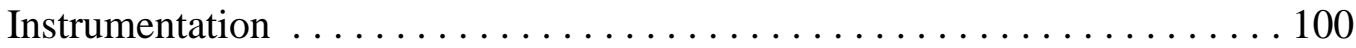

Data Analysis Procedures ............................... 101

Quality Control Measures ............................ 106 
Study Limitations . . . . . . . . . . . . . . . . . . . . . . . . . . . . 107

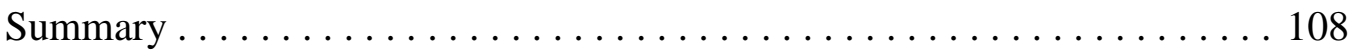

CHAPTER FOUR: RESULTS $\ldots \ldots \ldots \ldots \ldots \ldots \ldots \ldots \ldots \ldots \ldots \ldots$

Review of Historical Documents $\ldots \ldots \ldots \ldots \ldots \ldots \ldots \ldots \ldots \ldots \ldots$

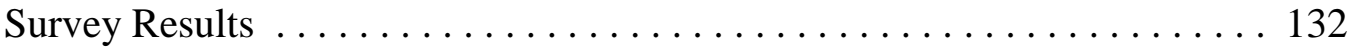

Research Questions: Analysis of Data ...................... 144

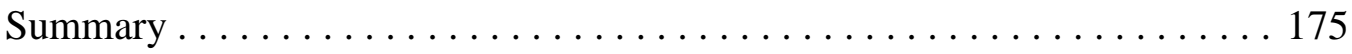

CHAPTER FIVE: DISCUSSION AND CONCLUSIONS . . . . . . . . . . . . 177

Research Questions Answered ........................... 177

Discussion ................................... 181

Review of Historical Documents . . . . . . . . . . . . . . . . . 192

Limitations ........................................ 197

Implications for Practice . . . . . . . . . . . . . . . . . . . . . 198

Suggestions for Future Research . . . . . . . . . . . . . . . . . . 202

Conclusion ...................................204

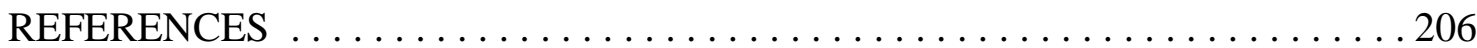

\section{APPENDICES:}

Appendix A: Cover Letter to Alumni requesting their Particip.in Survey ... 217 Appendix B: Informed Consent to Participate in Survey ............. 218 
Appendix C: Google Forms Online Survey sent to Alumni . . . . . . . . . 219

Appendix D: Mizzou IRB Approval Form . . . . . . . . . . . . 231

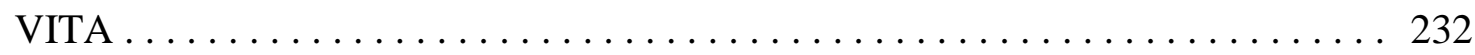




\section{LIST OF ILLUSTRATIONS}

Figure $1 \quad$ Total Graduates by Year $(B S$, MS \& Ed Spec) $\ldots \ldots \ldots \ldots \ldots \ldots$

Figure $2 \quad$ MS - Safety Graduates by Year. . . . . . . . . . . . . 131

Figure $3 \quad$ Number of Alumni who Received Online Survey . . . . . . . . . 133

Figure $4 \quad$ Demographic Distribution by Age $\ldots \ldots \ldots \ldots \ldots \ldots \ldots \ldots \ldots$

Figure $5 \quad$ Instruction Method for Alumni $\ldots \ldots \ldots \ldots \ldots \ldots \ldots \ldots$

Figure 6 Time to Obtain Employment after Graduation . . . . . . . . . . 136

Figure $7 \quad$ Years of Professional Work Experience for Alumni . . . . . . . . . 137

Figure $8 \quad$ Primary Area of Practice - Current Job and Career . . . . . . . . 139

Figure $9 \quad$ Annual Salary reported by Alumni $\ldots \ldots \ldots \ldots \ldots \ldots \ldots$

Figure $10 \quad$ OSHE Professionals in Alumni's Workplace .............. 141

Figure 11 Source of Information about Safety Program at UCM (Question 19) . 142

Figure 12 Breakdown of "Other" Responses from Alumni (Question 19) . . . . . 143

Figure 13 Common Approach in Resolving Occupational Safety Issues . . . . . . 143

Figure 14 Important Courses and Subjects for Safety Students (Question 24) . . .147

Figure $15 \quad$ Essential Skills/Knowledge in Alumni’s Job (Question 25) . . . . . . . 156

Figure 16 Instrument Usage in Alumni's Job (Question 26) . . . . . . . 162

Figure 17 Satisfaction with Safety Program by Eras of Time (Question 7). . . . 167 
Figure 18 Overall Satisfaction with Preparation by 7 Skill Sets (Question 22). . 168

Figure 19 Quality of Education by Courses (Question 23) . . . . . . . . 171 


\section{LIST OF TABLES}

Table 1 Timeline/Requirements/Nomenclature . . . . . . . . . . . . . . . . . 47-49

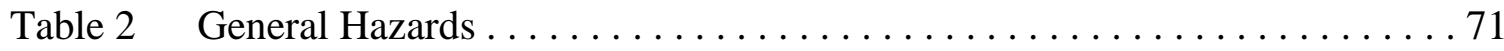

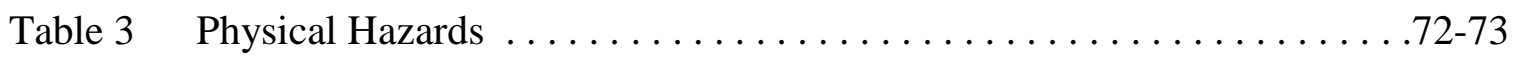

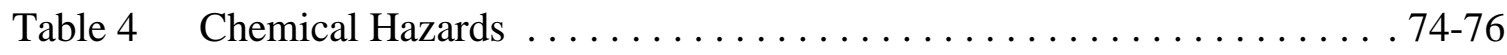

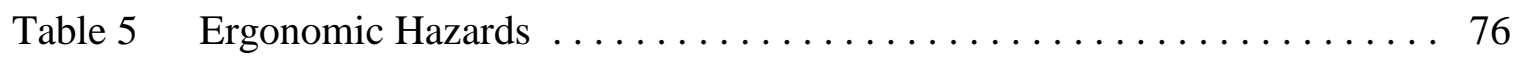

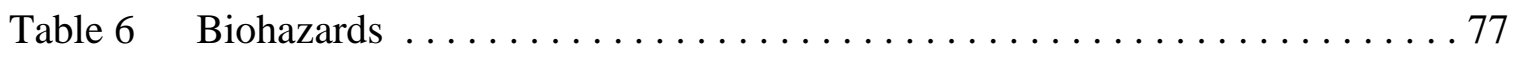

Table 7 Research Question/Survey Questions/Statistical Methods . . . . . . . . 103-105

Table 8 Leadership and Department Name Modifications . . . . . . . . . . . 112-113

Table 9 Curriculum for the Safety degree $\ldots \ldots \ldots \ldots \ldots \ldots \ldots \ldots \ldots \ldots \ldots \ldots$ 115-118

Table 10 Curriculum for each Industrial Safety degree . . . . . . . . . . . . 119-124

Table 11 Curriculum for Safety Management degree . . . . . . . . . . . . . 125-127

Table 12 Curriculum for each Occupational Safety Management degree . . . . . 127-129

Table 13 Number of Alumni by Time Period \& Number that rec'd the Survey. . . . 134

Table 14 Alumni Attainment of Certification .................. 138

Table 15 Importance of Specific Courses/Subjects for Safety Students (Q 24) . 145-146

Table 16 Kruskal-Wallis Test - Important Courses and Subjects for Students . 148-150

Table 17 Importance of Safety Skill Sets Related to Safety Jobs (Q 21) . . . . 151-152

Table 18 ANOVA - Importance of 8 Skill Sets (Total) in Alumni's Safety Job . . 152 
Table 198 Skill Sets needs in Practice of Safety (Question 21) . . . . . . . . . . 153

Table 20 Skill/Knowledge Sets Related to Safety Job (Question 25) . . . . . . . 154-155

Table 21 Kruskal-Wallis Test - Skills/Knowledge Sets (Question 25) . . . . . 157-159

Table 22 Instrument Usage in Current or Most Recent Job (Question 26) . . . . 160-162

Table 23 Kruskal-Wallis Test - Instrument Usage (Question 26). . . . . . . . 163-165

Table 24 Satisfaction with Preparation by Department (Question 7) . . . . . . 166

Table 25 Satisfaction with Preparation by Dept. by 7 Skill Sets (Question 22) . . . . 169

Table 26 Quality of Education in Academic Program-Percent.-Likert (Q23). . 169-170

Table 27 Kruskal-Wallis Test-Quality of Education-19 Courses (Q 23). . . . . 172-174 


\title{
A UTILIZATION-FOCUSED PROGRAM EVALUATION OF THE \\ GRADUATE SAFETY PROGRAM AT UNIVERSITY OF CENTRAL MISSOURI
}

\author{
Tammy J. Allen \\ Dr. Sandy Hutchinson, Dissertation Supervisor
}

\begin{abstract}
Program assessment has historically and continues to be a critical element for academic programs to ensure continuous quality improvement of their programs. In the recent years, occupational safety, health and environmental programs have embraced assessment by external groups to validate their internal assessments. One external group offers ABET accreditation to academia programs vetting their content and effectiveness in achieving desired outcomes. The University of Central Missouri, a mid-sized school in Western Missouri has produced approximately 1,000 alumni with graduate degrees in occupational safety management. The graduate program is within the Department of Safety Sciences in the College of Health, Science and Technology. A comprehensive evaluation was conducted with the goal to assess what alumni of the program think of their preparation by the Department, as well as their perspective on what courses and skills an entry level safety professional should have upon graduation. The assessment instruments used in this research study included an online survey to alumni with a review of historical documents by the researcher. The results reflected alumni believe their preparation by the Department for their careers in the safety profession was above average. The practitioner skills and courses far outweighed the research based courses on importance from alumni. The methodologies used in this research are applicable for use
\end{abstract}


by faculty from other academic departments or for other programs within the Department of Safety Sciences. The graduate occupational safety management program has maintained quality and sustainability across the forty four year tenure. The program has gone through many degree nomenclatures, curriculum changes, faculty and administration, but has stood the test of time. There have been peaks and valleys in the student numbers, but fortunately 2014 shows signs of continuing to climb to another peak in declared majors with more international students involved than ever before. 


\section{CHAPTER ONE}

\section{INTRODUCTION TO THE STUDY}

Safety is a continuous journey, not a final destination (Fitzroy, 2003). In our ever-changing, dynamic workplaces today safety is often stated to be the priority for the company. Many companies use slogans such as "Safety First". So, what is Safety? It has been defined to be the control of recognized hazards to achieve an acceptable level of risk (Long, 2013). This can take the form of being protected from the event or from exposure to something that causes health or economic losses. It can include protection of people or of possessions. Some have defined safety as simply the absence of harm (Quinlan \& Plog, 2012; Long, 2013). Others have defined it as something that is critical for most people in deciding where they go, what they buy and what they do (Long, 2013). It is a different thing for different people, oftentimes based on their personality, knowledge and nature. As a safety manager, depending on the stage of a program being implemented or modified, you may be managing employee's perceptions of management's commitment, behaviors, or work practices of employees. At the same time, human factor issues may not be at the forefront at all, equipment failure opportunities will be the focus (Long, 2013). Even Helen Keller once said: "Security (safety) is mostly a superstition. It does not exist in nature, nor do the children of men as a whole experience it. Avoiding danger is no safer in the long run than outright exposure. Life is either a daring adventure or nothing." (Keller, 1957, p. 17)

It has also been said that safety is something that happens between someone's ears, not something one holds in their hands (Long, 2013). So, is safety something one does, like 
drive safely? What does that mean? Is safe something that a person is? A person promises to be safe; that will sound good, but what does it really mean? Is safety something a person takes? They take safety precautions, take safety seriously? Is safety something a person ensures? They ensure the health and safety of others, how do they do that? Is safety a place they go to? The children were taken to safety, is it really safe? Is safety a more short-term or external physical thing as opposed to health? Is safety a real thing or something one feels? It looks safe, or does it feel safe? Is safety something one would think or actually are? I'm worried about their safety, but are they really safe here? Is safety something that just exists when one is not in danger? Is the workplace safe because it is hazard free? Are safety and danger the things that are mutually exclusive or is protection from danger called risk management? Do people have protection so it will be safe? Is it something that is always $100 \%$ guaranteed as some Zero Harm proponents would believe? What about when something is called "the safest" or "the safest way"? Is that a perception, has worked before or based on fact and data? Is safety first or should it be just part of everything people do (Long, 2013)?

The workers are a company's most valuable asset. Safety and health issues were being identified as far back as prehistoric times, but not many of those hazards were eliminated or mitigated at that time. And, for some, it is still problematic today. For instance, locally there is a facility exposing their employees to lead today which was identified as a significant health hazard as far back as 6500 B.C. In the 18th, 19th, and 20th centuries the worst outbreaks of lead poisoning of adults were occupational in origin. It became common knowledge that to work in an industry where you handled lead was certain to make you sick or worse. These workers absorbed lead from 
inhalation of fine lead dust or fumes, contamination of food eaten at the workplace, or by absorption through the skin. Charles Dickens describes in his essay "Star of the East" the horrible effects of lead poisoning on women who work in London's infamous white lead mills. Benjamin Franklin in 1763 wrote about the "dry gripes" (colic) and "dangles" (wrist drop) which affected tinkers, painters, and typesetters (DiNardi, 2007; Quinlan \& Plog, 2012). Lead's hazards to the reproductive process have been known for at least a century. British factory inspectors at the turn of the 20th century noted that women who were exposed to lead through working in the ceramic industry tended to be barren and that children who were born to those women were often short-lived. In most western countries during the 1930s through the 1970s, awareness among health workers was associated with more lead poisoning cases being reported and laws protecting workers were being enacted (DiNardi, 2007). Lead exposure is much more hazardous to children due to their brains still in the formative stages and it is the target organ that is affected the most. This exposure can be from residual lead dust their parents bring home from work on their clothing or lead tailings from mines spread on dirt roads. Studies reflect children who live in those "hot spots" throughout our country have reduced IQ scores. Even when the levels are far below the Centers for Disease Control (CDC) allowable limit, the children are affected. This indicates an adverse effect on children who have a blood-lead level substantially below the CDC standard, suggesting the need for more stringent regulations. The findings emphasize the very real dangers associated with low-level exposures (Canfield, 2007). 


\section{Background of Study}

The history of the safety and health movement is important to understanding the roots and future of safety for future generations. In prehistoric times, the Babylonians and Greeks dealt with health issues such as loss of eyesight and lead poisoning. Mercury exposure was experienced during this same time period by the Romans. Other health issues were identified during the $18^{\text {th }}$ century specific to the manufacturing of cotton (brown lung), wool, metal, wood and leather goods. Even after much attention was brought to silica exposure back in 1930, it continues to be an issue today. Miners continue to experience coal worker's pneumoconiosis (black lung) disease after many years of awareness of the dreadful outcome of poor ventilation in mines (Quinlan \& Plog, 2012).

The safety business has some strong economic drivers. The most recent "Injury Facts" for 2012 from the National Safety Council (NSC) detailed reporting on the incidence and costs of unintentional injuries and deaths. In 2010 there were an estimated 5 million "medically consulted injuries" and 3,783 deaths that occurred in the workplace. The total cost of work-related deaths and injuries was $\$ 176.9$ billion. The largest component was not the medical costs, it was wage and productivity losses ( $\$ 86.8$ billion). Medical costs were next at $\$ 43.2$ billion, and then administrative expenses of $\$ 32$ billion. The average cost of a medically consulted injury was $\$ 37,000$. The cost per worker of workplace injuries was $\$ 1,300$, meaning that each worker in America must produce $\$ 1,300$ of goods or services just to offset the cost of workplace injuries. An estimated 60 million days of work were lost in 2010 due to injuries and deaths (with deaths counted at 150 days for reasons that are not entirely clear); 50 million more days will have been 
missed in future years due to injuries that took place in 2010. A workplace injury takes place every six seconds, which means 96,000 each week. The incidence rate of occupational injury and illness decreased $3 \%$ in 2010, continuing a steady trend over the last several decades (NSC, 2014).

The total number of contractors fatally injured on the job in 2012 was 715 fatalities. Contract workers accounted for over 15 percent of all fatal work injuries in 2012. The number of fatal work-related roadway incidents in 2012 was 1,153 cases. The final 2012 total represented a 5-percent increase over the final 2011 count. The number of fatal work injuries involving Hispanic workers was 748 cases. That total was about the same as the 2011 total (749), but the fatality rate for Hispanic workers declined to 3.7 per 100,000 full time equivalent (FTE) workers in 2012, down from 4.0 in 2011. Workrelated suicides had a total of 249 . Workplace homicides in 2012 were 475 cases. In the private transportation and warehousing sector, fatal injuries of 44 cases were found in the truck transportation sector. There were 806 cases in the private construction sector. The 2012 total was an increase of 9 percent over the 2011 total and represented the first increase in fatal work injuries in private construction since 2006 (BLS, 2014).

\section{Industry to Academia}

Considering the high cost of hiring and training skilled workers, employers are finding low turnover and productive employees are their greatest asset to their operations. With the global economy putting competitiveness paramount, their employees are their greatest asset. A key component to this shift in public opinion brought about the development of academic programs in occupational safety and health (Zanko \& Dawson, 2012). These programs produced individuals trained to anticipate, recognize, evaluate, 
and control workplace hazards (Quinlan \& Plog, 2012). Among the programs that developed were occupational safety management programs such as the one at the University of Central Missouri, in the Department of Safety Sciences.

This dissertation is a utilization-focused program evaluation (Patton, 1997; Patton, 2008) of the graduate Occupational Safety Management (MS-OSM) program at the University of Central Missouri (UCM). The goal of this evaluation is to provide the Department of Safety Sciences within the School of Environmental, Physical and Applied Sciences with valuable information to make improvements to the curriculum and program as needed. The graduate program is now offered completely online for students desiring this format, which provides a competitive advantage with other universities still in the infancy of offering their program in this format. However; it is vital to the success of the continued growth of the program to assure the strengths are built upon and the weaknesses are identified and addressed to move forward in the competitive academia environment.

\section{Problem Statement}

Since 1970, the University of Central Missouri’s (UCM) occupational safety management program has produced over 1,000 alumni. During this 44 year time period, no comprehensive assessment of the program has been conducted by the department. Faculty and administrators are not certain how well the program has prepared entry level safety management students for employment. The occupational safety management program is not accredited by ABET (2013a). ABET, previously known as the Accreditation Board for Engineering and Technology, is the accrediting body for safety and industrial hygiene academic programs. UCM's graduate Industrial Hygiene program 
and undergraduate Occupational Safety and Health programs were awarded accreditation in 1998, 2004 and a subsequent renewal in Fall 2010 (ABET, 2013b). ABET requires programs to evaluate themselves on a continuing basis. If programs do not do selfevaluations, they are in danger of losing their accreditation.

Academic departments are under pressure to demonstrate that they offer a quality product. The cost of attending college continues to rise (Archibald \& Feldman, 2008). With the rising cost of college tuition, universities are focusing increased efforts on student recruiting. Parents, guardians, and students are more knowledgeable and more demanding in their selection of which college to attend. In addition, credit hours generated by a department and per each faculty member are closely watched by university administrators. The Department of Safety Sciences must provide evidence that it produces graduates who are adequately trained to be successful in their first job and have the knowledge of how to continue improving their skills to be successful long-term. The information collected from this research will be the baseline for an assessment activity that will be ongoing within the School of Environmental, Physical and Applied Sciences for the Occupational Safety Management graduate program. There are activities including pre-exams, exit exams, discussions with advisory boards and department retreats during which each course is evaluated for content. The information collected in this research study will help the Department of Safety Sciences make informed decisions for program planning and program improvement. Continual improvement of the department's academic programs is critical if the Department of Safety Sciences aspires to remain viable in this rapidly changing field (Thomas, 2001). 


\section{Research Purpose}

This research will provide valuable information concerning the quality of the UCM graduate program in occupational safety management since 1970 , the first year alumni graduated from the program. The research will also indicate current strengths and weaknesses of the occupational safety management program. The information collected can be utilized by: a) Department of Safety Sciences; b) the School of Environmental, Physical and Applied Sciences; c) the Dean of the College of Health, Science and Technology; d) other administrators of UCM; and e) constituents of the department in deciding what changes are needed to sustain and improve the quality of the occupational safety management academic program. The research methodologies can serve as a model for other academic departments to use in their program assessment activities. The methodologies used in this research are not specific for OSM program assessments. Faculty for any academic program could use these techniques, modifying where necessary to better fit their own needs.

Development of academic programs in industrial safety and industrial hygiene were foundational underpinnings to the evolving improvements in workplace conditions. A regional university in West Central Missouri, UCM developed both safety and industrial hygiene programs starting in the late 1960s through the early 1970s (Patterson, 1974). The focus of this research study is a comprehensive assessment of the occupational safety management program at the University of Central Missouri.

Assessment of the Occupational Safety Management program within the Department of Safety Sciences academic programs is being strongly encouraged from both internal and external review organizations such as ABET (2013b), and the National 
Institute for Occupational Safety and Health (2013). The OSM program is available in both live, online and hybrid versions and bringing in a notable amount of revenue into the department.

Information gleaned from the proposed research will be shared with all constituents of the occupational safety management program at UCM including faculty, advisory board members, students, alumni, and other interested parties. It will also be used for external review organizations, including ABET. This information will also be available in publications and on the UCM website, hence assuring that all constituents have access to it.

Specific issues investigated in this research include alumni satisfaction with the preparation for their career in occupational safety management. It will also assess the quality of the training by the department in nineteen subject areas. This will enable the researcher to assess if a trend exists in alumni opinions about the quality of the occupational safety management program from the early 1970 s to the current time. Other questions will assess alumni opinions of what knowledge and skills are needed by occupational safety management graduates entering the current job market. This will help the faculty determine if the most important knowledge and skills are currently included in the program. Finally, information will be collected on the career paths of graduates, including how long it took them to obtain employment following graduation, whether they obtained certification, how many other OSHE professionals they work with and what percentage of time they spend in the primary areas of the profession.

The graduate degree program in Occupational Safety Management has been in existence since 1970 and has never had a full program evaluation conducted with 
approximately 1,000 alumni. The information obtained from this research will attempt to include all of the alumni from this degree program since its beginning. The intention or purpose is for strengths, as well as weaknesses, to be identified to be utilized to strive for continuous improvement in the course offerings and curriculum. The ultimate stakeholders for this program evaluation will be our future students but the primary intended users (Patton, 2008) of the evaluation will be the faculty; the Department Chair of the School of Environmental, Physical and Applied Sciences; and the Dean of the College of Health, Science and Technology. The university, as a whole, will be the beneficial stakeholders of any improvements and increased participants in the program, as well as increased job security for all faculty members within our home department. With budget cuts continuing, the continued improvement and success of our programs is in the best interest of all faculty and staff. Tenure is of no value if the program in which you teach is eliminated. The Missouri Department of Higher Education continues to evaluate programs and determine their longevity solely on the number of graduates. Based on this evaluation, it is critical to recruit and retain students in our programs more than ever.

\section{Research Questions}

The following research questions will guide this study:

1. What courses do alumni view as most important for the safety management graduate students to take as part of their curricular studies?

2. What knowledge and skills do alumni view as critical for entry level safety professionals in the workplace? 
3. How has the overall satisfaction of alumni changed as far as career preparation since the Occupational Safety Management graduate program began in 1970?

\section{Conceptual Framework Guiding Study}

When conducting a utilization-focused evaluation, the first priority is to identify the primary intended users known as the stakeholders (Patton, 2008). Patton (1997) suggested that many assessments are conducted but most of them are never used to improve the program being evaluated. It is the belief of the researcher that the information gathered will be used to enhance the existing graduate Occupational Safety Management program by using the information collected to make necessary and desirable changes. This assessment will help guide the faculty, college administration, and the occupational safety management program advisory board in making informed changes. The research study to be conducted is a program assessment of an occupational safety management academic program. Program assessment has been around for decades but, according to Patton (1997), matured in the 1960s due to the growth of large government programs. Patton also noted that starting in the late 1890 s, education has been a subject for assessment.

The conceptual underpinnings for this study are based in the concepts of program evaluation and look at academic program assessment (Patton, 1997). Greene (1988) defines stakeholders of utilization-focused program assessments as: a) people who have decision authority over the program such as the advisory boards over the graduate programs; b) people who have direct responsibility for the program, such as the Dean and Department Chair of the program; c) people who are the intended beneficiaries of the program, their families, and their communities, such as the students in the program; and 
d) people disadvantaged by the program, as in lost funding opportunities, such as lost grants or scholarships for students due to credibility loss. Program assessments have been used in academia and fit the research to be conducted in this study. The desire to identify opportunities and improve the program through this assessment is important to me due to my position as a faculty member in the department. After working in industry for thirty-one years as a health and safety professional, my goal is to assure we are preparing our alumni to enter the workplaces with the most valuable information needed to be successful and effective. Our valuable workers across the world are depending on safety and health professionals to assist in making their workplaces safer.

\section{Design and Methods}

Evaluating the occupational safety management program in the School of Environmental, Physical and Applied Sciences at UCM will entail the quantitative research method. Prior to the development of the survey instrument, input was obtained from faculty and administrative officials of the College of Health, Science and Technology (Hatch, 2002). The purpose of input was to determine the type of information desired by departmental and college personnel. The primary intended users of the evaluation will be faculty so their input in the survey instrument is critical in making the first step in getting their "buy-in" to the process. Getting them on board from the beginning is the foundational building block of a utilization-focused program evaluation (Patton, 2008). When program assessments are conducted, there are political considerations and personal factors of the stakeholders that are critical to utilizationfocused evaluations. The personal factors represent: (a) leadership, (b) interest, (c) enthusiasm, (d) determination, (e) commitment, (f) assertiveness, and (g) caring of 
specific, individual people. These are people who actively seek information to learn, make judgments, get better at what they do, and reduce decision uncertainties. The personal factors perform a critical role in defining how much influence the evaluation will have (Cronbach, 1980; Patton, 2008). Feedback from department chair, faculty and undergraduate students formed the framework of the questionnaire survey that was administered to alumni via an on-line survey within Google forms.

\section{Data Sources}

The population for this study was approximately 1,000 alumni who have graduated from the Department of Safety Sciences since 1970 with a Master's degree in Occupational Safety Management. This included alumni who earned their degrees from 1970 through graduates who earned their degrees in 2014. This group of individuals represents one of the largest populations of occupational safety management alumni for any university in the United States. The sample was the number of alumni the researcher will be able to locate and contact using available databases. This will include the list of graduates from the UCM Alumni office. If they do not have contact information for the alumni on the list, the Board of Certified Safety Professionals and American Society of Safety Engineers organizations have databases of members and emeritus members that would have additional contact email addresses. As a last resort, searches on Google and other social media was conducted by the researcher to ascertain an email contact address. 


\section{Rationale for Data Sources}

The information from faculty and administration will be utilized to develop the survey instrument to assure the information collected was beneficial to the needs of the department. It was critical for the faculty to be involved in the design of the survey instrument since this same faculty will receive the results of the survey. They could be called upon by the Department Chair to make changes in their curriculum based on the survey results. With the OSM program of study being offered on campus, online, hybrid and at satellite locations throughout the 44 year period of this study; several parts of the survey instrument was challenging to develop. The quantitative data from alumni since 1970 were instrumental in curriculum evaluations and improvement for the program since no assessment had ever been conducted for the program. The survey instrument encompassed demographic data, and graduation date to correlate with the evolution of the program.

\section{Data Collection Methods}

The survey of alumni was collected electronically using an email link within Google forms. Initial discussions with faculty on the survey instrument determined email communication resulted in better feedback per the department chair. This mechanism of communication did produce an acceptable outcome. A second type of assessment technique for this study was a review of historical documents generated by or about the Department of Safety Sciences. Documents reviewed included minutes of department meetings and reports from internal reviews of the department. Two primary locations for documents of this type were the department files and the UCM archives. Results of this research will be provided to the faculty and administrators of the Department of Safety 
Sciences, entities that are responsible for the curriculum used in the M.S. Occupational Safety Management program. This information can then be used by these groups to make modifications to existing curricula. The same information will be provided to internal and external review boards and to all other constituents via publications in professional journals, articles in the department's newsletter and posting information on the department webpage. Internal and external review committees strongly encourage, and in some cases require, program assessment. The information collected will help the department satisfy those review groups.

\section{Data}

The online survey of approximately 1,000 alumni (Fink, 2009) was administered following the input from faculty and administration of the college. Review of archival data through the alumni office was utilized to obtain information on the graduates. Additional information was utilized through organizations and networking/social media to ascertain email addresses of graduates of the program that are not registered with the alumni office. The review of archival data of curriculum changes through the safety sciences department was conducted concurrently by reviewing files and electronic departmental meeting notes to define a timeline of progression of the program from 1970 through 2014.

\section{Instrumentation}

The survey instrument was developed within Google forms (Fink, 2009). There were three steps in the survey instrument development process: (a) review and input from five undergrad students, (b) review and input from eight faculty members and the department chair, and (c) pilot study of undergraduate students taking the survey while being monitored for instant feedback on clarity. Following these reviews, feedback and 
pilot study, the survey instrument was administered via email to the 1,000 alumni. With approximately 1,000 alumni, to get $+/-3 \%$ confidence, 525 responses would be required; to get $+/-5 \%$ confidence, 285 responses would be required while $+/-10 \%$ confidence would only require 90 responses. It would definitely be best to have as close to 525 responses as possible. Multiple attempts were made to alumni to achieve this. The initial survey request was made with a one week response. This request was followed by a one week reminder with one additional one week reminder when the return rate was still below the $+/-3 \%$ confidence level.

\section{Assumptions}

Since participants in this study included graduates over a 44 year time span, some of the survey questions were more appropriate for some alumni than others. There had been changes in: (a) the curriculum, (b) the pre-requisites, (c) the faculty, and (d) credit hour requirements. The faculty in the early years of the OSM program was from primarily academia with public safety backgrounds. Since approximately 2009, all new faculty hired have industrial safety and industrial hygiene experience to bring to the classroom.

The researcher's knowledge with the occupational safety management program may help in the research, such as being familiar with where records are located in the department. It was helpful to have relationships with personnel in the registrar's office and the alumni office to ascertain the contact information to send out the surveys. Membership in the professional organizations allowed researcher access to their databases to get information on safety professionals who are UCM/CMSU alumni. 


\section{Definition of Key Terms}

For the purpose of this study the following terms were defined:

ABET: This organization is a non-profit and non-governmental accrediting agency for academic programs in the disciplines of applied science, computing, engineering, and engineering technology. ABET is a recognized accreditor in the United State by the Council for Higher Education Accreditation. ABET accreditation provides assurance that a college or university program meets the quality standards established by the profession for which the program prepares its students. ABET accredits postsecondary programs housed in degree-granting institution which have been recognized by national or regional institutional accreditation agencies or national education authorities worldwide. The type of accreditation the MS-OSM would apply for would be specialized academic

accreditation. Specialized academic accreditation would evaluate an individual program of study, rather than an institution as a whole. This type of accreditation is granted to a specific program at a variety of degree levels to include graduate programs.

Occupational safety and industrial hygiene are two of the academic disciplines for which ABET offers third party accreditation. ABET accredits over 550 colleges and universities, including almost 3,000 academic programs (ABET, 2014). American Conference of Governmental Industrial Hygienists $\left(A C G I H^{\circledR}\right)$ : The ACGIH has approximately 3,000 members located in numerous countries. They are best known for developing one type of occupational exposure criteria, Threshold Limit Values. $\quad \mathrm{ACGIH}^{\circledR}$ has been considered a well-respected organization by individuals in the industrial hygiene and occupational and environmental health and safety industry. What began as a limited membership base has grown to the all-encompassing Voting 
Member category of today. During this time, $\mathrm{ACGIH}^{\circledR}$ has grown and expanded without losing sight of its original goal - to encourage the interchange of experience among industrial hygiene workers and to collect and make accessible such information and data as might be of aid to them in the proper fulfillment of their duties. This original goal is reflected in both our current mission - the advancement of occupational and environmental health - and in our tagline: Defining the Science of Occupational and Environmental Health (American Conference of Governmental Industrial Hygienists, 2013).

American Industrial Hygiene Association (AIHA): AIHA is a professional association that started in 1939. It has over 10,000 members and has expanded to become an international association with members in over 40 countries. AIHA publishes one of the leading professional journals for industrial hygienists, The Journal of Occupational and Environmental Hygiene. AIHA is a nonprofit organization devoted to achieving and maintaining the highest professional standards for its members. More than half of 10,000 members are certified industrial hygienists (CIHs), and many hold other professional designations. AIHA administers comprehensive education programs that keep occupational and environmental health and safety (OEHS) professionals' current in the field of industrial hygiene. AIHA is one of the largest international associations serving OEHS professionals practicing industrial hygiene and is a resource for those in large corporations, small businesses and who work independently as consultants. Their mission is creating knowledge to protect worker health. Their vision is the elimination of workplace illnesses. Industrial hygienists anticipate health and safety concerns and design solutions to prevent them. They are the 
guardians of workplace safety, applying science to identify and solve health and safety problems. Industrial hygienists also unite management, workers and all segments of a company behind the common goal of health and safety (American Industrial Hygiene Association, 2013).

American Society of Safety Engineers (ASSE): An organization founded in 1911, the ASSE is the world's oldest professional safety society of safety individuals practicing in the field in all types of industries and service organizations. ASSE promotes the expertise, leadership and commitment of its members, while providing them with professional development, advocacy and standards development. It also sets the occupational safety, health and environmental community's standards for excellence and ethics. ASSE is a global association of occupational safety professionals representing more than 35,000 members worldwide. The Society is also a visible advocate for safety, health and environmental (SH\&E) professionals through proactive government affairs at the federal and state levels, and in member-led relationships with key federal safety and health agencies. Our members create safer work environments by preventing workplace fatalities, injuries and illnesses. Besides recording less lost time and lower workers' compensation costs, organizations with strong safety performance enjoy increased productivity, a better reputation and higher employee satisfaction (American Society of Safety Engineers, 2014).

Associate Safety Professional (ASP): A safety professional that has successfully passed the fundamentals examinations offered by the Board of Certified Safety Professionals (BCSP) is considered an ASP. The professional must have completed a certain amount of work experience in the field of safety and be eligible by the Board of 
Certified Safety Professionals (BCSP) to meet the qualifications to take the exam. The examination includes demonstration of knowledge in: (a) biological hazards; (b) chemical hazards; (c) electrical hazards; (d) natural hazards; (e) radiation hazards including ionizing and non-ionizing; (f) structural and mechanical hazards; (g) hazards related to fires and explosions; (i) hazards related to human factors and ergonomics; (j) measurement and monitoring; (k) engineering controls; (1) administrative controls; (m) personal protective equipment; (n) training and communication methods; (o) management processes; (p) inspections and auditing; (q) group dynamics; (r) project management; (s) risk management; (t) safety, health and environmental management systems; (u) basic financial principles; (v) probability and statistics; and (w) performance metrics and indicators (BCSP, 2013).

Board of Certified Safety Professionals (BCSP): The Board of Certified Safety Professionals (BCSP) began in 1969 as a peer certification board. It is not a member organization and does not provide services usually offered by member organizations. Membership in any organization is not a requirement for certification. Its sole purpose is to certify practitioners in the safety profession. Safety professionals identify hazards and evaluate them for the potential to cause injury or illness to people or harm of property and the environment. The safety professional recommends administrative and engineering controls that eliminate or minimize the risk and danger posed by hazards. They work with professionals in other disciplines in many different job settings. They work for companies, government agencies and private organizations or offer individual professional services. They may engage in design, planning, program management, training, audit and other aspects of practice. In addition, they apply hazard recognition, 
evaluation and control knowledge and skills for equipment, systems, facilities and processes, or in operations, manufacturing, transportation, construction, insurance services and other enterprises (BCSP, 2013). The value of the safety certification continues to grow. In the U.S., numerous laws, regulations and standards cite it. More importantly, many companies include it in position standards, government agencies rely on it and contracts for safety services require it. The certification program is for individuals seeking to become certified in the practice of safety. Once certified, these individuals can use the term Certified Safety Professional and the acronym CSP (BCSP, 2013). Once an individual becomes a CSP, they are eligible with the proper work experience to take the comprehensive exam for the $\mathrm{ABIH}$ and become a Certified Industrial Hygienist (CIH). The Board of Certified Safety Professionals is recognized as the leader in high quality credentialing for safety, health, and environmental practitioners in order to enhance the safety of people, property, and the environment. The BCSP: (a) sets standards for professional, technician, technologist, and supervisory level safety practices, (b) evaluates the academic and professional experience qualifications of certification applicants, (c) administers examinations; and (d) issues certificates to candidates who meet BCSP's certification qualifications and successfully pass the examination(s). The BCSP also monitors continued professional development through mandatory recertification requirements (BCSP, 2013).

Centers for Disease Control and Prevention (CDC): CDC is part of the US Public Health Service. There are nine centers in the CDC. The National Institute for Occupational Safety and Health is one of the CDC centers. CDC works around the clock to protect America from health, safety and security threats, both foreign and in the U.S. 
Whether diseases start at home or abroad, are chronic or acute, curable or preventable, human error or deliberate attack, CDC fights disease and supports communities and citizens to do the same. CDC increases the health security of our nation. As the nation's health protection agency, CDC saves lives and protects people from health threats. To accomplish their mission, CDC conducts critical science and provides health information that protects our nation against expensive and dangerous health threats, and responds when these arise (Centers for Disease Control and Protection, 2013).

Certified Industrial Hygienist (CIH): A certified industrial hygienist is a person who has passed a certification examination offered by the American Board of Industrial Hygiene. Over 10,000 individuals have obtained the CIH designation. Currently, there are approximately 7,000 practicing CIHs worldwide. A Certified Industrial Hygienist $(\mathrm{CIH})$ is an individual who has met the minimum requirements for education and experience, and through examination, has demonstrated a minimum level of knowledge and skills in the following rubric (subject matter) areas: (a) air sampling and instrumentation, (b) analytical chemistry, (c) basic science, (d) biohazards, (e) biostatistics and epidemiology, (f) community exposure, (g) engineering controls/ventilation, (h) ergonomics, (i) health risk analysis and hazard communication, (j) IH program management, (k) noise, (l) non-engineering controls, (m) radiationionizing and non-ionizing, (n) thermal stressors, (o) toxicology; and (p) work environments and industrial processes (American Board of Industrial Hygiene, 2013).

Certified Safety Professional (CSP): A certified safety professional is a person who has passed a certification examination offered by the Board of Certified Safety Professionals. The graduates from the undergraduate Occupational Safety and Health 
program from UCM are one step toward this certification upon graduation, as they receive the Graduate Safety Professional certification (GSP). The GSP serves the same purpose as the Associate Safety Professional (ASP) certification. Graduates obtain the adequate number of points for work experience after graduation, and are eligible to sit for the CSP examination without taking the fundamental exam. Knowledge areas included in examination are: (a) collecting, (b) assessing; and (c) managing safety, health, environmental, and security risk information (BCSP, 2013). This examination is applying all knowledge from the previous examination as well as an additional five years of practical work experience. The certified safety professional (CSP) examination is properly identified as a "Comprehensive" examination (BCSP, 2013).

Constituent Groups: Individuals who have a vested interest in the success of an organization are referred to as constituent groups. For the occupational safety management program at UCM, they include alumni, students, potential students, potential employers, the advisory board, department faculty, and the UCM administration.

Higher Learning Commission: This group is responsible for assessment within the North Central Association of Schools and Universities. North Central is the accreditation body charged with conducting the assessments of colleges and universities in their region that apply for academic accreditation. It is an independent corporation and one of two commission members of the North Central Association of Colleges and Schools (NCA), which is one of six regional institutional accreditors in the United States. The Higher Learning Commission accredits degree-granting post-secondary educational institutions in the North Central region. The Commission's Determining Qualified Faculty: Guidelines for Institutions and Peer Reviewers amplifies the Criteria for Accreditation 
and Assumed Practices that speak to the importance of institutions employing qualified faculty for the varied and essential roles faculty members perform (Higher Learning Commission, 2014).

Industrial Hygiene: This is a field of applied science that involves the anticipation, recognition, evaluation, and control of potential occupational hazards, be they chemical, physical, biological, or ergonomic in nature (Institute of Medicine, 2000; Quinlan \& Plog, 2012).

Industrial hygiene code of ethics: These ethical guidelines were developed by the American Board of Industrial Hygiene with input from interested constituents. The ethical guidelines include: (a) deliver competent services with objective and independent professional judgment in decision-making; (b) recognize the limitations of one's professional ability and provide services only when qualified based on education, knowledge, skills, practice, and experience; (c) make a reasonable effort to provide appropriate professional referrals when unable to provide competent professional assistance; (d) maintain and respect the confidentiality of sensitive information obtained in the course of professional activities; (e) properly use professional credentials, and provide truthful and accurate representations concerning education, experience, competency and the performance of services; (f) provide truthful and accurate representations to the public in advertising, public statements or representations, and in the preparation of estimates concerning costs, services and expected results; and (g) recognize and respect the intellectual property rights of others and act in an accurate, truthful and complete manner (American Board of Industrial Hygiene, 2007; Quinlan \& Plog, 2012). 
National Institute for Occupational Safety and Health (NIOSH): The lead government body assigned the responsibility for conducting research into occupational safety and health hazards. NIOSH was established under the OSH Act of 1970. NIOSH develops recommended exposure limits (REL) that are used by occupational safety and health professionals to safeguard the health of workers. NIOSH research is instrumental in these efforts and provides practical solutions to identified problems. The Institute's work in this area protects the safety and health of the nation's 155 million workers. NIOSH provides the only dedicated federal investment for research needed to prevent the societal cost of work-related fatalities, injuries and illnesses in the United States, estimated in 2007 at $\$ 250$ billion in medical costs and productivity losses alone. These safety and health risks take huge tolls on workers, their families, businesses, communities, and the nation's economy. NIOSH works to promote a healthy, safe and capable workforce that can rise to the challenges of the 21st Century. NIOSH produces new scientific knowledge and provides practical solutions vital to reducing risks of injury and death in traditional industries, such as agriculture, construction, and mining. NIOSH also supports research to predict, prevent, and address emerging problems that arise from dramatic changes in the 21st Century workplace and workforce. NIOSH partners with diverse stakeholders to study how worker injuries, illnesses, and deaths occur. NIOSH scientists design, conduct, and support targeted research, both inside and outside the institute, and support the training of occupational health and safety professionals to build capacity and meet increasing needs for a new generation of skilled practitioners. NIOSH and its partners support U.S. economic strength and growth by moving research into practice through concrete and practical solutions, recommendations, and interventions for 
the building of a healthy, safe and capable workforce (National Institute for Occupational Safety and Health, 2014).

Occupational Exposure Limits (OEL): Criteria that have been developed by the federal government (e.g., permissible exposure limit, and permissible exposure limit) and professional societies (e.g., threshold limit value), OELs are designed to protect the majority of workers whose exposures do not exceed the airborne concentration or energy level specified by the OEL. Occupational exposure limits are developed by toxicologists within organizations who manufacture chemicals or compounds that are mixtures and do not have established permissible exposure limits from OSHA or threshold limit values from ACGIH. These OELs are put under a scrutiny of testing, safety factors are built in to protect the more sensitive workers before these limits are used as the allowable limits for employee exposure in their work environment (Quinlan \& Plog, 2012).

Occupational Safety: A discipline in the health field whose mission is to prevent injuries and deaths on the job. Experts estimate that there are over 50,000 safety jobs in the United States. Reportedly, many of the people in current safety positions do not have academic degrees in OSH but learned the safety craft through experience, short courses and mentors (ASSE, 2014).

Occupational Safety and Health Act (OSH Act): The federal legislation that established both NIOSH and OSHA. The Act was signed into law by President Richard Nixon on December 29, 1970. It established OSHA and NIOSH as the lead organizations assigned the responsibility of protecting the American worker and also helped promote the discipline of occupational safety and health (Occupational Safety and Health Administration, 2013). 
Occupational Safety and Health Administration (OSHA): The Federal agencies established under the OSH Act of 1970 (United States Department of Labor, 2013) to protect the health and safety of the American worker, OSHA promulgates permissible exposure limits that are legally enforceable standards. OSHA is in the Department of Labor (Occupational Safety and Health Administration, 2013).

Program Evaluation: Program evaluation means to assess or ascertain the worth or value of some program (Rossi, Lipsey, \& Freeman, 2004).

Recommended Exposure Limits (REL): Occupational exposure criteria developed by the National Institute for Occupational Safety and Health. RELs are designed to protect most workers if the occupational exposure amount is maintained below the level specified. For NIOSH RELs, the time-weighted average (TWA) indicates the concentration for up to a 10-hour workday during a 40-hour workweek. A short-term exposure limit (STEL) is a 15-minute TWA exposure that should not be exceeded at any time during a workday. A ceiling REL is the ceiling value that should not be exceeded at any time (National Institute for Occupational Safety and Health, 2010).

Safety professional code of ethics: These ethical guidelines were developed by the American Society of Safety Engineers with input from interested constituents. The code of professional conduct must include their commitment to professionalism: (a) serve the public, employees, employers, clients, the ASSE, and the profession with fidelity, honesty, and impartiality; (b) in all professional relationships, treat others with respect, civility, and without discrimination; (c) abstain from behavior that will unjustly cause harm to the reputation of the ASSE, its members, and the profession; (d) Continually improve professional knowledge, skills, competencies, and awareness of relevant new 
developments through training, education, networking, and work experiences; (e) consider qualifications before undertaking any professional activity and perform only those services that may be handled competently; (f) make informed decisions in the performance of professional duties that adhere to all relevant laws, regulations, and recognized standards of practice; $(\mathrm{g})$ inform all appropriate parties when professional judgment indicates that there is an unacceptable level of risk of injury, illness, property damage, or environmental harm; (h) maintain the confidentiality of information acquired through professional practice that is designated or generally recognized as non-public, confidential, or privileged; (i) accurately represent professional qualifications including education, credentials, designations, affiliations, titles, and work experience; and (j) avoid situations that create actual, potential or perceived conflicts between personal and professional interests, and if a potential conflict of interest arises disclose all applicable facts to potentially affected parties (American Society of Safety Engineers, 2014).

Threshold Limit Values (TLV): Occupational exposure criteria developed by the American Conference of Governmental Industrial Hygienists designed to protect most workers if workplace exposure concentrations are maintained below the TLV level (American Conference of Governmental Industrial Hygienists, 2009).

Utilization-Focused Program Evaluation: Utilization-Focused Evaluation (UFE), developed by Michael Quinn Patton, is an approach based on the principle that an evaluation should be judged on its usefulness to its intended users. Therefore evaluations should be planned and conducted in ways that enhance the likely utilization of both the findings and of the process itself to inform decisions and improve performance. UFE has two essential elements. Firstly, the primary intended users of the evaluation must be 
clearly identified and personally engaged at the beginning of the evaluation process to ensure that their primary intended uses can be identified. Secondly, evaluators must ensure that these intended uses of the evaluation by the primary intended users guide all other decisions that are made about the evaluation process. Rather than a focus on general and abstract users and uses, UFE is focused on real and specific users and uses. The evaluator's job is not to make decisions independently of the intended users, but rather to facilitate decision making amongst the people who will use the findings of the evaluation. Patton argues that research on evaluation demonstrates that: "Intended users are more likely to use evaluations if they understand and feel ownership of the evaluation process and findings and are more likely to understand and feel ownership if they have been actively involved. By actively involving primary intended users, the evaluator is preparing the groundwork for use" (Patton, 2008).

\section{Limitations of the Study}

This research contained various limitations. The researcher was unable to locate some of the alumni due to their passing, ill health or the unavailability of current contact information. This created the possibility of having obtained biased data if the majority of the missing individuals held common beliefs different from those obtained in the survey. These individuals may have never entered the field of occupational safety management or they may have worked in the discipline for only a few years before leaving to raise children or to enter into another profession. They also may have entered into the profession, but not remained in contact with the University. This made tracking these individuals more difficult. 
The researcher's familiarity with the Department of Safety Sciences was another limitation in this research. The researcher has taught in the department for 4 years. The lack of familiarity from the previous years might have influenced the tone of questions asked of alumni and how the information was summarized. Several additional steps were taken to offset this potential bias. Five undergraduate students were requested to review the questionnaire prior to finalization along with seven faculty members and the department chair. Comments were collaborated and implemented as appropriate. The presence of historical minutes of department meetings, internal review reports, news articles, and other miscellaneous documents helped enhance the quality of the information collected.

\section{Summary}

The purpose of this study was to determine the skills and knowledge that alumni viewed as important for entry level occupational safety management professionals, the courses and topics alumni believed were important for graduate students to take as part of their curriculum, and to assess if a trend existed in alumni perceptions of how well the occupational safety management program at UCM prepared them for their first job. In addition, a comprehensive database was compiled of information on what certifications alumni obtained, where alumni work and what their annual salaries were. Data were collected through an on-line survey and from a review of historical documents. The review of historical documents provided information on the creation of and significant developments affecting the Occupational Safety Management program. It also enabled the researcher to correlate some of the information obtained from the online survey. The Department of Safety Sciences must demonstrate value to constituents inside and outside 
of UCM of the MS-OSM program. More universities are starting programs identical or very similar, especially online offerings. Continuous improvement is of the essence. Mark Twain quoted, "If you always do what you always did, you always get what you always got" (Twain, 1957, p. 492). With the program not having been evaluated in over 40 years, the feedback received can be instrumental if utilized efficiently to make the program stand above all others among the competitors. In order to keep the program at the University of Central Missouri viable, the quality of the program must be maintained and, if possible, improved. This was accomplished by surveying alumni and reviewing historical documents. The information collected will be made available to constituents of the occupational safety management program.

In the following chapter the background of occupational safety management and the development of academic programs in occupational safety management will be reviewed. The development of the Missouri Safety Center and the School of Public Services at the University of Central Missouri will be discussed. Both of these entities were instrumental in the development of the initial occupational safety management academic program. In addition, the personnel who established and directed the early years of the OSM program at UCM and played a key role in the foundational underpinnings that formed the basic structure of the current program will be discussed. An overview of the methods used in this assessment and why specific assessment techniques were selected will be provided in Chapter Three. In Chapter Four the author will summarize the results of the survey of alumni. In addition, an overview will be provided of the review of archival records and feedback from constituents on the survey instrument. In Chapter Five the author will include an interpretation of the results of this 
assessment of the graduate Occupational Safety Management program. In addition the author will include suggestions for how the department might use the information obtained during this assessment to improve its responsiveness to students, alumni and other constituents. Suggestions for future research will also be included. 


\section{CHAPTER TWO}

\section{LITERATURE REVIEW}

Simplicity is the ultimate sophistication in this day and age. Even when what we do as safety professionals is save life and limb while protecting health, less is more. Communication must be authentic and inspirational to people; however, oftentimes it is vague and confusing. Managers in an organization are often overwhelmed when faced with the many things they need to do to comply with health and safety legislation. To foster better communication and reduce this complexity, safety professionals need to become activists by building trust and active partnerships. When these partnerships are developed, trust and engagement in the safety process will follow as a better understanding of where they are coming from becomes apparent. As safety professionals, focus must be on the outcomes of the safety process not on the regulations with management and employees. Only the critical parts of the regulations that are applicable to the company should be summarized and presented to management and incorporated in to interactive training for employees (Roddis, 2012).

As safety professionals addressing manmade disasters, such as the horrific school shootings from 1996 to 2014 leading to the deaths of 129 students and 31 teachers/staff while wounding another 171 students and 14 teachers/staff in the United States, the task of developing a proactive plan of prevention is monumental (History Channel, 2014). Acts of God that have taken a large number of lives are the natural disasters in the United States from 1996 through 2013 resulting in over 3,800 fatalities. These include hurricanes, tornadoes, floods, wildfires, heat waves, landslides, blizzards and rip currents (Centers for Disease Control, 2014). Natural disasters are much more difficult, if not 
impossible, to eliminate. In many cases, loss of life can be minimized by adequate emergency planning and response where safety professionals have been a pivotal part of the development and implementation of such programs (Hagan, Montgomery \& O’Reilly, 2009a).

The literature review in this chapter includes several topics as background for this research study. An overview of utilization-focused program evaluation is provided. Also, background information on the field of study of occupational safety management and the history of safety management is included. Safety legislation, safety statistics, workers' compensation, as well as the mechanism of a safety management system are discussed. Safety leadership and ethics are also included since they are pivotal in making a safety program successful. The safety legislation discussed in detail includes the Occupational Safety and Health Act of 1970 (OSHA, 2014). This act encompassed many of the regulations that are still in place today or the initial version of newer regulations in place today.

\section{Program Evaluation}

Program evaluation involves collecting, analyzing, interpreting and communicating information about how a program functions and its effectiveness. Evaluations are conducted to determine if programs should be continued, improved, expanded or compressed. New programs and initiatives are assessed while the effectiveness of program management and administration are increased. It is appropriate that accountability is defined for program sponsors. Evaluations are tracked from design, implementation, measurable impact and efficiency of the program. Certain

environmental conditions exist for evaluations such as discretion of resources that require 
funders to prioritize programs and intensive interrogation of existing programs that continue to only support those that are effective and efficient. Program evaluation is defined as a use of research methods to systematically examine the effectiveness of programs in ways that are attuned to the political and organizational environments (Rossi, Lipsey, \& Freeman, 2004).

Program evaluation is the process of determining the value, merit and worth of things. The evaluation is the output of this undertaking. The evaluation is not the mere collection and summarizing of data that are clearly relevant for decision making. Evaluation has two arms. One arm being engaged in data accumulation, while the other arm in collecting, clarifying and confirming that relevant values and standards are accurate. Evaluation is to "Do Good" by holding them accountable for their contribution to the common good. The evaluation of a program generally involves assessing one or more of the five domains: (a) the need for the program, (b) the program's design, (c) its implementation and service delivery, (d) its impact or outcomes, and (e) its efficiency. The evaluation plan is designed by the evaluation sponsor and other relevant stakeholders who authorize the evaluation, by defining the questions to be posed about the program. These relevant stakeholders can include individual participants, groups, departments, or administration that have a significant interest in how well a program serves the customers (Rossi et al., 2004).

The purpose of evaluation is to provide responses to questions about a program that will be actionable and will be applied. It is fundamental to evaluation because its purpose is to advise stakeholders and sponsors of the initiative. The evaluation research will have an inherent competition between the requirements of systematic inquiry and 
data collection (Rossi et al., 2004). Balance must be found between scientific and pragmatic considerations during the design of the evaluation instrument (Campbell, 1969). The purpose of evaluation strongly separates it from scientific research. Evaluation is more art than science and should be initiated toward meeting the needs of program decision makers and stakeholders. Evaluations should be fervent to provide the applicable information that the political circumstances, program limitations, and attainable resources allow. Scientific studies strive to meet research standards (Cronbach, 1982). The appropriate evaluation questions for the study, with frequent communications with the stakeholders throughout the evaluation, will ensure that it will meet the needs of often-competing interest. The benefit of this effort will be "buy-in" of the recommendations from the final report of the evaluation by the stakeholders (Grasso, 2003). When stakeholders are treated with respect and listened to, and the evaluator is able to tell them something they do not already know, trust and "buy-in" to implement recommendations will be the final outcome from the stakeholders (Grob, 2003).

\section{Definition of Program Evaluation}

Since the mission of every evaluation has a different and distinctive profile of attributes, it defines the most rigorous aspect of these evaluations as being no "one size fits all" methodology. The most significant features of the situation to consider have to do with the purposes of the evaluation; the program's structure and circumstances; and the resources available for the evaluation (Rossi et al., 2004). The two types of evaluations are formative and summative. Formative evaluation is intended to provide information for guiding program improvement. The purpose is to help form or shape the program to improve performance. Evaluative activities performed to make a summary 
judgment on certain critical aspects of the program's performance are called a summative evaluation. This would include a determination that specific goals and objectives were being accomplished (Scriven, 1991).

\section{Utilization-Based Focused Evaluation}

The utilization-based focused evaluation (Patton, 1997; Patton, 2008) is described as the theoretical underpinning for this research study and some segments of a formative evaluation are utilized to furnish information to guide program improvement (Rossi et al., 2004). The utilization-focused evaluation is designed around the information requirements of involved consumers with whom the evaluator collaborates very closely. It is the best option to assure utilization of the evaluation findings through implementation (Patton, 1997; Vassar, Wheeler, Davison, \& Franklin, 2010). The worth of education programs is reflected by the effectiveness of the graduates in their respective workplaces. In the field of safety management, practitioners who are equipped to apply "reflection-in-action", or think about what they are doing while they are doing it, are the most successful (Cervero, 1988; Guskey, 2000; Rothwell \& Cookson, 1997; Schon, 1983; Sork, 2000; Wilson \& Hayes, 2000). An assessment information packet is identified as a template to begin the process of developing a process of conducting the utilization focused program evaluation (NIU, 2012).

Primary users can serve a function in defining their own program theory in useroriented (Alkin, 1991) or utilization-focused evaluations (Patton, 1997; Patton, 2008). The theoretical approach used to direct the user-oriented evaluation accentuates stakeholder participation in various phases of the evaluation. The identification of pertinent issues for study is the starting point (Christie \& Alkin, 2003). The goal of a 
utilization-focused evaluation is to increase the probability that an evaluation will be used by the primary users as well as have an impact on them while they are using the evaluation findings. Patton (2008) states to differentiate between stakeholders. The stakeholders are those who have a stake or vested interest in the evaluation, and the primary users. Primary users are the stakeholders who have a principal role in decision making and in turn are in the position to utilize results. Primary user involvement is intended to increase the utilization of evaluation results (Christie \& Alkin, 2003; Patton, 2008). Active participation of stakeholders is vital at every phase of the evaluation including planning, performing the evaluation, and in dissemination of findings (Patton, 2008).

When the evaluator starts with a utilization-focused evaluation framework, the primary users' needs drive the evaluation process, not the program theory. The two primary features that utilization-focused evaluation (UFE) and theory-driven evaluation (TDE) share are program theory development and stakeholder participation (Christie \& Alkin, 2003). UFE is concerned with the individual primary users and their evaluation needs. These needs are often quite nebulous and require structuring and development. The user-focused approach is puzzling because practitioners are seldom aware of their theory of action (Patton, 1997). Theories of action refer specifically to how to produce desired results, in contrast to theories which explain why some phenomenon of interest occurs. The user-focused approach to developing a theory of action requires working with intended users to extract and specify their implicit theory of action. Hence, the evaluator works with the primary intended users to understand the relationship between 
what the program is actually doing, how what is being done will have an impact, and how that impact relates to the intended program outcomes (Patton, 1997).

The utilization-focused evaluation is developed on the hypothesis that stakeholders, especially primary users, should ultimately be involved in every phase of the evaluation process. It is this involvement that increases primary users buy-in into the evaluation which increases utilization. Stakeholder participation serves as the underpinning for this theoretical perspective. The bottom line is that the success of a UFE is ascertained by the degree to which the evaluation is utilized, but this is not the case for the TDE. As UFE evaluators, the informational needs of the primary users are defined (Patton, 1997). Theories contain flaws that get translated into practice (Christie, 2003). Utilization-focused evaluations are constructed to answer a specific information need of an identified person. Evaluators are involved in purposefully identifying intended users and directing beneficial questions in the appropriate way. They are responsive in listening to intended users and providing feedback to them regarding the particular situation. Evaluators are not only genuinely immersed in the challenges of each new setting but also authentically responsive to the intended users of each new evaluation. It is apparent that a dedicated UFE evaluator must be prepared to execute an array of evaluation designs. It is the needs of the primary users that direct which design is suitable. The UFE evaluator may be asked to conduct an evaluation that is best directed by a design that is more closely related with another theoretical model. A hypothetical situation to reinforce this point is that it may be that a specific set of primary users favorably regard the use of experimental or quasi-experimental designs. The results of the study utilizing the primary users favored design will be more likely to be 
implemented, thereby being considered more effective by the evaluators and the primary users (Patton, 1997). The program theory has six conditions to include: (a) culture, (b) identity, (c) curriculum, (d) teaching, (e) support, and (f) connections (Christie \& Alkin, 2003).

Connections or connectors are people who know both the right people as well as many people in an organization. These connectors are critical in getting the evaluation findings out to a broad range of people, therefore being the ideal primary intended users of the program evaluation. A great analogy presented is the hub of a wheel where the spokes are connected. They make the wheels of change turn (Gladwell, 2002).

When program assessments are being conducted, there are political considerations and personal factors of the stakeholders that are critical to utilization-focused evaluations. The personal factor represents leadership, interest, enthusiasm, determination, commitment assertiveness, and caring of specific, individual people. These are people who actively seek information to learn, make judgments, get better at what they do, and reduce decision uncertainties. The personal factors perform a critical role in defining how much influence the evaluation will have (Cronbach, 1980; Patton, 2008).

Practical implications to focus on include the following: (a) find the right people based on the personal factor considerations, (b) find and train information users, (c) find tipping point connectors, (d) facilitate high quality interactions, (e) nurture interest and develop capacity in education, (f) develop facilitation skills, (g) strategize about appropriate involvement, (h) demonstrate cultural sensitivity and competence, (i) anticipate turnover of intended users, and (j) strategize about different levels of evaluation influence (Patton, 2008). 


\section{University of Central Missouri Program Evaluation}

The goal of the program evaluation is to identify and address any gaps which might exist between what the alumni have received from the curriculum/degree program over the last 44 years and what expectations they encounter in the workplace. The learning or outcome of the evaluation needs to be applicable to the current situation (Cafarella, 2002).

The degree program in Occupational Safety Management was developed in the early 1970s at Central Missouri State College later to become the University of Central Missouri. Improvements throughout this historical period have been made to the regulations (OSHA) as well as to the program curriculum to graduate competent safety professionals to enter the workforce (CMSU Graduate Catalog, UCM Graduate Catalogs). Summaries of some of the leading professional networking and governmental organizations in safety will be incorporated in the research. The purpose of this program evaluation is to evaluate the overall effectiveness of the graduate Occupational Safety Management program for the students. Because the program is over forty years old and has never been evaluated, the program effectiveness is being measured by feedback from the alumni in regard to the program and its curriculum. This review of the academic program assessment will be provided as an assessment of the graduate Occupational Safety Management program in the Department of Safety Sciences within the School of Environmental, Physical and Applied Sciences. Information from previous UCM Fact Books will be used to understand faculty load, as well as the number of students in the degree program currently and in the past years. Advisory council meeting minutes will be reviewed as part of the evaluation. The assessment is needed for both the faculty and 
administration of the school to meet the requirements of the National Institute of Occupational Safety and Health (NIOSH) and the Board of Certified Safety Professionals (BCSP). To conclude, a line of reasoning will be provided to how program assessment by external constituents has become more important for academic programs in safety management. Due to economic constraints being placed on universities requiring educational programs to be self-supporting and producing profits, occupational safety management programs have become more competitive geographically with more universities offering online programs. These universities all strive for additional accreditations as well as scholarships and grant appropriations. Results from this program evaluation will enable UCM to remain competitive among all institutions.

Systematic program evaluations are a suitable and essential part of the programming process; however, four major drawbacks must be circumvented by program planners. The outcomes of some educational programs may be too complex and the number of variables influencing those outcomes too many to permit planners to validate that a given program truly produced the preferred rankings. Existing evaluation techniques, though methodically precise, may not be able to deliver rigid verification that the more perceptive, and at times the most essential, facets of the education and training programs have been accomplished. Conducting systematic program evaluations comes at a price in the form of time and money, neither of which some organizations and groups are inclined to impart, particularly when an evaluation seems to be an "after-thought" once the program has commenced. When staff recognize that no action will or can be taken on the basis of evaluation findings, it may be better not to collect the data at all, 
since the evaluation process builds expectations on the part of participants and/or sponsors that changes will be upcoming (Cafarella, 2002).

\section{University of Central Missouri's M. S. Occupational Safety Management Program. Review of graduate safety degree history.}

Other university programs referenced were evaluated prior to forty years postdevelopment. The determination will be made as to whether the design and delivery of the safety management program is effective and proposed outcomes are met. The current graduate program is different in nomenclature and content than what was initially offered in 1970, and the progression has been a gradual change. Research on the changes in curriculum content is provided to assure feedback from alumni will be grouped appropriately for validity and reliability of the study. Careful reflection will be required when comparing to other studies due to this caveat.

By 1971, there were over 300 graduate students enrolled in the five specialty safety degree programs available at Central Missouri State College. The National Education Association stated this program constituted the largest graduate program in safety in the nation. The specialty programs were Master of Science in Education, Safety Education; Master of Science, Safety; Master of Science, Industrial Safety; Master of Science, Traffic Engineering; and Master of Science, Criminal Justice Administration. A specialist degree in Safety was being offered as well (Patterson, 1974).

From 1971 to 1973, the School of Public Services offered graduate degrees in the major emphasis areas of safety education, agricultural safety, industrial hygiene, industrial safety, safety, traffic engineering, and transportation safety. The Specialist degree in these same areas was offered (Patterson, 1974). 
The two main graduate safety degree programs in the early 1970s were Safety and Industrial Safety. The Industrial Safety curriculum is more comprehensive under the required courses in that it requires courses in loss control, industrial hygiene, industrial safety engineering, and human factors in engineering design. Whereas, the safety graduate degree is more general in requiring principles of accident prevention, organization administration and supervision of safety programs, philosophy of safety and current literature and research. With the industrial safety degree being more comprehensive on the required courses, it requires less elective courses. Both degree programs still require a total of 32 credit hours (CMSU, 1975).

In 1976, an Industrial Security specialty was made available under the School of Public Services. The degree program required a 2.0 grade point average with a minimum of 15 semester hours in specific areas of safety, fire science, criminal justice or related fields (CMSU Catalog, 1976). This degree program only had a small number of graduates on record.

In 1979, the graduate exit exam was implemented as a requirement for candidacy for graduation. Required courses were changed as follows for graduate Safety curriculum: SAFE 4060 Introduction to System Safety was added, while SAFE 4010 Principles of Accident Prevention was made a prerequisite for the program rather than a required course. The electives were grouped into areas of research, historical, social, and philosophical foundations, psychological foundations, and the school program. A thesis or research paper was elected as a portion of the program as an option 3 (CMSU, 1979).

Beginning in 1982, a new prerequisite requirement was put in place for the Industrial Safety degree program. It stated a student not have fewer than 15 approved 
graduate or undergraduate hours in industrial safety and/or related fields to meet background requirements (CMSU, 1982-84).

Starting in 1984, in the Industrial Safety curriculum, the IndM 5210 Human Factors in Engineering Design course increased from a 2.0 hour to a 3.0 hour course. The IS\&H 4850 Industrial Fire Protection course was added to the required courses, thereby increasing the credit hours in the required curriculum from 17.0 to 21.0. The number of electives was reduced to keep the number of total hours at 32.0.

Also in 1984, a new prerequisite requirement was put in place for the Safety degree program. It stated a student not have fewer than 30 semester hours of approved graduate/undergraduate hours in non-individualized safety/industrial safety courses to meet background requirements (CMSU, 1982-84). All records reviewed show that the name of the graduate Safety degree name was changed to M.S. Safety Management in 1985 with no curriculum or prerequisite changes (CMSU, 1985; Meeting Minutes, 1985).

In 1987, curriculum changes were made to the graduate Safety Management degree. The SAFE 4060 Introduction to System Safety was deleted as a required course, while SAFE 5530 Loss Control Management and SAFE 6920 Seminar in Safety Science and Technology were added. Research was also increased from a 3 credit hour requirement to a 9 credit hour requirement, so the total increased in required graduate course hours was from 12 to 19-22. The number of electives was reduced, so the number of credit hours required for the degree was reflected as $32-35$ as the minimum required (CMSU, 1987-88).

Also in 1987, changes were made to the graduate Industrial Safety degree program to include the removal of SAFE 4410 Total Loss Control and the addition of 
SAFE 5530 Loss Control Management and SS\&T 6920 Seminar in Safety Science and Technology. The research hours were also increased from 3 credit hours to a 9-12 credit hour requirement. By increasing these required graduate course hours, the elective hours were adjusted; however, the total number of minimum showed a range of 32-25 credit hours as the minimum requirements for graduation (CMSU, 1987-88).

Three specific background courses were defined for the graduate Industrial Safety degree in 1989. They were Accident Causation and Prevention, Analysis and Development of Safety, and Health Criteria or equivalents (CMSU, 1989-90).

The graduate Industrial Safety Management degree program was established in 1991. It required an additional course in Commercial and Institutional Security (3.0 credit hours) that was not required in the curriculum for the Industrial Safety degree. All other requirements were the same. The specialization areas remained the same as well (CMSU, 1991-93).

In 2008, a change was made to the Occupational Safety Management program to reduce the credit hour requirements from 34.0 to 33.0. SAFE 6920 Seminar in Safety Sciences was deleted as a required course, while SAFE 5800 Managing Fire Risk was added as a required course. SAFE 6940 was removed as an option on the department approved elective list. It is still strongly encouraged but not required (UCM, 2008). 
Table 1

Timeline/Requirements/Nomenclature

\begin{tabular}{|c|c|c|c|}
\hline $\begin{array}{l}\text { Yrs. Alumni in Study } \\
\text { Graduated }\end{array}$ & $\begin{array}{l}\text { Credit } \\
\text { Hours } \\
\text { Req'd }\end{array}$ & Entry Requirements & $\begin{array}{c}\text { Name of Degree } \\
\text { Program }\end{array}$ \\
\hline 1969-1994, 1998 & 32 & $\begin{array}{l}\text { B.S. degree-GPA } 2.0 \\
\text { (1969-1988); GPA } 2.25 \\
\text { (1989-1998) } \\
\text { (Starting in 1979: SAFE } \\
\text { 4010 Principles of Acc. } \\
\text { Prevention, with a Course } \\
\text { name change in } 1982 \text { to } \\
\text { SAFE 3000 Principles of } \\
\text { Acc. Causation and } \\
\text { Prevention) }\end{array}$ & $\begin{array}{l}\text { Safety, Safety } \\
\text { Mgmt. } \\
\text { (Could get an Ed. } \\
\text { Specialist degree } \\
\text { with } 1 \text { yr. of } \\
\text { additional } \\
\text { coursework in } \\
\text { addition to } \\
\text { graduate degree.) }\end{array}$ \\
\hline 1969-1994, 1998 & 32 & $\begin{array}{l}\text { B.S. degree-GPA } 2.0 \\
\text { (1969-1983); GPA } 2.25 \\
\text { (1984-1998) } \\
\text { Principles of Accident } \\
\text { Causation, Philosophy of } \\
\text { Safety \&Psychology in } \\
\text { Safety Education and Acc. } \\
\text { Prevention or equivalent. }\end{array}$ & $\begin{array}{l}\text { Industrial Safety } \\
\text { (Could get an Ed. } \\
\text { Specialist degree } \\
\text { with } 1 \text { yr. of } \\
\text { additional } \\
\text { coursework in } \\
\text { addition to } \\
\text { graduate degree.) }\end{array}$ \\
\hline 1987-1998 & $32-35$ & $\begin{array}{l}\text { B.S. degree-GPA } 2.0 \\
\text { (1987-1988); GPA } 2.25 \\
(1989-1998)\end{array}$ & $\begin{array}{l}\text { Safety, Safety } \\
\text { Mgmt. } \\
\text { (Could get an Ed. } \\
\text { Specialist degree } \\
\text { with 1 yr. of } \\
\text { additional } \\
\text { graduate } \\
\text { coursework. }\end{array}$ \\
\hline 1987-1998 & $32-35$ & $\begin{array}{l}\text { B.S. degree GPA } 2.25 \\
\text { (1984-1998) } \\
\text { Principles of Accident } \\
\text { Causation, Philosophy of } \\
\text { Safety \& Psychology in } \\
\text { Safety Education and } \\
\text { Accident Prevention or } \\
\text { equivalent. }\end{array}$ & $\begin{array}{l}\text { Industrial Safety } \\
\text { (Could get an Ed. } \\
\text { Specialist degree } \\
\text { with } 1 \text { yr. of } \\
\text { additional } \\
\text { coursework in } \\
\text { addition to } \\
\text { graduate degree.) }\end{array}$ \\
\hline
\end{tabular}


Table 1 (Cont'd)

Timeline/Req./Nomencl.

\begin{tabular}{|c|c|c|c|}
\hline $\begin{array}{l}\text { Yrs. Alumni in Study } \\
\text { Graduated }\end{array}$ & $\begin{array}{c}\text { Credit } \\
\text { Hours } \\
\text { Required }\end{array}$ & Entry Requirements & $\begin{array}{c}\text { Name of Degree } \\
\text { Program }\end{array}$ \\
\hline $\begin{array}{l}1981,1984-86,1991- \\
2003,2005,2008\end{array}$ & 36.0 & $\begin{array}{l}\text { B.S. degree GPA } 2.25 \\
\text { Undergrad program in } \\
\text { safety satisfied core } \\
\text { requirements }\end{array}$ & $\begin{array}{l}\text { Industrial Safety } \\
\text { Mgmt. with } \\
\text { Option of: } \\
\text { Safety, Security, } \\
\text { Public Services } \\
\text { Administration, } \\
\text { Fire Science, or } \\
\text { Transportation } \\
\text { Safety }\end{array}$ \\
\hline 1993-1999 & 36.0 & $\begin{array}{l}\text { B.S. degree GPA } 2.5 \text { or } \\
\text { completed } 9 \text { hrs. of } \\
\text { department specified } \\
\text { courses and earned at least } \\
\text { a } 3.0 \text { GPA in these courses. } \\
\text { Submit a letter of intent } \\
\text { along with their application } \\
\text { to the Dept. Chair. } \\
\text { Complete a minimum of } 15 \\
\text { semester hours of } \\
\text { background courses. } \\
\text { Attend exit interview prior } \\
\text { to graduation. }\end{array}$ & $\begin{array}{l}\text { Industrial Safety } \\
\text { Mgmt. with } \\
\text { Option of: } \\
\text { Safety, Security, } \\
\text { Public Services } \\
\text { Administration, } \\
\text { Fire Science, or } \\
\text { Transportation } \\
\text { Safety }\end{array}$ \\
\hline $2000-2007$ & 34.0 & $\begin{array}{l}\text { B.S. degree-GPA } 2.5 \\
\text { Essay-Writing Skills } \\
3.0 \text { credit hrs. of business } \\
\text { or industrial mgmt., } \\
\text { behavioral science, algebra } \\
\text { and statistics and } 8.0 \text { hrs. } \\
\text { science classes with lab. } \\
\text { Exit exam. }\end{array}$ & $\begin{array}{l}\text { Occupational } \\
\text { Safety Mgmt. } \\
\text { with or without } \\
\text { option of: } \\
\text { Industrial Safety, } \\
\text { Transportation } \\
\text { Safety, Public } \\
\text { Safety, Loss } \\
\text { Control, Fire } \\
\text { Science, or } \\
\text { Security }\end{array}$ \\
\hline
\end{tabular}


Table 1 (Continued)

Timeline/Req/Nomencl

\begin{tabular}{cccc}
$\begin{array}{c}\text { Yrs. Alumni in Study } \\
\text { Graduated }\end{array}$ & $\begin{array}{c}\text { Credit } \\
\text { Hours } \\
\text { Required }\end{array}$ & \multicolumn{1}{c}{ Entry Requirements } & $\begin{array}{c}\text { Name of Degree } \\
\text { Program }\end{array}$ \\
\hline $2008-14$ & 33.0 & B.S. degree-GPA 2.5 & $\begin{array}{c}\text { Occ. Safety } \\
\text { Essay-Writing Skills }\end{array}$ \\
& & Mgmt. \\
& industrial mgmt., \\
& behavioral science, algebra & \\
& and statistics and 6.0 hrs.- & \\
& science classes with lab. & \\
& Exit exam. & \\
& & \\
& & \\
& &
\end{tabular}

Note. Adapted from Patterson, N. E. W. (1974). A history of the Missouri safety center and the school of public service. Central Missouri State University. Warrensburg, MO. Thesis; Central Missouri State University (1974-2006). 1974-2006 Graduate Catalog; University of Central Missouri (2007-2013

Graduate Catalog, Occupational Safety Management program.

\section{Program Evaluations from other Universities and the University of Central}

\section{Missouri’s M. S. Industrial Hygiene Program.}

University of Pittsburgh. An evaluation at the University of Pittsburgh revealed the perception of graduates, their employers and their faculty, of a professional education curriculum to prepare persons for professions in occupational safety and health. The purpose of the study was to examine the degree to which graduates of an occupational safety degree program, as well as their employers and faculty, consider their curriculum prepared them for duties related to their current positions. It was created to determine what the three groups perceived as strengths and weaknesses of the safety sciences curriculum. The similarities and differences between the perceptions of the three groups were studied while recommendations for changes in the curriculum were requested. Survey questionnaires were used for intentions of this study with a return rate of $40.8 \%$ of graduates, with $43.9 \%$ of their employers returning their questionnaires. All six 
faculty members who were surveyed returned their instruments (Soule, 1993). There were new subjects within the discipline identified as areas that were essential to be added to the curriculum, but overall the feedback was positive about the degree program. This study represented the multi-faceted nature of the safety career. Most graduates were currently employed in locations that approved and expected them to utilize the concepts of occupational safety and health management. The main strength of the program was the all-encompassing technical underpinning of coursework, faculty with real-world experience, and an internship program that offered particular hands-on practical experience. Recommendations for changes in the curriculum concentrated on subject areas that recently have become a function of the safety/health professional within the organization where they are employed. The most important among these subject areas were environmental management, risk management, workers' compensation, and applied management skills (Soule, 1993).

Murray State University. An internship inquiry survey questionnaire was sent to 208 bachelor's and master's degree graduates from 1987-1991 in the occupational safety and health program from Murray State University. They were only included in the study if they had completed at least one internship experience. A survey questionnaire with proven validity and reliability containing 66 statements was created. The survey collected demographic data and perceptions of internship experiences by occupational safety and health graduates (Kraemer, 1992).

Findings of the study revealed the average occupational safety and health intern was white, 27 years old, male, single who finished his first internship while obtaining an undergraduate degree. The representative internship locations were manufacturing and 
chemical industries with greater than $50 \%$ of the interns experiencing responsibility and accountability as safety generalists. The internship attributes which were acknowledged as having the highest levels of significance were: (a) utilizing and expanding basic skills, (b) acquiring proficiencies from experience, (c) increasing self-confidence in technical skills and abilities, (d) gaining ability to take responsibility/accountability, (e) acknowledging consequences of actions whether good or bad, (f) working together by good two-way communication with management, and (g) working cooperatively/supportively with others. The level of satisfaction of particular attributes of the internship experience ranged from a "low" on receiving pre-employment material to a "high" on working cooperatively/supportively with others (Kraemer, 1992).

Noteworthy progressive correlations were identified between the salary earned by interns and the personal, professional and career worth and satisfaction results of the occupational safety and health internship experience. The outcomes of the inquiry of variance on the degree of satisfaction and the degree of personal, professional and career importance of the occupational safety and health internship experience signified that considerable differences did occur between the means of different internship locations. Based on the results, future research was recommended, as well as for occupational safety and health internship programs (Kraemer, 1992).

Stevens Institute of Technology. The Systems Engineering Program at Stevens Institute of Technology has established the Open Academic Model (OAM) to guide its strategic planning and operations since its launch in 2001. Guided by OAM, the Stevens Systems Engineering Program (SSEP) has matured from the beginning in 2001 into one of the most prevalent in the United States. The principal purposes of the current research 
are to officially describe and characterize OAM, its values and related application approaches for the first time, and to assess the outcome of OAM on the influence of SSEP for the period 2001-2010, which is assessed based on a predefined array of impact measures correlated to size, excellence, scholarly publications, faculty leadership and mentorship.

OAM is built on the following values and beliefs: (a) Broad Comprehensive Partnerships, (b) Indistinct Boundaries, (c) Responsive Atmosphere, (d) Community Involvement, and (e) Second-Career Faculty. Assessment of their outcomes on the influence of SSEP discovered that OAM guided SSEP into one of the principal systems of engineering programs in the United States. It had an unequivocal influence on the impact of SSEP to flourish and present the finest systems engineering (SE) education customized to sponsors' requests. It also improved SSEP's reputation and character within industry and academia, facilitated SSEP corporate partners to productively implement SE ideas and raise the value of SE to their organizations. In addition, it facilitated hiring executives from industry to impart their leadership and SE knowledge and expertise through teaching, mentoring, research, and administrative duties.

Because of the challenges that engineering education encounters as a whole, and systems engineering education specifically, OAM is an innovative model that can be utilized at other institutions, particularly smaller ones, that have adaptable guidelines and the appropriate leadership team. Additional recommendations for enhancements of OAM and its execution at Stevens, as well as at other systems engineering programs, are afforded (Lasfer, 2012). 
Capella University. The objective of this inquiry review was to advance a practice of program review by extrapolating from best practices and industry-proven proficiencies, while being authentic to the organizational values and mission. The organization's overall purpose was to construct an instrument of appraisal that linked the new measures for accreditation and cultivated a process of step-by-step change that progresses the organization in the direction of its vision. A qualitative evaluation of the group interview of program leaders, faculty, staff, and learners offered discernment to program values and culture. Coding of the interview transcript reinforced the need for aligning program objectives with industry established competencies and elements of the mission, such as a learner-focused curriculum, and performing a groundwork of learners for a global environment. A process of program review was recommended that consisted of the use of an advisory committee to evaluate the embraced theory of the human resources degree program and deliberately planned for quality improvement (Meyer, 2012; Mauerman, 2009).

University of Central Missouri-Industrial Hygiene Program. The graduate degree in industrial hygiene at UCM had a utilization-focused program assessment conducted in 2010. The overall participation of the approximate 400 graduates was above $40 \%$, which was considered a representative sample. The outcome of the evaluation reflected an overall acceptable satisfaction with the program curriculum (Zey, 2010). The primary information gained from this research study is that the Department of Safety Sciences has more than adequately prepared students for a career in industrial hygiene over the past 36 years. Over two-thirds of responding alumni rated the training they received from the Department of Safety Sciences as "above average." The 
Department of Safety Sciences should continue the focus on practitioner skills and knowledge, since practitioner skills were found to be preferred in not only the current study, but also in other similar studies that have been reported (Brosseau, 2005; Rodgers, 2007; Zey, 2010). Communication skills were very highly rated by alumni in several survey questions. Those activities that emphasize communication skills (writing and presentations) should continue to be among the primary activities in which industrial hygiene students engage. Research and business skills and knowledge are rated as important but not essential by most of the alumni. While research did not receive the highest rating, alumni viewed this skill and knowledge as important. The Department of Safety Sciences modified their curriculum in 2008 by reducing internship hours from six to three and adding a requirement of three hours of a research class (Individual Research or Thesis) to the curriculum (University of Central Missouri, 2008b). Since that change, industrial hygiene students still typically work a full summer and thus receive the same amount of field experience. Now they only pay for three hours of internship, not six. These results validate the direction the Department has guided the industrial hygiene program over the last 36 years. This research also points out the importance of "word of mouth" activities and their effectiveness for recruiting purposes for the Department of Safety Sciences. A critical aspect of this issue is keeping constituents informed of department activities. With increasing budget constraint and a past history of cyclic increases and decreases in student numbers, Value Stream Mapping (VSM) with careful utilization of money and time will be even more important in the future.

This research also suggests that the general studies course may have had a tremendous impact on the student numbers in the industrial hygiene program. It is 
noteworthy that the original approval for a general studies course in the early 1970s and the re-approval of the general studies course in 2005 were followed within a few years by rapid expansions in the student numbers in all academic programs in the Department of Safety Sciences. In both instances, the number of industrial hygiene students increased along with the number of students in the other department programs. The high percentage of M. S. Industrial Hygiene alumni who earned an undergraduate degree at UCM before beginning their graduate Industrial Hygiene program, supports the possibility that awareness of the academic program offered by Safety Sciences programs is a key component to student recruitment for the industrial hygiene program.

This research also lays the foundation for the Department of Safety Sciences to continue assessing their academic programs using online surveys. Plans are already underway for similar assessments of one other academic program in the Department of Safety Sciences. University administrators are looking for validation of the quality of academic programs they offer. Program assessments are valuable for both internal and external reviews. In the current state of financial difficulties and constant reviews by internal and external constituents, such research is not only useful but vital (Zey, 2010).

\section{Graduate degrees in Occupational Safety Management (OSM)}

A number of universities offer a similar OSM degree program as UCM, some are $100 \%$ online and others require some classroom or laboratory accessibility. Several of the most popular programs will be outlined.

Indiana State University. ISU offers the M. S. and the M. A. in Occupational Safety Management to students who are interested in advancing their careers or education in business or industrial safety management. It is a 33 credit hour program. The 
university is accredited by the Higher Learning Commission of the North Central Association of Colleges and Schools. The Occupational Safety Management Program is accredited by the Association of Technology, Management, and Applied Engineering also known as ATMAE (ISU, 2014).

Tulane University. Tulane offers a Masters of Public Health (MPH) degree program in Occupational Health and Safety Management. The program is offered in distance learning format. Students must earn a minimum of 42 credit hours to earn the degree, of which an internship is a requirement. This program is ABET accredited (Tulane, 2014).

Oakland University. Within their School of Health Sciences, Oakland University offers a Master of Science in Safety Management (MSSM) degree. The student must earn 32 credit hours to be awarded the degree while maintaining a 3.0 grade point average (Oakland, 2014).

Keene State College. Keene offers a Master of Science in Safety and Occupational Health Applied Science degree. It is a 36 credit hour program (Keene, 2014).

Columbia Southern University. Columbia Southern offers a M. S. in Occupational Safety and Health. The Board of Certified Safety Professionals will recognize their degree for the application process under both the Associate Safety Professional designation and the Certified Safety Professional designation. The program requires 37 credit hours to complete (Columbia, 2014).

Murray State University. Murray State offers a Master of Occupational Safety and Health program. The university also has a new online program launching in July 
2014 with an emphasis in Safety Management. Their cohort program requires completion of 30 credit hours. A comprehensive exam is required at the end of the program (Murray, 2014).

University of Alabama-Birmingham. UAB offers a M. S. in Advanced Safety Engineering and Management. It is a 33 credit hour program (UAB, 2014).

\section{History of Occupational Safety Management}

Occupational safety management provides a systematic way to identify hazards and control risks while maintaining assurance that these risk controls are effective. It is merely a way of mitigating hazards. Some hazards can be eliminated while others can only be managed to an acceptable level of risk. This can include the protection of people as well as the protection of possessions. Goals must be set. Plans must be defined and executed while performance is measured to assure results are achieved (Hagan, Montgomery \& O’Reilly, 2009b).

Some types of hazards to identify and manage are mechanical, thermal, radiant, chemical, and electrical (Stout, 2008). All of these hazards can exist simultaneously, particularly work involving tasks requiring Control of Hazardous Energy governed by OSHA Standard 29 CFR 1910.147 (OSHA, 2014). The ongoing incidents of long-term industrial diseases from exposure to dust, chemicals, and other toxins that are a part of high tech industries, have put new generations of American workers at risk. Every year greater than four million workers are seriously injured or sickened by exposure to toxic agents (Markowitz \& Rosner, 2011).

Historical Perspective. When safety is reflected upon, ancient history is the starting point. This is followed by notable tragedies which led to regulations and to 
current literature on safety leadership. Over one hundred years ago, President Theodore Roosevelt defined the quote still used today, "Nobody cares how much you know, until they know how much you care” (Roosevelt \& O’Toole, 2012). Leaders must take the lead themselves with the proper mindset, skillset and toolset. The best leaders believe in improving the safety and health of those around them. These safety leaders know they can take steps that will bear positive results where their actions become a visible force for change. Going through the motions or leading lackadaisically will never be adequate to make a difference. Safety leaders must embody a passion for safety excellence and show energy and enthusiasm to others in the organization (Mathur \& Pater, 2014). Embracing change, by providing quick responses to employee requests for information or improvements, shows care for the employees which come back to President Roosevelt's belief and value aforementioned.

Background of Occupational Safety. Safety's roots can be traced back to ancient history. The ancient Chinese (circa 2500 BC) applied "risk management" (Greer 2001). In 2100 BC, Hammurabi dictated a body of laws, including various safety and indemnification-related requirements such as accountability, where if one caused another to lose an eye, they were to lose an eye. This led to occupational safety management (Smitha, 1998). Early Egyptians (1600 BC) recognized the exposures of breathing fumes generated by melting silver and gold. Even though these hazards were identified, there is no documentation reflecting any mitigation steps taken to reduce or eliminate the hazards. In 1770, Benjamin Ramizzini, an Italian physician, published the first thesis endeavoring to prove the correlation between occupation and disease. He later became the "Father of Occupational Medicine". In 1730, Benjamin Franklin structured the first 
firefighting company in the United States. In 1812, the first loss control and injuryprevention methods that policyholders could implement to secure low insurance premiums were implemented. In 1864, the Pennsylvania Mine Safety Act was approved into law. In 1877, the state of Massachusetts adopted a law necessitating guarding for dangerous machinery. In 1896, the National Fire Protection Association, a group dedicated to fire prevention and code development, was established. In the early years of the American Society of Safety Engineers, it was committed to creating accident prevention techniques and enhancing safety engineering as a profession. This mission continues today. The group of leaders who were spearheading the American Society of Safety Engineers included true visionaries in progressing through the industrial revolution and making a difference in the lives of workers every day (Greer, 2001). In 1908, Alice Hamilton, the Mother of U.S. Occupational Medicine, was asked by the governor of her home state of Illinois to spearhead the commission investigating industrial illnesses. Lead, as well as other industrial toxins, was evaluated by doing inspections and interviews with workers. These interviews were held away from their workplaces so they had the freedom to speak without retribution. There were at least 121 cases of lead poisoning in New York City in 1911, only accounting for the serious cases. Some industries involving lead exposure included making of storage batteries, pottery work, making of rubber, making of paints and colors, and the use of lead as a tempering agent. Lead poisoning was summarized and published in 1914 in the American Journal of Public Health (Baron, \& Brown, 2009).

Specific Industry Safety Efforts. The Iron and Steel Electrical Engineers Association was established in 1907 to focus on accident prevention. The Association of 
Iron and Steel Electrical Engineers learned that not only had they been negligent as management in conserving minerals, forests and other natural resources, they had been wasteful of the lives and limbs of their most valuable asset, their industrial workers (Bryson, 2011; Palmer, 1926). During their 1911 convention, Dr. John McDowell's address included a quote that should be a foundation for the safety movement:

The purpose to save life is the noblest of all purposes; It embodies the highest ideal of humanity; Conserves the best asset of the nation; Provides the best protection for the nation; Creates the real glory of the nation; It incarnates the only spirit which offers a solution for all our modern problems, namely, the spirit of democracy and brotherhood; It answers in the affirmative - we are our brother's keeper, and, more than that, we are our brother's brother (Palmer, 1926, p.10).

The National Safety Council and the Railway Safety Movement are monumental forces that have made strides in many areas (Palmer, 1926). The Public Health Model of Injury Prevention lists the following priorities: (a) identify and prioritize problems through surveillance, (b) quantify and prioritize risk factors through analytic research, (c) identify existing or develop new strategies or technologies to prevent occupational injuries, (d) transfer and implement the most effective injury control measures, and (e) evaluate and monitor the results of intervention efforts (Stout, 2008).

Fire Incidents. On March 25, 1911, fire spread in the Triangle Shirtwaist Company facility in New York City. The business, which inhabited the top three floors in a 10-story building, had padlocked the doors leading to the exits to keep the employees at their sewing machines. As the fire broke out quickly, with thousands of pounds of 
fabric supporting it, employees scurried to the stairs, freight elevator and fire escape. Many died once the rear fire escape collapsed, and numerous others jumped to their deaths in an attempt to escape the burning building. Even though firefighters reached the scene quickly, their ladders only extended to the sixth floor. Overall, 146 women died. Even with the public protest, the owners were found innocent of manslaughter charges. They were ordered to pay $\$ 75$ to the families of 23 victims. As a result of the fire, the city instituted the Bureau of Fire Investigation. This horrific incident continues to be a graphic image of the necessity for all companies to ensure a safe workplace (Greer, 2001; Markowitz, \& Rosner, 2011).

On November 28, 1942, the Cocoanut Grove Nightclub in Boston was filled with over 1,000 patrons. With the club capacity being 600 , the recipe for disaster was in the works. It made a major impact on building occupant safety. A young bar attendant lit a match to screw in an electric bulb due to low lighting, causing a flash fire. The fire quickly spread up a palm tree decoration, propagating to draperies and covering the area with a choking smoke. All lighting failed within three minutes of the fire beginning. Almost 500 people died in this fire due to the night club being over capacity and the exits not being appropriate and not working (Greer, 2001).

Several occupancy and fire safety regulations were promulgated because of this incident such as: (a) revolving doors must have additional means of egress that provide a clear path of travel, (b) exit doors must swing in the direction of the exit, (c) authorized occupant capacity must not be exceeded, (d) exits must be maintained free and clear of storage or any obstructions, (e) decorative material must be fire-resistant, flame-retardant or non-combustible, and (f) at least two means of egress must be available in places of 
public assembly. Also, this fire drove regulatory requirements for emergency lighting and the placement of fire exits (Greer, 2001; Life Safety Code, 2012).

Marine Incidents. On April 15, 1912, the RMS Titanic sank. It had been named the unsinkable ship. It was constructed to cater to the rich and famous. The owner and officers decided to reduce the number of lifeboats, since they would clutter the deck, in an effort to make a good impression to the travelers. When the ship departed, it carried enough boats for 1,178 people, too few for the 2,207 passengers and crew on board. The rationality for this decision was that the boat was unsinkable, so lifeboats would not be needed. In the course of the tragic voyage across the Atlantic Ocean, the ship's officers obtained at least seven forewarnings about icebergs. However, just after 11:40 p.m., the ship ran into an iceberg, sealing its catastrophic outcome. Other contributing factors played a part to the mass loss of life as well. Of the few lifeboats to be had, a large number of them were launched with only one-third of the people they could hold. Whereas some passengers were rescued from the icy waters, a rescue plan that was well activated by the officers and staff could have assisted in the rescue of many more. Of the 2,207 people on board, only 705 survived, with a loss of life of 1,502 people.

Consequently, due to this tragedy, all ships must provide the adequate number of lifeboats for all the passengers and crew. Also, the universal distress call "SOS" was adopted. It is easy to send and receive. Ships must have 24-hour radio watch. Travelers on large ships are required to participate in lifeboat training and be knowledgeable about donning life preservers. This tragedy also inspired the formation of the International Ice Patrol, which notifies ships of ice conditions near shipping routes and channels (Greer, 2001). 
Mining Disasters. The Stag Canyon Mine experienced two horrific incidents, one on October 22, 1913, in No. 2 mine, with an explosion claiming the lives of 263 miners. The second worst mining disaster in United States history occurred there on February 8, 1923, with a fire in mine No. 1 killing 125 miners. On November 5, 1930, a methane gas explosion in the Sunday Creek Coal Company mine in Millfield, $\mathrm{OH}$ claimed the lives of 82 miners. These three incidents, as well as others, have led to the nation's mining regulations. Mine safety became regulated as early as 1891 . It instituted minimal ventilation requirements, and also built in child labor laws which do not allow children twelve years of age or younger from working in mines. The Bureau of Mines was established by Congress in 1910. A full ten year period had reflected at least 2,000 mining fatalities per year. The agency was given authority to conduct research and mandated to strive to reduce accidents in the coal mining industry. Inspections in mines were not allowed until 1941 (Greer, 2001). Even with strict mining regulations, accidents still happen. On April 5, 2010, West Virginia’s Upper Big Branch mine exploded leaving twenty nine miners dead (Markowitz, \& Rosner, 2011).

Construction Safety. The Empire State Building was under construction from 1930 to 1931 . It was considered the world's tallest building in 1930, measuring 1,472 feet tall with 102 stories. There were 3,400 workers that worked more than seven million hours. Only one fatality was due to a fall, in spite of exposure to falls being paramount. The hazards these workers confronted to finish this massive structure were beyond compare, which still graces the New York horizon. One can value the advances made since this time period to ensure that workers do not have to depend on good fortune to stay safe. 
The Golden Gate Bridge, built from January 1933 to May 1937, is a combination of cantilever and suspension design. It spans 9,266 feet with some 4,200 feet of that distance over water. There was positive safety procedures put into action during this project that were very effective. Due to the overhead hazards, protective headgear was required. Glare free goggles, as well as special hand and face cream for wind protection over the bay, made workers much more comfortable. The use of safety nets suspended the full length of the expanse of the bridge was a proactive aspect of fall protection. This net saved 19 workers who fell. Only one fatality was reported, being quite an accomplishment considering all the factors involved in constructing this bridge. Yet, on February 17,1937 , due to the collapse of a scaffold supporting 12 paving contractors, the workers fell 220 feet to the water below resulting in 10 fatalities (Greer, 2001).

The "Hawk's Nest Tunnel” was built beginning on March 31, 1930 and completed eighteen months later. The major impact from this construction project was the silica exposure to the workers from the hard quartz. The mere use of a wet method of quartz removal would have spared workers this horrific exposure. Silicosis can exist in three forms including chronic, accelerated and acute. The workers who perished from acute silicosis are uncertain. Estimates range from 400 on the low side to 1,500 on the high side. Official estimates, that were considered realistic by many, agree the deaths were at 764 from just acute silicosis, with approximately 1,500 other workers suffering from the chronic and accelerated forms of silicosis. The best legislation, that was a response to this horrific incident, was the Walsh-Healy Act of 1936, making it unlawful for companies supplying the federal government to carry out contract work under 
working conditions that were unsanitary, hazardous or dangerous to the safety and health of their employees. This act remains in place today (Stalnaker, 2006).

Hoover Dam was built between 1931 and 1936. It is 726 feet high and weighs more than 6.6 million tons. It consists of more than 4.4 million cubic yards of concrete. There were 3,500 construction workers on site as an average, with up to 5,218 during the summer of 1934. The summer working conditions were very hard on the workers due to heat stress. The temperatures would rise to as high at 130 degrees $\mathrm{F}$ during the day and only drop to the 90 degrees F range at night. There were a total of 213 fatalities during this project. Many of the fatalities, categorized as being caused from heart attacks, heat prostration and other natural causes, were not included in the total number of fatalities (Greer, 2001).

Oil Industry Challenges. The catastrophic disaster at the BP oil rig, Deepwater Horizon, occurred on April 20, 2010 and left eleven men dead with numerous others injured and traumatized. The environmental impact of this disaster was insurmountable (Markowitz \& Rosner, 2011). The catastrophic incident on Piper Alpha highlights the importance of safe management practices, behavioral responses and work climate. The design of the rig itself contributed to such an enormous loss of life, totaling 111 . The Process Safety Management standard finally succeeded in being promulgated following this horrific incident (Zanko, \& Dawson, 2012).

\section{Workplace Injuries.}

Since the Occupational Safety and Health Administration was established on April 28,1971 , fatalities have been reduced by $65 \%$, while occupational injuries and illnesses have been reduced by $67 \%$. However, every day 12 fatalities still occur in our 
workplaces across the United States. Each year, at least 3.3 million working men and women suffer from job related injuries and illnesses. Millions more are exposed to toxic chemicals that may have short term effects or others that may have long term effects such as chronic obstructive pulmonary disease or cancer (OSHA, 2014).

According to the Bureau of Labor Statistics, the 2012 total of 4,628 fatal work injuries decreased slightly from the 4,693 fatal work injuries reported for 2011 . The rate of fatal work injuries in 2012 was 3.4 fatal work injuries per 100,000 full-time equivalent workers, down slightly from 3.5 in 2011 . More fatal work injuries resulted from transportation incidents than from any other event in 2012. Roadway incidents alone accounted for one out of every four fatal work injuries. Overall, 65 fewer fatal occupational injuries occurred in 2012 compared to 2011. The greatest decrease was seen in the exposure to harmful substances or environments event category (U. S. BLS, 2014).

Violence and other injuries by persons or animals increased, while there was also an increase in injuries from contact with objects and equipment. The injury categories of falls, slips, and trip events showed an increase as well. Roadway incidents accounted for the greatest share of work-related transportation fatal injuries for 2012. Of these, 565 deaths (29 percent) resulted from a roadway collision with another vehicle. Pedestrian vehicular incidents constituted the second greatest number of transportation-related fatal injuries. In 2012, falls to lower level accounted for 570 fatal work injuries. Forty-five percent of falls to lower level involved falls of 20 feet or less. Another 20 percent of cases involved falls from more than 30 feet. A disproportionate share of fatal work injuries involved men relative to their hours worked in 2012. A higher percentage of fatal work injuries involving women resulted from homicides compared to men. Men 
incurred a higher percentage of fatal work injuries resulting from roadway incidents, contact with objects and equipment, and exposure to harmful substances or environments compared to women. Men and women experienced similar proportions of fatal injuries from falls, slips, trips and fires and explosions. A higher percentage of fatal work injuries involving women resulted from homicides compared to men. Men incurred a higher percentage of fatal work injuries resulting from roadway incidents, contact with objects and equipment, and exposure to harmful substances or environments compared to women. Men and women experienced similar proportions of fatal injuries from falls, slips, trips and fires and explosions (U. S. BLS, 2014).

The 2012 total for fatal work injuries involving Hispanic or Latino workers was about the same as the total for 2011. Sixty-five percent of fatally-injured Hispanic or Latino workers in 2012 were born outside of the United States. Workers born in Mexico accounted for the largest portion (39 percent) of foreign-born workers who died from work-related injuries in the United States in 2012. Fatal work injury rate for workers 45 years of age and over were higher than the overall U.S. rate, and the rate for workers 65 years of age and over was around 3 times the rate for all workers.

Construction had the highest count of fatal injuries in 2012, but the agriculture, forestry, fishing and hunting sector had the highest fatal work injury rate. Fifteen percent of all fatal work injuries in 2012 involved contractors. One third of those who died while employed in the private construction industry were actually contracted to another industry, such as government or real estate, when the fatal injury occurred. Three industry groups (construction, professional and business services), and transportation and warehousing, were net providers of contract workers. All other industry groups were net 
receivers. Fatal injuries in government increased by one third, and those in financial activities by 59 percent, when workers contracted into the industry were included (U. S. BLS, 2014).

The number of fatal work injuries in the private mining industry increased by 17 percent in 2012. Fatalities in the oil and gas extraction industries accounted for 78 percent of the fatal work injuries in the mining sector in 2012. Although transportation and material moving occupations had the highest number of fatal work injuries in 2012, the major occupational group with the highest fatal work injury rate was farming, fishing, and forestry. The data for 2012 showed fatal work injury rates were high for logging workers and fishers and related fishing workers. Twenty-one states and the District of Columbia had final counts showing more fatal injuries in 2012 than in 2011 . Twenty-six states or $52 \%$ of states had fewer fatal workplace injuries in 2012 compared to 2011 (U.S. BLS, 2014).

In 2012, U.S. fire departments responded to an estimated 1,375,000 fires. These fires resulted in 2,855 civilian fire fatalities, 16,500 civilian fire injuries and an estimated $\$ 12,427,000,000$ in direct property loss. There was a civilian fire death every 3 hours and 4 minutes and a civilian fire injury every 32 minutes in 2012. Home fires caused 2,380 , or $83 \%$, of the civilian fire deaths. Fires accounted for four percent of the $31,854,000$ total calls. Seven percent of the calls were false alarms; sixty-eight percent of the calls were for aid such as emergency medical services (NFPA, 2014).

During 2006-2010, an estimated 42,800 fires in or at industrial or manufacturing properties (including utility, defense, agriculture, and mining) were reported to U.S. fire departments per year, with associated annual losses of 22 civilian deaths, 300 civilian 
injuries, and $\$ 951$ million in direct property damage. Seventy percent of these fires occurred outside or in unclassified locations, $20 \%$ occurred in structures and $9 \%$ in vehicles. Two-thirds (66\%) of the combined industrial or manufacturing facility structure fires occurred specifically in manufacturing facilities (as opposed to utility, industrial, defense, agriculture, and mining properties) (NFPA, 2014).

\section{Establishment of OSHA}

The "Williams-Steiger" Occupational Safety and Health Act was signed into law by President Richard M. Nixon in December 1970. This law led to the establishment of the Occupational Safety and Health Administration (OSHA), the National Institute of Occupational Safety and Health (NIOSH), and the independent Occupational Safety and Health Review Commission. OSHA's mission is to ensure safe and healthful working conditions for working men and women by setting and enforcing standards and by providing training, outreach, education and assistance.

The Occupational Safety and Health Act was promulgated and put into place in 1970. This established the Occupational Safety and Health Administration and the National Institute for Occupational Safety and Health. OSHA's enforcement arm required many companies to get in compliance, a circumstance which persists in many locations today (Greer, 2001). The Occupational Safety and Health Act of 1970 mandated under the general duty clause that all workers are entitled to safe and healthful working conditions. The employers are required to provide a workplace free of recognized hazards. When OSHA does not have a specific standard for a particular issue, they will cite under the general duty clause (OSHA, 2013; Silverstein, 2008). OSHA continues to promulgate standards that address many work-related hazards, offer 
compliance assistance, conduct outreach through consultation, and conduct training designed to advance safety and health in the workplace (Greer, 2001). In April 1978, the establishment of OSHA's New Directions Training and Education grants was made to support the development of occupational safety and health training education programs for workers and employers in high hazard occupations. Over 1 million individuals have been trained as a result of this initiative.

\section{OSHA's response to Man-made and Natural Disasters}

On September 11, 2011, OSHA responded to Ground Zero in New York City and the Pentagon to monitor worker exposures to hazards during cleanup and recovery operations. They also fit tested and distributed respiratory protection to all personnel. OSHA hurricane response workers, joined by staff from State Plans and On-site Consultation Programs, pulled together in August 2005 after Hurricane Katrina. The consultation program personnel spread out across the Gulf States to help protect workers involved in cleanup and recovery operations (OSHA, 2014).

\section{Enactment of Standards}

The OSHA standards that have been enacted are being separated by the types of hazards they are designed to protect. The four major groupings of hazards are physical (Table 3), chemical (Table 4), ergonomic (Table 5) and biohazards (Table 6). A general section (Table 2) is provided for standards that are not specific to a group of hazards (OSHA, 2014). 
Table 2

General Hazards

Year OSHA Standard Issued

$1980 \quad$ Access to Employee Exposure and Medical Records

1989

Voluntary Guideline - Effective Safety and Health Program Management

2007

Employers must cover cost of Personal Protective Equipment (i.e. earplugs, respirators and protective gloves)

2010

2010

Employers implement systematic program to identify and correct workplace hazards.

$2010 \quad$ Reissued Shipbreaking National Emphasis Program - Updated Shipyard PPE (Personal Protective Equipment) directive.

2011

Department of Labor issued final rule to protect shipyard workers.

2013

Final rule to broaden exemption for digger derricks in the Cranes and Derricks standard.

2013

Proposed rule to improve tracking of workplace injuries and illnesses.

Note. Adapted from Occupational Safety and Health Administration. (2014). Occupational safety and health administration homepage. Retrieved from http://www.osha.gov 
Table 3

Physical Hazards

Year OSHA Standard Issued

1972 Protection of construction workers operating electric power transmission and distribution equipment, aerial lifts and helicopters.

1977

Protection of workers in commercial diving operations.

1981

OSHA issued the hearing conservation standard which required that hearing protection be provided to workers exposed to noise levels above 85 decibels. The new standard also required employers to perform hearing tests on workers to monitor how these protection measures were working.

1986

OSHA issued a standard for ground-fault circuit interrupter protection on construction sites.

1987

Grain handling standard to protect workers in the grain industry from the risk of fire and explosion from highly combustible grain dust. The standard also protects workers from suffocation hazards when entering grain bins.

1989

Lockout/Tagout standard, establishing procedures to safeguard employees from the unexpected energization or startup of machinery and equipment or the release of hazardous energy during service or maintenance activities.

1989

Trenches and excavations for construction workers.

1992

Process Safety Management to reduce the risk of deadly fires and explosions.

Confined Space (i.e. underground vaults, tanks, storage bins, manholes, pits, silos, process vessels, and pipelines) required safe procedures and permits for entry.

1994

Fall protection for construction workers strengthened. Employers had to begin providing the safety harnesses and lines or guardrails.

1994

Safety requirements covering all logging operations, regardless of the end use of the forest products. 
Table 3 (Continued)

Physical Hazards

Year OSHA Standard Issued

1996 Scaffolding standard required safety measures for workers.

1997 Strengthened health and safety protections for workers at long shoring and marine terminal operations.

2001

2004

2009

Steel Erection Standard that protected construction workers in steel erection.

2010

Standard for increased protection for shipyard workers from fire hazards on vessels and at land-side facilities.

Initiated rulemaking to comprehensively address the fire and explosion hazards of combustible dust.

Walking/Working Surface Safety proposal for general industry to improve worker protection from falls, the leading cause of work-related injuries and death.

2010

Act to protect residential roofing workers under U. S. Labor Department.

2011

Revised directive for reducing and eliminating hazards in commercial diving operations.

2011

Issued hazard alerts on dangers of worker engulfment and suffocation in grain bins as well as issued a hazard alert on the dangers to workers of incorrectly rebuilt circuit breakers.

2011

New guidance document to help construction employers and workers to prevent nail gun injuries

2014

Final rule revising the standards for electric power generation, transmission and distribution, following up later that month with a publication in the Federal Register.

Note. Adapted from Occupational Safety and Health Administration. (2014). Occupational safety and health administration homepage. Retrieved from http://www.osha.gov 
Table 4

Chemical Hazards

Year OSHA Standard Issued

1971-73 Initial safety and health consensus standards were enacted; the development of OSHA's first standard was enacted, on asbestos fibers, a known human carcinogen.

OSHA adopted existing national consensus and established Federal standards during this same time period to provide a baseline for safety and health protection in American workplaces.

1972

Standard limiting workplace exposure to asbestos fibers to protect workers from lung cancer, asbestosis (serious lung disease) and mesothelioma (cancer of the lining of the lungs and abdomen).

1973-75

Protection of workers from a variety of carcinogens, those chemicals known to cause cancer in humans.

1974

Final rule that established comprehensive standards for 14 cancer-causing substances.

1974

Established a permissible exposure limit of 1 part per million for workers exposed to vinyl chloride, a flammable gas and a carcinogen.

1976

Issued coke oven emission standard. Coke oven emissions are associated with lung cancer. Companies had to implement engineering controls to control exposures.

1978

OSHA issued the cotton dust standard to protect workers from the crippling hazards of "brown lung" (byssinosis) in the textile industry.

1977-81 Cotton dust, benzene, dibromochloropropane (DBCP), inorganic arsenic and acrylonitrile standards.

1978

Lead standard for general industry. Lead has long been recognized as a toxin that can cause damage to the kidney, nervous system and reproductive system. 
Table 4 (Continued)

Chemical Hazards

Year OSHA Standard Issued

1984 Final standard for ethylene oxide (EtO), a highly toxic chemical used as a sterilizing agent in healthcare and in fumigants. It includes provisions for personal protective equipment, measurement of employee exposure, training, signs and labels, medical surveillance, regulated areas, emergencies, and recordkeeping.

1986-89

Eleven safety standards and four health standards. The rulemaking strengthened OSHA's standards for hundreds of toxic substances (Permissible Exposure Limits, PELs), but this effort was overturned by the courts in 1992 .

1987

Revised standard to protect workers from benzene, a highly toxic chemical that cause leukemia.

1989

Final rule to protect public and private sector workers exposed to toxic substances from spills or at hazardous waste sites.

1990

Laboratory Safety Standard for the protection of laboratory workers recognizing the unique dangers posed to workers in laboratories while handling hazardous chemicals.

1993-97

Protection of workers from the toxic chemical 1,3butadiene by reducing the permissible exposure limit from 1,000 parts per million (ppm) to $1 \mathrm{ppm}$. 1,3butadiene is used in the production of synthetic rubber.

1994

Stronger asbestos standard with lower permissible exposure limits, offering significantly increased protection to exposed workers.

Lead standard to protect workers in the construction industry

Protection of workers from exposure to methylene chloride, a chemical widely used in a variety of industrial processes and industries, including paint stripping, pharmaceutical manufacturing and metal cleaning and degreasing. Methylene chloride exposure increases the risk of cancer and other effects. 
Table 4 (Continued)

Chemical Hazards

Year OSHA Standard Issued

2006 Hexavalent Chromium standard that provided greater protection to workers exposed. Health effects with hexavalent chromium included lung cancer and dermatitis.

2009

Established a Global Harmonization System for Hazard Communication.

$2011 \quad$ National Emphasis Program for chemical facilities established.

2012

Revised the Hazard Communication standard.

2012

OSHA and NIOSH issued a hazard alert on ensuring workers in hydraulic fracturing operations have appropriate protections from silica exposure.

2013

OSHA and NIOSH issued a hazard alert on 1-bromopropane and urged efforts to safeguard workers from exposure to this toxic chemical.

2013

Proposed rule to reduce exposure limits to protect workers exposed to crystalline silica.

Note. Adapted from Occupational Safety and Health Administration. (2014). Occupational safety and health administration homepage. Retrieved from http://www.osha.gov

Table 5

Ergonomic Hazards

Year OSHA Standard Issued

$1988 \quad$ OSHA issued the Ergonomic Program Management Guidelines for Meatpacking Plants and it still exists today.

Note. Adapted from Occupational Safety and Health Administration. (2014). Occupational safety and health administration homepage. Retrieved from http://www.osha.gov

In 1988, in the wake of Congressional hearings, OSHA began an inspection and outreach effort at several large meatpacking plants. Meatpacking remains one of the 
nation's most dangerous industries, and these plants have high rates of serious injuries and illnesses, especially cumulative trauma disorders. All efforts to get an ergonomic standard for general industry and construction have failed to get promulgated despite the high rate of musculoskeletal injuries. OSHA continues to cite companies using the General Duty Clause 5 (a) (1) in the original OSH Act of 1970: All employers are required to provide a workplace free of recognized hazards (OSHA, 2014).

Table 6

Biohazards

\begin{tabular}{ll}
\hline Year & OSHA Standard Issued \\
\hline 1987 & $\begin{array}{l}\text { A standard that required employers of 11 or more field } \\
\text { workers to provide toilets, potable drinking water, and hand } \\
\text { washing facilities to hand laborers in the field. }\end{array}$ \\
& $\begin{array}{l}\text { Bloodborne Pathogen Standard to protect workers from } \\
\text { HIV/AIDS (human immunodeficiency virus/acquired immune } \\
\text { deficiency syndrome) and hepatitis B. }\end{array}$ \\
& $\begin{array}{l}\text { Strengthened worker protections for blood borne pathogens } \\
\text { after passage of the Needlestick Safety and Prevention Act }\end{array}$
\end{tabular}

Note. Adapted from Occupational Safety and Health Administration. (2014). Occupational safety and health administration homepage. Retrieved from http://www.osha.gov

\section{Establishment of OSHA Training Institute/Summits}

The OSHA Training Institute was established on January 17, 1972 to train OSHA compliance officers and the private sector, as well as other government, safety personnel. In April 2010, OSHA held a historic summit, bringing together over 1,000 participants, with the goal of increasing Latino and other vulnerable workers' knowledge of their OSHA rights and their ability to use their rights (OSHA, 2014). 


\section{Establishment of OSHA State Plans}

In 1972, the first OSHA state plan was approved, extending coverage to state and local government workers. OSHA approved South Carolina and Oregon to adopt and enforce the agency's standards in their states. They became the first state plans. In addition to the private sector, OSHA state plans extend OSHA coverage to state and local government workers who are otherwise not protected by the OSH Act. Currently, 27 states and territories operate OSHA-approved state plans. In July 1991, California State OSHA adopted the first comprehensive statewide Injury and Illness Prevention Program standard. Since then, fourteen additional states have adopted required injury and illness prevention programs. In July 1997, California adopted rules to protect workers from work-related musculoskeletal disorders, one of the most prevalent of all workplace injuries and illnesses, called the Ergonomics Standard (OSHA, 2014).

\section{OSHA Consultation Program}

In 1975, the on-site consultation program was established to assist small businesses. This is a free service funded by OSHA to help small, high hazard employers identify and correct serious hazards, as well as train workers and supervisors to recognize workplace hazards and develop effective safety and health management systems at their worksites. With significant financial support from Federal OSHA, state-run agencies, using well-trained professional staff, deliver these services. Since its creation, the program has made over 1 million visits to small businesses (OSHA, 2014).

\section{Catastrophic Incidents Leading to New Standards}

Between 1975 and 1976, the pesticide Kepone, produced at a manufacturing plant in Hopewell, Virginia, poisoned workers and polluted the environment. Fifty-seven 
workers suffered sterility, tremors, and liver damage. The tragedy prompted OSHA to develop and expand its expertise to respond to complex hazards.

In April 1978, fifty-one construction workers plunged to their death when the scaffolding they were on collapsed at a power plant's cooling tower construction site in Willow Island, West Virginia. The Willow Island tragedy is considered the worst construction disaster in U. S. history.

In December 1984, the catastrophic release of the toxic chemical methyl isocyanate at Union Carbide's plant in Bhopal, India killed at least 3,800 immediately, resulting in thousands of additional deaths and affecting half a million people. The disaster sparked worldwide concern, prompted OSHA to inspect all U. S. facilities manufacturing or processing this chemical, and led OSHA to increase inspections of chemical plants during 1985-1986 (OSHA, 2014).

In April 1987, L’Ambiance Plaza collapsed in Bridgeport, Connecticut during construction. This disaster killed 28 workers and led to stronger regulation of the "lift slab" construction method, which is now rarely used.

In March 1989, the Exxon Valdez oil tanker spilled 11 million gallons of crude oil into Alaska's Prince William Sound. OSHA sent inspectors to monitor worker protection and required safety and health training.

In October 1989, twenty-three workers were killed in a petrochemical plant explosion owned by Phillips 66 in Pasadena, Texas. The disaster led OSHA to issue the Process Safety Management standard in 1992.

In September 1991, a disastrous fire at Imperial Foods in Hamlet, North Carolina, killed 25 poultry workers. Many of these workers could not escape the raging fire 
because the company had locked exit doors. The tragic fire led to Federal OSHA resuming concurrent jurisdiction in North Carolina (a state-run OSHA program) and resulted in a revamped North Carolina State Plan.

An explosion and fire at the BP refinery in Texas City Texas occurred on March 23, 2005 resulting in the death of 15 workers and injuries of more than 160 others. In response to this event, OSHA issued the largest fines in its history and initiated increased inspections in oil refineries across the country (OSHA, 2014).

In April 2010, BP Oil's Deepwater Horizon oil rig experienced a catastrophic explosion killing 11 workers, and resulted in an unprecedented oil spill. OSHA worked as part of the coordinated federal response, making over 4,200 site visits to ensure that $\mathrm{BP}$ and its contractors were protecting workers involved in the cleanup of health and safety hazards. To ensure that workers were not inhaling dangerous levels of hazardous chemicals, OSHA took over 7,000 independent air samples at clean-up areas, both onand off-shore, and reviewed over 90,000 air samples taken by other federal agencies and BP (OSHA, 2014).

In Yonkers, NY in March 2011 there was a scaffold collapse on a high rise building. However, due to the advances made in scaffolding standards, it shows that fall protection saves lives. Two workers were painting the side of a 28 story building when the cable on one side of the apparatus they were standing on broke. The workers were clinging on for their lives from the upended structure, approximately thirteen stories above the ground, for nearly an hour. Fortunately, the workers were rescued by firefighters (OSHA, 2014). 


\section{Fines and Penalties}

OSHA issued the first "egregious" penalties to Union Carbide of Institute, West Virginia in April 1986. The seriousness of the violations prompted OSHA to create a new level of fines for egregious violations, and to propose record penalties of nearly $\$ 1.4$ million against the company (OSHA, 2014).

In October 2009, OSHA announced $\$ 87.4$ million in penalties against BP resulting from its inspection of the Texas City plant earlier that year. A total of $\$ 56.7$ million of that penalty was levied for BP's failure to abate the hazards behind the fatal 2005 explosion. In November 2009, U. S. Department of Labor attorneys, in preparation for filing with the Occupational Safety and Health Review Commission, discovered that an OSHA clerical error had led to the duplication of 29 "failure-to-abate" violations, totaling \$6.1 million. The department attorneys immediately moved to amend the citations, and the full penalty was adjusted to $\$ 50.6$ million, still the highest fine ever issued by OSHA and paid by an employer (OSHA, 2014).

\section{Court Rulings and Executive Orders}

In February 1980, the Supreme Court, in Whirlpool Corporation v. Marshall, issued a landmark decision affirming that the OSH Act provides workers with the right to refuse to perform an assigned task on the basis of a reasonable apprehension of death or serious injury, coupled with a reasonable belief that no less drastic alternative was available. The Court held that workers who use this OSHA protection may not be discriminated against in such action. Also, President Carter issued an Executive Order providing OSHA coverage for millions of federal workers (OSHA, 2014). 


\section{Reaching for the Star}

Between March 1981 and April 1984, the OSHA Voluntary Protection Programs (VPPs) were launched. The VPP recognizes workplaces with exemplary safety and health management systems and encourages other employers to follow suit. A company receives "Star" status when they are proven, through an extensive application, review of all their safety statistics, safety programs, safety records such as audits, and an extensive wall-to-wall inspection of their facility, to be beyond reproach/going above and beyond the standards.

Safety Legislation. All of these safety tragedies have caused the public to see the need for occupational safety. Legislation has had a positive effect on our profession and industry throughout the years (Greer, 2001; Silverstein, 2008). The American Standard Association was initially put into place in 1918 and later became the American National Standards Institute (ANSI), as we know it today. It produces voluntary safety standards or guidelines that get referenced in OSHA standards and then become law. Federal regulations for mining were authorized by Congress in 1947; however, the Federal Coal Mine Safety Act was not enacted until 1952. It authorized annual inspections of underground coal mines. The Bureau of Mines still only had a limited amount of enforcement authority, such as issuing violations and imminent danger withdrawal orders, to shut down mining operations. If the inspectors were denied access to the mine or the owners did not follow orders issued by the inspectors, only civil penalties could be levied (Greer, 2001).

Congress passed the Federal Mine Safety and Health Act in 1977. This act consolidated federal safety and health regulations of the mining industry to include coal 
and non-coal mining. All the way through history, the safety profession and safety professionals have been striving to improve working conditions. Because of these efforts and commitment, many lives are spared each day.

The safety management field is a journey not a destination, it is never complete. The ultimate goal is for each worker to return home in the same condition they came to work. Safety professionals remain with a challenging but rewarding task at hand (Greer, 2001). The changing political, economic, and legal landscape of work is creating potential new dangers to today's workers. Included in these changes are lean manufacturing, outsourcing, aging workforce, declining unionization, changing immigration patterns, and breakdown of long-term employer/employee relationship. There are four barriers to OSHA's success. First, OSHA enforcement is limited because only $1 \%$ of workplaces are inspected annually with only a glimpse of evidence that inspections have an impact. Second, there is little evidence that OSHA's consultation and other voluntary programs have any measurable impact on hazards of injuries/illnesses. Third, OSHA sends its small number of inspectors to inspect one workplace at a time, which is very inefficient with 2,000 inspectors and 8 million workplaces. Finally, the OSH Act was written when employees were more likely than they are today to hold a long-term job with a single, stable employer and to be represented by a union (Markowitz, \& Rosner, 2011; Silverstein, 2008). The safety representatives for the union workers act as conduits for the passage of information from management to labor by attending safety meetings, being involved in accident investigations, and most importantly, doing proactive contributions (Harris, Kirsten, \& Walker, 2012; Travis, 2002). 
Safety Statistics. When looking at the death rate between 1912 and 1999 per 100,000 population, it has dropped more than 90 percent (Greer, 2001). However, one death is still unacceptable. The number of workplace deaths in 1999 was 5,100 compared to 4,628 in 2012 (BLS, 2014). Fourteen workers die on the job each day, a powerful reminder of the risks faced by workers across the country each day. Miners, railroad workers, construction workers and others are less likely to die on the job today than they were a century ago. However, the American workplaces are far from safe. Every year nearly five thousand U. S. workers continue to die from accidents on the job. Thousands of others succumb to debilitating illnesses such as silicosis, lead poisoning, cancer and heart disease, all linked to toxic material exposure (Markowitz, \& Rosner, 2011).

Workers' Compensation. In 1900, no state in the United States had a workers' compensation law; however, by 1915, every highly-industrialized state had passed an act for some form of workers' compensation. Some companies are under state approved programs while others are self-insured. It is a requirement that all employers cover their employees on workers' compensation insurance. It is not voluntary (Markowitz, \& Rosner, 2011).

\section{Control of Hazards}

The hierarchy of controls is a means for use in assessing the effectiveness of inherently safer technologies. The purpose is to eliminate occupational hazards which will eliminate risks (Myers, Durborrow \& Cole, 2012). Prevention through design focuses on ways to prevent and control occupational injuries and illnesses by designing out or minimizing hazards and risks early in the design process (Walter, 2011). In a safety through design concept, a four-level order of precedence is used that applies to all 
design and redesign processes. This includes design for minimum risk by eliminating the hazard, incorporating safety devices, providing warning devices, and developing and instituting operating procedures and training. The first two levels are best in that they are passive controls, where the last two levels are active, requiring human intervention (Manuele, 1999).

\section{Safety Management System}

A safety management system is woven into the fabric of an organization. It becomes part of the culture, the way people do their jobs. For the purposes of defining safety management, safety can be defined as the reduction of risk to a level that is as low as is reasonably practicable. There are three imperatives for adopting a safety management system for a business which includes ethical, legal, and financial. There is an implied moral obligation placed on an employer to ensure that work activities and the place of work be safe. There are legislative requirements defined in most every jurisdiction on how this is to be achieved. There is a substantial body of research which shows that effective safety management (which is the reduction of risk in the workplace) can reduce the financial exposure of an organization by reducing direct and indirect costs associated with accidents and incidents. To address these important elements, an effective Safety Management System should define how the organization is set up to manage risk. It should identify workplace risk and implement suitable controls. In addition, it should implement effective communications across all levels of the organization, implement a process to identify and correct non-conformities, and implement a continual improvement process. A safety management system can be created to fit any business type and/or industry sector (Smitha, 1998; Zanko, \& Dawson, 
2012). Evidence shows that a good safety program can reduce occupational injuries and illness. It can also reduce operating costs to a fraction of what they would be otherwise (Grimaldi \& Simonds, 1998).

\section{Professional Organizations}

The American Industrial Hygiene Association (AIHA) is a professional association that started in 1939. It has over 10,000 members and has expanded to become an international association with members in over 40 countries. AIHA publishes one of the leading professional journals for industrial hygienists, The Journal of Occupational and Environmental Hygiene. AIHA is a nonprofit organization devoted to achieving and maintaining the highest professional standards for its members. More than half of its 10,000 members are certified industrial hygienists (CIHs), and many hold other professional designations. AIHA administers comprehensive education programs that keep occupational and environmental health and safety (OEHS) professionals current in the field of industrial hygiene. AIHA is one of the largest international associations serving OEHS professionals practicing industrial hygiene and is a resource for those in large corporations, small businesses and who work independently as consultants. Their mission is creating knowledge to protect worker health. Their vision is the elimination of workplace illnesses. Industrial hygienists anticipate health and safety concerns and design solutions to prevent them. They are the guardians of workplace safety, applying science to identify and solve health and safety problems. Industrial hygienists also unite management, workers and all segments of a company behind the common goal of health and safety (American Industrial Hygiene Association, 2013). 
The American Society of Safety Engineers (ASSE) is an organization founded in 1911. The ASSE is the world's oldest professional safety society of safety individuals practicing in the field in all types of industries and service organizations. ASSE promotes the expertise, leadership and commitment of its members, while providing them with professional development, advocacy and standards development. It also sets the occupational safety, health and environmental community's standards for excellence and ethics. ASSE is a global association of occupational safety professionals representing more than 35,000 members worldwide. The Society is also a visible advocate for safety, health and environmental (SH\&E) professionals through proactive government affairs at the federal and state levels and in member-led relationships with key federal safety and health agencies. Our members create safer work environments by preventing workplace fatalities, injuries and illnesses. Besides recording less lost time and lower workers' compensation costs, organizations with strong safety performance enjoy increased productivity, a better reputation and higher employee satisfaction (American Society of Safety Engineers, 2014).

\section{Safety Ethics}

Safety, health and environmental professionals wanting to do the right thing versus management making decisions based on cost-benefit, risk, business or factors that may be contrary to doing the right thing, can lead to underlying tension. Morality refers to values that are subscribed to and fostered by society. The origin of these values may be cultural, personal based on family or experiences, educational, or religious. Ethics is internal morality applied to external everyday life. Ethics is about taking a particular course of action, exhibiting a set of specific behaviors, embracing a group of standards, 
and defining a set of expectations based on moral values. It is when the rubber of reality hits the moral high road. For a safety professional, ethics also involves having courage of one's conviction. Several core values shape ethical behavior and influence decision making for safety professionals. Core values are knowledge, truth, and avoidance of error. Other ethical values are trust, accountability, mutual respect, fairness, impartiality, candor, dignity, compassion, and courage. However, the most essential value to have is reciprocity, also called the Golden Rule, treating others as you would like to be treated. As safety professionals, tension can be faced between being safe (without risk) and safety (operating at an acceptable level of risk). Decisions on how far to reduce risk are based on three factors: (a) what the law dictates, (b) the need to achieve a balance between losses and safety costs, and (c) the willingness to take risks (culture) but maintain ethics. The most significant ethical burden on a safety professional is not being able to fully execute their perceived moral/ethical responsibilities to provide a safe workplace, care for employees, and remove hardships due to organization constraints such as costs and culture (Wachter, 2011).

Upton Sinclair's The Jungle was published over 100 years ago. This novel brings to light the difficulty of the working class during the early 20 th century and vividly describes the corruption and terrible safety conditions of the American meatpacking industry. It strongly portrays the hopelessness of the working class. At the end of the novel, there is a resounding plea for workers to unite and organize in order to make positive and permanent changes in the work environment and conditions in Chicago (Sinclair, 1946). A similar battle cry is relevant today to excite, unite and organize safety 
professionals to promote and embrace the preferred basis of safety management ethics (Wachter, 2011).

\section{Safety Leadership}

If a person could only learn the secrets of leadership, they could become a great leader. The top core leadership skills for motivating a group toward a common goal are giving positive recognition, building teams, setting team goals, keep score publicly, and positioning supervisors as trainers. Leaders can only be successful if the workers see their leaders as team players who are watching out for their common good. Leadership is a "we" thing, not an "I" thing, and requires soft skills. This can only be accomplished with face-to-face interaction between the leader and the individuals. Effective leadership is the talent to motivate a group of people toward a common goal. A common identity with the leader is vital for the leader's effectiveness in rallying individual efforts toward collective goals. In the employee's eyes, the supervisor is the company. Leadership is not a unique, charismatic or natural talent. It can be learned, observed and measured (Drennan \& Richey, 2012).

Five elements of all safety program leadership are employee involvement, accountability, developing a safety culture, professional safety responsibility, and management engagement. Leadership dialogue within the safety community can be used to identify common ground with an organization's leadership model, so safety can become an integral part of that model. Employee commitment is essential to the success of a workplace safety management system. There needs to be an authentic relationship between employees and management to have healthy communication in all directions within the organization. Employees need to be empowered over certain things in their 
work environment to bring about true engagement (Bryson, 2011; Dunlap, 2011).

Managers must be accountable for safety to ensure that injury reduction efforts are successful (Dunlap, 2011).

There must be a cultural component to safety. The definition of the culture must be understood by all employees so clear communication can occur up and down the organization as to what is required to initiate and grow the safety culture. The safety professionals provide guidance on regulatory issues and are a resource to spearhead programs to reduce injuries and illnesses. Management engagement in the safety process is critical to make it a core issue that leadership sees as an important area for which they are directly responsible. Leaders must do proactive activities for safety. Their actions are being watched by their employees. Actions speak louder than words, and credibility is at risk if no correlation exists between the two (Dunlap, 2011).

\section{Preparing Graduates for the Future}

The University of Central Missouri's Safety Sciences graduate program in Occupational Safety Management is designed to enhance graduate students' professional success in the fields of health and safety. Safety professionals can find careers in a wide variety of organizations, companies and departments as environmental, health and safety specialists, safety managers, industrial hygienists, risk managers and more (UCM, 2014). These graduates are oftentimes already employed in the field of health and safety while working on their education as non-traditional students. The graduates already work or obtain employment in industry, construction, mining, service organizations, insurance, manufacturing, governmental agencies, transportation, oil exploration/refining and many others. 


\section{Summary}

Our workplaces, whether on a highway as a truck driver or in a factory doing assembly work, continue to pose safety and ergonomic hazards. The employees are the greatest asset a company has to be competitive in our global marketplace. It is an open field to harvest for our safety professionals being taught in the Occupational Safety Management degree program. While supported by regulations, the safety profession is much more rewarding when working for upper management who takes responsibility for safety and takes their moral and ethical obligation to heart.

The objective of this utilization-focused program evaluation is to ascertain the skills and knowledge that alumni defined as essential for entry level safety professionals, the courses or discipline areas the alumni thought were crucial for graduate students to take as part of their curriculum, and to investigate if a trend exists in alumni perceptions of how successful the Occupational Safety Management program at UCM prepared them for their first job. Furthermore, a comprehensive database will be set up for information on the alumni certifications, where alumni work and their annual salaries. Data will be collected through an on-line survey and from a review of historical documents. The information on the creation of the Occupational Safety Management program in 1970 will be obtained from historical documents as well as important developments affecting the Occupational Safety Management program.

Chapter 3 of this evaluation outlines the theoretical framework that directed this utilization-focused program evaluation. It also provides the rationale supporting the use of a quantitative method design. Data collection and analysis techniques are also described, as well as the role of researcher in this evaluation. 


\section{CHAPTER THREE}

\section{RESEARCH DESIGN AND METHODOLOGY}

The assessment of a graduate degree in Occupational Safety Management in our global economy will reflect leadership styles of our safety leaders in our workplaces. The assessment of the University of Central Missouri (UCM) graduate degree in Occupational Safety Management determined if the curriculum was comprehensive in the area of leadership and other areas to meet the needs from a technical and leadership perspective that our graduates have found in the workplaces. In this chapter, a synthesis of the problem and purpose helped to frame the research problems. In addition, the researcher highlighted for the reader the purpose of this quantitative inquiry. The research design rationale is presented along with the population and sample, the instrumentation and the data analyses.

\section{Purpose of the Study}

A normal day in a safety professionals' job can turn into a complete catastrophic event and crisis management scenario in a millisecond. It is important that university programs prepare students for the challenges they will face in the workplace. Our graduate degree program needs to include courses that promote critical thinking skills and allow students the opportunity to work through "real life" scenarios, do role playing and get field experience at a minimal in an internship to be prepared to meet their first real job. Leadership qualities are a necessity in this field no matter what level in an organization a graduate will start their career.

The purpose of this study was to provide constituents with strengths and weaknesses of the graduate Occupational Safety Management program with appropriate 
recommendations based on the findings identified from the study. It is trusted that the data collected from this study will improve the sustainability and effectiveness of the degree program due to the competitiveness with other online programs.

\section{Research Design}

Surveys of alumni have been used for program assessment by academic departments in a variety of disciplines to assess program outcomes, alumni perceptions, evaluate educational and career attitudes, and alumni satisfaction with advising and academic preparation (Al-Nashash et al, 2009; Brosseau \& Frederick, 2009; Finney, Snell, \& Sebby, 1989; Hoyt \& Allred, 2008). The survey instrument was vetted through the faculty and department chair of the Safety Sciences department through three reviews and a pilot study of undergraduate students prior to being submitted to the Institutional Review Board.

The initial method of information collection for this research was a review of historical documents. Specific documents reviewed included 5-year progress reports, minutes of department meetings, and copies of university catalogs going back to the early 1970s. In addition, a dissertation by Patterson from February 1974 provided a wealth of information concerning the very early years of the School of Public Services, the Department of Industrial Safety and Industrial Hygiene, and specifically the occupational safety management program.

Ethical considerations and human subjects requirements were addressed by submitting the proposed research through the University of Missouri's Institutional Review Board (IRB) before any data were collected. Study participants were informed of their rights and assured they could withdraw from the research study at any time. Emails, 
sent to each alumnus, contained a link to the online survey and an explanation that by taking the survey, the alumni was agreeing to participate in the study.

This research provided critical information concerning the strengths and weaknesses of the UCM graduate program in Occupational Safety Management and helped determine if a trend existed in alumni satisfaction with the program at the time of their graduation. The information collected will be utilized by the Department of Safety Sciences, the Dean of the College of Health, Science and Technology, the administration of UCM, and other constituents of the department in deciding what changes are needed to sustain and improve the quality of the academic program. This information will also assist the department with internal and external reviews of the occupational safety management program.

The study examined the extent to which variables interact and how these impact individual alumni perceptions relating to their education and preparation for their employment as well as professional development. Such an undertaking was described as a descriptive study (Kerlinger \& Lee, 2000) with multiple independent variables. A descriptive study determines and reports things the way they are (Gay, 1981). Isaac and Michael (1997) explained the purposes of descriptive research as follows: (a) to collect detailed factual information that describes existing phenomenon, (b) to identify problems or justify current conditions and practices, (c) to make comparisons and evaluations, and (d) to determine what others are doing with similar problems or situations as well as benefit from their experience in making future plans and decisions. According to Van Dalen (1973), this method is useful to gather practical information that may be relevant for the improvement or justification of an existing situation. Information gathered might 
also provide a foundation upon which further research can be conducted. The purpose of this kind of research is to "discover relationship between variables" (Borg \& Gall, 1989, p. 573) and identify comparisons between groups. The broad methodology was quantitative. This methodology enabled the data to be gathered through a questionnaire to the alumni.

\section{Population and Representative Sample}

The graduate degree program in Occupational Safety Management has been in existence since 1970 and has never had a full program evaluation conducted with approximately 1,000 alumni. The information obtained from this research attempted to include all of the alumni from this degree program since its beginning. The intention is for strengths, as well as weaknesses, to be identified to be utilized to strive for continuous improvement in the course offerings and curriculum. The ultimate stakeholders for this program evaluation will be our future students but the primary intended users (Patton, 1997) of the evaluation will be the faculty; the Department Chair of the School of Environmental, Physical and Applied Sciences; and the Dean of the College of Health, Science and Technology. The university as a whole will be the beneficial stakeholders of any improvements and increased participants in the program, as well as increased job security for all faculty members within the safety department. With budget cuts continuing, the continued improvement and success of the program is in the best interest of all faculty and staff. Tenure is of no value if the program in which faculty teach is eliminated.

The desire to identify opportunities and improve the program through this assessment was important to me due to my position as a faculty member in the 
department. After working in industry for thirty-one years as a health and safety professional, my goal was to ensure we are preparing our alumni to enter the workplaces with the most valuable information needed to be successful and effective. Our valuable workers across the world are depending on safety and health professionals to assist in making their workplaces safer.

The purpose of this evaluation was to determine the skills and knowledge that alumni view as important for entry level occupational safety professionals, the courses and topics alumni believe are important for graduate students to take as part of their curriculum, and to assess if a trend exists in alumni perceptions of how well the occupational safety management program at UCM prepared them for their initial position in the safety and health field. In addition, a comprehensive database was compiled of information on what certifications alumni have obtained, where the alumni work and what their annual salaries are currently or during their last job. Demographic data were collected through the survey also. Data were collected through an on-line survey and a review of historical documents was conducted. The review of historical documents provided information on the creation of degrees, and significant developments or changes in curriculum that have affected the graduate Occupational Safety Management program. Evaluating the occupational safety management program in the School of Environmental, Physical and Applied Sciences at UCM entailed the quantitative research method.

\section{Research Questions}

The following research questions guided this study:

1. What courses do alumni view as most important for the safety management graduate students to take as part of their curricular studies? 
2. What knowledge and skills do alumni view as critical for entry level safety professionals in the workplace?

3. How has the overall satisfaction of alumni changed as far as career preparation since the Occupational Safety Management graduate program began in $1970 ?$

\section{Sampling Procedures: Design and Methods}

Evaluating the occupational safety management program in the School of Environmental, Physical and Applied Sciences at UCM entailed the quantitative research method. Prior to the development of the survey instrument, input was obtained from faculty and administrative officials of the College of Science and Technology (Hatch, 2002). The purpose of input was to determine the type of information desired by departmental and college personnel. Feedback from this group formed the framework of the questionnaire survey. The survey was field tested to provide evidence of the validity and reliability of the instrument. Pilot tests were utilized in this process with five undergraduate students. The online survey was administered to alumni via email with a link within Google forms.

\section{Rationale for Quantitative Design}

Heppner and Heppner (2004) stated the quantitative approach allows the researcher to collect data from multiple sources that could be meaningful to a broad range of practitioners within the field. Since the purpose of this study was to examine how alumni from a 44 year span of the graduate Occupational Safety Management program have viewed their educational background and preparedness for the workplace, as well as have utilized their education to gain certifications and years of experience in the field, the 
quantitative approach was determined to be most appropriate. Furthermore, the epistemological view of the researcher should be closely tied to the purpose of the inquiry. Merriam (1998) argued, "Choosing a study design requires understanding the philosophical foundations underlying the type of research" (p. 1). Quantitative research generally follows a positivist form of study where reality is argued to be observable and measurable. Furthermore, the advantage of identifying attributes of a large population from gathering data from a small group of individuals is an advantage of quantitative inquiry (Creswell, 2009). Therefore, examining the descriptive information from the alumni from a different conjectural perspective through a quantitative method will add to the available body of research on the topic.

\section{Data Sources}

The population for this study was approximately 1,000 alumni who have graduated from the Department of Safety Sciences with a graduate degree in Occupational Safety Management. This includes alumni who earned their graduate degree from 1970 through 2014. This group of individuals represented one of the largest populations of occupational safety management alumni for any university in the United States. The sample was the number of alumni the researcher was able to locate and contact using available databases. This included information from the UCM Alumni

office, American Society of Safety Engineers, American Industrial Hygiene Association, Board of Certified Safety Professionals and other social media.

The population for this quantitative inquiry consisted of alumni from the graduate Occupational Safety Management program from UCM. The researcher established that the nonprobability sample of the participants would be the group of alumni that are 
presently in contact with the Alumni Association and have a current email contact on file. Babbie (1990) noted that convenience sampling occurs based on the respondents' availability and convenience. Fraenkel, Wallen and Hyun (2011) articulated the importance of sampling the population for the purpose of research and generalizability. There were three distinct steps used to select the sample of alumni included in this study. First, purposefully identified was the pool of alumni and then the search for contact information was the challenge. This was accomplished by using the alumni online directory established by UCM Alumni Association. Secondly, in order to obtain a representative sample of the alumni, who did not have current information with the alumni office available, the national associations' databases were searched followed by a social media search. Fraenkel, Wallen and Hyun (2011) argued whenever representative sampling is used, "generalization is made more plausible if data are presented to show that the sample is representative of the intended population on at least some relevant variables" (p. 110).

\section{Data Collection}

The online survey of 1,000 alumni (Fink, 2009) was administered following the input from the faculty and other constituents for this study. Review of archival data through the alumni office was utilized to obtain information on the graduates. Additional information was utilized through organizations and networking/social media to ascertain email addresses of graduates of the program that were not registered with the alumni office. Once IRB approval was obtained (Appendix D), the Alumni office sent out the alumni packet to all alumni with email addresses. The packet consisted of the letter explaining the study, purpose and seeking their participation (Appendix A); the Informed 
Consent Form (Appendix B) and Google forms survey (Appendix C). Participants were informed of the purpose of the study in this information letter to persuade the participants that their contribution to the study was very important and to insure that their responses would be completely confidential. These steps were taken to gain the confidence of the participating alumni and to obtain their responses to the survey. Participants were also provided an informed consent form. Directions included with each survey instructed participants about the survey process and that the informed consent was an "implied consent document", meaning that if the participant completed the survey and returned the survey that the completion of the survey implied that they agreed to participate in the study. A written consent would not be required. In addition, within the letter, the participants were told that their taking of the survey implied their informed consent and that they should keep the informed consent email as well as the researchers' email and phone number was included if further questions arose. Participant confidentiality was maintained, as participant responses were sent individually to the Google website and gathered for data analysis purposes.

\section{Instrumentation}

The survey instrument was developed within Google forms (Fink, 2009). The survey was pilot tested on undergraduate students to address the issue of validity. These pilot tests were conducted in the presence of the author. Pilot test participants were instructed to complete the survey questionnaire and to make suggestions that would clarify the questionnaire to the researcher. The purpose for each pilot test was to ensure survey domain and question clarity which was necessary in documenting the validity of the survey. These pilot tests were also used to assess the time required to complete the 
questionnaire. The pilot tests resulted in further revisions of question clarity as well as revisions in the instructions for completing the survey. The survey (Appendix C) contained 27 items. There were two questions asking what year they graduated from their undergraduate program and their graduate program, and 22 questions about their careers and satisfaction of the degree program. The specific curriculum questions were asked in either a four or five point Likert-type scales ranging from "low to high", or on skills from "not necessary to essential" while on use of equipment from "never to frequently". Likert-type scales represented a type of response format known as closedended. This format clarified response alternatives for the respondent and reduced the ambiguity of answers (Breakwell, Hammond, \& Fife-Schaw, 2000).

The survey was seeking demographic information in areas of age, income, years of experience in the field as well as the main discipline area in which the safety professional works. Descriptive statistics including frequency distributions were performed on this survey information.

\section{Data Analysis Procedures}

This research involved an on-line survey open to all alumni with available email addresses who have graduated from the occupational safety management program at the University of Central Missouri. After completion of data collection, the information was downloaded to Excel® from Google forms, compiled, organized and analyzed. For the survey questions that were appropriate for statistical manipulations, the data were loaded into Statistical Package for Social Sciences (SPSS) Version 24 (Field, 2009). A myriad of statistical methods were applied to each of the three research questions. 
Descriptive data for the study group and each group (age and years of work experience) were presented in a summary report. Data were analyzed by computing mean, standard deviations and presented in tabular and narrative forms for interval and ratio data. The categorical and nominal variables such as work specialty area, data were analyzed by frequency distributions. Variables include: (a) work area of specialty, (b) alumni perception of education provided at UCM/CMSU, (c) alumni perception of preparation for work environment, (d) how important program outcomes relate to their position, (e) the quality of education they received based on the program outcomes, (f) how essential certain courses are in the curriculum, $(\mathrm{g})$ how essential certain skills are in their position, and (h) what instruments are utilized in their current or most recent position. The data are presented in a table showing the different categories for each variable and the frequency with corresponding percentage of responses within each category. The overall satisfaction of the alumni was determined by adding the frequency distributions of each category by the eras of time they graduated when major curriculum changes were made. A frequency distribution was utilized to determine if there was a relationship between the categorical variables. The Kruskal-Wallis test was conducted to compare perceptions across different time periods. When analyzing the ANOVA Single Factor and Kruskal-Wallis tests, the $\rho$ value had to be less than 0.05 to be considered statistically significant. As Fraenkel and Wallen (2003) stated, "To make any sense out of data, we must put it into some sort of order" (p. 201).

Represented in Table 7 are the research questions with the corresponding survey questions that were analyzed to answer them along with the statistical methods utilized: 
Table 7

Research Questions/Survey Questions/Statistical Methods

\begin{tabular}{|c|c|c|}
\hline Research Question & Survey Question to answer: & Statistical Method \\
\hline $\begin{array}{l}\text { 1. What courses do alumni } \\
\text { view as most important for } \\
\text { the safety management } \\
\text { graduate students to take } \\
\text { as part of their } \\
\text { curricular studies? }\end{array}$ & $\begin{array}{l}\text { 24. How important are the } \\
\text { following courses and subjects } \\
\text { for safety students to take } \\
\text { during their program? } \\
\text { (A list of } 20 \text { courses with an } \\
\text { accompanying Likert Scale of } \\
\text { Not Applicable, Low, Below } \\
\text { Average, Above Average, and } \\
\text { High) }\end{array}$ & $\begin{array}{l}\text { Descriptive Statistics } \\
\text { Kruskal-Wallis Test }\end{array}$ \\
\hline $\begin{array}{l}\text { 2. What knowledge and } \\
\text { skills do alumni view as } \\
\text { critical for entry level } \\
\text { safety professionals in } \\
\text { the workplace? }\end{array}$ & $\begin{array}{l}\text { 21. How important are the } \\
\text { following skill sets as they } \\
\text { relate to your current or most } \\
\text { current safety related job } \\
\text { (select one category for each } \\
\text { skill)? (A list of } 8 \text { skill sets } \\
\text { with an accompanying Likert } \\
\text { Scale of Not Necessary, Useful, } \\
\text { Important, and Essential) }\end{array}$ & $\begin{array}{l}\text { ANOVA Single } \\
\text { Factor } \\
\text { Test } \\
\text { Descriptive Statistics }\end{array}$ \\
\hline
\end{tabular}


Table 7 (Continued)

Research/Survey

Quest./Stat.Methods

Research Question

Survey Question to answer: $\quad$ Statistical Method

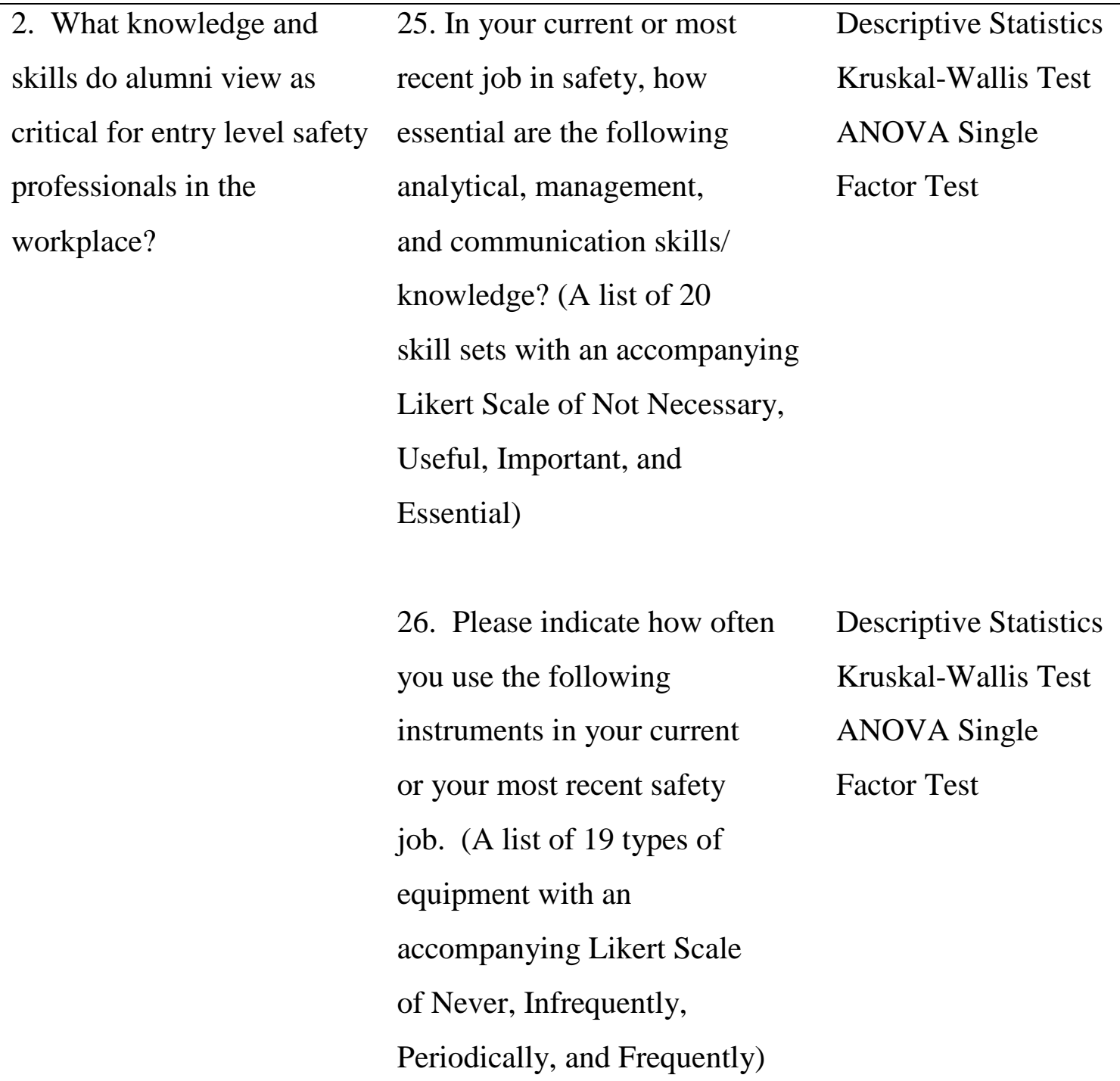


Table 7 (Continued)

Research/Survey

Quest./Stat.Methods

Research Question

Survey Question to answer: $\quad$ Statistical Method

\begin{tabular}{|c|c|c|}
\hline $\begin{array}{l}\text { 3. How has the overall } \\
\text { satisfaction of alumni }\end{array}$ & $\begin{array}{l}\text { 1. What year did you graduate } \\
\text { from the safety program? }\end{array}$ & $\begin{array}{l}\text { Descriptive Statistics } \\
\text { ANOVA Single }\end{array}$ \\
\hline changed as far as career & 7. When you graduated, which & Factor Test \\
\hline preparation since the & best describes your level of & Kruskal-Wallis Test \\
\hline Occupational Safety & preparedness to enter the safety & \\
\hline \multirow{19}{*}{$\begin{array}{l}\text { Management graduate } \\
\text { program began in } 1970 ?\end{array}$} & and health field? (4 options to & \\
\hline & select only 1 ) & \\
\hline & 22. Considering your graduate & \\
\hline & degree from Central, please rate & \\
\hline & the quality of your education in & \\
\hline & each of the following skill sets. & \\
\hline & (A list of 8 skill sets with an & \\
\hline & accompanying Likert Scale of & \\
\hline & Low, Below Average, Above & \\
\hline & Average, and High) & \\
\hline & 23. Please rate the quality of & Descriptive Statistics \\
\hline & the education you received from & Kruskal-Wallis Test \\
\hline & Central in each of the following & \\
\hline & areas during your academic & \\
\hline & program. (A list of 19 areas & \\
\hline & with accompanying Likert scale & \\
\hline & of Not Applicable, Low, Below & \\
\hline & Average, Above Average and & \\
\hline & High) & \\
\hline
\end{tabular}


The data from historical record input were utilized to develop the survey questions to collect the quantitative data. Using an inductive process, the information along with the research questions was part of the data analysis process. With the quantitative model, the method provided the necessary framework for analyzing the data gathered to answer the research questions (Creswell, 2009).

\section{Quality Control Measures}

The validity and reliability of the survey instrument was evaluated. The reliability needed to have a coefficient of 0.90 since the survey was evaluating educational needs. The validity of the survey was evaluated by reviewing similar surveys previously administered for other program evaluations within the safety department and throughout the university. Program evaluations for similar programs from out of state universities were reviewed and show significant similarities to what have been evaluated internally.

While developing the review of related literature the researcher was able to identify several important constructs that aided in the process of developing survey items. According to Fraenkel and Wallen (2003), validity is important and allows the researcher to draw solid conclusions from the instrument that can then be used to make inferences about the topic. Several important constructs connected the survey instrument to the review of related literature. The use of multiple questions improved the strength of the statistical analysis. The average response per subscale was calculated for statistical purposes. Additionally, the researcher allowed undergraduate students to review the survey, as well as the entire safety faculty to review the survey to provide feedback to improve the survey to address validity issues. Upon completion of this activity, the 
survey was changed to reflect the observations of the students and faculty. These suggestions were important for improving the wording and ensuring that alumni could answer the survey instrument questions. Next, the survey was field tested by a group of undergraduate students to improve reliability. According to Fraenkel and Wallen (2003) reliability "refers to the consistency of the scores obtained-how consistent they are for each individual from one administration of an instrument to another and from one set of items to another" (p. 165).

The test-retest format was used, with the group having a week between the time it was first taken and then retested. The participants in the field test were asked to take the survey, but to examine the content and point out any problematic wording. Modifications based on their feedback were done accordingly. The results of the field testing yielded a reliability coefficient of $r=.92$ across all subscales. Field testing of the instrument not only monitored reliability, but also helped improve validity.

\section{Study Limitations}

Several limitations to this study exist. These limitations include the following:

1. Changes in the curriculum through the life cycle of the Occupational Safety Management program show some disparities in the responses. It was necessary to define certain characteristics for a "group of years", etc. Since participation in this study included graduates over a 44 year time span, some of the survey questions may have been more appropriate for some alumni than others.

2. The differences in professors during this time period have been monumental, not with just different people, but different academia background altogether. Prior to the last ten years, the professors were primarily academia or public safety 
background. All new faculty brought in during the last ten years have been industrial backgrounds from construction, petrochemical and manufacturing. It is bringing a different set of training to the classroom for the students.

3. Another limitation and caveat to the study is that some students had taken the program $100 \%$ online while others had been on campus with others having participated in hybrid courses.

4. The researcher is a faculty member in the program being studied.

5. One underlying assumption made by the researcher was the notion that the graduate program had improved through the years.

6. Another assumption by the research was that the more current graduates would be eager to respond to the online survey. This assumption was based on the fact that it is believed the younger generation is more computer savvy and their interest and knowledge of the program would be fresh.

\section{Summary}

After a review of literature on program evaluations of academic programs, it was evident that little was known about the efficacy of academic programs, especially those that are not ABET-accredited across the United States. Furthermore, the review of literature has found that universities are being held to a much higher standard than in years past to show generated revenues by individual programs with number of graduates as the measurement device. The number of graduates rather than the quality of education has become the measurement of success.

This program evaluation identified strengths and weaknesses of the Occupational Management Program, which will provide information to strengthen the OSM program, 
leading to a better education for our future graduates. The information from this study was communicated to the faculty, the Department Chair and the Dean. The appropriate corrective measures were proposed based on the outcome of the surveys.

The population of the study was the approximate 1,000 alumni from the graduate Occupational Safety Management program from 1970 through 2014. The alumni was categorized by the years they graduated into four eras of time for the forty-four year period followed by years of work experience and their primary specialty area of work. The data was gathered through an alumni electronic survey, an instrument created by the author (Appendix C). The survey was field tested to provide evidence of the validity and reliability of the instrument. Pilot tests were utilized in this process. The data were analyzed using descriptive and inferiential analyses. Presented in Chapter Three was the information related to the design and methodology used to carry out this examination of the graduate program through the online survey and review of historical files. A rationale was provided for the use of a quantitative design research method. The population and sample were described, as well as data collection and instrumentation. The two-phased data analysis was articulated, as well as the researcher's biases and assumptions. In Chapter Four the quantitative analysis of each research question was presented with the research findings. Conclusions based on the findings along with recommendations and implications for further study were included in Chapter Five. 


\section{CHAPTER FOUR}

\section{RESULTS}

The focus of this study was to evaluate the relative satisfaction of alumni of the graduate safety program at the University of Central Missouri (UCM) with their preparation by the Department of Safety Sciences within the School of Environmental, Physical and Applied Sciences. In addition, this research assessed the views of alumni concerning the most important courses and topics to be included in the curriculum for an occupational safety management program, as well as what skills and knowledge entry level occupational safety professionals should have upon graduation. The study involved both a review of historical documents and a survey of program alumni consisting of 27 questions. The survey was completed using Google forms which enabled the researcher to collect alumni responses via an on-line survey.

\section{Review of Historical Documents}

A review of historical documents helped to establish details of the development of the safety management program at UCM. These documents included minutes of department meetings, internal 5-year progress reports, course catalogs, fact books and assorted other items. Dr. Robert Marshall, who was hired to establish the School of Public Services at Central Missouri State College (the name later changed to Central Missouri State University and later to the University of Central Missouri) in the late 1960s, along with those he hired to assist him, managed in just a few years to establish an organization that combined various aspects of safety under the overarching structure of the School of Public Services. The idea of housing so many different but associated programs into one academic unit was ahead of its time. The school of Public Services 
housed driver's training, criminal justice, consumer product safety, occupational (industrial) safety, and the Missouri Safety Center. The school was unique in that it was the only school of its kind in the nation. Dr. Marshall also served as the first Chair of the Safety Department in the School of Public Services. Almost all of the leaders in the School of Public Services had backgrounds in Driver's Training or Driver's Safety. This was appropriate as the School of Public Services was heavily involved in driver's safety and transportation safety. In 1969, the programs consisted of a Master of Science in Safety Education with a proposal being submitted for a Master of Science in Industrial Safety. A general studies course in safety, Principles of Safe Living, was approved by 1971. In the early 1970s, Dr. Marshall and the other administrators made a decision to expand available degrees to include industrial safety industrial hygiene (Patterson, 1974). Both programs were housed in a new department, the Department of Industrial Safety and Industrial Hygiene. Dr. Marshall served as the first Chair of this Department. In 1971, four graduate programs were available in safety: a) Master of Science in Education, Safety Education; b) Master of Science, Safety; c) Master of Science, Industrial Safety; and d) Master of Science, Traffic Engineering. A specialist degree in safety was also being offered. Over 300 students were enrolled in the programs making it the largest graduate program in safety in the nation (Patterson, 1974). A meeting was held in January of 1970 to establish curriculum for the new graduate Safety program. Attending the meetings were representatives of Armco Steel, Ford Motor Company, the Presidents of the St. Louis ASSE and AIHA, the President of the Great Plains Industrial Physicians Association, and the President of the Greater Kansas City Association of Industrial Nurses. Also in 1972, Mr. Herbert H. Jones was hired to head the industrial safety and 
hygiene program. He joined the Department after a twenty-seven year career in the US Public Health Service. Dr. Robert A. Ulrich became the Head of the Safety Department on September 1, 1973. Dr. Robert Semonisck was hired as the first full-time chair of the Department of Industrial Safety and Industrial Hygiene. Since the inception of the graduate degree program through September 1, 1973, there were nearly 200 degrees awarded. From 1971 to 1973, major emphasis areas were established for the Master of Science Public Services degree: a) Safety Education, b) Agricultural Safety, c) Industrial Hygiene, d) Industrial Safety, e) Safety, f) Traffic Engineering, and g) Transportation Safety. The specialist degree in Public Services was also offered in the same emphasis areas for the graduate degree (Patterson, 1974). Mr. Jones left the program in 1980 to enter retirement full time. Reflected in Table 8 are the interim department chairs and department chairs since the 1980 s to present as well as the department name changes.

Table 8

Leadership and Department Name Modifications

\begin{tabular}{lcl}
\hline Department Chair & Yrs. Served & Department Name \\
\hline $\begin{array}{l}\text { Robert Ulrich } \\
\text { (Interim) }\end{array}$ & $1980-1983$ & Dept. of Safety \& Dept. of Industrial Safety \\
Robert Ulrich & $1984-1986$ & $\begin{array}{l}\text { Safety Science \& Technology (Dept. of } \\
\text { Safety/Dept. of Industrial Safety/Industrial } \\
\text { Hygiene merged into one dept.) }\end{array}$ \\
Richard Bojanoski & $1986-1988$ & Safety Science \& Technology \\
Eldon Yung (Interim) & $1988-1989$ & Safety Science \& Technology \\
J. Thomas Pierce & $1989-1990$ & $\begin{array}{l}\text { Safety Science \& Technology (Called away- } \\
\text { Gulf War) }\end{array}$ \\
Eldon Yung (Interim) & $1990-1991$ & Safety Science \& Technology
\end{tabular}


Table 8 - Continued

Ldrshp/Dept.Modific.

Department Chair Yrs. Served Department Name

J. Thomas Pierce 1991-1992 Safety Science \& Technology

John Prince (Interim 1992-2000 Safety Science \& Technology (Name

then full chair)

changed to Safety Sciences)

\begin{tabular}{lcc} 
Alice Griefe & $2000-2002$ & Safety Sciences \\
$\begin{array}{l}\text { Larry Womble } \\
\text { (Interim) }\end{array}$ & $2002-2004$ & Safety Sciences \\
\hline
\end{tabular}

Dennis Laster

2004-2007 Safety Sciences

(Interim)

Larry Womble

2007-2008 Safety Sciences

(Interim)

Leigh Ann Blunt

2008-2011 Safety Sciences

Leigh Ann Blunt

2011-

School of Environmental, Physical \& Applied Sciences

For most of the safety program's existence the department has had between ten to thirteen full-time safety faculty that teach both safety and industrial hygiene courses. In 1994, the Department lost the approval for the general studies course following university changes to the requirements for general studies courses. The loss of the general studies course, originally approved in 1971, may have played a key role in the dramatic increase in student numbers in the department in the mid to late 1970s. With large student numbers, at times over 500, it is possible the department faculty or administration did not realize the potential impact this course had on student enrollment. A few years after the course was disapproved, the Department experienced a gradual reduction in student numbers and the number of students graduating from all programs, including safety. The 
course was re-approved in November 2005 with a different course name, Safety: A Societal and Personal Focus. John Zey was hired from NIOSH in 1996 and Larry Ferguson to set up and teach the safety and health laboratory for students in 1998. In 2005, Dr. Allen Iske was hired. He had a PhD in Chemistry from the University of Nebraska, was certified in both industrial hygiene and safety, and had over 30 years of industrial experience. In 2008, Dr. Georgi Popov, a PhD from Bulgaria, was hired into a tenure track position. He had ten years of experience, including work he had done internationally. In 2009, Scott Ammon was hired into a tenure track position predominantly focusing on fire safety curriculum development and teaching. Also in 2009, Anthony Hirner was hired into a tenure track position with a CSP certification as well as construction and environmental remediation background. In 2010, Vencislav Parvanov, a PhD from Bulgaria, was hired as an Assistant Professor for the laboratory replacing Larry Ferguson. Also in 2010, Tammy Allen was hired into a tenure track position from the petrochemical and heavy manufacturing industry with thirty-one years of field experience. In 2012, Steve Hicks was hired into a tenure track position from the manufacturing industry with approximately twenty-five years of experience. In 2013, Linda Lengfellner was hired as the online assistant professor for the department.

The curriculum for the original safety graduate degree included 32 hours which full-time students could complete in approximately 1.5 years. In 1981, the curriculum was expanded to 36 hours with specialty areas and in 2000 was reduced to 34 hours. In 2008 the hours were reduced again to 33 hours. The 33 hour curriculum was maintained through the end of this study. The initial curriculum and the subsequent primary curricular changes are shown in Table 9 for the Master of Science in Safety degree. 
Represented in Table 10 is the curriculum for the Master of Science in Industrial Safety degree. Illustrated in Table 11 are the curriculum requirements for the Master of Science in Safety Management degree that began in 1985 while Table 12 is for the Master of Science degree in Occupational Safety Management that began in 2000. Listed in Table 1 are the entry requirements, changes made to the entry requirements since the program began as well as the degree nomenclature changes.

Table 9

Curriculum for the Safety degree (R represents Required Courses, E-1 represents Elective Courses from Group 1, while E-2 represents Elective Courses from Group 2)

\begin{tabular}{|c|c|c|c|c|c|c|c|}
\hline Course Name & Hrs. & $\begin{array}{c}1970 \\
\text { to } \\
1974\end{array}$ & $\begin{array}{c}1975 \\
\text { to } \\
1978\end{array}$ & 1979 & $\begin{array}{c}1980 \\
\text { to } \\
1981\end{array}$ & $\begin{array}{c}1982 \\
\text { to } \\
1983\end{array}$ & 1984 \\
\hline Principles of Accident Prevention & 3 & $\mathrm{R}$ & $\mathrm{R}$ & E-1 & E-1 & E-1 & E-1 \\
\hline Org.Adm. \& Supv. of Safety Progr. & 3 & $\mathrm{R}$ & $\mathrm{R}$ & $\mathrm{R}$ & $\mathrm{R}$ & $\mathrm{R}$ & $\mathrm{R}$ \\
\hline Philosophy of Safety & 3 & $\mathrm{R}$ & $\mathrm{R}$ & $\mathrm{R}$ & $\mathrm{R}$ & $\mathrm{R}$ & $\mathrm{R}$ \\
\hline Introduction to System Safety & 3 & & & $\mathrm{R}$ & $\mathrm{R}$ & $\mathrm{R}$ & $\mathrm{R}$ \\
\hline Current Literature \& Research & 3 & $\mathrm{R}$ & $\mathrm{R}$ & $\mathrm{R}$ & $\mathrm{R}$ & $\mathrm{R}$ & $\mathrm{R}$ \\
\hline Legal Aspects of Safety Programs & 3 & $\mathrm{E}-1$ & E-1 & E-1 & E-1 & E-1 & E-1 \\
\hline Humanism in Safety & 3 & & & E-1 & E-1 & E-1 & E-1 \\
\hline Adult Programs in Safety Education & 2 & & & E-1 & E-1 & E-1 & \\
\hline Mgmt. Oversight and Risk Tree & 2 & & & E-1 & E-1 & E-1 & \\
\hline Field Experiences in Safety & 3 & E-1 & E-1 & E-1 & E-1 & E-1 & \\
\hline $\begin{array}{l}\text { Internship in Safety (Increased to } 9 \\
\text { hrs. in 1984) }\end{array}$ & $\begin{array}{l}1-6 \\
1-9\end{array}$ & E-1 & E-1 & E-1 & E-1 & E-1 & E-1 \\
\hline $\begin{array}{l}\text { Externship in Safety (Increased up } \\
\text { to } 6 \mathrm{hrs} \text {. in 1984) }\end{array}$ & $\begin{array}{l}1-3 \\
1-6\end{array}$ & & & & & E-1 & E-1 \\
\hline
\end{tabular}


Table 9 (Continued)

Curriculum for the Safety degree

\begin{tabular}{|c|c|c|c|c|c|c|c|}
\hline Course Name & Hrs. & $\begin{array}{c}1970 \\
\text { to } \\
1974\end{array}$ & $\begin{array}{c}1975 \\
\text { to } \\
1978\end{array}$ & 1979 & $\begin{array}{c}1980 \\
\text { to } \\
1981 \\
\end{array}$ & $\begin{array}{c}1982 \\
\text { to } \\
1983 \\
\end{array}$ & 1984 \\
\hline $\begin{array}{l}\text { Driving Simulators \& Multiple-Car } \\
\text { Driving Ranges }\end{array}$ & 3 & E-1 & E-1 & E-1 & E-1 & E-1 & E-1 \\
\hline Motorcycle Safety Education & 2 & E-1 & E-1 & E-1 & E-1 & E-1 & E-1 \\
\hline $\begin{array}{l}\text { Curriculum Development in Driver } \\
\& \text { Traffic Safety Education }\end{array}$ & 3 & E-1 & E-1 & E-1 & E-1 & & \\
\hline $\begin{array}{l}\text { Driver Improvement Programs \& } \\
\text { Techniques }\end{array}$ & 2 & E-1 & E-1 & E-1 & E-1 & E-1 & \\
\hline $\begin{array}{l}\text { Civil Defense \& Emergency } \\
\text { Procedures }\end{array}$ & 2 & E-1 & E-1 & E-1 & E-1 & & \\
\hline $\begin{array}{l}\text { Emergency Planning and } \\
\text { Operations }\end{array}$ & 2 & & & & E-1 & E-1 & E-1 \\
\hline $\begin{array}{l}\text { Supervision of School } \\
\text { Transportation }\end{array}$ & 2 & E-1 & E-1 & E-1 & E-1 & E-1 & E-1 \\
\hline Principles of Industrial Hygiene & 3 & & E-1 & E-1 & E-1 & E-1 & E-1 \\
\hline Total Loss Control & 3 & E-1 & E-1 & E-1 & E-1 & E-1 & E-1 \\
\hline Industrial Safety Engineering & 3 & E-1 & E-1 & E-1 & E-1 & E-1 & E-1 \\
\hline Traffic Engineering I & 2 & E-1 & E-1 & E-1 & E-1 & E-1 & \\
\hline Traffic Engineering II & 2 & & & E-1 & E-1 & E-1 & \\
\hline Traffic Characteristics & 3 & & & E-1 & E-1 & E-1 & \\
\hline Highway Planning & 3 & & & E-1 & E-1 & E-1 & \\
\hline Urban Planning for Traffic & 2 & & & E-1 & E-1 & E-1 & \\
\hline $\begin{array}{l}\text { Management of Safe Transportation } \\
\text { Systems }\end{array}$ & 3 & & & E-1 & E-1 & E-1 & E-1 \\
\hline
\end{tabular}


Table 9 (Continued)

Curriculum for the Safety degree

\begin{tabular}{|c|c|c|c|c|c|c|c|}
\hline Course Name & Hrs. & $\begin{array}{l}1970 \\
\text { to } \\
1974\end{array}$ & $\begin{array}{c}1975 \\
\text { to } \\
1978\end{array}$ & 1979 & $\begin{array}{c}1980 \\
\text { to } \\
1981 \\
\end{array}$ & $\begin{array}{c}1982 \\
\text { to } \\
1983\end{array}$ & 1984 \\
\hline $\begin{array}{l}\text { Traffic Safety Program } \\
\text { Development }\end{array}$ & 3 & & & & E-1 & E-1 & \\
\hline $\begin{array}{l}\text { Traffic Safety Program } \\
\text { Management }\end{array}$ & 3 & & & & E-1 & E-1 & E-1 \\
\hline Traffic Safety Program Evaluation & 3 & & & & E-1 & E-1 & E-1 \\
\hline $\begin{array}{l}\text { Transportation Laws and } \\
\text { Regulations }\end{array}$ & 3 & & & E-1 & E-1 & E-1 & E-1 \\
\hline $\begin{array}{l}\text { Innovations in Transportation } \\
\text { Safety }\end{array}$ & 2 & & & E-1 & E-1 & E-1 & \\
\hline $\begin{array}{l}\text { Supervision of School } \\
\text { Transportation }\end{array}$ & 2 & & & & E-1 & E-1 & E-1 \\
\hline Industrial Fire Protection & 3 & & & E-1 & E-2 & $\mathrm{E}-2$ & E-1 \\
\hline Readings in Safety & $1-5$ & E-1 & E-1 & E-1 & E-1 & $\mathrm{E}-1$ & E-1 \\
\hline Thesis & $2-6$ & E-1 & E-1 & E-1 & E-1 & $\mathrm{E}-1$ & E-1 \\
\hline Selected Investigations in Public & $1-5$ & & & & E-1 & $\mathrm{E}-1$ & \\
\hline \multicolumn{8}{|l|}{ Services } \\
\hline Selected Investigations in Safety & $1-3$ & & & & & & E-1 \\
\hline Current Problems in Traffic Safety & 2 & E-1 & E-1 & E-1 & E-1 & E-1 & \\
\hline Seminar in Safety & 2 & E-1 & E-1 & E-1 & E-1 & $\mathrm{E}-1$ & E-1 \\
\hline Individual Research Problems & $2-4$ & E-1 & E-1 & E-1 & E-1 & $\mathrm{E}-1$ & E-1 \\
\hline The Computer as a Research Tool & 3 & E-2 & E-2 & & & & \\
\hline Automotive Systems & 3 & E-2 & $\mathrm{E}-2$ & E-2 & & & \\
\hline
\end{tabular}


Table 9 (Continued)

Curriculum for the Safety degree

\begin{tabular}{|c|c|c|c|c|c|c|c|}
\hline Course Name & Hrs. & $\begin{array}{c}1970 \\
\text { to } \\
1974 \\
\end{array}$ & $\begin{array}{c}1975 \\
\text { to } \\
1978 \\
\end{array}$ & 1979 & $\begin{array}{c}1980 \\
\text { to } \\
1981 \\
\end{array}$ & $\begin{array}{c}1982 \\
\text { to } \\
1983 \\
\end{array}$ & 1984 \\
\hline Case Preparation \& Courtroom & 3 & E-2 & E-2 & E-2 & & & \\
\hline \multicolumn{8}{|l|}{ Procedure } \\
\hline Motor Vehicle Law & 3 & E-2 & E-2 & E-2 & & & \\
\hline Industrial Sociology & 3 & E-2 & E-2 & E-2 & E-2 & E-2 & \\
\hline Public Opinion and Communication & 3 & E-2 & E-2 & & & & \\
\hline Sociology of Law & 2 & E-2 & E-2 & E-2 & & & \\
\hline Sociological Investigations & 3 & E-2 & E-2 & E-2 & & & \\
\hline Methods of Sociological Research & 2 & E-2 & E-2 & E-2 & & & \\
\hline Introduction to Research & 2 & E-2 & E-2 & E-2 & & & \\
\hline Industrial Psychology & 3 & E-2 & E-2 & & & & \\
\hline Stimulants and Depressants & 2 & E-2 & E-2 & E-2 & & & \\
\hline $\begin{array}{l}\text { Psychology in Safety \& Accident } \\
\text { Prevention }\end{array}$ & 2 & E-2 & E-2 & E-2 & E-2 & E-2 & E-1 \\
\hline Required Hours & & 12 & 12 & 12 & 12 & 12 & 12 \\
\hline Elective Hours from Group E-1 & & 12 & 12 & $8-20$ & $8-20$ & $8-20$ & $8-20$ \\
\hline Elective Hours from Group E-2 & & 8 & 8 & $0-12$ & $0-12$ & $0-12$ & $0-12$ \\
\hline Total Credit Hours Required & & 32 & 32 & 32 & 32 & 32 & 32 \\
\hline
\end{tabular}


Table 10

Curriculum for each Industrial Safety degree - 1969 through 1988 (R represents

Required Courses, OR represents Optional Required Courses, E represents Elective Courses, E-1 represents Group 1 Electives, E-2 represents Group 2 Electives)

\begin{tabular}{|c|c|c|c|c|c|c|c|}
\hline Course Name & Hrs. & $\begin{array}{c}1969 \\
\text { to } \\
1974 \\
\end{array}$ & $\begin{array}{c}1975 \\
\text { to } \\
1976\end{array}$ & $\begin{array}{c}1977 \\
\text { to } \\
1978 \\
\end{array}$ & $\begin{array}{c}1979 \\
\text { to } \\
1983 \\
\end{array}$ & $\begin{array}{c}1984 \\
\text { to } \\
1986 \\
\end{array}$ & $\begin{array}{c}1987 \\
\text { to } \\
1988 \\
\end{array}$ \\
\hline Total Loss Control & 3 & $\mathrm{R}$ & $\mathrm{R}$ & $\mathrm{R}$ & $\mathrm{R}$ & $\mathrm{R}$ & $\mathrm{E}$ \\
\hline Loss Control Management & 3 & & & & & & $\mathrm{R}$ \\
\hline $\begin{array}{l}\text { Organizational Admin./ } \\
\text { Supervision of Safety Prog. }\end{array}$ & 3 & $\mathrm{R}$ & $\mathrm{R}$ & $\mathrm{R}$ & $\mathrm{R}$ & $\mathrm{R}$ & $\mathrm{R}$ \\
\hline Industrial Safety Engineering & 3 & $\mathrm{R}$ & $\mathrm{R}$ & $\mathrm{R}$ & $\mathrm{R}$ & $\mathrm{R}$ & $\mathrm{R}$ \\
\hline Current Literature \& Research & 3 & $\mathrm{R}$ & $\mathrm{R}$ & $\mathrm{R}$ & $\mathrm{R}$ & $\mathrm{R}$ & $\mathrm{R}$ \\
\hline Human Factors in Eng. Design & 2 & $\mathrm{R}$ & $\mathrm{R}$ & $\mathrm{R}$ & & & \\
\hline Human Factors in Eng. Design & 3 & & & & $\mathrm{R}$ & $\mathrm{R}$ & $\mathrm{R}$ \\
\hline Principles of Ind. Hygiene & 3 & & $\mathrm{R}$ & $\mathrm{R}$ & $\mathrm{R}$ & $\mathrm{R}$ & $\mathrm{R}$ \\
\hline Industrial Fire Protection & 3 & & & E-1 & E-1 & $\mathrm{R}$ & $\mathrm{R}$ \\
\hline $\begin{array}{l}\text { Occupational Safety and } \\
\text { Health Legislation }\end{array}$ & 3 & & & & E-1 & $\mathrm{E}$ & $\mathrm{E}$ \\
\hline $\begin{array}{l}\text { Legal Aspects of Safety } \\
\text { Programs }\end{array}$ & 3 & E-1 & E-1 & E-1 & E-1 & $\mathrm{E}$ & $\mathrm{E}$ \\
\hline Safety Program Management & 3 & & & & & & $\mathrm{E}$ \\
\hline Philosophy of Safety & 3 & & & & E-1 & $\mathrm{E}$ & $\mathrm{E}$ \\
\hline Introduction of System Safety & 3 & & & & E-1 & $\mathrm{E}$ & $\mathrm{E}$ \\
\hline Humanism in Safety & 3 & & & & E-1 & $\mathrm{E}$ & $\mathrm{E}$ \\
\hline $\begin{array}{l}\text { Management Oversight and } \\
\text { Risk Tree }\end{array}$ & 3 & & & & E-1 & & \\
\hline
\end{tabular}


Table 10 (Continued)

Curriculum for Industrial

Safety-1969-1988

Course Name

$\begin{array}{lllllll}\text { Hrs. } & 1969 & 1975 & 1977 & 1979 & 1984 & 1987\end{array}$

to to to to to to

$\begin{array}{llllll}1974 & 1976 & 1978 & 1983 & 1986 & 1988\end{array}$

Civil Defense \& Emergency

E-1 E-1 E-1

Procedures

Field Experiences in Safety -

Readings in Safety - Starting

E-1 E-1

E-1

E-1 E

$\mathrm{E}$ in 1976

\begin{tabular}{|c|c|c|c|c|c|c|c|}
\hline Field Experiences in Safety & 3 & & E-1 & E-1 & E-1 & & \\
\hline $\begin{array}{l}\text { Externship in Safety (Took } \\
\text { effect in } 1982 \& \text { increased up } \\
\text { to } 6 \text { hrs. in 1984) }\end{array}$ & $\begin{array}{l}1-3 \\
1-6\end{array}$ & & & & E-1 & $\mathrm{E}$ & $\mathrm{E}$ \\
\hline $\begin{array}{l}\text { Internship in Safety (Increased } \\
\text { up to } 9 \text { hours in 1984) }\end{array}$ & $\begin{array}{l}1-6 \\
1-9\end{array}$ & E-1 & E-1 & E-1 & E-1 & $\mathrm{E}$ & OR \\
\hline Thesis or Individual Research & $2-6$ & E-1 & E-1 & E-1 & E-1 & $\mathrm{E}$ & OR \\
\hline $\begin{array}{l}\text { Selected Investigations in } \\
\text { Safety }\end{array}$ & $1-3$ & & & & & $\mathrm{E}$ & \\
\hline $\begin{array}{l}\text { Individual Research Problems } \\
\text { in Public Services }\end{array}$ & $2-4$ & & & & E-1 & & \\
\hline $\begin{array}{l}\text { Selected Investigations in } \\
\text { Public Services }\end{array}$ & $4-6$ & & & & E-1 & & \\
\hline $\begin{array}{l}\text { Emergency Planning and } \\
\text { Operations (Started in 1980) }\end{array}$ & 2 & & & & E-1 & $\mathrm{E}$ & $\mathrm{E}$ \\
\hline $\begin{array}{l}\text { Management of Safe } \\
\text { Transportation Systems }\end{array}$ & 3 & & & E-1 & E-2 & $\mathrm{E}$ & $\mathrm{E}$ \\
\hline $\begin{array}{l}\text { Traffic Safety Program } \\
\text { Management }\end{array}$ & 3 & & & & & $\mathrm{E}$ & $\mathrm{E}$ \\
\hline $\begin{array}{l}\text { Transportation Safety Program } \\
\text { Evaluation }\end{array}$ & 3 & & & & & $\mathrm{E}$ & \\
\hline
\end{tabular}


Table 10 (Continued)

Curriculum for Industrial

Safety-1969-1988

\begin{tabular}{|c|c|c|c|c|c|c|c|}
\hline Course Name & Hrs. & $\begin{array}{c}1969 \\
\text { to } \\
1974\end{array}$ & $\begin{array}{l}1975 \\
\text { to } \\
1976\end{array}$ & $\begin{array}{l}1977 \\
\text { to } \\
1978\end{array}$ & $\begin{array}{l}1979 \\
\text { to } \\
1983\end{array}$ & $\begin{array}{l}1984 \\
\text { to } \\
1986\end{array}$ & $\begin{array}{c}1987 \\
\text { to } \\
1988\end{array}$ \\
\hline $\begin{array}{l}\text { Transportation Laws and } \\
\text { Regulations }\end{array}$ & 3 & & & & & $\mathrm{E}$ & $\mathrm{E}$ \\
\hline $\begin{array}{l}\text { Supervision of School } \\
\text { Transportation }\end{array}$ & 2 & & & & & $\mathrm{E}$ & \\
\hline $\begin{array}{l}\text { Directed Studies in Safety } \\
\text { Programs }\end{array}$ & $1-6$ & & & E-1 & E-1 & & \\
\hline $\begin{array}{l}\text { Introductory Quantitative } \\
\text { Methods in Public Services }\end{array}$ & 3 & & & & E-2 & $\mathrm{E}$ & \\
\hline Special Security Problems & 3 & & & E-1 & & & \\
\hline $\begin{array}{l}\text { Document and Personnel } \\
\text { Security - Changed to "Info. \& } \\
\text { Personnel Security" in } 1978\end{array}$ & 3 & & & E-1 & & & \\
\hline $\begin{array}{l}\text { Current Problems in Traffic } \\
\text { Safety }\end{array}$ & 3 & & & & E-1 & & \\
\hline $\begin{array}{l}\text { Seminar in Safety (Name } \\
\text { changed to Seminar in Safety } \\
\text { Science \& Tech./ reduced to } 1 \\
\text { hr. in 1987) }\end{array}$ & $2 / 1$ & & & & E-1 & $\mathrm{E}$ & $\mathrm{R}$ \\
\hline $\begin{array}{l}\text { Statistics for the Behavioral } \\
\text { Sciences }\end{array}$ & 3 & E-2 & E-2 & E-2 & E-2 & $\mathrm{E}$ & $\mathrm{E}$ \\
\hline Industrial Psychology & 3 & E-2 & E-2 & E-2 & E-2 & $\mathrm{E}$ & $\mathrm{E}$ \\
\hline Stimulants \& Depressants & 2 & E-2 & E-2 & E-2 & & & \\
\hline Industrial Sociology & 3 & E-2 & E-2 & E-2 & E-2 & $\mathrm{E}$ & $\mathrm{E}$ \\
\hline Industrial Audiology & 2 & $\mathrm{E}-2$ & E-2 & E-2 & E-2 & $\mathrm{E}$ & $\mathrm{E}$ \\
\hline Industrial Management & 3 & $\mathrm{E}-2$ & E-2 & E-2 & E-2 & $\mathrm{E}$ & $\mathrm{E}$ \\
\hline
\end{tabular}


Table 10 (Continued)

Curriculum for Industrial

Safety-1969-1988

Course Name

$\begin{array}{lllllll}\text { Hrs. } & 1969 & 1975 & 1977 & 1979 & 1984 & 1987\end{array}$

to to to to to to

Construction Safety

$\begin{array}{llllll}1974 & 1976 & 1978 & 1983 & 1986 & 1988\end{array}$

Data Processing in Business

$3 \quad$ E-2

E-2

E-2

E-2

988

Adv. First Aid \& Emergency 3

3

Care

Required Hours

$\begin{array}{llllll}14 & 17 & 17 & 18 & 21 & 28-31\end{array}$

Elective Hours from Group E-1

$\begin{array}{llllll}10-15 & 10-12 & 10-12 & 10-12 & 11 & 4\end{array}$

Elective Hours from Group E-2

$\begin{array}{llllll}3-5 & 3-5 & 3-5 & 2-4 & 0 & 0\end{array}$

Total Credit Hours Required

$32 \quad 32$

32

32

32

$32 \quad 32-35$

NOTE: Starting in 1984, no segregation of electives, just stated Departmentally approved graduate electives ( $E=$ Elective Courses, $\mathrm{R}=$ Required Courses, $\mathrm{OR}=\mathrm{Optional}$ Required Courses). 
Table 10 - Continued

Curriculum for each Industrial Safety degree - 1989 through 1999 (R represents

Required Courses, OR represents Optional Required Courses, while E represents Elective Courses)

\begin{tabular}{|c|c|c|c|c|}
\hline Course Name & Hrs. & $\begin{array}{l}1989 \\
\text { to } \\
1990\end{array}$ & $\begin{array}{l}1991 \\
\text { to } \\
1997\end{array}$ & $\begin{array}{l}1998 \\
\text { to } \\
1999\end{array}$ \\
\hline Loss Control Management & 3 & $\mathrm{R}$ & $\mathrm{R}$ & $\mathrm{R}$ \\
\hline $\begin{array}{l}\text { Organizational Administration and Supervision of } \\
\text { Safety Programs }\end{array}$ & 3 & $\mathrm{R}$ & $\mathrm{R}$ & $\mathrm{R}$ \\
\hline $\begin{array}{l}\text { Industrial Safety Engineering - Name changed to } \\
\text { Industrial Hazard Management in } 1989\end{array}$ & 3 & $\mathrm{R}$ & $\mathrm{R}$ & $\mathrm{R}$ \\
\hline Current Literature \& Research & 3 & $\mathrm{R}$ & $\mathrm{R}$ & $\mathrm{R}$ \\
\hline Human Factors in Engineering Design & 3 & $\mathrm{R}$ & & \\
\hline Principles of Industrial Hygiene & 3 & $\mathrm{R}$ & $\mathrm{R}$ & $\mathrm{R}$ \\
\hline Commercial and Institutional Security & 3 & & $\mathrm{R}$ & $\mathrm{R}$ \\
\hline Industrial Fire Protection & 3 & $\mathrm{R}$ & $\mathrm{R}$ & $\mathrm{R}$ \\
\hline $\begin{array}{l}\text { Total Loss Control - Changed name to } \\
\text { Comprehensive Loss Control in } 1989 \text { then to Loss } \\
\text { Control in } 1991\end{array}$ & 3 & $\mathrm{E}$ & $\mathrm{E}$ & \\
\hline Industrial Environmental Monitoring & 3 & $\mathrm{E}$ & $\mathrm{E}$ & \\
\hline Occupational Safety and Health Legislation & 3 & $\mathrm{E}$ & $\mathrm{E}$ & \\
\hline Legal Aspects of Safety, Security and Fire & 3 & $\mathrm{E}$ & $\mathrm{E}$ & $\mathrm{E}$ \\
\hline Safety Program Management & 3 & $\mathrm{E}$ & $\mathrm{E}$ & $\mathrm{E}$ \\
\hline Philosophy of Safety & 3 & $\mathrm{E}$ & & \\
\hline Psychology of Safety Management & 3 & $\mathrm{E}$ & $\mathrm{E}$ & $\mathrm{E}$ \\
\hline Introduction of System Safety & 3 & $\mathrm{E}$ & $\mathrm{E}$ & $\mathrm{E}$ \\
\hline $\begin{array}{l}\text { Field Experiences in Safety - Readings in Safety } \\
\text { - Starting in } 1976\end{array}$ & $1-6$ & $\mathrm{E}$ & $\mathrm{E}$ & $\mathrm{E}$ \\
\hline
\end{tabular}


Table 10 - Continued

Curriculum for each Industrial Safety degree - 1989 to 1999

\begin{tabular}{|c|c|c|c|c|}
\hline Course Name & Hrs. & $\begin{array}{c}1989 \\
\text { to } \\
1990\end{array}$ & $\begin{array}{c}1991 \\
\text { to } \\
1997\end{array}$ & $\begin{array}{c}1998 \\
\text { to } \\
1999 \\
\end{array}$ \\
\hline Internship in Safety (Increased to 9 hours in 1984) & $1-6 / 9$ & OR & $\mathrm{E}$ & $\mathrm{E}$ \\
\hline Thesis or Individual Research & $2-6$ & OR & $\mathrm{E}$ & $\mathrm{E}$ \\
\hline $\begin{array}{l}\text { Emergency Planning and Operations (Started in } \\
\text { 1980, Changed to } 3 \text { hrs. in 1989) }\end{array}$ & $2 / 3$ & $\mathrm{E}$ & $\mathrm{E}$ & $\mathrm{E}$ \\
\hline Management of Safe Transportation Systems & 3 & $\mathrm{E}$ & $\mathrm{E}$ & $\mathrm{E}$ \\
\hline Traffic Safety Program Management & 3 & $\mathrm{E}$ & $\mathrm{E}$ & $\mathrm{E}$ \\
\hline $\begin{array}{l}\text { Seminar in Safety (Name changed to Seminar in } \\
\text { Safety Science \& Tech \& reduced to } 1 \mathrm{hr} \text {.in } 1987 \text { ) }\end{array}$ & $2 / 1$ & $\mathrm{R}$ & $\mathrm{E}$ & $\mathrm{E}$ \\
\hline Statistics for the Behavioral Sciences & 3 & $\mathrm{E}$ & $\mathrm{E}$ & $\mathrm{E}$ \\
\hline Industrial Psychology & 3 & $\mathrm{E}$ & $\mathrm{E}$ & $\mathrm{E}$ \\
\hline Industrial Sociology & 3 & $\mathrm{E}$ & $\mathrm{E}$ & $\mathrm{E}$ \\
\hline Industrial Audiology & 2 & $\mathrm{E}$ & $\mathrm{E}$ & $\mathrm{E}$ \\
\hline Industrial Management & 3 & $\mathrm{E}$ & $\mathrm{E}$ & $\mathrm{E}$ \\
\hline Construction Safety & 3 & $\mathrm{E}$ & $\mathrm{E}$ & $\mathrm{E}$ \\
\hline Data Processing in Business & 3 & E & E & $\mathrm{E}$ \\
\hline Advanced First Aid and Emergency Care & 3 & $\mathrm{E}$ & $\mathrm{E}$ & $\mathrm{E}$ \\
\hline Required Hours & & $28-31$ & 21 & 21 \\
\hline Elective Hours & & 4 & 15 & $13-15$ \\
\hline Elective Hours from Group E-2 & & 0 & 0 & 0 \\
\hline Total Credit Hours Required & & $32-35$ & 36 & $34-36$ \\
\hline
\end{tabular}

Note. Industrial Safety Mgmt. with Option of: Safety, Security, Public Services Administration, Fire Science, or Transportation Safety took effect in 1998 (E=Elective Courses, $\mathrm{R}=$ Required Courses, OR=Optional Required Courses). 
Table 11

Curriculum for the Safety Management degree ( $R$ represents Required Courses, OR represents Optional Required Courses, E represents Elective Courses, E-1 represents Group 1 Electives, while E-2 represents Group 2 Electives)

\begin{tabular}{|c|c|c|c|c|}
\hline Course Name & Hrs. & $\begin{array}{c}1985 \\
\text { to } \\
1986\end{array}$ & $\begin{array}{c}1987 \\
\text { to } \\
1988\end{array}$ & $\begin{array}{c}1989 \\
\text { to } \\
1990\end{array}$ \\
\hline Org. Adm. \& Supv. Of Safety Programs & 3 & $\mathrm{R}$ & $\mathrm{R}$ & $\mathrm{R}$ \\
\hline Philosophy of Safety & 3 & $\mathrm{R}$ & $\mathrm{R}$ & $\mathrm{R}$ \\
\hline Loss Control Management & 3 & & $\mathrm{R}$ & $\mathrm{R}$ \\
\hline Current Literature \& Research & 3 & $\mathrm{R}$ & $\mathrm{R}$ & $\mathrm{R}$ \\
\hline Psychology of Safety Management & 3 & & & $\mathrm{R}$ \\
\hline Introduction to System Safety & 3 & $\mathrm{R}$ & $\mathrm{E}$ & $\mathrm{E}$ \\
\hline Safety Program Management & 3 & & $\mathrm{E}$ & $\mathrm{E}$ \\
\hline Safety and Health Legislation & 3 & & $\mathrm{E}$ & $\mathrm{E}$ \\
\hline Humanism in Safety & 3 & E-2 & $\mathrm{E}$ & \\
\hline $\begin{array}{l}\text { Internship in Safety (Increased up to } 9 \mathrm{hrs} \text {. in } \\
\text { 1984) }\end{array}$ & $\begin{array}{l}1-6 \\
1-9\end{array}$ & E-1 & OR & $\mathrm{E}$ \\
\hline $\begin{array}{l}\text { Externship in Safety (Increased up to } 6 \text { hrs. in } \\
\text { 1984) }\end{array}$ & $\begin{array}{l}1-3 \\
1-6\end{array}$ & E-1 & & \\
\hline $\begin{array}{l}\text { Driving Simulators \& Multiple-Car Driving } \\
\text { Ranges }\end{array}$ & 3 & E-2 & $\mathrm{E}$ & \\
\hline Motorcycle Safety Education & 2 & E-2 & $\mathrm{E}$ & \\
\hline $\begin{array}{l}\text { Emergency Planning and Operations (Became a } \\
3 \text { hr. course in 1989) }\end{array}$ & $2 / 3$ & E-2 & $\mathrm{E}$ & $\mathrm{E}$ \\
\hline Supervision of School Transportation & 2 & E-2 & $\mathrm{E}$ & \\
\hline
\end{tabular}


Table 11 (Continued)

Curriculum for the Safety Management degree

\begin{tabular}{|c|c|c|c|c|}
\hline Course Name & Hrs. & $\begin{array}{l}1985 \\
\text { to } \\
1986\end{array}$ & $\begin{array}{l}1987 \\
\text { to } \\
1988\end{array}$ & $\begin{array}{l}1989 \\
\text { to } \\
1990\end{array}$ \\
\hline Industrial Environmental Monitoring & 3 & & & $\mathrm{E}$ \\
\hline $\begin{array}{l}\text { Total Loss Control - Name changed to } \\
\text { Comprehensive Loss Control in } 1989\end{array}$ & 3 & E-1 & $\mathrm{E}$ & $\mathrm{E}$ \\
\hline $\begin{array}{l}\text { Industrial Safety Engineering - Name changed } \\
\text { to Industrial Hazard Management in } 1989\end{array}$ & 3 & E-1 & $\mathrm{E}$ & $\mathrm{E}$ \\
\hline Management of Safe Transportation Systems & 3 & E-2 & $\mathrm{E}$ & $\mathrm{E}$ \\
\hline Traffic Safety Program Management & 3 & E-2 & $\mathrm{E}$ & $\mathrm{E}$ \\
\hline Traffic Safety Program Evaluation & 3 & E-2 & & \\
\hline Transportation Laws and Regulations & 3 & E-2 & $\mathrm{E}$ & \\
\hline Supervision of School Transportation & 2 & E-2 & & \\
\hline Industrial Fire Protection & 3 & E-1 & $\mathrm{E}$ & $\mathrm{E}$ \\
\hline Readings in Safety & $1-5$ & E-1 & $\mathrm{E}$ & $\mathrm{E}$ \\
\hline Thesis & $2-6$ & E-1 & OR & OR \\
\hline Selected Investigations in Safety & $1-3$ & E-1 & & \\
\hline $\begin{array}{l}\text { Seminar in Safety (Changed name to Seminar in } \\
\text { Safety Science \& Technology in 1987-reduced } \\
\text { to } 1 \mathrm{hr} \text {.) }\end{array}$ & $2 / 1$ & E-1 & $\mathrm{R}$ & $\mathrm{E}$ \\
\hline Individual Research Problems & $2-4$ & E-1 & OR & OR \\
\hline Psychology in Safety \& Accident Prevention & 2 & E-2 & E-2 & \\
\hline
\end{tabular}


Table 11 (Continued)

Curriculum for the Safety Management degree

\begin{tabular}{lccc}
\hline Course Name & $\begin{array}{r}\text { Hrs. } \\
1985 \\
\text { to }\end{array}$ & $\begin{array}{c}1987 \\
\text { to }\end{array}$ & $\begin{array}{c}1989 \\
\text { to }\end{array}$ \\
& 1986 & 1988 & 1990 \\
\hline Required Hours & 12 & $19-22$ & $21-24$ \\
Elective Hours from Group E-1 & $8-20$ & 13 & 11 \\
Elective Hours from Group E-2 & $0-12$ & 0 & 0 \\
Total Credit Hours Required & 32 & $32-35$ & $32-35$
\end{tabular}

NOTE: Starting in 1987, no segregation of electives, just stated Departmental approved graduate electives $(\mathrm{E}=$ Elective Courses, $\mathrm{R}=$ Required Courses, $\mathrm{OR}=\mathrm{Optional}$ Required Courses). Degree was no longer offered as of the beginning of the 1991 catalog.

Table 12

Curriculum for each Occupational Safety Management degree - 2000 through 2014 (R represents Required Courses, OR represents Optional Required Courses and E represents Elective Courses)

\begin{tabular}{|c|c|c|c|c|}
\hline Course Name & Hrs. & $\begin{array}{c}2000 \\
\text { to } \\
2001\end{array}$ & $\begin{array}{c}2002 \\
\text { to } \\
2007\end{array}$ & $\begin{array}{c}2008 \\
\text { to } \\
2014\end{array}$ \\
\hline Organizational Admin. and Superv. Safety Prog. & 3 & $\mathrm{R}$ & $\mathrm{R}$ & $\mathrm{R}$ \\
\hline Current Literature \& Research & 3 & $\mathrm{R}$ & $\mathrm{R}$ & $\mathrm{R}$ \\
\hline Principles of Industrial Hygiene & 3 & $\mathrm{R}$ & $\mathrm{R}$ & $\mathrm{R}$ \\
\hline Managing Fire Risk & 3 & & & $\mathrm{R}$ \\
\hline Introductory Quantitative Methods & 3 & $\mathrm{R}$ & & \\
\hline Seminar in Safety Science \& Technology & 1 & $\mathrm{R}$ & $\mathrm{R}$ & $\mathrm{E}$ \\
\hline Internship in Safety (Increased to 9 hours in 1984) & $\begin{array}{l}1-6 \\
1-9\end{array}$ & OR & OR & $\mathrm{E}$ \\
\hline Special Project in Safety Science and Technology & 3 & OR & OR & $\mathrm{E}$ \\
\hline Thesis or Individual Research & $2-6$ & $\mathrm{R}$ & $\mathrm{E}$ & $\mathrm{R}$ \\
\hline
\end{tabular}


Table 12 (Continued)

Curriculum for each Occupational Safety

Management degree - 2000 through 2014

\begin{tabular}{|c|c|c|c|c|}
\hline Course Name & Hrs. & $\begin{array}{c}2000 \\
\text { to } \\
2001\end{array}$ & $\begin{array}{c}2002 \\
\text { to } \\
2007\end{array}$ & $\begin{array}{c}2008 \\
\text { to } \\
2014\end{array}$ \\
\hline Ergonomics in Safety and Health & 3 & IS & IS & $\mathrm{E}$ \\
\hline Emergency Planning and Operations & 3 & $\begin{array}{l}\text { IS-PS- } \\
\text { FS }\end{array}$ & $\begin{array}{l}\text { IS-PS- } \\
\text { FS }\end{array}$ & $\mathrm{E}$ \\
\hline Management of Safe Transportation Systems & 3 & IS-TS & IS-TS & $\mathrm{E}$ \\
\hline Introduction to Systems Safety & 3 & IS & IS & E \\
\hline Industrial Fire Protection & 3 & $\begin{array}{l}\text { IS-PS- } \\
\text { LC-FS }\end{array}$ & $\begin{array}{l}\text { IS-PS- } \\
\text { LC-FS }\end{array}$ & $\mathrm{E}$ \\
\hline Transportation and Storage of Hazardous Materials & 3 & TS & TS & $\mathrm{E}$ \\
\hline Traffic Engineering & 3 & TS & TS & $\mathrm{E}$ \\
\hline Management of Fleet Safety Programs & 3 & TS & TS & $\mathrm{E}$ \\
\hline Traffic Safety Program Management & 3 & TS-PS & TS-PS & $\mathrm{E}$ \\
\hline Principles of Epidemiology & 3 & PS & PS & $\mathrm{E}$ \\
\hline Public Administration & 3 & PS & PS & $\mathrm{E}$ \\
\hline $\begin{array}{l}\text { Industrial Hazard Management - Changed name to } \\
\text { Occupational Hazard Management in } 2008\end{array}$ & 3 & LC & $\mathrm{R}$ & $\mathrm{R}$ \\
\hline Safety and Risk Analysis & 3 & LC & LC & $\mathrm{E}$ \\
\hline Loss Control & 3 & & LC & $\mathrm{E}$ \\
\hline Loss Control Management & 3 & $\mathrm{LC}$ & LC & $\mathrm{E}$ \\
\hline Commercial and Institutional Security & 3 & LC-S & LC-S & $\mathrm{E}$ \\
\hline Water and Sprinkler System Analysis & 3 & FS & FS & $\mathrm{E}$ \\
\hline Fire Extinguishing and Alarm Systems & 3 & FS & FS & $\mathrm{E}$ \\
\hline
\end{tabular}


Table 12 (Continued)

Curriculum for each Occupational Safety

Management degree - 2000 through 2014

\begin{tabular}{|c|c|c|c|c|}
\hline Course Name & Hrs. & $\begin{array}{c}2000 \\
\text { to } \\
2001\end{array}$ & $\begin{array}{c}2002 \\
\text { to } \\
2007\end{array}$ & $\begin{array}{c}2008 \\
\text { to } \\
2014\end{array}$ \\
\hline Fire Investigation & 3 & FS & FS & $\mathrm{E}$ \\
\hline Security Technology & 3 & $\mathrm{~S}$ & $\mathrm{~S}$ & $\mathrm{E}$ \\
\hline Personnel and Information Security & 3 & $\mathrm{~S}$ & $\mathrm{~S}$ & $\mathrm{E}$ \\
\hline History of Security & 3 & $\mathrm{~S}$ & $\mathrm{~S}$ & $\mathrm{E}$ \\
\hline Security Statutes and Codes & 3 & $\mathrm{~S}$ & $\mathrm{~S}$ & $\mathrm{E}$ \\
\hline Required Hours & & 19 & 19 & 15 \\
\hline Option Area Hours & & 15 & 15 & 0 \\
\hline Research Hours & & & & $3-6$ \\
\hline Department Approved Graduate Electives & & & & $12-15$ \\
\hline Total Credit Hours Required & & 34 & 34 & 33 \\
\hline
\end{tabular}

Note. Occupational Safety Mgmt. with Option of: Industrial Safety (IS), Transportation Safety (TS), Public Safety (PS), Loss Control (LC), Fire Science (FS) or Security (S) took effect in 2000. Legend: E=Elective Courses, $\mathrm{R}=$ Required Courses, OR=Optional Required Courses.

Full-time students typically complete the current MS-OSM program in two years, with the recommended but not required internship conducted during the summer after the first year. Other changes that occurred over the 44 years of the program include a reduction in credit hours, multiple changes from offering options or specialty areas to a more general degree program. Students can still select elective courses that will enhance certain areas of their curriculum. The review of historical documents revealed other information concerning the history of the department. Among the data gleaned from this 
review are the numbers of total students graduating by year, including BS, MS and Educational Specialists. The number of total graduates from the Department of Safety Sciences between 1970 and 2013 is shown in Figure 1. Over 3,200 individuals have earned degrees from the Department of Safety Sciences. There have been two time periods when the numbers of students graduating peaked and then dropped off. Shown in Figure 2 are the numbers of MS-OSM graduates by year. After the first peak in safety graduates the numbers gradually decreased and then peaked in the early 1990s.

However, based on these figures, the department and the occupational safety management program appear to be heading into a third period of high student numbers. From these two figures, one can see a very similar pattern of the number of graduates by year. The ebbs and flows in student numbers were consistent for both the safety program and for the Department. This suggests that the number of students in the department's undergraduate programs may strongly influence the number of safety graduate students.

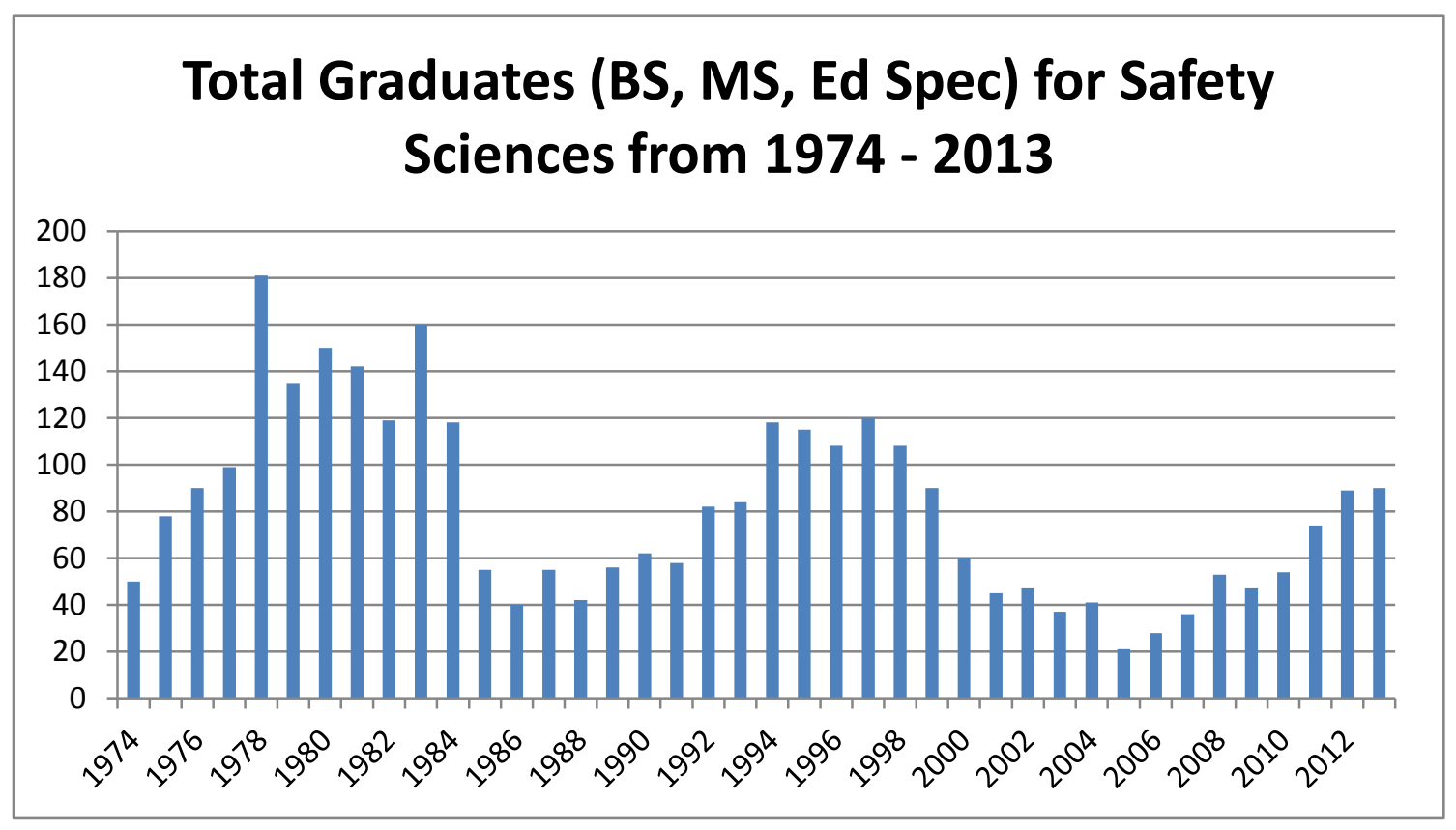

Figure 1. Total Graduates (BS, MS \& Ed Specialist) by year. 


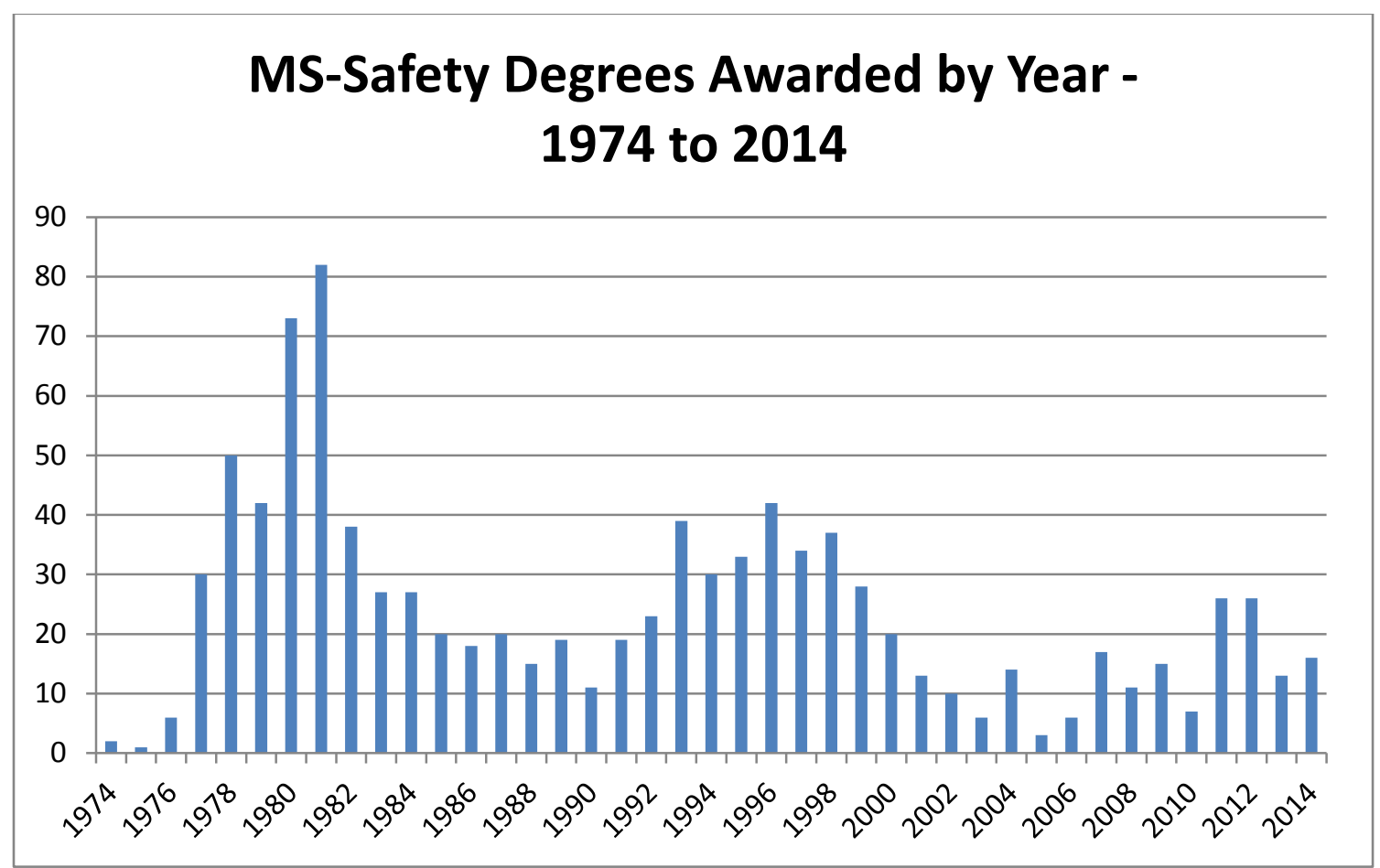

Figure 2. MS-Safety graduates by year.

Since the Spring semester of 2007, the Department has offered 6-7 sections of Safe 2010 each Fall and Spring Semester. This course helps increase awareness of the department and its programs throughout the University. This could explain the increase in the number of students in the safety program. Another important item taken from the review of documents concerns the number of MS-Safety students who took courses at Central before enrolling in the MS-Safety program. Almost fifty-three percent (509 of the 969) MS-Safety alumni had earned an undergraduate degree at UCM before obtaining the graduate degree.

Other items of record taken from reviewing historical documents include the approval of a general studies safety course in the early 1970s, which was disapproved in 1994 and the number of safety alumni who obtained certification. In 2005, the Department achieved approval for a revised general studies course. 


\section{Survey Results}

A total of 126 individuals responded to the series of emails inviting them to participate in the online survey, resulting in an overall response rate of $19.8 \%$. Those 126 alumni answered at least one question. Only one individual did not answer all of the questions.

The Google forms program allowed tracking of responses by the day received. A review of the responses by day shows that responses were received on 18 of the 36 days the survey was open. Most responses were received on the days the original or a "reminder" email was sent out. The size of the response was smaller for each succeeding email: initial email with 81, first reminder email with 43, and 2 responses were received following the third reminder email being sent out. Responses were less for each of the succeeding days. This response rate is what is typically reported for online surveys, probably due to the salience aspect of this study.

The internal database maintained by the alumni office had 1,375 alumni (graduate research office reflecting 969 confirmed graduates) but only contact email addresses for 608 of the initial report. After additional research and checking on email addresses, approximately 150 email addresses were no longer active and ten alumni were found to be deceased. The survey was sent to 635 alumni. Shown in Figure 3 is the number of alumni who received the online survey by year. The shape of the data in Figure 3 is very similar to that for both total graduates (Figure 1) and graduates (Figure 2) from the MSSafety program. This is not definitive proof that those alumni are truly representative of the entire population, but it does suggest the sample of safety alumni who received the survey is generally representative of the total population. This combined with other 
factors provides stronger evidence that the sample of safety alumni is indeed representative.

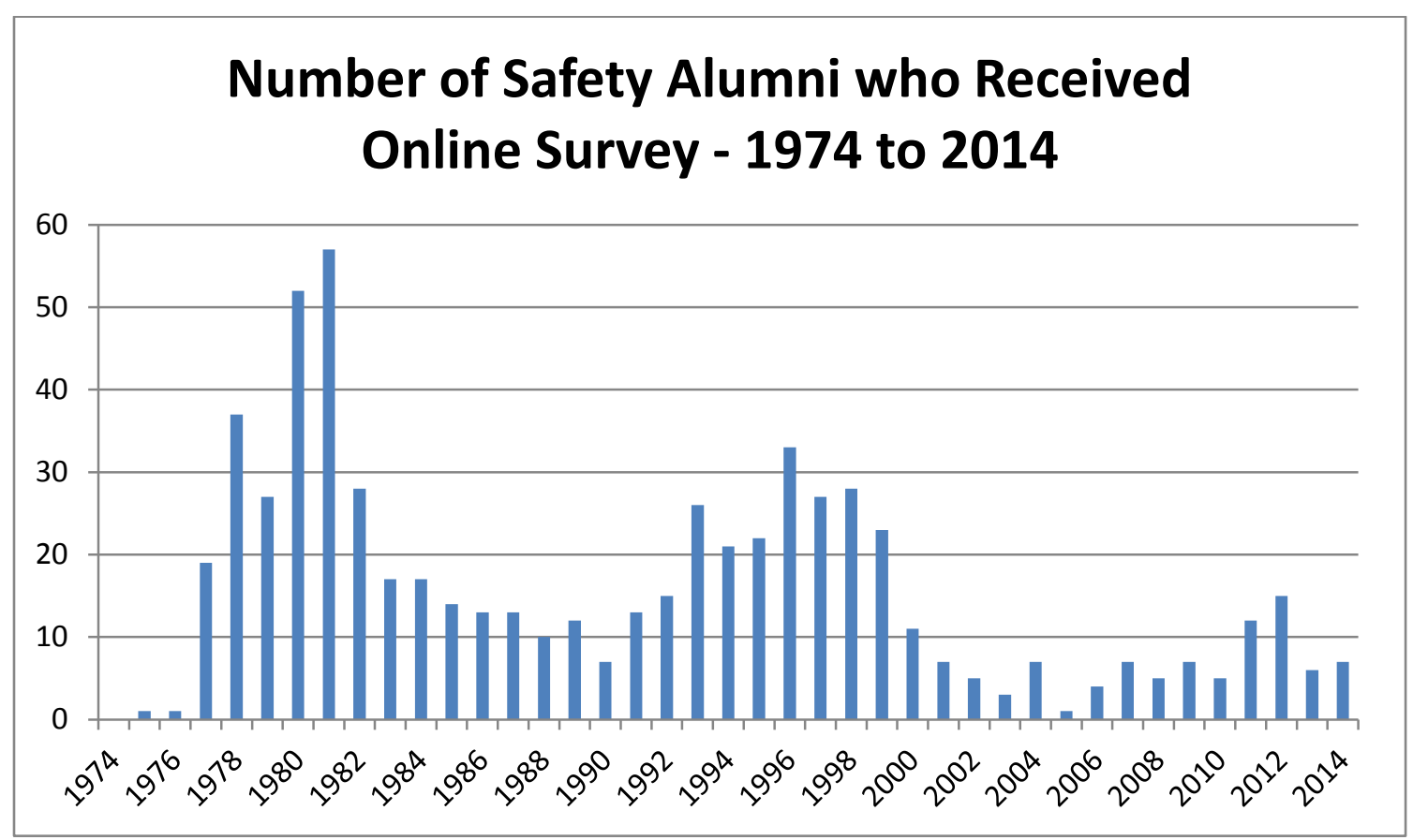

Figure 3. Number of Safety Alumni Who Received the On-Line Survey.

All recipients of the online survey were asked in the cover letter via email to participate in the survey. If they were willing to participate, they were to open the link to the Google form which was the consent to participate thereby answering the group of 28 questions.

Survey question one asked what year the alumni had graduated from UCM. The years of graduation were established into four time periods (1970-1980, 1981-1990, 1991-2000, and 2001 through 2014) based on significant changes in curriculum. The breakdown for the number of respondents by time period was 35 (1970-1980), 42 (19811990), 27 (1991-2000), and 22 (2001-2014). More important than the actual numbers of responses are the percentages of alumni from each time period who responded. The percentages for the number of alumni who responded from each of the four time periods 
divided by the number of alumni for whom emails were available (from that time period) give the following results: $25.6 \%$ for $1970-1980,22.3 \%$ for $1981-1990,12.3 \%$ for 1991 2000, and $24.2 \%$ for the time period from 2000-2014 (Table 13).

Survey question two asked for demographic information on alumni's age. The respondents were divided into five age groups (22-30, 31-40, 41-50, 51-60, and 61 or over). Shown in Figure 4 is the distribution of the different age groups.

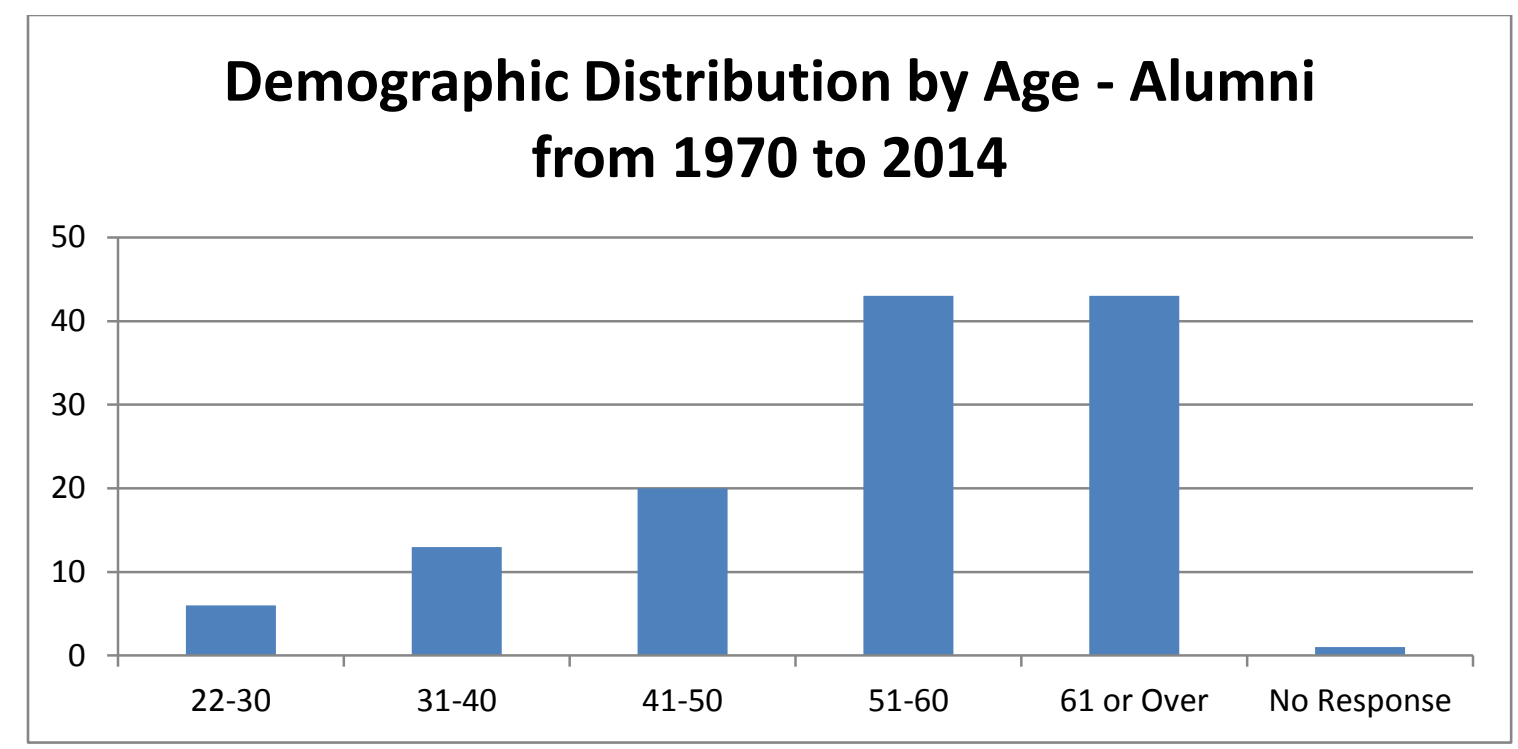

Figure 4. Alumni Demographic Distribution - Age.

Table 13

Number of Alumni by Time Period \& Number that received the Survey

\begin{tabular}{ccccccc}
\hline & \multicolumn{3}{c}{ Total Number of Alumni } & \multicolumn{4}{c}{ Alumni with E-Mail Addresses } \\
\hline $\begin{array}{c}\text { Time } \\
\text { Period }\end{array}$ & $\begin{array}{c}\text { Number } \\
\text { of Alumni }\end{array}$ & $\begin{array}{c}\text { Number } \\
\text { Responded }\end{array}$ & $\begin{array}{c}\text { \% of Total } \\
\text { Alumni }\end{array}$ & $\begin{array}{c}\text { Number } \\
\text { of Alumni }\end{array}$ & $\begin{array}{c}\text { Number } \\
\text { Responded }\end{array}$ & $\begin{array}{c}\% \\
\text { Responded }\end{array}$ \\
\hline $1970-1980$ & 204 & 35 & 17.2 & 137 & 35 & 25.6 \\
$1981-1990$ & 277 & 42 & 15.2 & 188 & 42 & 22.3 \\
$1991-2000$ & 305 & 27 & 8.9 & 219 & 27 & 12.3 \\
$2001-2014$ & 183 & 22 & 12.0 & 91 & 22 & 24.2 \\
\hline
\end{tabular}


Survey question five asked for the percentage of online, hybrid, face-to-face or live, and ITV instruction that was utilized in their degree program. Reflected in Figure 5 is the outcome from the alumni. Face-to-face instruction was the predominant delivery option provided among the respondents.

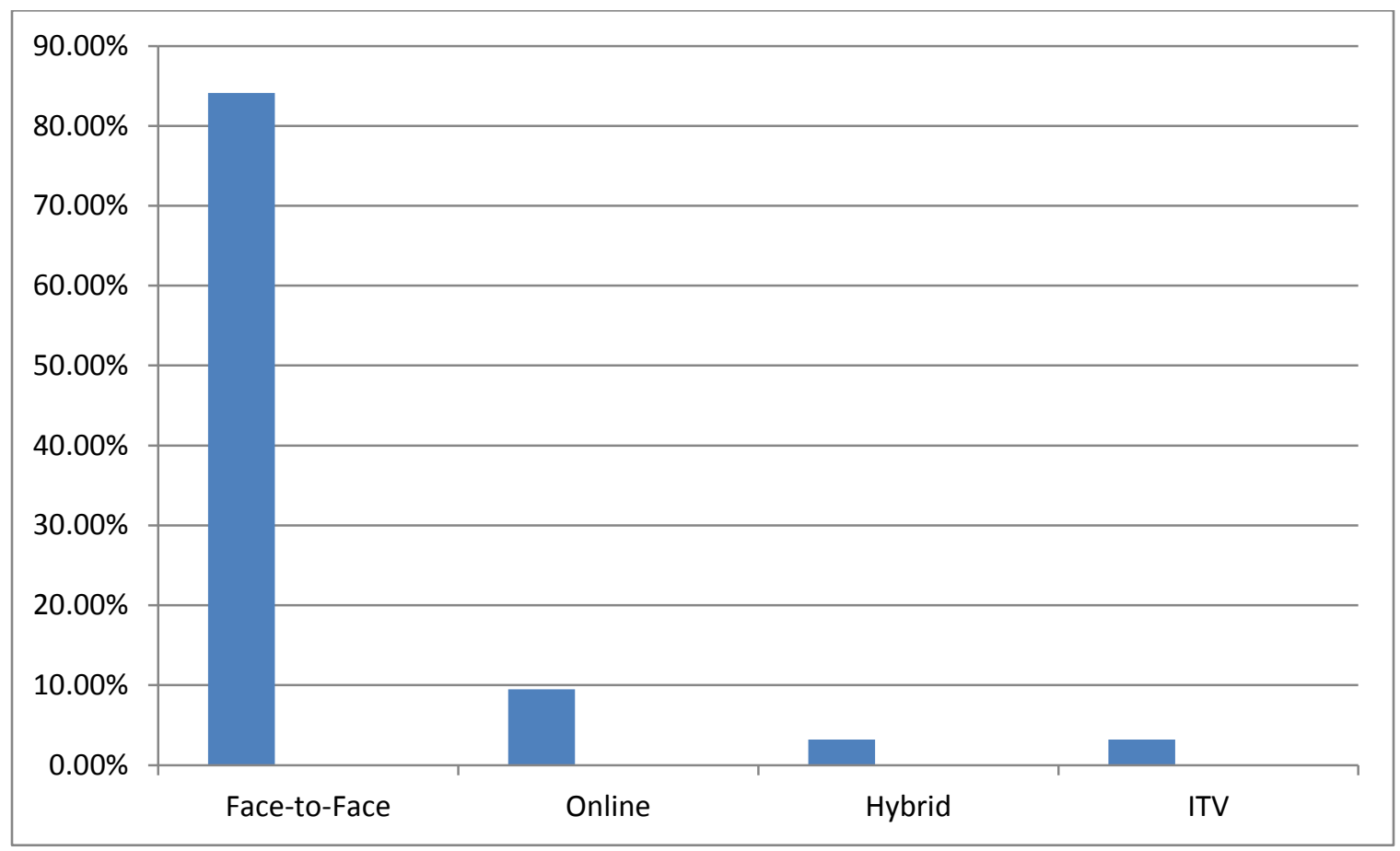

Figure 5. Instruction Method for Alumni for MS-Safety Program from 1970 to 2014.

Survey question six asked for the amount of time it took to get employment in the health and safety profession following graduation. Ninety-two $(73.0 \%)$ of the respondents were either already working in the field or attained employment in three months or less. Results are shown in Figure 6. 


\section{Time to Obtain Employment in Safety Profession following Graduation - MS Safety Alumni - 1970 to 2014}

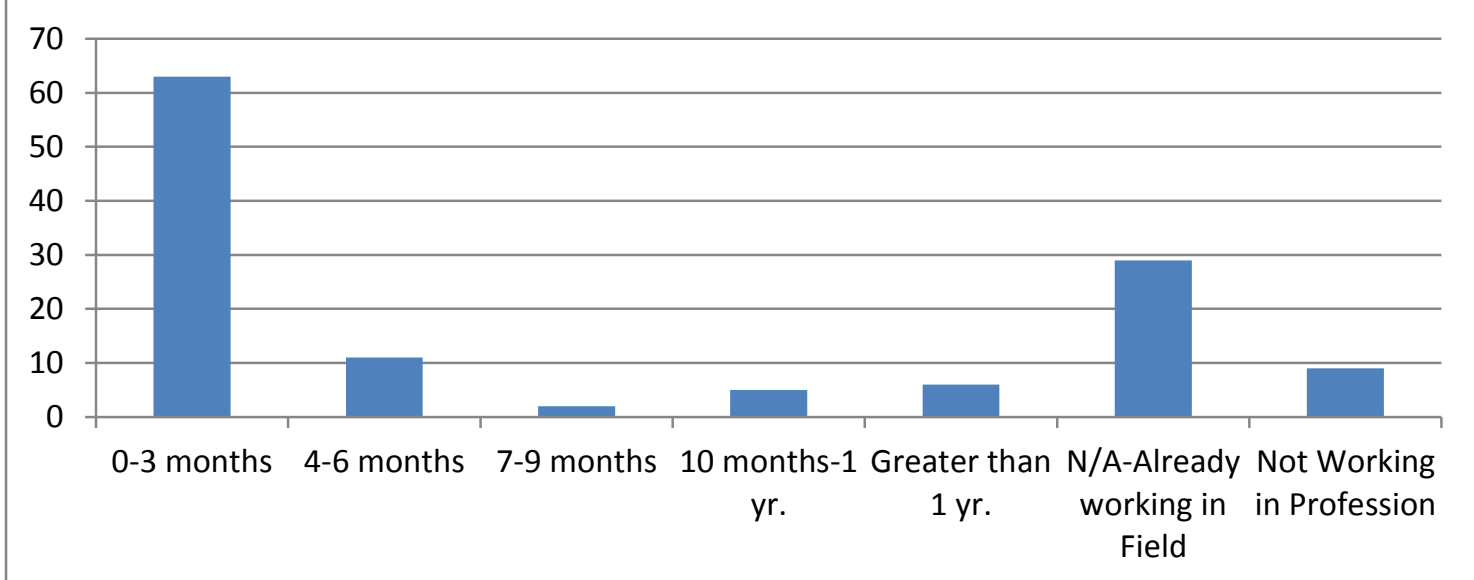

Figure 6. Time to obtain employment following graduation.

Survey question eight asked for the number of years of professional experience each recipient had (Figure 7). Only 24 alumni had ten or fewer years or experience. Fifty-two alumni had between 11 to 30 years of experience, while thirty-nine alumni had 31 or more years of experience. This is consistent with the data from survey question one. Over 82 percent of the alumni who responded to question number one graduated before 2001. 


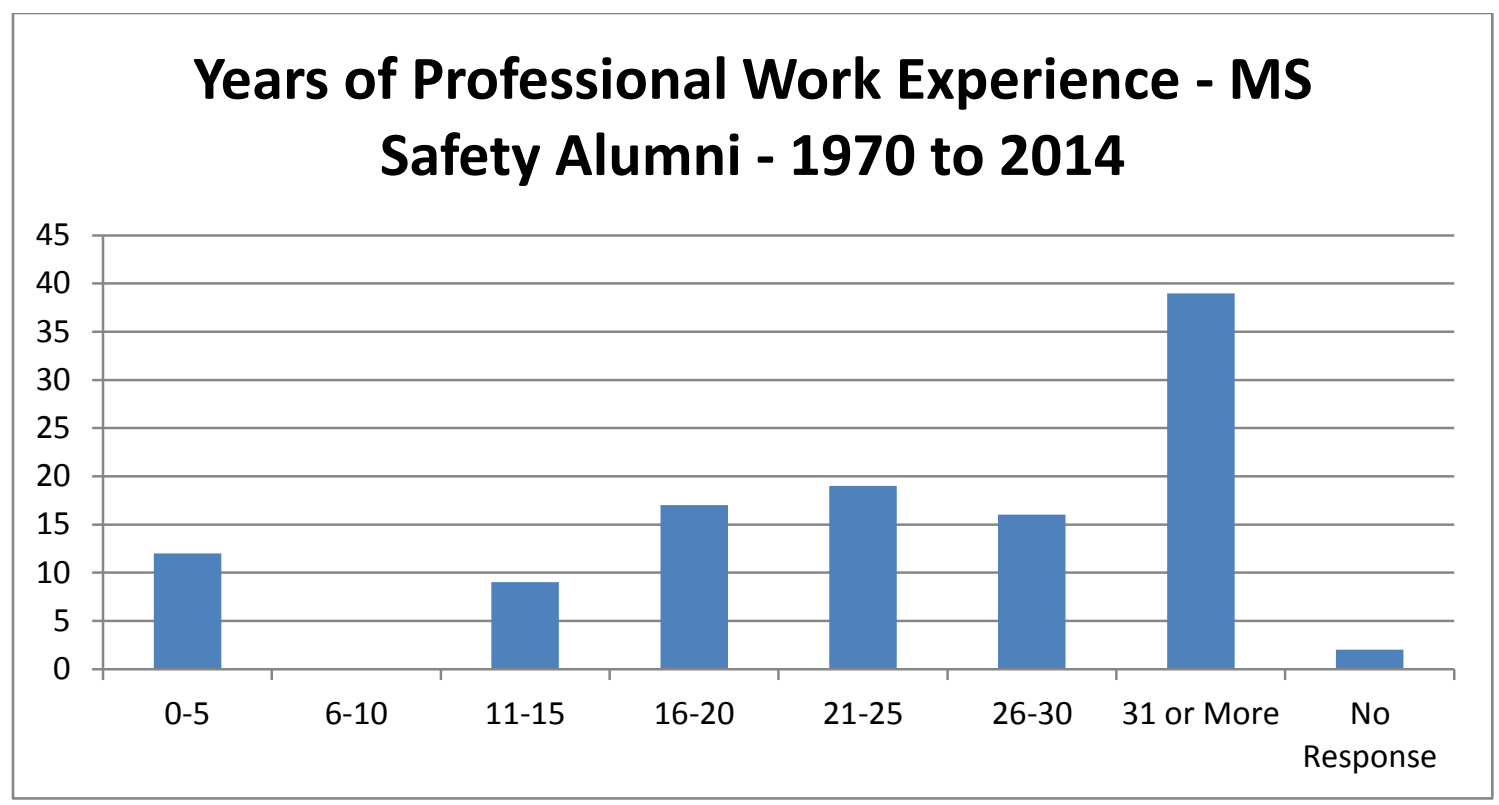

Figure 7. Years of Professional Experience for MS-Safety Alumni.

Survey questions numbers 9 and 10 asked about certifications held by the alumni. Forty-five alumni (35.7\%) reported having the CSP (certified safety professional), 12 (9.5\%) reported having the ARM (Associate Risk Manager) and 8 alumni (6.4\%) indicated they had obtained the Certified Hazardous Materials Manager (CHMM) certification. Three alumni (2.4\%) reported having one of the following: Certified Safety and Health Technician (CHST), Certified Industrial Hygienist (CIH) or Occupational Health and Safety Technician (OHST). Other certifications obtained by alumni included the Graduate Safety Professional (GSP), Professional Engineer (PE), Certified Risk Manager (CRM), Certified Professional Environmental Auditor (CPEA) and Certified Environmental Trainer (CET). These results are shown in Table 14. Reasons for not having obtained certification included: never viewed certification as important, the company did not support it, have been eligible to sit for the exam but haven't taken it, military duty inhibited ability to pursue it as well as took the test but did not obtain a passing score. 
Table 14

Alumni Attainment of Certification

\begin{tabular}{lcc}
\hline & Number & $\%$ \\
\hline Total Alumni & 126 & 100.0 \\
CSP & 45 & 35.7 \\
ARM & 12 & 9.5 \\
CHMM & 8 & 6.4 \\
CHST & 3 & 2.4 \\
CIH & 3 & 2.4 \\
OHST & 3 & 2.4 \\
Other & 26 & 20.6 \\
Alumni with 2 or more certifications & 22 & 17.5 \\
Alumni with no certifications & 58 & 46.0 \\
\hline
\end{tabular}

Survey question 11 asked about each alumni's current job status. One hundred and twenty-six alumni responded to this question. Eighty-two alumni (65.1\%) were employed full-time, two (1.6\%) were employed part-time, ten (7.9\%) were not employed in OSHE, and thirty two (25.4\%) alumni were fully retired.

Survey question 12 asked in what business sector they currently worked. Most alumni are employed in five primary areas: government, loss control/insurance, construction, general industry, and consulting. Twenty-three worked in government (18.3\%), $13.5 \%$ in loss control/insurance while $11.9 \%$ work in construction and $11.1 \%$ work in general industry. All other areas included such industries as environmental 
remediation, oil and gas, healthcare, transportation, consulting, and automotive industries.

Survey question 14 was similar, asking in what primary area of practice alumni worked during their careers. The results are shown in Figure 8. Most alumni indicated that general industry safety was their primary area of practice. Construction was next, followed closely by loss control/insurance. A few alumni indicated they worked primarily in regulatory compliance agencies.

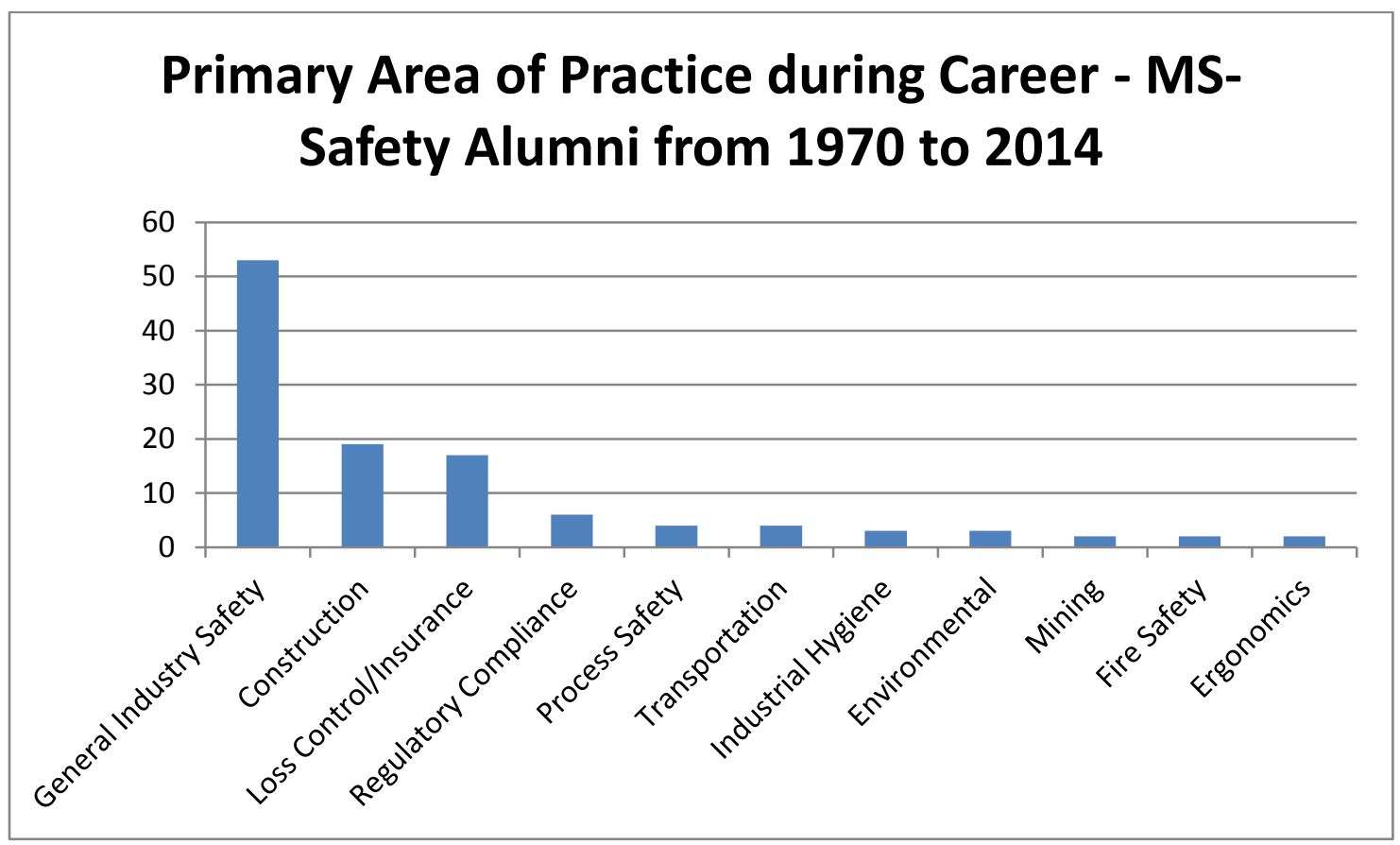

Figure 8. Primary Area of Practice during Career.

Responses for questions 12 and 14 were very consistent for both the most recent job (business sector) and for their career. General industry safety has been one of the top business sectors in which the alumni were working as well as was the primary job responsibility for most alumni’s career. Construction, loss control/insurance and government (regulatory compliance) were also the top business sectors which carried over to the top areas of alumni's primary job responsibilities during their career. 
Survey question 15 asked what percentage of time alumni spent doing OSHE activities. More than $73 \%$ of alumni reported spending over $51 \%$ of their work time on OSHE activities. Sixty-five alumni reported spending over $90 \%$ of their work time on these activities.

Survey question 16 inquired about the alumni's annual income (Figure 9).

Sixteen (12.7\%) alumni reported making $\$ 60,999$ or less, meaning that approximately $87 \%$ of the alumni were earning over $\$ 61,000$ per year. Forty-eight alumni $(38.1 \%)$ reported making between $\$ 61,000$ and $\$ 100,999,35$ alumni $(27.8 \%)$ reported making between $\$ 101,000$ and $\$ 150,999$, and $22(17.5 \%)$ reported making over $\$ 151,000$ per year. Most of the alumni making the higher income had been out of school the longest. Nine of the 35 alumni making between $\$ 101,000$ and $\$ 150,999$ per year graduated in the first time period (1970-1980). Nine of the 22 alumni making over $\$ 151,000$ per year graduated in the first time period as well. Five respondents did not disclose this salary information.

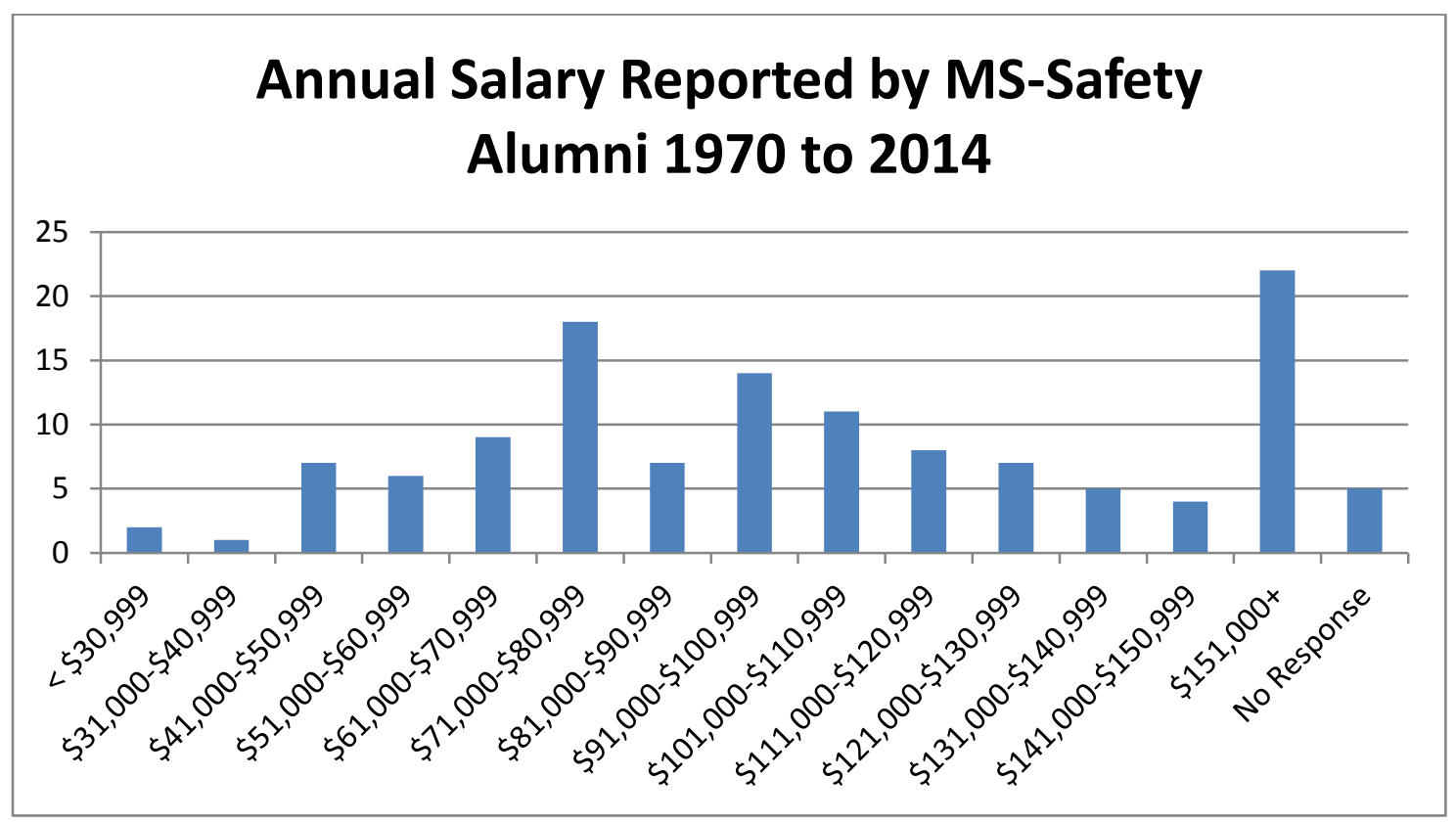

Figure 9. Annual Salary Reported by Alumni. 
Survey question 17 asked alumni how many other OSHE professionals they worked with presently or had previously worked with during their last employment. The results are shown in Figure 10. These results indicate that fifteen alumni presently work by themselves or did so during their last employment. Fifty-one (40.5\%) alumni reported working with at least nine other OSHE professionals.

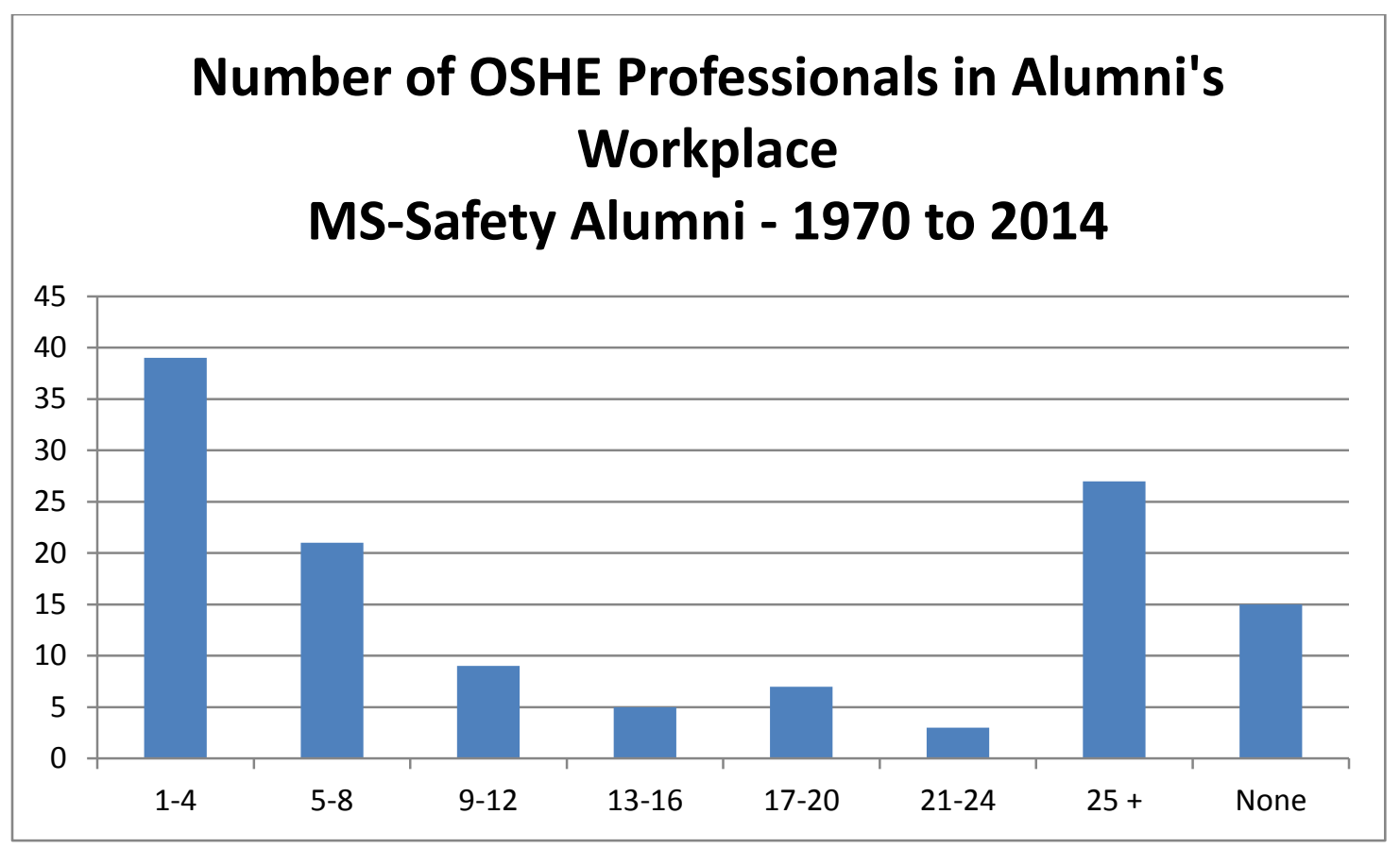

Figure 10. OSHE Professionals in Alumni's Workplace.

Survey question 19 asked how alumni found out about the safety program at UCM (Figure 11). A friend or relative was selected by 52 alumni (41.3\%). The College Advisor was selected by 16 alumni (12.7\%), Air Force was selected by 12 alumni (9.5\%) while the General Studies course was selected by 11 alumni (8.7\%). Other sources were low, indicating that advertisements were not how most alumni learned of the program. Twenty-five "other" answers were given for this question. The other responses were evaluated and grouped to better understand what information sources alumni had used. 


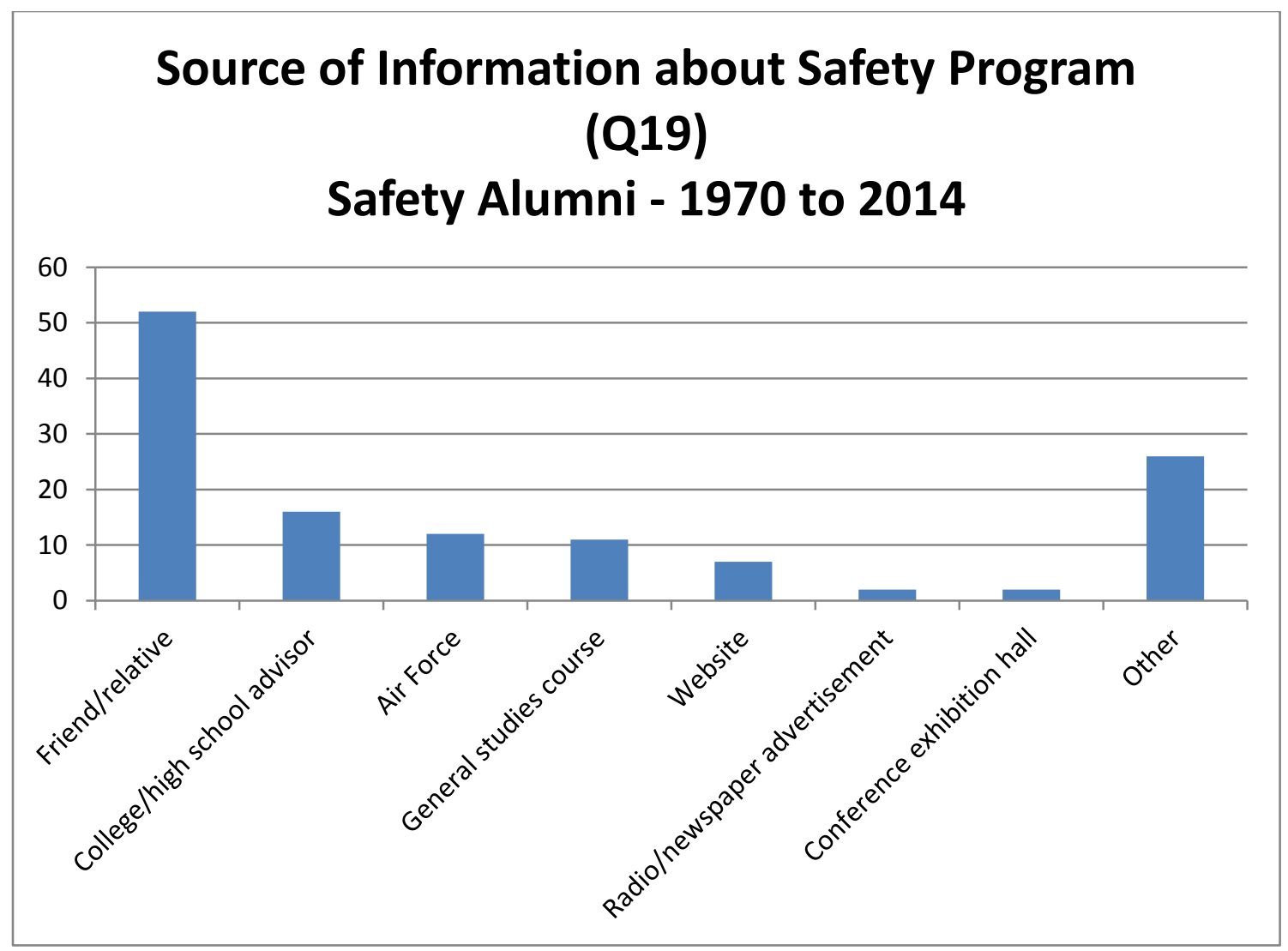

Figure 11. Source of Information about Safety Program at UCM.

Illustrated in Figure 12 is the breakdown of these "other" responses for survey question 19. Highest in this category was contact with UCM alumni, faculty or students $(68 \%)$. The ASSE (American Society of Safety Engineers) was selected by two (8.0\%) alumni while course catalogs were also selected by two $(8.0 \%)$ alumni. One $(4.0 \%)$ alumni reported a NIOSH publication as their response. One (4.0\%) alumnus reported no memory of how they found out about the safety program. 


\section{Breakdown of "Other" Responses from Alumni - Q19- Source of Information about Safety Program}

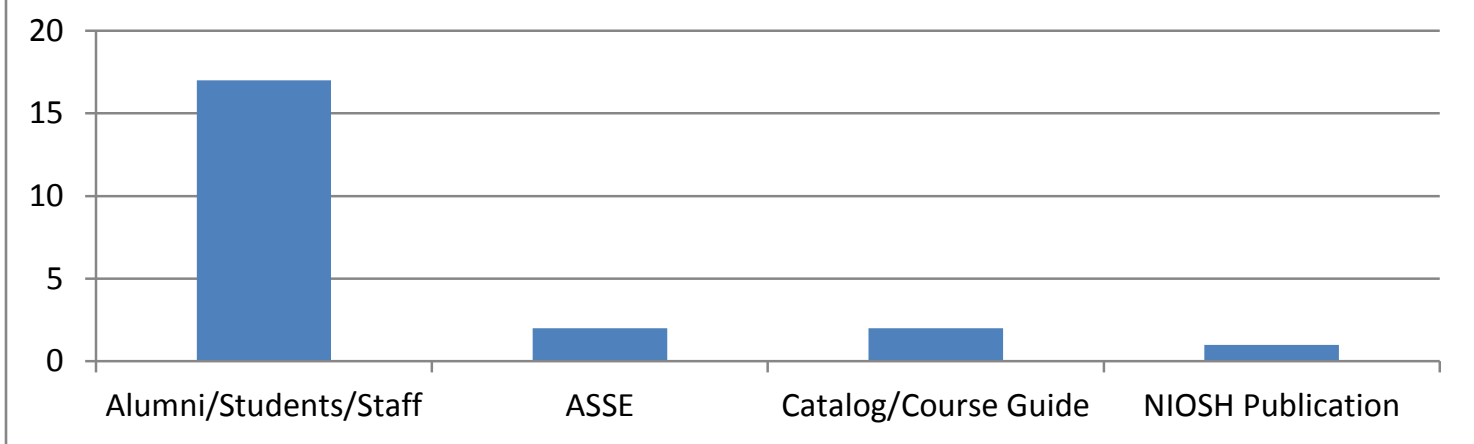

Figure 12. Breakdown of "Other" Responses for Question 19.

Survey question 20 asked the alumni what was their most common approach in resolving and handling occupational safety issues in their current or most recent position. Sixty-six (52.4\%) reported they conducted all assessments/work themselves, 39 (31.0\%) direct others in specific work assignments, and $12(9.5 \%)$ hire consultants or experts. Four alumni indicated they used a mix of the various options. The results are shown in Figure 13.

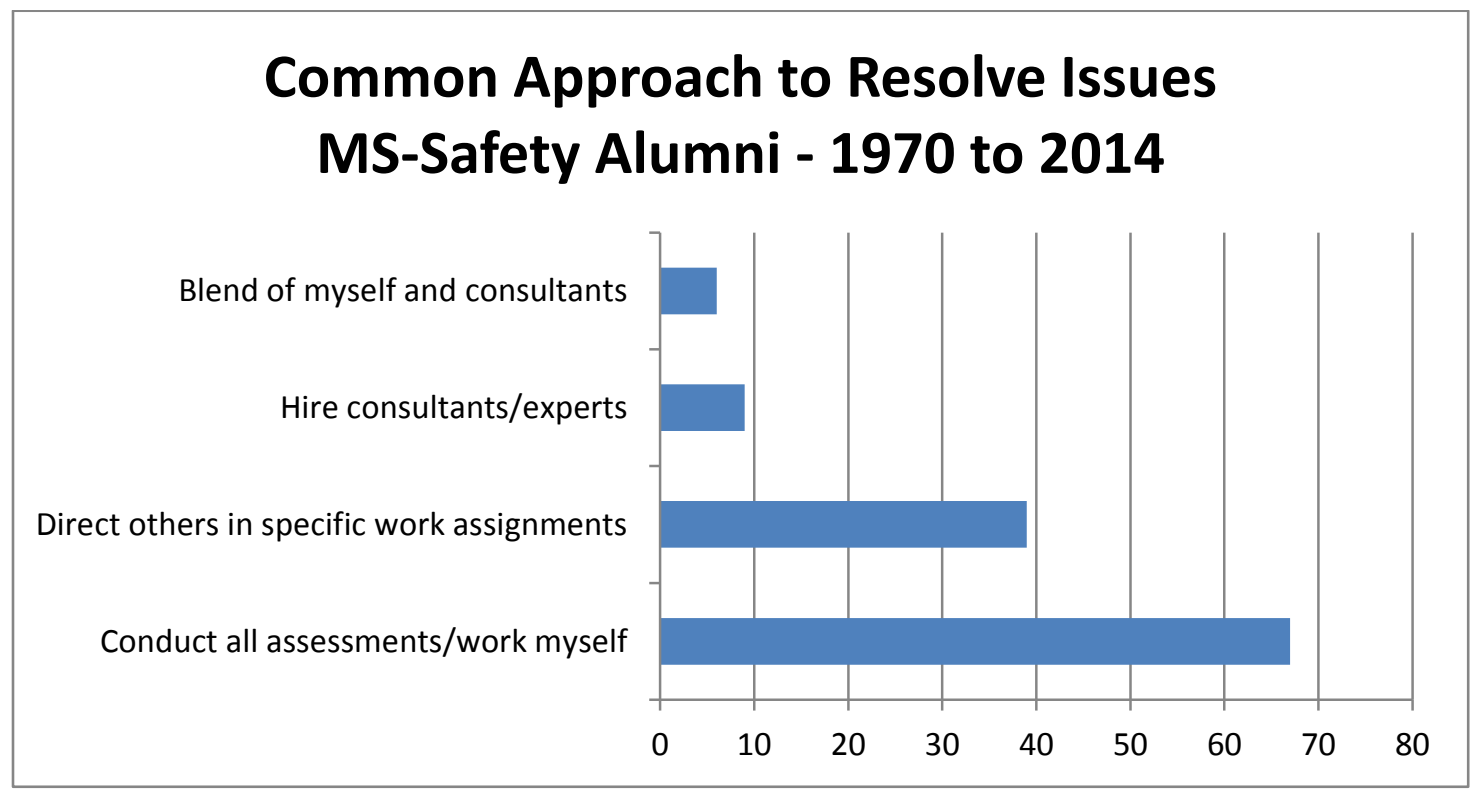

Figure 13. Common Approach in Resolving Occupational Safety Issues. 


\section{Research Questions: Analysis of Data}

Responses from the online survey collected from graduate alumni were entered into SPSS 24.0. Data were first analyzed using descriptive statistics as well as ANOVA single factor test for average data. The Kruskal-Wallis test was conducted for data by era of time for the large populations of perception data that was not averaged.

The written comments found on the surveys were also evaluated. The researcher noted patterns in the responses from the surveys as they related to the framework of the research questions. These patterns were used to provide additional substance to the quantitative statistical analyses and to guide the researcher in addressing the following research questions:

\section{Research Question 1}

What courses do alumni view as most important for the safety management graduate students to take as part of their curricular studies?

Descriptive statistics and the Kruskal-Wallis test were conducted. These analyses were to evaluate differences between the four groups of alumni in their responses to survey question 24 which asked how important 20 courses or subject areas were for safety graduate students to take during their program. The tests showed no significance between the four groups for all 20 courses as reported in Table 15.

Eleven of the 20 topic areas were selected as "high" by the biggest group of alumni. Those areas selected as "above average" importance included biohazards, ergonomics, monitoring and instrumentation, physical hazards (noise/vibration/radiation), research methods, industrial hygiene, managing fire risk, system safety, and individual research. Table 15 shows the results for question 24. Five topics were selected as "high" 
importance by $60-70 \%$ of the respondents. The five topics were: engineering controls, ethics, management, safety leadership, and safety program management.

Table 15

Importance of Specific Courses and Subjects for Safety Students in Program (Q24)

\begin{tabular}{|c|c|c|c|c|c|}
\hline $\begin{array}{l}\text { Survey Question 24: How } \\
\text { important are the following } \\
\text { courses and subjects for safety } \\
\text { students to take during their } \\
\text { program? }\end{array}$ & $\begin{array}{c}\text { Not } \\
\text { Applicable }\end{array}$ & Low & $\begin{array}{c}\text { Below } \\
\text { Average }\end{array}$ & $\begin{array}{l}\text { Above } \\
\text { Average }\end{array}$ & High \\
\hline 1. Biohazards & $\begin{array}{c}0.0 \% \\
(0)\end{array}$ & $\begin{array}{l}5.7 \% \\
(7)\end{array}$ & $\begin{array}{l}28.7 \% \\
(35)\end{array}$ & $\begin{array}{c}44.3 \% \\
(54)\end{array}$ & $\begin{array}{l}21.3 \% \\
(26)\end{array}$ \\
\hline 2. Engineering Controls & $\begin{array}{c}0.0 \% \\
(0)\end{array}$ & $\begin{array}{l}0.0 \% \\
(0)\end{array}$ & $\begin{array}{l}2.4 \% \\
(3)\end{array}$ & $\begin{array}{l}35.8 \% \\
(44)\end{array}$ & $\begin{array}{c}61.8 \% \\
(76)\end{array}$ \\
\hline 3. Administrative Controls & $\begin{array}{l}0.0 \% \\
(0)\end{array}$ & $\begin{array}{l}1.6 \% \\
(2)\end{array}$ & $\begin{array}{l}2.4 \% \\
(3)\end{array}$ & $\begin{array}{l}41.1 \% \\
(51)\end{array}$ & $\begin{array}{c}54.8 \% \\
(68)\end{array}$ \\
\hline $\begin{array}{l}\text { 4. Personal Protective } \\
\text { Equipment }\end{array}$ & $\begin{array}{l}0.0 \% \\
(0)\end{array}$ & $\begin{array}{l}1.6 \% \\
(2)\end{array}$ & $\begin{array}{c}8.9 \% \\
(11)\end{array}$ & $\begin{array}{l}43.1 \% \\
(53)\end{array}$ & $\begin{array}{c}46.3 \% \\
(57)\end{array}$ \\
\hline 5. Ergonomics & $\begin{array}{l}0.0 \% \\
(0)\end{array}$ & $\begin{array}{l}0.8 \% \\
(1)\end{array}$ & $\begin{array}{c}6.6 \% \\
(8)\end{array}$ & $\begin{array}{l}53.3 \% \\
(65)\end{array}$ & $\begin{array}{c}39.3 \% \\
(48)\end{array}$ \\
\hline 6. Ethics & $\begin{array}{l}0.0 \% \\
(0)\end{array}$ & $\begin{array}{l}0.0 \% \\
(0)\end{array}$ & $\begin{array}{l}6.5 \% \\
(8)\end{array}$ & $\begin{array}{l}28.2 \% \\
(35)\end{array}$ & $\begin{array}{c}65.3 \% \\
(81)\end{array}$ \\
\hline 7. Management & $\begin{array}{l}0.0 \% \\
(0)\end{array}$ & $\begin{array}{l}0.0 \% \\
(0)\end{array}$ & $\begin{array}{l}1.6 \% \\
(2)\end{array}$ & $\begin{array}{l}35.8 \% \\
(44)\end{array}$ & $\begin{array}{c}62.6 \% \\
(77)\end{array}$ \\
\hline 8. Business & $\begin{array}{l}0.0 \% \\
(0)\end{array}$ & $\begin{array}{l}0.8 \% \\
(1)\end{array}$ & $\begin{array}{l}8.1 \% \\
(10)\end{array}$ & $\begin{array}{l}45.2 \% \\
(56)\end{array}$ & $\begin{array}{l}45.9 \% \\
(57)\end{array}$ \\
\hline $\begin{array}{l}\text { 9. Monitoring and } \\
\text { Instrumentation }\end{array}$ & $\begin{array}{l}0.0 \% \\
(0)\end{array}$ & $\begin{array}{l}0.8 \% \\
(1)\end{array}$ & $\begin{array}{l}17.1 \% \\
(21)\end{array}$ & $\begin{array}{l}52.0 \% \\
(64)\end{array}$ & $\begin{array}{c}30.1 \% \\
(37)\end{array}$ \\
\hline $\begin{array}{l}\text { 10. Physical Hazards } \\
\text { (Noise/Vibration/Radiation) }\end{array}$ & $\begin{array}{l}0.0 \% \\
(0)\end{array}$ & $\begin{array}{l}0.8 \% \\
(1)\end{array}$ & $\begin{array}{c}10.6 \% \\
(13)\end{array}$ & $\begin{array}{l}53.7 \% \\
(66)\end{array}$ & $\begin{array}{c}34.9 \% \\
(43)\end{array}$ \\
\hline 11. Legislation and Standards & $\begin{array}{c}0.0 \% \\
(0)\end{array}$ & $\begin{array}{l}1.6 \% \\
(2)\end{array}$ & $\begin{array}{l}8.1 \% \\
(10)\end{array}$ & $\begin{array}{l}37.1 \% \\
(46)\end{array}$ & $\begin{array}{c}53.2 \% \\
(66)\end{array}$ \\
\hline
\end{tabular}


Table 15 (Continued)

Importance of Specific Courses

\begin{tabular}{|c|c|c|c|c|c|}
\hline $\begin{array}{l}\text { Survey Question 24: How } \\
\text { important are the following } \\
\text { courses and subjects for safety } \\
\text { students to take during their } \\
\text { program? }\end{array}$ & $\begin{array}{c}\text { Not } \\
\text { Applicable }\end{array}$ & Low & $\begin{array}{l}\text { Below } \\
\text { Average }\end{array}$ & $\begin{array}{l}\text { Above } \\
\text { Average }\end{array}$ & High \\
\hline 12. Research Methods & $\begin{array}{c}0.0 \% \\
(0)\end{array}$ & $\begin{array}{c}6.5 \% \\
(8)\end{array}$ & $\begin{array}{c}25.0 \% \\
(31)\end{array}$ & $\begin{array}{c}42.7 \% \\
(53)\end{array}$ & $\begin{array}{c}25.8 \% \\
(32)\end{array}$ \\
\hline 13. Safety Leadership & $\begin{array}{c}0.0 \% \\
(0)\end{array}$ & $\begin{array}{c}0.0 \% \\
(0)\end{array}$ & $\begin{array}{c}4.0 \% \\
(5)\end{array}$ & $\begin{array}{c}31.5 \% \\
(39)\end{array}$ & $\begin{array}{c}64.5 \% \\
(80)\end{array}$ \\
\hline 14. Industrial Hygiene & $\begin{array}{l}0.8 \% \\
(1)\end{array}$ & $\begin{array}{l}0.8 \% \\
(1)\end{array}$ & $\begin{array}{l}9.7 \% \\
(12)\end{array}$ & $\begin{array}{c}\mathbf{5 0 . 0 \%} \\
(\mathbf{6 2})\end{array}$ & $\begin{array}{c}38.7 \% \\
(48)\end{array}$ \\
\hline $\begin{array}{l}\text { 15. Occupational Hazard } \\
\text { Management }\end{array}$ & $\begin{array}{l}0.0 \% \\
(0)\end{array}$ & $\begin{array}{l}0.0 \% \\
(0)\end{array}$ & $\begin{array}{l}2.4 \% \\
(3)\end{array}$ & $\begin{array}{l}41.5 \% \\
(51)\end{array}$ & $\begin{array}{c}56.1 \% \\
(69)\end{array}$ \\
\hline 16. Managing Fire Risk & $\begin{array}{c}0.0 \% \\
(0)\end{array}$ & $\begin{array}{c}3.3 \% \\
(4)\end{array}$ & $\begin{array}{c}14.6 \% \\
(18)\end{array}$ & $\begin{array}{l}\mathbf{4 8 . 0 \%} \\
(59)\end{array}$ & $\begin{array}{c}34.1 \% \\
(42)\end{array}$ \\
\hline 17. System Safety & $\begin{array}{c}0.0 \% \\
(0)\end{array}$ & $\begin{array}{l}4.8 \% \\
(6)\end{array}$ & $\begin{array}{c}13.7 \% \\
(17)\end{array}$ & $\begin{array}{l}42.7 \% \\
(53)\end{array}$ & $\begin{array}{c}38.7 \% \\
(48)\end{array}$ \\
\hline $\begin{array}{l}\text { 18. Safety Program } \\
\text { Management }\end{array}$ & $\begin{array}{c}0.0 \% \\
(0)\end{array}$ & $\begin{array}{l}0.0 \% \\
(0)\end{array}$ & $\begin{array}{l}1.6 \% \\
(2)\end{array}$ & $\begin{array}{l}36.1 \% \\
(44)\end{array}$ & $\begin{array}{l}62.3 \% \\
(76)\end{array}$ \\
\hline 19. Internship & $\begin{array}{l}1.6 \% \\
(2)\end{array}$ & $\begin{array}{l}4.1 \% \\
(5)\end{array}$ & $\begin{array}{c}10.6 \% \\
(13)\end{array}$ & $\begin{array}{l}34.2 \% \\
(42)\end{array}$ & $\begin{array}{c}49.6 \% \\
(61)\end{array}$ \\
\hline 20. Individual Research & $\begin{array}{c}2.4 \% \\
\text { (3) }\end{array}$ & $\begin{array}{c}12.1 \% \\
(15)\end{array}$ & $\begin{array}{c}21.0 \% \\
(26)\end{array}$ & $\begin{array}{c}33.9 \% \\
(42)\end{array}$ & $\begin{array}{c}30.6 \% \\
(38)\end{array}$ \\
\hline
\end{tabular}

The Likert scale from the survey question 25 which was a "text" feedback was converted to "numerical" by changing "high to 4", "above average 3", "below average to 2 ", "low to 1", and "not applicable to 0" to conduct the statistical analysis is shown in Figure 14 for the four eras of time. The research based courses and subjects are consistently rated low as importance across the eras of time compared to all the other courses. The percentages noted in bold reflect the highest rating for each course. 


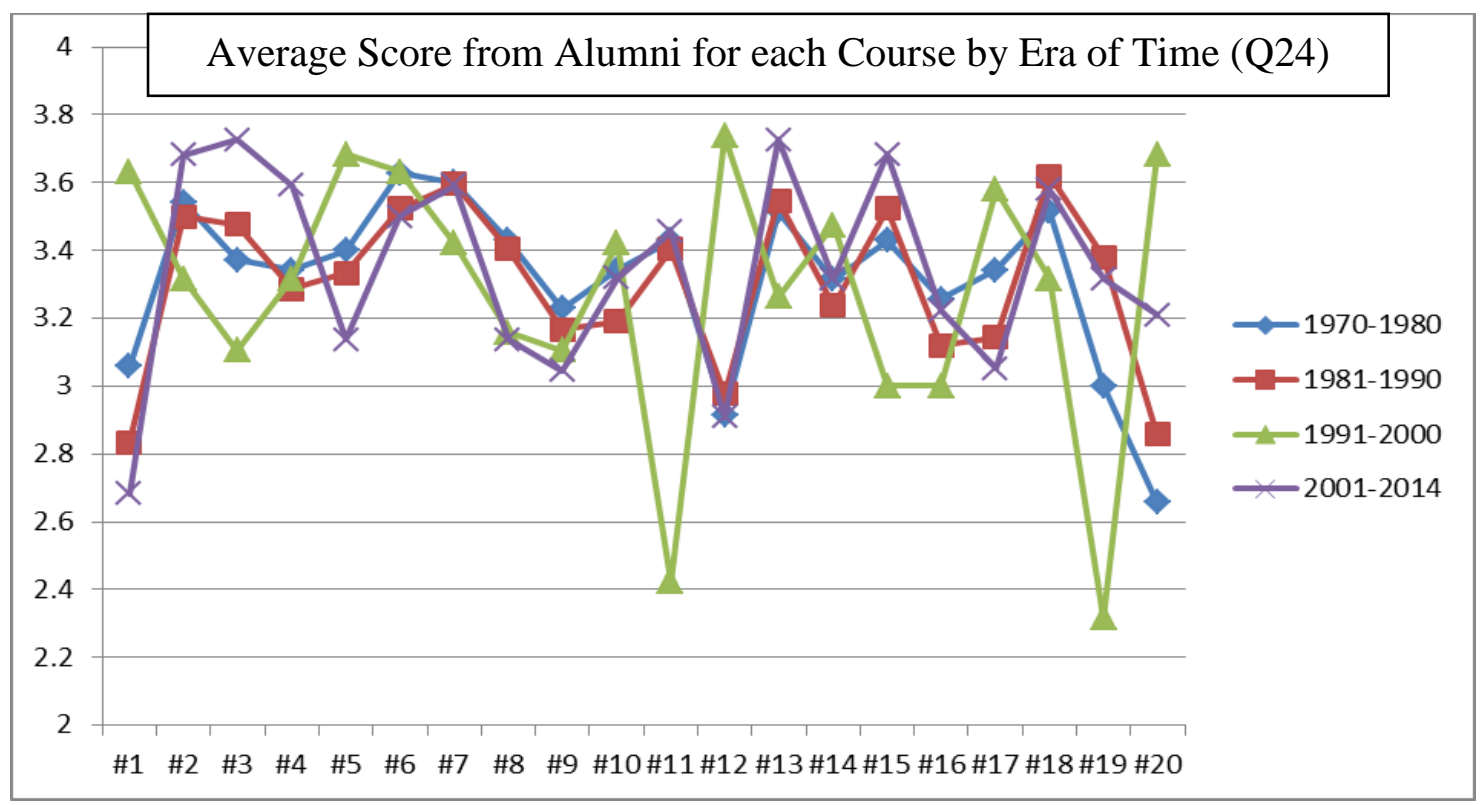

Figure 14. Important courses and subjects for safety students to take during program.

An ANOVA Single Factor test was conducted on the mean (eras of time) for each of the 20 courses reflecting a $\rho$ value of 0.06 thereby showing insignificant difference between the groups (eras of time). Upon further review of the 1991-2000 group of responses and analyses of the data, the comments made by the respondents illogically correspond to the ratings for these courses. Where a few respondents stated additional knowledge in OSHA standards was needed when they got into the working world, they rated the importance for the course very low. The same situation was found on occupational hazard management and the need for internships. The biohazards, research methods and individual research courses that were rated of higher importance by the 1991-2000 group were confirmed by the researcher as being covered in the current curriculum. 
Table 16

Kruskal-Wallis Test - Important Courses and Subjects for Safety Students to Take During Program (Q24).

Survey Question 24: How important are the following courses and subjects for safety students to take during their program?

1. Biohazards

Tin

Time Period

1970-1980 $\quad 3.06$

$1981-1990 \quad 2.83$

1991-2000 $\quad 3.63$

2001-2014 2.68

0.12

2. Engineering Controls

$1970-1980 \quad 3.54$

$1981-1990 \quad 3.50$

$1991-2000 \quad 3.32$

2001-2014 $\quad 3.68$

0.41

3. Administrative Controls

1970-1980

3.37

1981-1990

3.48

1991-2000

3.11

2001-2014

3.73

0.21

4. Personal Protective Equipment

1970-1980

3.34

1981-1990

3.29

$1991-2000$

3.32

2001-2014

3.59

0.21

5. Ergonomics

1970-1980 $\quad 3.40$

$1981-1990 \quad 3.33$

$1991-2000 \quad 3.68$

2001-2014

3.14

0.46

6. Ethics

1970-1980

3.63

$1981-1990 \quad 3.52$

$1991-2000 \quad 3.63$

2001-2014

3.05

0.63

7. Management

1970-1980 $\quad 3.60$

1981-1990 $\quad 3.59$

1991-2000 $\quad 3.42$

2001-2014 3.59

0.88

8. Business

1970-1980

3.43

1981-1990

3.40

1991-2000

3.16

2001-2014

3.14

0.51 
Table 16 (Continued)

Kruskal-Wallis Test - Important Courses

Survey Question 24: How important are the following courses and subjects for safety students to take during their program?

9. Monitoring and Instrumentation

?

10. Physical Hazards

(Noise/Vibration/Radiation)

$1970-1980$

Time Period

Mean

1970-1980

3.23

1981-1990

3.17

1991-2000

3.11

2001-2014

3.05

0.35

1981-1990

3.34

1991-2000

3.19

2001-2014

3.42

3.32

0.33

11. Legislation and Standards

$1970-1980$

3.43

1981-1990

3.40

1991-2000

2.42

2001-2014

3.45

0.96

12. Research Methods

1970-1980

2.91

1981-1990

2.98

1991-2000

3.74

2001-2014

2.91

0.53

13. Safety Leadership

1970-1980

3.51

1981-1990

3.55

1991-2000

3.26

2001-2014

3.73

0.50

14. Industrial Hygiene

1970-1980

3.31

1981-1990

3.24

1991-2000

3.47

2001-2014

3.32

0.47

15. Occupational Hazard Management

1970-1980

3.43

1981-1990

3.52

1991-2000

3.00

2001-2014

3.68

0.29

16. Managing Fire Risk

$\begin{array}{ll}1970-1980 & 3.26 \\ 1981-1990 & 3.12 \\ 1991-2000 & 3.00 \\ 2001-2014 & 3.22\end{array}$

3.26

3.12

3.00

3.22

0.31 
Table 16 (Continued)

Kruskal-Wallis Test - Important Courses

Survey Question 24: How important are the following courses and subjects for safety students to take during their program?

17. System Safety

Time Period

1970-1980

1981-1990

$1991-2000$

2001-2014

1970-1980

1981-1990

3.62

1991-2000

3.32

2001-2014

3.58

0.79

19. Internship

1970-1980

3.00

1981-1990

3.38

1991-2000

2.32

2001-2014

3.32

0.29

20. Individual Research

1970-1980

2.66

1981-1990

2.86

1991-2000

3.68

2001-2014

3.21

0.12

Survey question 24 asked alumni how important certain courses and subjects were for safety students to take during their program. Per the Kruskal-Wallis test, none of the 20 courses showed significant difference between groups (eras of time). Those are shown in Table 16. Trends reflect that there is more importance in the last group (20012014) on the following courses: a) administrative controls, b) legislation and standards, c) occupational hazard management, d) internship and e) individual research. Ergonomics and individual research show less importance during the last group (2001-2014). 


\section{Research Question 2}

What knowledge and skills do alumni view as critical for entry level safety professionals in the workplace?

Descriptive statistics and the ANOVA Single Factor test were conducted. These analyses were to evaluate differences between the four groups of alumni in their responses to survey question 21. Survey question 21 asked "How important are eight skill sets as they relate to your current or most recent safety related job?" Seven of the eight skill sets were selected as essential (the highest rating) by more alumni than any other category (Table 17). One skill set, awareness of contemporary, global and societal issues as they pertain to OSHE, was selected as important (the second highest category) by the largest group of alumni.

Table 17

Importance of Safety Skill Sets Related to Safety Job (Q21)

\begin{tabular}{lllll}
\hline Survey Question 21: How important are & Not & Useful & Important & Essential \\
the following MS-safety skill sets as they & Necessary & & &
\end{tabular}
relate to your current/most recent job?

The ability to communicate $0.8 \%$ $2.4 \%$ $7.3 \%$ $89.5 \%$ professionally both verbally/in writing.

Knowledge of professional integrity and $0.8 \%$ ethics.

$4.8 \%$

$21.0 \%$

$73.4 \%$

Awareness of contemporary, global and societal issues as they relate to the practice of occupational safety and $29.0 \%$

$41.1 \%$ $26.6 \%$ health.

The ability to develop, coordinate and participate in multi-disciplinary teams to $1.6 \%$ (36) protect people, property and the environment. 
Table 17 (Continued)

Import.of Safety Skill Sets to Safety Job

Survey Question 21: How important are the following MS-safety skill sets as they Necessary

relate to your current/most recent job?

\begin{tabular}{lcccc}
\hline $\begin{array}{l}\text { The ability to analyze injury, illness and } \\
\text { liability trends to help establish priority } \\
\text { and direction. }\end{array}$ & $\begin{array}{c}3.3 \% \\
(4)\end{array}$ & $\begin{array}{c}9.8 \% \\
(12)\end{array}$ & $\begin{array}{c}31.7 \% \\
(39)\end{array}$ & $\begin{array}{c}\mathbf{5 5 . 3 \%} \\
\mathbf{( 6 8 )}\end{array}$ \\
$\begin{array}{l}\text { The ability to organize limited resources } \\
\text { to optimize risk control. }\end{array}$ & $\begin{array}{c}2.5 \% \\
(3)\end{array}$ & $\begin{array}{c}10.7 \% \\
(13)\end{array}$ & $\begin{array}{c}30.6 \% \\
(37)\end{array}$ & $\begin{array}{c}\mathbf{5 6 . 2 \%} \\
\mathbf{( 6 8 )}\end{array}$ \\
$\begin{array}{l}\text { The ability to develop, implement and } \\
\text { evaluate hazard control processes for a } \\
\text { performance safety program. }\end{array}$ & $\begin{array}{c}2.4 \% \\
(3)\end{array}$ & $\begin{array}{c}8.1 \% \\
(10)\end{array}$ & $\begin{array}{c}26.6 \% \\
(33)\end{array}$ & $\begin{array}{c}\mathbf{6 2 . 9 \%} \\
\mathbf{( 7 8 )}\end{array}$ \\
$\begin{array}{l}\text { Ability to develop, implement and assess } \\
\text { a comprehensive safety and health prog. } \\
\text { in a variety of occupational settings. }\end{array}$ & $\begin{array}{c}3.2 \% \\
(4)\end{array}$ & $\begin{array}{c}7.3 \% \\
(9)\end{array}$ & $\begin{array}{c}37.1 \% \\
(46)\end{array}$ & $\begin{array}{c}\mathbf{5 2 . 4 \%} \\
\mathbf{( 6 5 )}\end{array}$ \\
\hline
\end{tabular}

When comparing the results of survey question 21 by four eras of time (Table 18)

across all eight skill sets, there is not a significant difference between the forty-four year tenure of the program. The Likert scale from the survey which was a "text" feedback was converted to "numerical" by changing "essential to 4", "important to 3", "useful to 2" and "not necessary to 1" to conduct the statistical analysis. The outcome of the ANOVA single factor test is not statistically significant with a $\rho$ value of 0.55 . The percentages noted in bold reflect the highest rating for each course.

Table 18

ANOVA-Importance of 8 Skills Sets (Total) in Alumni's safety job by Eras of Time (Q 21)

\begin{tabular}{ccc}
\hline Time Period & $\begin{array}{c}\text { Mean } \\
\text { (by Time Period) }\end{array}$ & $\rho$ value \\
\hline $1970-1980$ & 3.47 & \\
$1981-1990$ & 3.51 & \\
$1991-2000$ & 3.32 & \\
& & \\
$2001-2014$ & 3.35 & 0.55 \\
\hline
\end{tabular}


When evaluating by each of the eight skill sets across the eras of time, Table 19 reflects the findings utilizing descriptive statistics. Skill set three of "Awareness of contemporary, global and societal issues as they relate to the practice of occupational safety and health" is rated as the lowest needed area in the practice of safety from the alumni (Table 17). This same correlation was found when doing the descriptive analysis by skill set. The skill set of "The ability to communicate professionally both verbally and in writing" has remained the most essential throughout the entire tenure of the program. Table 19

Eight Skill Sets needed in practice of safety - Mean - Eras of Time - Q21

\begin{tabular}{ccccccccc}
\hline $\begin{array}{c}\text { Era of } \\
\text { Time }\end{array}$ & $\begin{array}{c}\text { Skill } \\
\text { Set \#1 }\end{array}$ & $\begin{array}{c}\text { Skill } \\
\text { Set \#2 }\end{array}$ & $\begin{array}{c}\text { Skill } \\
\text { Set \#3 }\end{array}$ & $\begin{array}{c}\text { Skill } \\
\text { Set \#4 }\end{array}$ & $\begin{array}{c}\text { Skill } \\
\text { Set \#5 }\end{array}$ & $\begin{array}{c}\text { Skill } \\
\text { Set \#6 }\end{array}$ & $\begin{array}{c}\text { Skill } \\
\text { Set \#7 }\end{array}$ & $\begin{array}{c}\text { Skill } \\
\text { Set \#8 }\end{array}$ \\
\hline $1970-1980$ & 3.89 & 3.77 & 2.83 & 3.49 & 3.34 & 3.51 & 3.49 & 3.43 \\
$1981-1990$ & 3.86 & 3.64 & 3.03 & 3.52 & 3.45 & 3.51 & 3.57 & 3.50 \\
$1991-2000$ & 3.86 & 3.64 & 2.64 & 3.32 & 3.23 & 3.27 & 3.50 & 3.14 \\
$2001-2014$ & 3.82 & 3.59 & 3.05 & 3.14 & 3.43 & 3.05 & 3.36 & 3.36 \\
$\chi$ & 3.86 & 3.66 & 2.88 & 3.37 & 3.36 & 3.34 & 3.48 & 3.36 \\
$\sigma$ & 0.03 & 0.08 & 0.19 & 0.18 & 0.10 & 0.22 & 0.09 & 0.16 \\
\hline
\end{tabular}

Survey question 25 asked the alumni to rate twenty skill sets of analytical, management and communication knowledge in their current or most recent job in safety. The Likert scale from the survey was a "text" feedback. The feedback was converted to "numerical" values to conduct the statistical analysis by changing "essential to 4", “important to 3", "useful to 2" and "not necessary to 1 ". 
Table 20

Analytical,Management, and Communication Skills/Knowledge Sets Related to Safety Job

\begin{tabular}{lcccc}
\hline Survey Question 25: How essential are & Not & Useful & Important & Essential \\
the following analytical, management & Necessary & & & \\
and communication skills knowledge in & & & & \\
your current or most recent job in safety? & & & & \\
\hline
\end{tabular}

1. Hazard anticipation and recognition

$0.8 \% \quad 1.6 \% \quad 21.8 \% \quad \mathbf{7 5 . 8 \%}$

(1) (2) (27) (94)

2. Data analysis

$2.4 \%$

$7.3 \%$

$39.8 \%$

$50.4 \%$

(9)

(49)

(62)

3. Exposure control (Hierarchy of controls)

$2.4 \%$

$8.1 \% \quad 39.8 \%$

$49.6 \%$

(10)

(49)

(61)

4. Operation of field testing equipment

$9.0 \%$

$27.1 \%$

$43.4 \%$

$20.5 \%$

(33)

(53)

(25)

5. Critical and analytical thinking

$1.7 \%$

$4.1 \% \quad 24.8 \%$

$69.4 \%$

(5)

(30)

(84)

6. Organizational skills

$0.8 \%$

$3.3 \%$

$27.1 \%$

$68.9 \%$

(1)

(4) (33)

(84)

7. Detail-oriented

$1.7 \%$

$9.1 \%$

$28.1 \%$

$61.2 \%$

(11)

(34)

(74)

8. Financial planning/budgeting

$5.0 \%$

$28.9 \%$

$38.8 \%$

$27.3 \%$

(6)

(47)

9. Effective team building

$2.5 \%$

$9.8 \%$

$34.4 \%$

$53.3 \%$

(12)

(42)

(65)

10. Problem solving

$0.8 \%$

$4.1 \%$

$19.7 \%$

$75.4 \%$

(5)

(24)

(92)

11. Objectivity

$0.8 \%$

$3.3 \%$

$34.4 \%$

$61.5 \%$

(4)

(75)

12. Self-motivation

$1.6 \%$

$3.3 \%$

$13.9 \%$

(4) (17)

$81.2 \%$

(99) 
Table 20 (Continued)

Skill/Knowledge Sets Related to Safety $\operatorname{Job}(Q 25)$

Survey Question 25: How essential are the following analytical, management and communication skills knowledge in your current or most recent job in safety?

13. Ability to demonstrate value-added services to your organization

$1.7 \%$

Not
Useful Important Essential Necessary

14. Time management

$0.8 \%$

(5)

$25.6 \%$

(31)

$68.6 \%$

(83)

15. Public speaking

$1.6 \%$

(2)

$4.1 \%$

(5)

$31.2 \%$

$62.3 \%$

$0.8 \%$

(1)

$3.3 \%$

(4)

(38)

(76)

16. Interpersonal skills

$0.8 \%$

$5.0 \%$

$27.9 \%$

(34)

$66.4 \%$

(81)

17. Risk communication

(6)

$19.7 \%$

(24)

$76.2 \%$

(93)

18. Crisis management

$1.6 \%$

$14.8 \%$

(18)

$33.1 \%$

$61.2 \%$

(40)

(74)

19. Written communication

$1.6 \%$
$(2)$

$39.3 \%$

(48)

43.4\%

(53)

20. Research methodology 


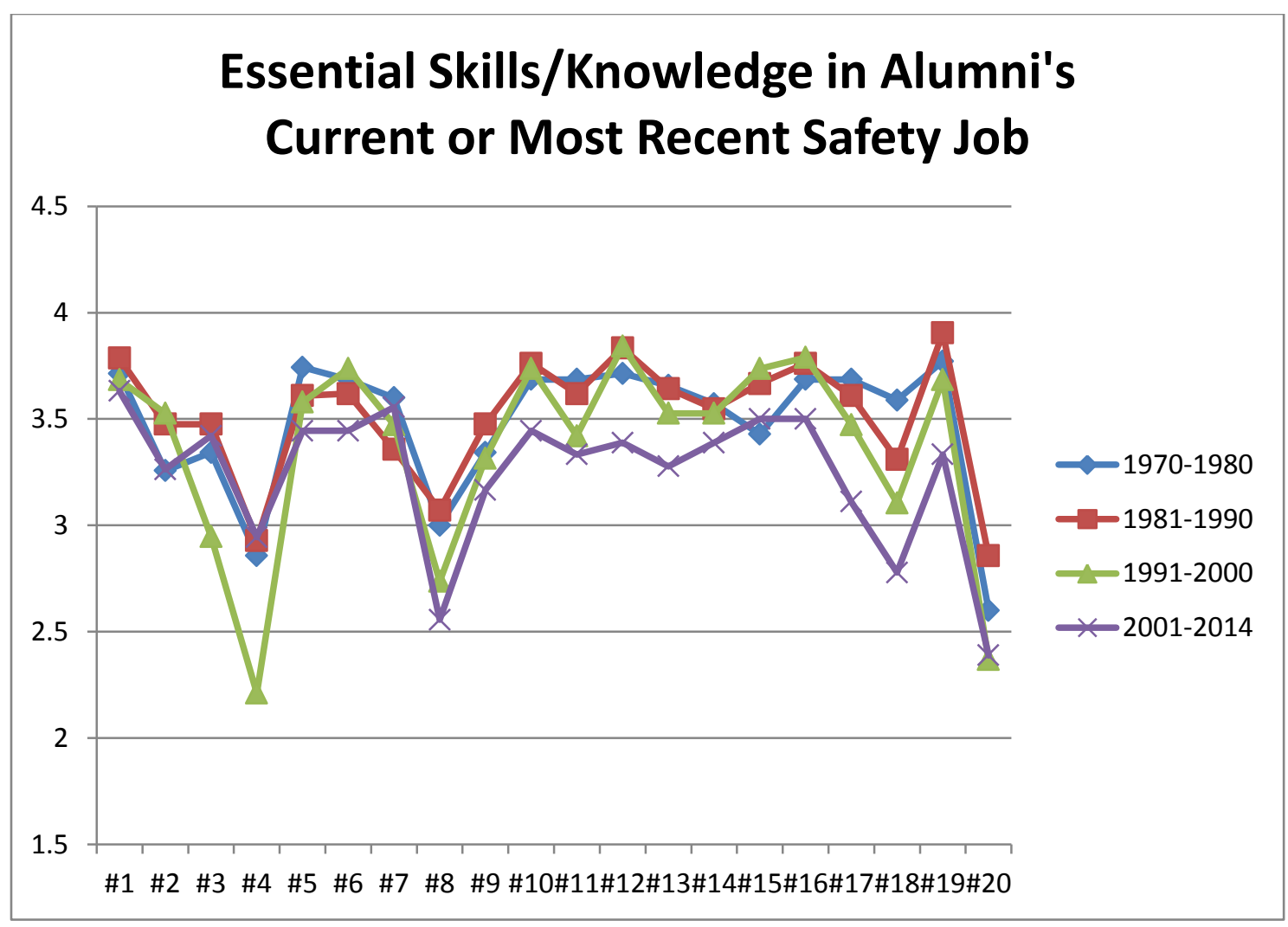

Figure 15. Essential skills/knowledge in Alumni's current/most recent safety job (Q25).

Descriptive statistical analyses were conducted. These analyses were to evaluate differences between the four groups of alumni in their responses to survey question 25 . Survey question 25, asked, "How essential are the following analytical, management and communication skills/knowledge as they relate to your current or most recent safety related job?" Seventeen of the twenty skill sets were selected as essential (the highest rating) by more alumni than any other category (Table 20). Two skill sets being “Operation of field testing equipment" and "Financial planning/budgeting" were selected as important (the second highest category) by the largest group of alumni. The skill set "Research methodology" was selected as useful (the third highest category) by the largest group of alumni. The percentages noted in bold reflect the highest rating for each course. 
Table 21

Kruskal-Wallis Test - Analytical, Management and Communication Skills/Knowledge Sets Related to Safety Job (Q25).

Survey Question 25: How essential are the following analytical, management and communication skills knowledge in your current or most recent job in safety?

Time Period Mean $\rho$

1. Hazard anticipation and recognition

$\begin{array}{ll}1970-1980 & 3.71 \\ 1981-1990 & 3.79 \\ 1991-2000 & 3.68 \\ 2001-2014 & 3.63\end{array}$

0.81

2. Data analysis

$\begin{array}{ll}1970-1980 & 3.26 \\ 1981-1990 & 3.48 \\ 1991-2000 & 3.53 \\ 2001-2014 & 3.26\end{array}$

0.38

3. Exposure control (Hierarchy of controls)

$\begin{array}{ll}1970-1980 & 3.34 \\ 1981-1990 & 3.48 \\ 1991-2000 & 2.95 \\ 2001-2014 & 3.42\end{array}$

0.31

4. Operation of field testing equipment

$\begin{array}{ll}1970-1980 & 2.86 \\ 1981-1990 & 2.93 \\ 1991-2000 & 2.21 \\ 2001-2014 & 2.89\end{array}$

0.01

5. Critical and analytical thinking

1970-1980

3.74

$1981-1990 \quad 3.57$

$1991-2000 \quad 3.58$

2001-2014

3.37

0.24

6. Organizational skills

1970-1980 $\quad 3.69$

$1981-1990 \quad 3.62$

$1991-2000 \quad 3.74$

2001-2014 3.37

0.75

7. Detail-oriented

$\begin{array}{ll}1970-1980 & 3.60 \\ 1981-1990 & 3.36 \\ 1991-2000 & 3.47 \\ 2001-2014 & 3.47\end{array}$

3.60

3.36

3.47 
Table 21 (Continued)

Kruskal-Wallis Test-Skill/Knowledge Sets

Survey Question 25: How essential are the following analytical, management and communication skills knowledge in you current or most recent job in safety?

8. Financial planning/budgeting

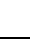

?

$\begin{array}{ll}1970-1980 & 2.97 \\ 1981-1990 & 3.07 \\ 1991-2000 & 2.74 \\ 2001-2014 & 2.53\end{array}$

0.05

9. Effective team building

$\begin{array}{ll}1970-1980 & 3.34 \\ 1981-1990 & 3.48 \\ 1991-2000 & 3.32 \\ 2001-2014 & 3.11\end{array}$

10. Problem solving

$\begin{array}{ll}1970-1980 & 3.69 \\ 1981-1990 & 3.76 \\ 1991-2000 & 3.74 \\ 2001-2014 & 3.37\end{array}$

11. Objectivity

$\begin{array}{ll}1970-1980 & 3.69 \\ 1981-1990 & 3.62 \\ 1991-2000 & 3.42 \\ 2001-2014 & 3.26\end{array}$

\subsection{3}

0.56

$1970-1980 \quad 3.71$

12. Self-motivation

$1981-1990 \quad 3.83$

1991-2000 $\quad 3.84$

2001-2014 $\quad 3.32$

0.03

13. Ability to demonstrate value-added services to your organization

1970-1980 $\quad 3.66$

$1981-1990 \quad 3.64$

$1991-2000 \quad 3.53$

2001-2014 $\quad 3.21$

0.02

14. Time management

1970-1980 $\quad 3.57$

$1981-1990 \quad 3.55$

$1991-2000 \quad 3.53$

2001-2014 $\quad 3.32$

0.89

15. Public speaking

1970-1980 $\quad 3.43$

$1981-1990 \quad 3.67$

1991-2000 $\quad 3.74$

2001-2014 $\quad 3.42$

0.72 
Table 21 (Continued)

Kruskal-Wallis Test-Skill/Knowledge Sets

Survey Question 25: How essential are the following analytical, management and communication skills knowledge in your current or most recent job in safety?

16. Interpersonal skills

17. Risk communication

1970-1980

3.69

1981-1990

3.60

1991-2000

3.47

2001-2014

3.05

0.02

18. Crisis management

1970-1980

3.54

1981-1990

3.31

1991-2000

3.11

2001-2014

2.74

0.00

19. Written communication

1970-1980

3.77

1981-1990

3.90

1991-2000

3.68

2001-2014

3.26

0.05

20. Research methodology

1970-1980

2.60

1981-1990 2.86

1991-2000 2.37

2001-2014 2.37

0.13

Survey question 25 asked alumni how essential certain analytical, management and communication skills/knowledge were in their current or most recent job in safety. Per the Kruskal-Wallis test, 15 of the 20 skills showed no significant difference ( $\rho>.05)$. Those are shown in Table 21. In looking at trends for the fifteen significant skills all four time periods were rated higher for at least one of the skill sets. Four of the 20 areas that showed consistent lower importance were: a) operation of field testing equipment, b) 
financial planning and budgeting, c) crisis management and d) research methodology. The five skills that had a statistical significance $(\rho<.05)$ between the four eras of time were: a) operation of field testing equipment, b) self-motivation, c) ability to demonstrate value-added services to your organization, d) risk communication, and e) crisis management. The Kruskal-Wallis test was comparing across all four eras, so it's possible one could be different from the others even when the Kruskal-Wallis was not significant.

Survey question 26 asked the alumni to indicate how often certain instruments were used in their current or most recent job in safety. The Likert scale from the survey which was a "text" feedback was converted to "numerical" format to conduct the statistical analysis by changing "frequently to 4", "periodically to 3", "infrequently to 2 " and "never to 1 ".

Table 22

Instrument usage in current or most recent safety job (Q26)

\begin{tabular}{|c|c|c|c|c|}
\hline $\begin{array}{l}\text { Survey Question 26: Please } \\
\text { indicate how often you use the } \\
\text { following instruments in your } \\
\text { current/most recent safety job. }\end{array}$ & Never & Infrequently & Periodically & Frequently \\
\hline 1. Photoionization Detector & $\begin{array}{c}66.9 \% \\
(81)\end{array}$ & $\begin{array}{l}20.7 \% \\
(25)\end{array}$ & $\begin{array}{l}9.9 \% \\
(12)\end{array}$ & $\begin{array}{l}2.5 \% \\
(3)\end{array}$ \\
\hline $\begin{array}{l}\text { 2. Colorimetric Tubes - Chemical } \\
\text { Specific }\end{array}$ & $\begin{array}{l}51.2 \% \\
(62)\end{array}$ & $\begin{array}{l}23.1 \% \\
(28)\end{array}$ & $\begin{array}{l}20.7 \% \\
(25)\end{array}$ & $\begin{array}{l}5.0 \% \\
(6)\end{array}$ \\
\hline 3. Sound Level Meter & $\begin{array}{l}16.3 \% \\
(20)\end{array}$ & $\begin{array}{l}22.8 \% \\
(28)\end{array}$ & $\begin{array}{l}39.8 \% \\
(49)\end{array}$ & $\begin{array}{l}21.1 \% \\
(26)\end{array}$ \\
\hline 4. Noise Dosimeter & $\begin{array}{l}23.0 \% \\
(28)\end{array}$ & $\begin{array}{l}23.0 \% \\
(28)\end{array}$ & $\begin{array}{c}36.0 \% \\
(44)\end{array}$ & $\begin{array}{l}18.0 \% \\
(22)\end{array}$ \\
\hline 5. Heat Stress Monitor (WBGT) & $\begin{array}{l}43.0 \% \\
(52)\end{array}$ & $\begin{array}{c}30.6 \% \\
(37)\end{array}$ & $\begin{array}{c}16.5 \% \\
(20)\end{array}$ & $\begin{array}{l}9.9 \% \\
(12)\end{array}$ \\
\hline
\end{tabular}


Table 22 (Continued)

Instrument usage (Q26)

Survey Question 26: Please

indicate how often you use the

following instruments in your

current/most recent safety job.

\begin{tabular}{|c|c|c|c|c|}
\hline $\begin{array}{l}\text { 6. Radiation Monitor (Non- } \\
\text { Ionizing) }\end{array}$ & $\begin{array}{l}\mathbf{5 9 . 0 \%} \% \\
(\mathbf{7 2})\end{array}$ & $\begin{array}{c}26.2 \% \\
(32)\end{array}$ & $\begin{array}{l}10.7 \% \\
(13)\end{array}$ & $\begin{array}{c}4.1 \% \\
(5)\end{array}$ \\
\hline 7. Radiation Monitor (Ionizing) & $\begin{array}{c}\text { 63.4\% } \\
(\mathbf{7 8})\end{array}$ & $\begin{array}{c}22.0 \% \\
(27)\end{array}$ & $\begin{array}{c}10.6 \% \\
(13)\end{array}$ & $\begin{array}{c}4.0 \% \\
(5)\end{array}$ \\
\hline $\begin{array}{l}\text { 8. Ventilation Monitor } \\
\text { (Anemometer) }\end{array}$ & $\begin{array}{c}45.5 \% \\
(56)\end{array}$ & $\begin{array}{c}29.3 \% \\
(36)\end{array}$ & $\begin{array}{c}15.5 \% \\
(19)\end{array}$ & $\begin{array}{l}9.7 \% \\
(12)\end{array}$ \\
\hline $\begin{array}{l}\text { 9. Active-flow IH Sampling } \\
\text { Pumps }\end{array}$ & $\begin{array}{c}43.3 \% \\
(52)\end{array}$ & $\begin{array}{c}24.2 \% \\
(29)\end{array}$ & $\begin{array}{c}20.8 \% \\
(25)\end{array}$ & $\begin{array}{c}11.7 \% \\
(14)\end{array}$ \\
\hline $\begin{array}{l}\text { 10. Setting up IH Sampling Train } \\
\text { and using calibration equipment }\end{array}$ & $\begin{array}{c}48.8 \% \\
(60)\end{array}$ & $\begin{array}{c}24.4 \% \\
(30)\end{array}$ & $\begin{array}{l}17.9 \% \\
(22)\end{array}$ & $\begin{array}{r}8.9 \% \\
(11)\end{array}$ \\
\hline 11. Passive IH Sampling Badges & $\begin{array}{c}\mathbf{5 0 . 8 \%} \\
(\mathbf{6 2})\end{array}$ & $\begin{array}{c}25.4 \% \\
(31)\end{array}$ & $\begin{array}{c}15.6 \% \\
(19)\end{array}$ & $\begin{array}{l}8.2 \% \\
(10)\end{array}$ \\
\hline $\begin{array}{l}\text { 12. 4-5 Gas Direct Reading } \\
\text { Instrument }\end{array}$ & $\begin{array}{c}38.2 \% \\
(47)\end{array}$ & $\begin{array}{c}17.9 \% \\
(22)\end{array}$ & $\begin{array}{c}22.8 \% \\
(28)\end{array}$ & $\begin{array}{c}21.1 \% \\
(26)\end{array}$ \\
\hline $\begin{array}{l}\text { 13. Ergonomic Assessment } \\
\text { Instruments and Tools }\end{array}$ & $\begin{array}{c}33.1 \% \\
(40)\end{array}$ & $\begin{array}{c}28.1 \% \\
(34)\end{array}$ & $\begin{array}{c}24.0 \% \\
(29)\end{array}$ & $\begin{array}{c}14.9 \% \\
(18)\end{array}$ \\
\hline 14. Illumination Meters & $\begin{array}{c}45.9 \% \\
(56)\end{array}$ & $\begin{array}{c}31.1 \% \\
(38)\end{array}$ & $\begin{array}{l}15.6 \% \\
(19)\end{array}$ & $\begin{array}{c}7.4 \% \\
(9)\end{array}$ \\
\hline $\begin{array}{l}\text { 15. Quantitative Respiratory Fit } \\
\text { Test Equipment }\end{array}$ & $\begin{array}{c}37.4 \% \\
(46)\end{array}$ & $\begin{array}{c}27.6 \% \\
(34)\end{array}$ & $\begin{array}{c}22.8 \% \\
(28)\end{array}$ & $\begin{array}{c}12.2 \% \\
(15)\end{array}$ \\
\hline 16. Flame Ionization Detector & $\begin{array}{c}70.5 \% \\
(86)\end{array}$ & $\begin{array}{c}18.9 \% \\
(23)\end{array}$ & $\begin{array}{l}5.7 \% \\
(7)\end{array}$ & $\begin{array}{c}4.9 \% \\
(6)\end{array}$ \\
\hline 17. Infrared Analyzer & $\begin{array}{c}66.7 \% \\
(82)\end{array}$ & $\begin{array}{c}26.8 \% \\
(33)\end{array}$ & $\begin{array}{l}4.1 \% \\
(5)\end{array}$ & $\begin{array}{c}2.4 \% \\
(3)\end{array}$ \\
\hline
\end{tabular}


Table 22 (Continued)

Instrument usage (Q26)

Survey Question 26: Please indicate how often you use the following instruments in your Never Infrequently Periodically Frequently current/most recent safety job.

\begin{tabular}{lcccc}
\hline 18. Thermal Imaging Camera & $\mathbf{6 0 . 2 \%}$ & $25.1 \%$ & $10.6 \%$ & $4.1 \%$ \\
& $\mathbf{( 7 4 )}$ & $(31)$ & $(13)$ & $(5)$ \\
& & & & \\
19. Particle/Dust Sampler (Direct & $\mathbf{5 1 . 6 \%}$ & $29.6 \%$ & $13.1 \%$ & $5.7 \%$ \\
$\begin{array}{l}\text { Reading) } \\
\text { (63) }\end{array}$ & $(36)$ & $(16)$ & $(7)$ \\
\hline
\end{tabular}

Survey question 26 asked how often 19 different instruments were used in the alumni's current or most recent safety job. Seventeen of the 19 instruments were selected by the majority of the alumni as "never" used. The two instruments selected as most used by alumni were noise monitoring equipment. When evaluating for trends across the four eras of time, the alumni input remained consistent. Figure 16 shows the results for question 26.

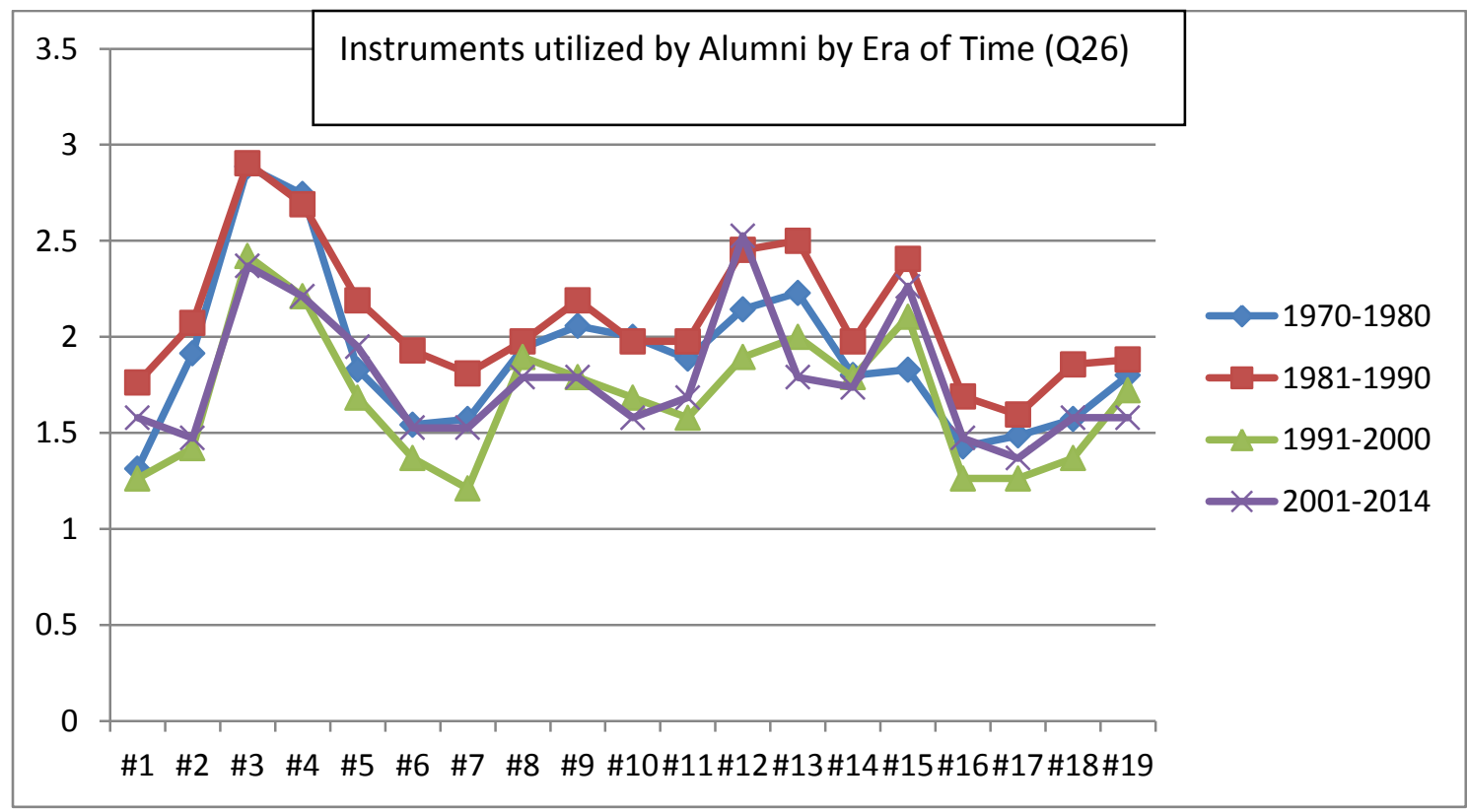

Figure 16. Instrument Usage in Alumni's current or most recent safety job (Q26). 
Table 23

Kruskal-Wallis Test - Instrument usage in Alumni's current or most recent safety job $(Q 26)$

Survey Question 26: Please indicate how often you use the following instruments in your current or your most recent safety job.

1. Photoionization Detector

or

(1)

198

2. Colorimetric Tubes - Chemical Specific

197

3. Sound Level Meter

$\begin{array}{ll}1970-1980 & 2.89 \\ 1981-1990 & 2.90 \\ 1991-2000 & 2.42 \\ 2001-2014 & 2.3\end{array}$

4. Noise Dosimeter

$\begin{array}{ll}1970-1980 & 2.74 \\ 1981-1990 & 2.69 \\ 1991-2000 & 2.2 \\ 2001-2014 & 2.2\end{array}$

1.91

$\begin{array}{ll}1981-1990 & 2.07 \\ 1991-2000 & 1.42\end{array}$

2001-2014 $\quad 1.47$

0.02

0.03

$\begin{array}{lll}1970-1980 & 1.31 & \\ 1981-1990 & 1.76 & \\ 1991-2000 & 1.26 & \\ 2001-2014 & 1.58 & 0.03\end{array}$

5. Heat Stress Monitor (WBGT)

$1970-1980 \quad 1.83$

$1981-1990 \quad 2.19$

1991-2000 $\quad 1.68$

2001-2014 $\quad 1.95$

0.25

6. Radiation Monitor (Non-Ionizing)

$1970-1980 \quad 1.54$

$1981-1990 \quad 1.93$

$1991-2000 \quad 1.37$

2001-2014 $\quad 1.53$

0.02

7. Radiation Monitor (Ionizing)

1970-1980 $\quad 1.57$

1981-1990 $\quad 1.81$

$1991-2000 \quad 1.21$

2001-2014 $\quad 1.53$

0.07

8. Ventilation Monitor (Anemometer)

$\begin{array}{lll}1970-1980 & 1.94 & \\ 1981-1990 & 1.98 & \\ 1991-2000 & 1.89 & \\ 2001-2014 & 1.79 & 0.79\end{array}$


Table 23 (Continued)

Kruskal-Wallis Test-Instrument usage (Q26)

Survey Question 26: Please indicate how

often you use the following instruments in

your current or your most recent safety job.

9. Active-flow IH Sampling Pumps

Time Period

1981-1990

1991-2000

2001-2014

1970-1980

1981-1990

1991-2000

2001-2014

$1970-1980$

$1981-1990$

$1991-2000$

2001-2014

$1970-1980$

1981-1990

$1991-2000$

2001-2014

1970-1980

1981-1990

1991-2000

2001-2014

1970-1980

1981-1990

1991-2000

2001-2014

1970-1980

1981-1990

1991-2000

2001-2014

1970-1980

1981-1990

1991-2000

2001-2014
2.00

1.98

1.68

1.58

0.51

1.89

1.98

1.58

1.68

0.28

2.14

2.45

1.89

2.53

0.41

2.23

2.50

2.00

1.79

0.07

1.80

1.98

1.79

1.74

0.63

1.83

2.40

2.11

2.26

0.10

16. Flame Ionization Detector

1.43

1.69

1.26

1.47

0.03 
Table 23 (Continued)

Kruskal-Wallis Test-Instrument usage (Q26)

Survey Question 26: Please indicate how often you use the following instruments in your current or your most recent safety job. 17. Infrared Analyzer

$\begin{array}{ccc}\text { Time Period } & \text { Mean } & \rho \\ 1970-1980 & 1.49 & \\ 1981-1990 & 1.60 & \\ 1991-2000 & 1.26 & \\ 2001-2014 & 1.37 & 0.06\end{array}$

18. Thermal Imaging Camera $1970-1980 \quad 1.57$ $1981-1990 \quad 1.86$ $1991-2000 \quad 1.37$ 2001-2014 $\quad 1.58$ 0.05

19. Particle/Dust Sampler (Direct Reading) $\quad 1970-1980 \quad 1.80$ $1981-1990 \quad 1.88$

$1991-2000 \quad 1.72$

2001-2014 $\quad 1.58$ 0.26

Survey question 26 asked alumni how often certain instruments were used in their current or most recent job in safety. Per the Kruskal-Wallis test, 12 of the 19 instruments showed no significant difference ( $\rho>.05)$ across the different eras of time. Those are shown in Table 23.

Research Question 3: How has the overall satisfaction of alumni changed as far as career preparation since the Occupational Safety Management graduate program began in 1970?

Survey question 7 asked alumni to rate their satisfaction with their preparation by the department. Satisfaction has been above average through all four time periods, with $62.7 \%$ ranking their preparation as above average or excellent. All seven of the alumni who responded with the lowest satisfaction score were prior to 1990 graduates. The mean score showed significant improvement during the last two time periods; however with the Kruskal-Wallis test, there showed no statistically significant difference among 
the time periods (Table 24). The test revealed a $\rho$ value of 0.32 between the four time periods.

Table 24

Satisfaction with Preparation By Department (Q 7)

\begin{tabular}{cccc}
\hline $\mathrm{N}$ & Time Period & $\begin{array}{c}\text { Mean } \\
\text { (by Time Period) }\end{array}$ & $\rho$ value \\
\hline 35 & $1970-1980$ & 2.91 & \\
27 & $1981-1990$ & 2.86 & \\
22 & $1991-2000$ & 2.63 & 0.32 \\
\hline
\end{tabular}

Responses to Question 7 for overall satisfaction with preparation for a career in safety were very consistent over all four time periods. The majority of alumni believe their preparation was very good. Across time periods, almost $63 \%$ of the alumni ranked their preparation by the Department of Safety Sciences as "adequately prepared" or "very well prepared" (Figure 14). This included 37 (29.4\%) who ranked their preparation as very well prepared, $42(33.3 \%)$ who ranked their preparation as adequate, $30(23.8 \%)$ who ranked their preparation as somewhat prepared while $7(5.6 \%)$ ranked it as inadequate. There is a slight dip in satisfaction during the third time period, but the results are still very good. When the data are evaluated by time period by specific skill sets, the results are similar (Figure 18). The responses are evaluated using the KruskalWallis test. It showed no significant difference across the four time periods ( $\rho$ value $=$ 0.32). The means do not show much variability over the forty-four year period. 


\section{Satisfaction with Safety Program by Eras of Time by Alumni (1970 to 2014)}

I felt very well prepared with technical knowledge.

I felt adequately prepared with technical knowledge.

I felt somewhat prepared but wished I had more technical knowledge.

I felt inadequately prepared with technical knowledge.

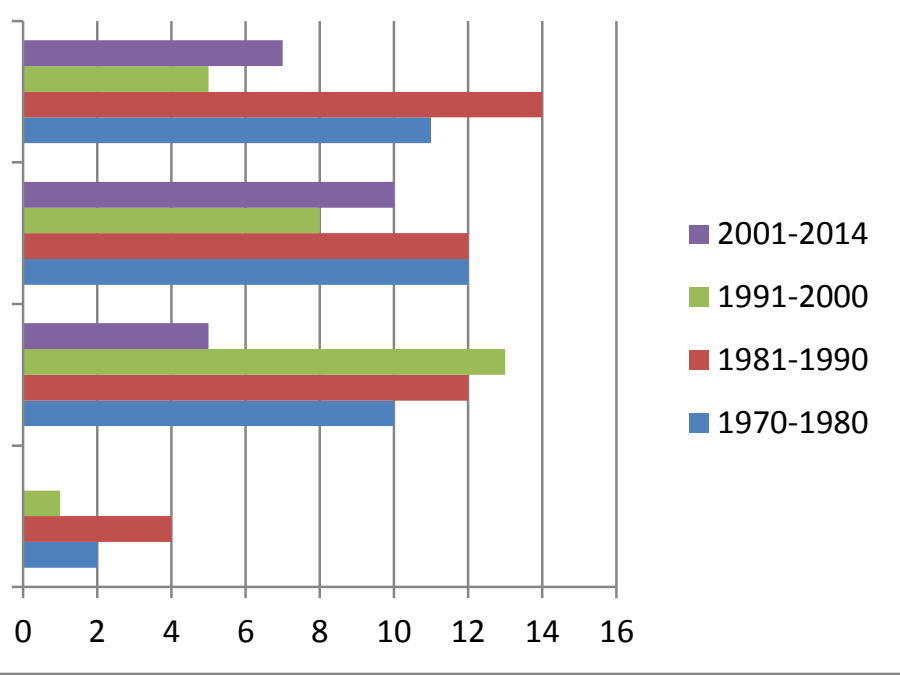

Figure 17. Satisfaction with Safety Program by Eras of Time (Q7) - Number of Alumni -1970 to 2014.

Responses to Question 22 for overall satisfaction with preparation for a career in safety based on seven skill sets were very consistent over all four time periods. The majority of alumni believe their preparation was very good. Across time periods, almost $75 \%$ of the alumni ranked their quality of education provided by the Department of Safety Sciences as above average or high (Figure 18). Out of the seven skill sets evaluated with 896 responses, 672 of those responses were above average over the forty four year time period. Only twenty four $(2.7 \%)$ responses ranked skill sets in the low category of which all of those responses preceded 1990. Table 25 reflects the data evaluated by time period, the results are similar. The responses are evaluated using the Single Factor ANOVA test. It showed no significant difference across the four time periods ( $\rho$ value $=0.17$ ). The means do not show much variability over the forty-four year period. 


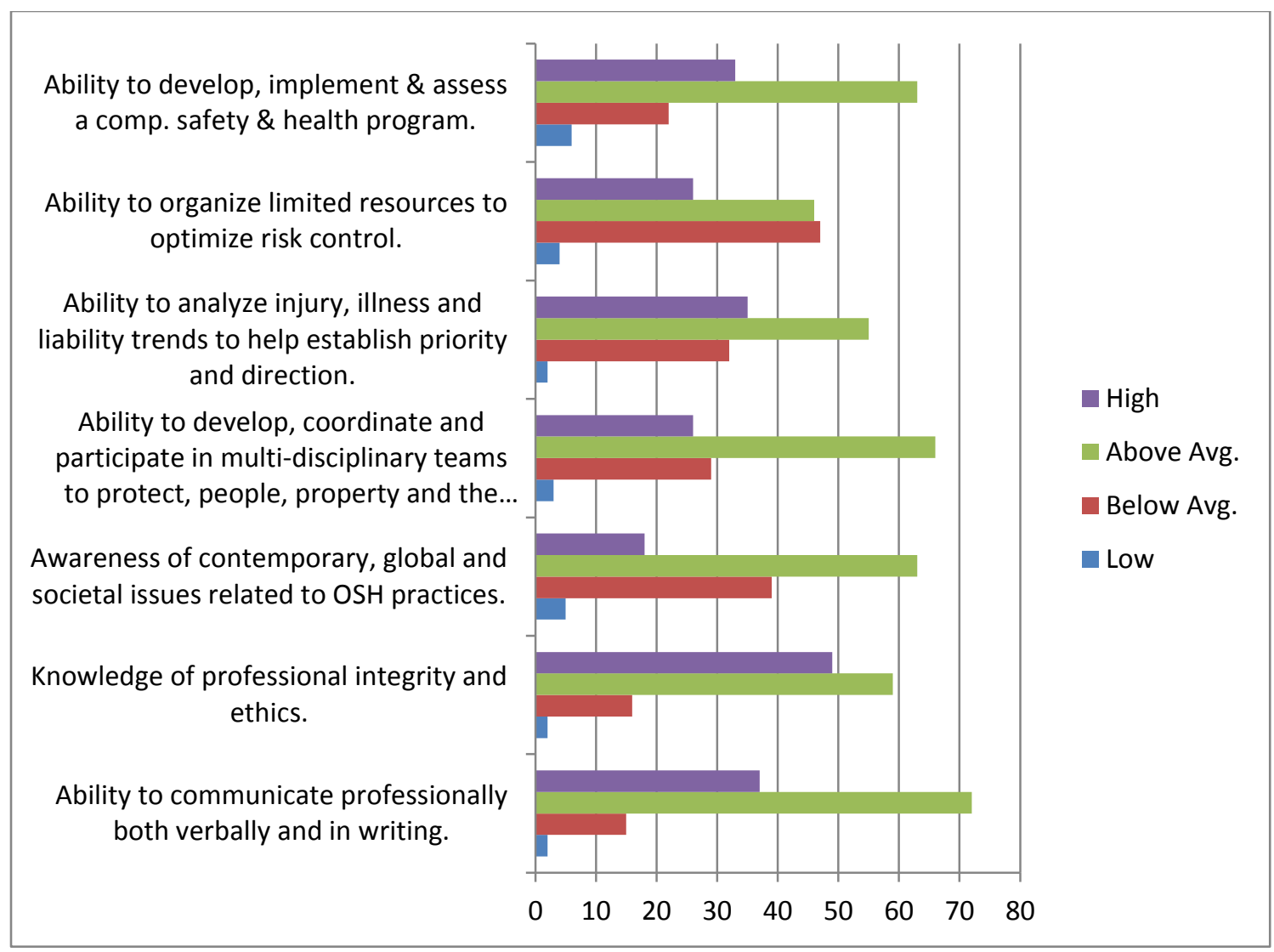

Figure 18. Overall Satisfaction with Preparation by Seven Skill Sets (Q22).

Reflected in Table 25 are the data evaluated by each of the four time periods for Question 22 for the seven skill sets, the results are similar. The responses are evaluated using the Single Factor ANOVA test. It showed no significant difference across the four time periods $(\rho$ value $=0.20)$. The means do not show much variability over the fortyfour year period. 
Table 25

ANOVA-Satisfaction with Preparation by Dept. by 7 Skill Sets by Eras of Time (Q22)

\begin{tabular}{cccc}
\hline $\mathrm{N}$ & Time Period & $\begin{array}{c}\text { Mean } \\
\text { (by Time Period) }\end{array}$ & $\rho$ value \\
\hline 35 & $1970-1980$ & 2.9163 & \\
42 & $1981-1990$ & 3.1088 & \\
27 & $1991-2000$ & 2.8148 & 0.20 \\
\hline
\end{tabular}

Table 26

Quality of education received by Alumni during their academic prog. in 19 areas (Q23)

\begin{tabular}{|c|c|c|c|c|c|}
\hline $\begin{array}{l}\text { Survey Question 23: Please } \\
\text { rate the quality of the } \\
\text { education you received from } \\
\text { Central in each of the } \\
\text { following areas during your } \\
\text { academic program. }\end{array}$ & $\begin{array}{c}\text { Not } \\
\text { Applicable }\end{array}$ & Low & $\begin{array}{l}\text { Below } \\
\text { Average }\end{array}$ & $\begin{array}{l}\text { Above } \\
\text { Average }\end{array}$ & High \\
\hline 1. Technical Knowledge & $\begin{array}{c}0.8 \% \\
(1)\end{array}$ & $\begin{array}{l}5.7 \% \\
(7)\end{array}$ & $\begin{array}{c}14.8 \% \\
(18)\end{array}$ & $\begin{array}{c}59.0 \% \\
(72)\end{array}$ & $\begin{array}{l}19.7 \% \\
(24)\end{array}$ \\
\hline 2. Biohazards & $\begin{array}{c}10.6 \% \\
(13)\end{array}$ & $\begin{array}{l}22.0 \% \\
(27)\end{array}$ & $\begin{array}{c}36.6 \% \\
(45)\end{array}$ & $\begin{array}{l}25.2 \% \\
(31)\end{array}$ & $\begin{array}{l}5.6 \% \\
(7)\end{array}$ \\
\hline 3. Engineering Controls & $\begin{array}{l}3.3 \% \\
(4)\end{array}$ & $\begin{array}{l}7.3 \% \\
(9)\end{array}$ & $\begin{array}{l}20.3 \% \\
(25)\end{array}$ & $\begin{array}{c}52.9 \% \\
(65)\end{array}$ & $\begin{array}{l}16.2 \% \\
(20)\end{array}$ \\
\hline 4. Administrative Controls & $\begin{array}{l}0.8 \% \\
(1)\end{array}$ & $\begin{array}{l}2.4 \% \\
(3)\end{array}$ & $\begin{array}{l}12.9 \% \\
(16)\end{array}$ & $\begin{array}{c}61.3 \% \\
(76)\end{array}$ & $\begin{array}{l}22.6 \% \\
(28)\end{array}$ \\
\hline $\begin{array}{l}\text { 5. Personal Protective } \\
\text { Equipment }\end{array}$ & $\begin{array}{c}2.4 \% \\
(3)\end{array}$ & $\begin{array}{l}2.4 \% \\
(3)\end{array}$ & $\begin{array}{l}15.4 \% \\
(19)\end{array}$ & $\begin{array}{c}54.8 \% \\
(68)\end{array}$ & $\begin{array}{c}25.0 \% \\
(31)\end{array}$ \\
\hline 6. Ergonomics & $\begin{array}{l}6.5 \% \\
(8)\end{array}$ & $\begin{array}{l}11.3 \% \\
(14)\end{array}$ & $\begin{array}{l}25.8 \% \\
(32)\end{array}$ & $\begin{array}{l}38.7 \% \\
(48)\end{array}$ & $\begin{array}{l}17.7 \% \\
(22)\end{array}$ \\
\hline 7. Ethics & $\begin{array}{c}3.2 \% \\
(4)\end{array}$ & $\begin{array}{l}7.3 \% \\
(9)\end{array}$ & $\begin{array}{l}23.4 \% \\
(29)\end{array}$ & $\begin{array}{c}43.6 \% \\
(54)\end{array}$ & $\begin{array}{c}22.5 \% \\
(28)\end{array}$ \\
\hline
\end{tabular}


Table 26 (Continued)

Quality of education received

Survey Question 23: Please

rate the quality of the

education you received from

Central in each of the

following areas during your

academic program.

\begin{tabular}{|c|c|c|c|c|c|}
\hline 8. Management & $\begin{array}{l}0.8 \% \\
(1)\end{array}$ & $\begin{array}{l}4.0 \% \\
(5)\end{array}$ & $\begin{array}{l}21.8 \% \\
(27)\end{array}$ & $\begin{array}{c}45.2 \% \\
(56)\end{array}$ & $\begin{array}{c}28.2 \% \\
(35)\end{array}$ \\
\hline 9. Business & $\begin{array}{l}3.3 \% \\
(4)\end{array}$ & $\begin{array}{l}19.7 \% \\
(24)\end{array}$ & $\begin{array}{c}39.3 \% \\
(48)\end{array}$ & $\begin{array}{c}25.4 \% \\
(31)\end{array}$ & $\begin{array}{c}12.3 \% \\
(15)\end{array}$ \\
\hline $\begin{array}{l}\text { 10. Monitoring and } \\
\text { Instrumentation }\end{array}$ & $\begin{array}{l}5.7 \% \\
(7)\end{array}$ & $\begin{array}{c}10.6 \% \\
(13)\end{array}$ & $\begin{array}{l}27.6 \% \\
(34)\end{array}$ & $\begin{array}{c}38.2 \% \\
(47)\end{array}$ & $\begin{array}{c}17.9 \% \\
(22)\end{array}$ \\
\hline $\begin{array}{l}\text { 11. Physical Hazards } \\
\text { (Noise/Vibration/Radiation) }\end{array}$ & $\begin{array}{l}1.6 \% \\
(2)\end{array}$ & $\begin{array}{l}4.1 \% \\
(5)\end{array}$ & $\begin{array}{l}22.1 \% \\
(27)\end{array}$ & $\begin{array}{l}51.7 \% \\
(63)\end{array}$ & $\begin{array}{c}20.5 \% \\
(25)\end{array}$ \\
\hline 12. Legislation and Standards & $\begin{array}{l}2.4 \% \\
(3)\end{array}$ & $\begin{array}{l}2.4 \% \\
(3)\end{array}$ & $\begin{array}{l}20.0 \% \\
(25)\end{array}$ & $\begin{array}{c}45.6 \% \\
(57)\end{array}$ & $\begin{array}{l}29.6 \% \\
(37)\end{array}$ \\
\hline 13. Research Methods & $\begin{array}{l}4.1 \% \\
(5)\end{array}$ & $\begin{array}{c}13.0 \% \\
(16)\end{array}$ & $\begin{array}{c}35.8 \% \\
(44)\end{array}$ & $\begin{array}{c}32.5 \% \\
(40)\end{array}$ & $\begin{array}{c}14.6 \% \\
(18)\end{array}$ \\
\hline 14. Safety Leadership & $\begin{array}{l}0.0 \% \\
(0)\end{array}$ & $\begin{array}{l}4.0 \% \\
(5)\end{array}$ & $\begin{array}{l}26.4 \% \\
(33)\end{array}$ & $\begin{array}{c}43.2 \% \\
(54)\end{array}$ & $\begin{array}{c}26.4 \% \\
(33)\end{array}$ \\
\hline 15. Industrial Hygiene & $\begin{array}{l}4.8 \% \\
(6)\end{array}$ & $\begin{array}{l}6.4 \% \\
(8)\end{array}$ & $\begin{array}{l}14.4 \% \\
(18)\end{array}$ & $\begin{array}{l}49.6 \% \\
(62)\end{array}$ & $\begin{array}{c}24.8 \% \\
(31)\end{array}$ \\
\hline $\begin{array}{l}\text { 16. Occupational Hazard } \\
\text { Management }\end{array}$ & $\begin{array}{l}2.4 \% \\
(3)\end{array}$ & $\begin{array}{l}3.3 \% \\
(4)\end{array}$ & $\begin{array}{l}13.0 \% \\
(16)\end{array}$ & $\begin{array}{l}55.3 \% \\
(68)\end{array}$ & $\begin{array}{c}26.0 \% \\
(32)\end{array}$ \\
\hline 17. Managing Fire Risk & $\begin{array}{l}4.8 \% \\
(6)\end{array}$ & $\begin{array}{l}4.8 \% \\
(6)\end{array}$ & $\begin{array}{l}19.4 \% \\
(24)\end{array}$ & $\begin{array}{c}44.4 \% \\
(55)\end{array}$ & $\begin{array}{c}26.6 \% \\
(33)\end{array}$ \\
\hline 18. System Safety & $\begin{array}{l}2.4 \% \\
(3)\end{array}$ & $\begin{array}{c}10.5 \% \\
(13)\end{array}$ & $\begin{array}{l}27.5 \% \\
(34)\end{array}$ & $\begin{array}{l}39.6 \% \\
(49)\end{array}$ & $\begin{array}{c}20.0 \% \\
(25)\end{array}$ \\
\hline $\begin{array}{l}\text { 19. Safety Program } \\
\text { Management }\end{array}$ & $\begin{array}{l}1.6 \% \\
(2)\end{array}$ & $\begin{array}{l}3.2 \% \\
(4)\end{array}$ & $\begin{array}{l}16.0 \% \\
(20)\end{array}$ & $\begin{array}{c}44.8 \% \\
(56)\end{array}$ & $\begin{array}{c}34.4 \% \\
(43)\end{array}$ \\
\hline
\end{tabular}

$\begin{array}{cccc}\begin{array}{c}\text { Not } \\ \text { Applicable }\end{array} & \text { Low } & \begin{array}{c}\text { Below } \\ \text { Average }\end{array} & \begin{array}{c}\text { Above } \\ \text { Average }\end{array}\end{array}$ 


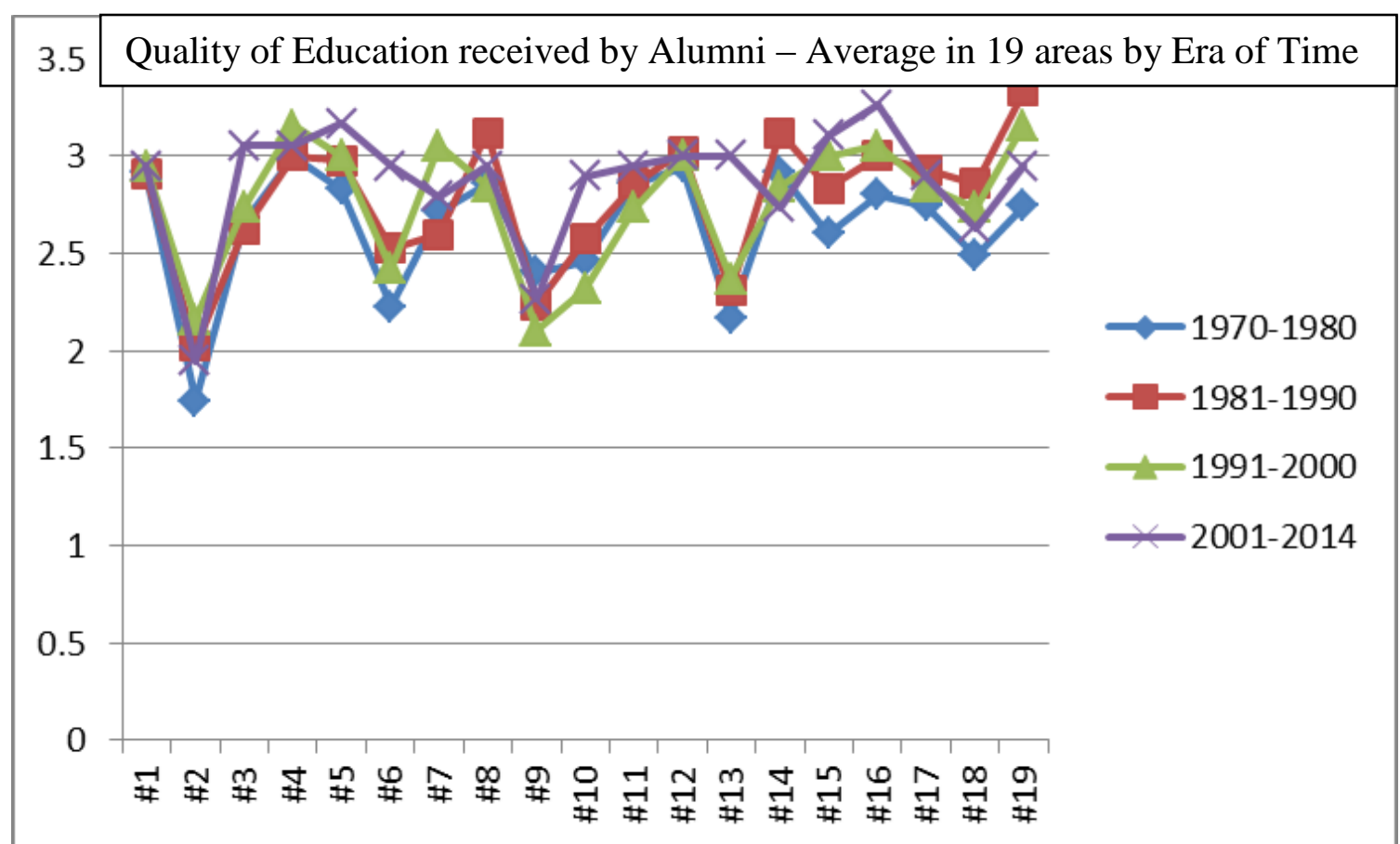

Figure 19. Quality of education received by Alumni in 19 areas (average for each era of time)-Q23.

Survey question 23 asked alumni to rate the quality of education they received from UCM/CMSU in each of 19 topic areas by the safety program. Per the KruskalWallis test, three of 19 subject areas showed a significant difference $(\rho<.05)$ across the eras of time. Those are shown in Table 27. In looking at trends, the program has maintained the quality of education across the forty-four year period. All four time periods were rated higher for at least seven of the subject areas. Possible reasons for this will be discussed in the next chapter. 
Table 27

Kruskal-Wallis Test for Quality of Education Specific Topics by Time Period (Q23)

Survey Question 23: Please rate the quality of the education you received from Central in each of the following areas during your academic program.

1. Technical Knowledge 1970-1980 2.91 $1981-1990 \quad 2.90$ $1991-2000 \quad 2.95$

2001-2014 2.95

0.93

2. Biohazards

1970-1980

1.74

1981-1990

2.02

1991-2000

2.16

2001-2014

1.95

0.66

3. Engineering Controls

$1970-1980$

4. Administrative Controls

$\begin{array}{ll}1970-1980 & 3.00 \\ 1981-1990 & 3.00 \\ 1991-2000 & 3.16 \\ 2001-2014 & 3.05\end{array}$

5. Personal Protective Equipment

1970-1980

2.83

1981-1990

2.98

1991-2000

3.00

2001-2014

3.17

0.24

6. Ergonomics

1970-1980

2.23

1981-1990

2.52

1991-2000

2.42

2001-2014

2.95

0.02 
Table 27 (Continued)

Kruskal-Wallis Test-Quality of Education

Survey Question 23: Please rate the quality of the education you received from Central in each of the following areas during your academic program.

7. Ethics

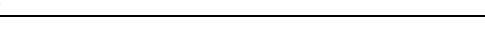

Time Period

$\begin{array}{lll}1970-1980 & 2.71 & \\ 1981-1990 & 2.60 & \\ 1991-2000 & 3.05 & \\ 2001-2014 & 2.79 & 0.69\end{array}$

$\rho$

8. Management

1970-1980 $\quad 2.86$

1981-1990 $\quad 3.12$

1991-2000 2.84

2001-2014 2.95

0.30

9. Business

$1970-1980 \quad 2.40$

$1981-1990 \quad 2.24$

$1991-2000 \quad 2.11$

2001-2014 2.26

0.39

10. Monitoring and Instrumentation

1970-1980 $\quad 2.46$

1981-1990 2.57

$1991-2000 \quad 2.32$

2001-2014 2.89

0.10

11. Physical Hazards

(Noise/Vibration/Radiation)

1970-1980 $\quad 2.86$

1981-1990 2.86

1991-2000 2.74

2001-2014 2.95

0.22

12. Legislation and Standards

1970-1980 $\quad 2.94$

$1981-1990 \quad 3.02$

1991-2000 $\quad 3.00$

2001-2014 $\quad 3.00$

0.93

13. Research Methods

$\begin{array}{lll}1970-1980 & 2.17 & \\ 1981-1990 & 2.31 & \\ 1991-2000 & 2.37 & \\ 2001-2014 & 3.00 & 0.01\end{array}$


Table 27 (Continued)

Kruskal-Wallis Test-Quality of Education

Survey Question 23: Please rate the quality of the education you received from Central in each of the following areas during your academic program.

14. Safety Leadership

15. Industrial Hygiene

$1970-1980$

1981-1990

2.60

1991-2000

3.00

2001-2014

3.11

0.17

16. Occupational Hazard Management

1970-1980 $\quad 2.80$

$1981-1990 \quad 3.00$

1991-2000 $\quad 3.05$

2001-2014

3.26

0.10

17. Managing Fire Risk

1970-1980

2.74

$1981-1990 \quad 2.93$

1991-2000 2.84

2001-2014

2.89

0.32

18. System Safety

1970-1980

2.49

$1981-1990 \quad 2.86$

$1991-2000 \quad 2.74$

2001-2014 2.63

0.29

19. Safety Program Management

1970-1980

2.74

1981-1990

3.33

1991-2000

3.16

2001-2014

2.95

0.03

The last survey question (\#27) asked for any other comments the respondent would like to share about the UCM Safety program. Seventy-five individuals added comments. Several alumni provided multiple comments. Most of the comments were positive about the program making a difference in their career success. There were a few 
negative comments about a need for more business related courses to cover budgeting in the program, as well as communication techniques to get management buy-in. There were a couple of suggestions about a psychology course to improve dealing with people. The emphasis on integrity and ethics was mentioned by several respondents, as well as a concern that the program is not ABET accredited. The overall program quality was mentioned by a number of the respondents as well as their pride of being a graduate of the program.

\section{Summary}

The purpose of this study was to evaluate the view of alumni from the Department of Safety Sciences' graduate safety program. Alumni were questioned concerning their views on which topics and courses should be included in the curriculum for a graduate level safety program. In addition, they were asked to identify, from a list, what skills and knowledge entry level safety professionals should possess after completion of their graduate degree. Finally, alumni were asked for their relative satisfaction for the education they received from the Department of Safety Sciences. The second part of this research included a review of historical documents pertaining to the establishment of the Department of Safety Sciences and the safety program, and key occurrences that may have impacted the safety program. Alumni opinions were collected using an online survey program. One hundred and twenty-six individuals responded to the survey. Items pursued in the review of historical documents included minutes of department meetings, internal progress reports produced by the Department of Safety Sciences or its predecessors, graduate catalogs, fact books, as well as other documents. Chapter 5 
includes a discussion of these results, limitations, implications for practice, and suggestions for future research. 


\section{CHAPTER FIVE}

\section{DISCUSSION AND CONCLUSIONS}

Program assessment is a pillar of academic programs that desire to demonstrate to their constituents the quality of their product (Brauer, 2002; Petersen, 1998). Academic program assessment began in the education field and expanded to include medicine, business, law and engineering programs. Education programs have been actively involved in program assessment for decades, while academic programs in occupational safety, health and environmental sciences (OSHE) are just now beginning to widely embrace program assessment (Greife, 2007; Patton, 1997). OSHE academic programs have lagged behind other disciplines in the area of program assessment, but that is changing (Boraiko, Zey \& Greife, 2010; Greife, 2007) as the need for validity of academic programs increase. Additional OSHE academic programs are likely to seek accreditation in the future as accreditation becomes an expected norm.

\section{Research Questions Answered}

The written comments found on the surveys were evaluated. The researcher noted patterns in the responses from the surveys as they related to the framework of the research questions. These patterns were used to provide additional substance to the quantitative statistical analyses and to guide the researcher in addressing the research questions.

Research Question One asked what courses alumni view as most important for the safety management graduate students to take as part of their curricular studies. This question was addressed by survey question 24 . Eleven of the 20 courses were selected as "high" by the biggest group of alumni. The nine areas selected as "above average" 
importance included biohazards, ergonomics, monitoring and instrumentation, physical hazards (noise/vibration/radiation), research methods, industrial hygiene, managing fire risk, system safety, and individual research. Five courses were selected as "high" importance by $60-70 \%$ of the respondents. The five topics were: engineering controls (61.8\%), ethics (65.3\%), management (62.6\%), safety leadership (64.5\%), and safety program management $(62.3 \%)$.

Research Question Two asked what skills and knowledge alumni view as critical for entry level safety professionals. This research question was addressed by survey questions number 21, 25 and 26. Survey question 21 asked how important the seven safety related skill sets are as they relate to the alumni's current or most recent job. Seven of the eight skill sets were rated as essential by the alumni. Those seven program objectives were the ability to communicate, both orally and in writing; knowledge of professional integrity and ethics; the ability to develop, coordinate, and participate in multidisciplinary teams; the ability to analyze injury, illness and liability trends to help establish priority and direction; the ability to organize limited resources to optimize risk control; the ability to develop, implement and evaluate hazard control processes for a performance safety program; and the ability to develop and assess a comprehensive safety and health program in a variety of occupational settings.

The third skill set of "awareness of contemporary, global and societal issues as they pertain to OSHE" was rated as important by the highest percentage of alumni. The first skill set being "the ability to communicate professionally both verbally and in writing" was rated as essential by $89.5 \%$ of the alumni. This was the highest percentage for the eight program objectives. When evaluated by each of the eight skill sets across 
the eras of time, descriptive statistics of skill set three of "Awareness of contemporary, global and societal issues as they relate to the practice of occupational safety and health" is rated as the lowest needed area in the practice of safety from the alumni. This same correlation was found when doing the descriptive analysis by skill set. The skill set of "The ability to communicate professionally both verbally and in writing" has remained the most essential throughout the entire tenure of the program.

Survey question 25 asked alumni to rate the importance of 20 different analytical, management, and communication skills and knowledge. Seventeen of the 20 different skills and knowledge categories listed were selected as essential by the largest group of alumni. Three of the skills were selected by more than $75 \%$ of the respondents: hazard anticipation and recognition (75.8\%), self-motivation (81.2\%) and written communication $(80.3 \%)$. The three skills and knowledge not selected by the majority of alumni as essential were operation of field testing equipment, financial planning/budgeting and research methodology. Alumni rated operation of field testing equipment as important (43.4\%) and financial planning/budgeting as important (38.8\%). Research methodology was selected as useful (36.9\%). In looking at trends for the thirteen significant skills, all four time periods were rated higher for at least one of the skill sets. Four of the 20 areas that showed consistent lower importance were: (a) operation of field testing equipment, (b) financial planning and budgeting, (c) crisis management and (d) research methodology.

Survey question 26 asked the alumni to indicate how often nineteen different instruments were used in the alumni's current or most recent safety job. Seventeen of the 19 instruments were selected by the majority of the alumni as "never" used. The two 
instruments selected as most used by alumni were noise monitoring equipment. When evaluating for trends across the four eras of time, the alumni input remained consistent. The Kruskal-Wallis statistical test reflected twelve of the 19 instruments showed no significant difference $(\rho>.05)$ across the different four eras of time.

Research Question Three asked "How has the overall satisfaction of alumni with their preparation by the Department of Safety Sciences for their career in occupational safety management changed since the program began?" This research question was addressed by survey questions number 1, 7, 22, 23 and 27. Survey question 7 asked each alumnus to rate their satisfaction with their preparation by the department. Satisfaction has been above average through all four time periods, with $62.7 \%$ ranking their preparation as above average or excellent. All seven of the alumni that responded with the lowest satisfaction score were prior to 1990 graduates. The mean score showed improvement during the last two time periods; however with the Kruskal-Wallis test of a $\rho$ value of 0.32 there showed no statistical significant difference between the four eras of time covering the forty-four year tenure of the program.

Survey question 22 asked alumni to rate the quality of their education by the department in the seven skill sets. For each of the seven skill sets, $75 \%$ of the respondents rated the quality of their education as above average or high. For six of the skill sets, $77.6 \%$ or more of the respondents rated their education as above average or high. The overall satisfaction with preparation for a career in safety based on the seven skill sets was very consistent over all four time periods. The majority of alumni believe their preparation was very good. Only twenty four $(2.7 \%)$ responses ranked skill sets in the low category of which all of those responses preceded 1990. The Single Factor 
ANOVA test showed no significant difference across the four time periods ( $\rho$ value $=$ 0.17). The means do not show much variability over the forty-four year period.

For survey question 23 , alumni were asked to rate the quality of education received in 19 subject areas by the safety program. Per the Kruskal-Wallis test, three of 19 subject areas showed a significant difference $(\rho<.05)$ across the eras of time. Those are shown in Table 27. In looking at trends, the program has maintained the quality of education across the forty-four year period. All four time periods were rated higher for at least seven of the subject areas. For 14 of the nineteen subject areas, $40 \%$ or more of the alumni rated their education as above average or high. The highest ratings were for the topics the department has concentrated on over the years.

\section{Discussion}

The graduate Occupational Safety Management program at UCM has remained viable over this forty-four year period (1970-2014) by concentrating on the practitioner skills aspect of industrial safety and safety management. Perhaps the decrease in student numbers seen in the late 1980s in the Department of Safety Sciences was occurring at other academic programs. With the future holding more universities moving to online programs to fill the need for distance learning, it is critical to continue to diligently assess the program's strengths and weaknesses to remain viable for the foreseeable future. This may prove to be a difficult task as budget constraints are likely to continue to be a challenge for OSHE academic programs. The low number of accredited occupational safety management programs should signal a concern for the Department of Safety Sciences, the College of Health, Science and Technology and UCM. Trained safety professionals are a critical need for the nation's workforce. UCM's academic units need 
to work collaboratively if the occupational safety management program is to remain viable. The history of both the Department of Safety Sciences and the occupational safety management program reveal that high student enrollment numbers can decrease within a short time period. The safety management program has averaged more than 55 graduates per year in the 1970 s, to 25 graduates per year in the 1980 s, to 31 graduates per year in the 1990 s, to 10 graduates per year in the 2000 s, and 20 graduates per year in the 2010s. Program graduates averaged 55 from 1978 through 1980 and 30.7 graduates from 1992 through 1994 (Figure 2). In both instances the average number of graduates dropped to less than 25 within five years. In the most recent example (1992-1994) the average number of graduates has remained under thirty since 1999 . Thirteen out of the last sixteen years (1999-2014) have had less than 20 graduates. Since 2004, the Department of Safety Sciences and the Occupational Safety Management program have both experienced an increase in student numbers. As of fall semester of 2014, the department had more than 100 active graduate occupational safety management students. Once again, the history of both the department and the occupational safety management program suggest that within a few years, these numbers could decrease dramatically. However; there is a strong employer demand for MS-OSM graduates (Figure 6). With the reputation of the program, long history and strong alumni base with the availability of program online, it is likely that potential students will select one of the few remaining strong programs in the country.

Being able to talk the business language to be a good practitioner is often mentioned as important for graduate occupational safety management programs. In this study, there were a notable number of comments about increasing curriculum content to 
include more information on this topic from the alumni. Research methods were ranked as low by $6.5 \%$, useful by $25.0 \%$, above average by $42.7 \%$ and high by $25.8 \%$. Research methodology was ranked as not necessary by $9.8 \%$, useful by $36.9 \%$, important by $33.6 \%$ and essential by $19.7 \%$. Individual research was also ranked low by the majority of alumni. These results suggest that more focus should be on business savvy and research should be covered in the curriculum but not be the focus on the occupational safety management program.

These results suggest the Department of Safety Sciences should continue emphasizing the practitioner skills of occupational safety and health. The five areas that were identified by alumni as being of highest importance included engineering controls, ethics, management, safety leadership and safety program management. Administrative controls, personal protective equipment, business, legislation and standards, occupational hazard management as well as the internship were also considered of high importance. As the researcher and being a safety professional in the field for 31 years, it is evident that these areas would be of paramount importance. The department has been focusing on practitioner skills over the first 44 years of the existence of the occupational safety management graduate program. This is consistent with previous studies on what occupational safety professionals view as critical for entry level (MS) occupational safety professional positions (Warburton, 2014). Considering the results of this research and the results obtained in previous studies there are no dramatic changes to be recommended for the Department of Safety Sciences. Even though there was very low usage reported of any instruments by alumni on the survey, the researcher knows from industrial experience and the global economy in our workplaces that graduates need to have 
knowledge of more instruments than just noise monitoring devices. Presently the program coordinator requires students without a work history to take Safe 4140 Safety and Health Laboratory or complete an occupational hazard assessment in their workplace involving monitoring as a project for their graduate degree. However; the financial constraints currently being experienced by UCM and thus the Department of Safety Sciences, may result in increased workloads for the faculty. In a few instances, students who should have taken the laboratory course were identified and the laboratory or project added to their program of study. There may well have been some students who were inadvertently allowed to complete the MS-OSM program without taking the laboratory course, even though they should have taken it. Making the laboratory course required would help reduce the potential for this to happen.

A second possibility exists that external review organizations may question a practitioner program designating the laboratory course as an elective. Making the course a required course would enhance the documentation of the department's commitment to practitioner's skills. Once again, these results highlight the importance of practitioner skills for graduates of a graduate occupational safety management program. The Department of Safety Science has focused on practitioner skills since the early years of the program. That focus has been enhanced in the last decade by incorporating more presentations, writing assignments and teamwork into courses. This focus on practitioner skills is consistent with what the department alumni believe, as indicated by the results of this research. The high rating given to communication skills, especially writing skills, is noteworthy. The increased emphasis placed on communication skills in the late 1990s was appropriate per these results. This information is critical for the department in 
providing feedback to internal and external review organizations. There are many potential measures of success for academic programs. This researcher believes one of the most meaningful measures of success is the success of program alumni. For an OSHE program, producing graduates who are able to, and do, obtain initial employment and then remain in the discipline 30 or more years as an indication that the program has provided quality education to the graduates they have produced.

According to the results for the first two research questions, practitioner skills are where the Department should be concentrating their efforts. This suggests the department should continue to focus on activities that enhance the practical nature of the occupational safety management curriculum. Internships, laboratory "hands-on" experience with projects in the field as well as hazard assessments are among the activities that help enhance the practitioner side of occupational safety management. The high percentage of respondents who have 10 or more years of experience in occupational safety management adds credibility to this issue. Over $80 \%$ of the alumni who responded to survey question seven had over ten years of experience in the OSHE field. Few safety professionals stay with one company for their entire careers. Therefore, OSHE professionals must have the skills and knowledge that other companies desire if they are to successfully move from one organization to another as the need or desire arises.

One aspect of the survey results suggests a future potential problem for the Department of Safety Sciences. The recent increase in student numbers experienced by the Department of Safety Sciences is encouraging. The occupational safety management program is once again experiencing the high number of students present in the late 1970s or early 1990s. The downside to this expansion is the workload on department faculty. 
Currently, students give multiple presentations and write papers and article critiques in most of their required courses. The workload on faculty to grade the increased amount of student work could become unmanageable. To add to this concern, the significant increase in credit hours generated by the Department of Safety Sciences over the last five years has occurred while the number of department faculty has decreased. In addition, the research component added to the curriculum in 2005 requires more faculty time than before the research hours were required. The change to allow for Individual Research rather than a Thesis has helped to reduce the load. The Department of Safety Sciences and the College of Health, Science and Technology should carefully evaluate this. If increases in faculty positions are not possible for the department, it may be necessary to limit the number of students the department accepts in the occupational safety management program and the other three academic programs in the department. All students in the Department do multiple assignments in classes, not just the occupational safety management students. This brings up the question of what is the appropriate number of students for the occupational safety management program. UCM administrators might desire to see student numbers increase to levels equal to those in the late 1970s. However, for the faculty such an occurrence could have drastic consequences. The most important issue is to stay focused on a quality product that is provided to all students who are the customers of the occupational safety management program at UCM.

When looking at the quality of training for the four eras of time of the 44 year tenure of the program in certain subjects, some significant differences were found. For survey question 23, three of 19 subject areas showed a significant difference $(\rho<.05)$ 
across the eras of time on the Kruskal-Wallis test (Table 27). In looking at trends, the program has maintained the quality of education across the forty-four year period. All four time periods were rated higher for at least seven of the subject areas. Business was the only course rated higher during the first (1970-1980) period. Management, legislation and standards, safety leadership, managing fire risk, system safety and safety program management were rated higher during the second (1981-1990) period.

Biohazards, administrative controls and ethics were rated higher during the third (19912000) period. Technical knowledge received the same rating for both the third (19912000) and fourth (2001-2014) period. Engineering controls, personal protective equipment, ergonomics, monitoring and instrumentation, physical hazards (noise/vibration/radiation), research methods, industrial hygiene, and occupational hazard management were rated higher during the fourth (2001-2014) period. It is difficult to explain most of the other categories for which a significant difference was found by time period. The difference could have been the result of different faculty in the different time periods. Four of the faculty taught courses in the Department for 30 years or more. It is interesting to evaluate how alumni satisfaction changed over the four time periods. However, the most impressive aspect of that survey question is that alumni satisfaction has remained steady and consistent over all four time periods. For the Department of Safety Sciences this suggests that the original program was developed very well and that subsequent changes to the curriculum occurred at appropriate times. This is excellent news for the Department of Safety Sciences. These results mean that alumni were generally pleased with the quality of education they received from the Department of Safety Sciences over four decades. An academic department should strive 
for satisfied alumni, but until those alumni are surveyed the issue of their satisfaction remains in question. This does not mean that the Department of Safety Sciences should remain static. On the contrary, the Department must continue to evolve and reinvent itself if it is to prosper in the next 44 years. Of note is the willingness of the Department to respond to changing times. The changes to curriculum both in total number of hours and in the specific courses required are key components to the alumni satisfaction. For example, required background for acceptance into the MS-Occupational Safety Management program resulted in recruiting safety students with better foundations in writing skills, business or industrial management, behavioral science, algebra, statistics, and two courses of science of which one had a laboratory.

Alumni ratings showed no significant difference among the four eras of time for twelve of the 19 instruments (Table 23) on survey question 26 that asked alumni how often certain instruments were used in their current or most recent job in safety. The seven instruments showing a significant difference across the four eras of time were the Photoionization Detector, Colorimetric Tubes-Chemical Specific, Sound Level Meter, Noise Dosimeter, Radiation Monitor (Non-Ionizing), Flame Ionization Detector and Thermal Imaging Camera. Noise dosimeter and Setting up IH Sampling Train and using Calibration Equipment were rated highest during the first time period. The largest group of the survey respondents were 1981-1990 (N=42). Sixteen of the 19 instruments were rated highest by this group based on the population size. The 4 or 5 gas direct reading instrument was rated highest by the last era of time (2001-2014). Some of these results can be explained by curriculum changes. The safety and health laboratory course (Safe 4140) was first offered as an elective course, during the summer of 1978. The laboratory 
in 1996 was inadequate in the quality of sampling equipment available. In 1998, Mr. Ferguson was hired to focus on improvements to the laboratory. The department was able to add newer equipment and increase the percentage of equipment with current calibrations.

Other useful information obtained via this research project included the average annual salaries of alumni, how alumni accomplish their occupational safety needs, the number of other OSHE professionals with whom alumni work, the certifications alumni have obtained, the industry segment in which alumni work, and the OSHE responsibilities alumni have in their current or most recent job. Survey question 16 inquired about the alumni's annual income (Figure 9). Alumni salaries ranged from below $\$ 30,999$ to over $\$ 151,000$. One hundred and eleven $(88.1 \%)$ alumni were earning over $\$ 51,000$ per year and 57 (45.2\%) were earning over $\$ 101,000$ per year. Slightly over $17 \%$ reported making over $\$ 151,000$ per year. Such salaries are impressive for potential recruits, and should help with recruiting efforts. Most students probably do not go into the safety profession to make money, but the high salaries may cause more students to consider this field of study. Most of the alumni making the higher income had been out of school the longest. Nine of the 35 alumni making between $\$ 101,000$ and $\$ 150,999$ per year graduated in the first time period (1970-1980). Nine of the 22 alumni making over $\$ 151,000$ per year graduated in the first time period as well. Five respondents did not disclose this salary information.

Two survey questions asked about certifications held by the alumni. Survey question number 9 asked what certifications they possessed. Forty five alumni (35.7\%) reported having the CSP (certified safety professional), $12(9.5 \%)$ reported having the 
ARM (Associate Risk Manager) and 8 alumni (6.4\%) indicated they had obtained the Certified Hazardous Materials Manager (CHMM) certification. Fifty-eight (46.0\%) indicated they had never been certified (Table 14). Three alumni (2.4\%) reported having one of the following: Certified Safety and Health Technician (CHST), Certified Industrial Hygienist (CIH) or Occupational Health and Safety Technician (OHST). Other certifications obtained by alumni included the Graduate Safety Professional (GSP), Professional Engineer (PE), Certified Risk Manager (CRM), Certified Professional Environmental Auditor (CPEA) and Certified Environmental Trainer (CET).

Survey question number 9 asked those alumni who were not certified why they had not obtained certification. Various reasons were chosen by alumni with no specific reason outweighing the other possibilities. "I never viewed certification as important" was selected by 19 (32.8\%) alumni. "The company did not support certification" was selected by $14(24.1 \%)$ alumni am not eligible" and "I am eligible to sit for the exam but I have not taken the exam" was selected by $13(22.4 \%)$ alumni. The remaining 12 (20.7\%) alumni had dropped their certification due to job changes, military duty that inhibited ability to pursue it or unable to obtain a passing score when took the test.

Survey question 20 asked how alumni approach resolving and handling occupational safety issues in their current or most recent safety position. Over $83 \%$ of the alumni reported either conducting all assessments/work themselves or directing others in specific work assignments. Approximately $10 \%$ of the respondents indicated they hired consultants or experts to do their assessments while approximately $3 \%$ of the respondents indicated they used a mix of the various options (Figure 13). 
A few UCM safety alumni work individually. Survey question number 17 asked alumni how many other OSHE professionals were in their workplace. Only fifteen (11.9\%) alumni indicated they worked individually. Thirty-nine (31.0\%) alumni reported working with one to four additional OSHE professionals. Forty-five (35.4\%) alumni reported working with between five and twenty-four other OSHE professionals and 27 (21.4\%) alumni reported working with over 25 additional OSHE professionals.

Several survey questions (questions 12, 13, 14 and 15) inquired about job duties of the alumni. When evaluated as a group, it was apparent that most alumni spend considerable portions of the job working in occupational safety management professional tasks. Survey question number 12 asked in what business sector the alumni worked. Twenty-three (18.3\%) alumni worked in government, seventeen $(13.5 \%)$ in loss control/insurance, fifteen $(11.9 \%)$ work in construction, fourteen $(11.1 \%)$ work in general industry and eight (6.4\%) work in consulting. Twenty-three alumni reported working in other business sectors with 26 reported as retired.

Survey question 14 was similar, asking what primary area of practice alumni worked during their career. The results are shown in Figure 8. Fifty-two (41.3\%) alumni indicated that general industry safety was their primary area of practice. Nineteen (15.1\%) alumni indicated construction, followed closely by seventeen (13.5\%) in loss control/insurance. Six (4.8\%) alumni indicated they worked primarily in regulatory compliance agencies.

Responses for questions 12 and 14 were very consistent for both the most recent job (business sector) and for their career. General industry safety has been one of the top business sectors the alumni were working as well as was the primary job responsibility 
for most alumni’s career. Construction, loss control/insurance and government (regulatory compliance) were also the top business sectors which carried over to the top areas of alumni's primary job responsibilities during their career.

Survey question 15 asked what percentage of time alumni spent doing OSHE activities. Ninety two (73\%) of alumni reported spending over $51 \%$ of their work time on OSHE activities. Sixty-five (51.6\%) alumni reported spending over $90 \%$ of their work time on these activities. Of the alumni reporting that they were working less than $25 \%$ of their work time on OSHE activities, the majority of those worked for governmental agencies.

\section{Review of Historical Documents}

The review of historical documents provided a wealth of information about the development of the School of Public Services, the Department of Safety Sciences (originally called the Department of Industrial Safety and Industrial Hygiene), and finally the occupational safety management program. Since 1970, when the School of Public Services was established, a series of reorganizations resulted in the Department of Safety Sciences being housed in at least three different colleges or schools. Technological advancements over the same time period transformed record keeping from primarily paper copies of forms to a combination of paper and electronic data. Over the years the records were moved, downsized, and sometimes discarded. During the last 44 years, department records for over 3,500 alumni have been housed in various academic units. As a result there are some inaccuracies in the databases that are available. The list of safety alumni gathered by this researcher from the alumni office on campus originally contained 1,375 names. During the review of historical documents the original list was 
compared to other lists of alumni. UCM has recently developed an online grouping of unofficial transcripts. In some instances the registrar's office was contacted for information on specific individuals. These resources enabled this researcher to determine that some names in the database were not actually graduate safety alumni. Some individuals had earned an undergraduate degree (approximately 400) but not a graduate degree. The course numbers had been mixed up in the computer system. Checking the various sources at UCM resulted in the elimination of 406 names from the original data base, leaving 969 names on the revised list of alumni. Names were removed from the list due to individuals having earned an undergraduate degree or being deceased. The reasons for errors in the database of names include the department not maintaining a complete list of MS-Safety alumni, and the reorganizations that occurred over a 44 year time period, the loss of some files over the years. Also, the technological changes that occurred in record keeping such that originally only paper files were maintained by the Department to the current time, and when online databases contain alumni information. This left 969 alumni who earned a graduate degree in safety. The 969 MS alumni are those who were included in this research.

Also of interest to the Department of Safety Science; the College of Health, Science and Technology; and UCM administrators is the number of personnel changes in the Department Chair position (Table 1) during the forty-four year tenure of the program. The chair position changed twelve times between nine different personnel. One Chair remained in the position for eight years, which was the longest period of stability. The last Chair has remained in the position for six years. Trustfully, no more rapid change in 
the lead departmental position will occur which suggests a lack of stability that could have a negative impact on the department.

Perhaps the most significant change during the 44 year history of the Department of Safety Sciences occurred in 1984, when the predecessor of the Department of Safety Sciences (the Department of Industrial Safety and Industrial Hygiene) was merged with the Department of Safety to form the Department of Safety Sciences. Several faculty members from the Safety Department with backgrounds in Drivers Training Safety were joined with the faculty from Industrial Safety and Industrial Hygiene. Noted, there was considerable animosity among some faculty that lasted into the current decade. One issue that has plagued the Department over the years is the rise and subsequent decline in student numbers. This increase and following decrease was dramatic for both the safety program and the entire department (Figure 1 and 2). UCM has also experienced a rise and fall in student numbers, but on a more moderate scale. While a definite explanation for this is well beyond the scope of this research, certain facts have been brought to light. This researcher believes the numerous increases and decreases in student numbers is a multi-factorial problem. A combination of the loss of the general studies safety course, rapid fluctuations in the position of Department Chair, as well as the merging of two separate departments and the apparent animosity that existed among the faculty for years afterwards likely affected the Department. All of these experiences likely negatively impacted the student numbers.

The general studies safety course that was disapproved in 1994 and then reapproved in 2005 probably played an indirect role in the student numbers in the occupational safety management program. The initial offering of Safe 2010 during 
Spring Semester of 2006 had an enrollment of 20 students. Almost 1,200 students have taken the course since 2011. Such a dramatic increase in student numbers hints at the potential impact this course had on department recruiting. This helps increase the awareness of the department among students currently enrolled at UCM, as well as their family and friends. Before the department can increase student numbers, those students must be aware of the academic programs the department offers. The low number of first semester freshmen who come to UCM as safety majors, combined with the number of students who switch to safety from some other major after they arrive on campus, suggest that students switch to safety after becoming aware of the existence of the Department of Safety Sciences.

Increasing the visibility of the Department of Safety Sciences to more students is directly related to increasing student numbers in the department. The fact that over 53\% of the MS-Safety alumni had previously earned a BS degree at UCM demonstrates the potential impact of increasing the awareness of the Department, on the occupational safety management program. This possibility is supported by the popularity of the Department of Safety Sciences General Studies course (Safe 2010). The number of sections offered has risen dramatically since the course was re-approved in 2005, with 13 sections offered in 2011-2012, 12 sections in 2012-2013, 10 sections in 2013-2014 and four sections are being offered during the fall of 2014. The increased awareness about the department and its academic programs could increase the number of students in the Safety program. The increased student numbers in the undergraduate programs provide a larger pool from which occupational safety management students could emerge. Several issues support this possibility. 
In fact, the majority (509) of these alumni earned a undergraduate degree from UCM before working on their graduate OSM degree. The number could be higher, as it was not feasible for the researcher to view every transcript for the MS-OSM alumni. The records reflect that very few freshmen (less than 15 per year) have come to UCM as Safety majors. Some Safety majors have been recruited through the open panel forums of "undecided" majors during their first semester, but most of the students find out about the Department of Safety Sciences and its academic programs after they arrive on campus from other avenues. The presence of the general studies course helps inform undergraduates of the availability of safety as a profession. This suggests that the Department of Safety Sciences should focus most of their recruiting efforts for the Safety program on current students. Collectively, the results suggest that on-campus undergraduate students are where a significant percentage of recruits for the occupational safety management program can be found.

Another finding of significance for the department is that over $40 \%$ of alumni had learned about the Occupational Safety Management program from other UCM contacts or their friends and colleagues. This combined with the knowledge that over $52 \%$ had earned an undergraduate degree before they worked on the graduate degree has significance for the Department's efforts in the area of recruiting. This means the Department must continue to keep alumni and others informed of the department's programs.

Another item of importance concerns the number of MS-OSM alumni who obtained certification during their careers. The review of historical documents included databases and business cards collected over the years. This also allowed the researcher to 
compare certification information from the online survey and from the review of historical documents. The population of 969 MS-Safety alumni includes some who chose to leave the field of safety due to a variety of issues. Some left to pursue corporate management positions and others into leadership roles in governmental agencies. The department has been unable to remain in contact with many of these individuals who left the field of occupational safety management. The alumni represented in the online survey, probably includes a higher percentage of alumni who remained in the profession throughout their careers. It is noteworthy that so many of the alumni are still active in the safety discipline. This information does support the validity of the online survey data.

\section{Limitations}

It is desired that others will benefit from the experiences of this researcher. Issues that arose include questions that were appropriate for some time periods, but not as suitable for other time periods. The survey questions that asked what topics were most important for an MS-Safety program spanned across the eras of time when alumni were specializing in transportation safety, driver's education, loss control, fire science, public safety and industrial safety. The survey was made more generic since the majority of the tenure of the program had been on industrial safety, safety management and occupational safety management. Some of the alumni provided comments about the questions not all being applicable to their curriculum.

An alternative aspect of the researcher's familiarity with the occupational safety management program is that it may have helped provide better results for this research. The researcher having four years of experience as a faculty member as well as the faculty advisor for a number of students in the graduate program, there were advantages of being 
familiar with the Department of Safety Sciences and the occupational safety management program. This included the knowledge of where historical documents were located, familiar with personnel in the graduate office and registrar's office. The staff in the alumni office was not familiar and presented a challenge. Due to family illness in the alumni office with two personnel, four people became involved with differing perspectives and it was a difficult excursion to get the survey sent out electronically through their department. Due to email constraints through the UCM Campus Alumni office and the university, at least five academia professional graduates of the program did not receive the online survey to complete. There were no other alternatives available due to university policies and confidentiality issues, so this must be considered a monumental limitation to this research.

Records and other information were obtained from all locations. Additionally, departmental files of interim reports, five year program reviews and department faculty meeting minutes were readily available to the researcher. The access to these records within the department proved invaluable.

\section{Implications for Practice}

The primary information to be gained from this research study is that the Department of Safety Sciences has more than adequately prepared students for a career in occupational safety management over the past 44 years. Almost two-thirds of responding alumni rated the training they received from the Department of Safety Sciences as "above average" (Figure 14). In looking at trends, the program has maintained the quality of education across the forty-four year period. The Department of Safety Sciences should continue the focus on practitioner skills and knowledge, as practitioner skills have been 
found to be preferred in not only the current study, but also in other similar studies that has been reported (Brosseau, 2005, Rodgers, 2007).

Communication skills were very highly rated by alumni in several survey questions. Those activities that emphasize communication skills (writing and presentations) should continue to be among the primary activities that occupational safety management students engage. Safety leadership and ethics are rated the highest by the majority of alumni. Physical hazards (noise/vibration/radiation) and ergonomics are rated as important by the majority of alumni (Table 15). Research related courses received lower ratings, which is expected in the practitioner based degree program such as occupational safety management. The research skill and knowledge is important, and has an improved rating in the last era of time reflecting that the Individual Research option is having a positive impact over the Thesis requirement. The Department of Safety Sciences modified their curriculum in 2008 by reducing internship hours from six to three and adding a requirement of three hours of a research class (Individual Research or Thesis) to the curriculum (University of Central Missouri, 2008b). Since that change, occupational safety management students still typically work a full summer and thus receive the same amount of field experience. Now they only pay for three hours of internship, not six. These results validate the direction the Department has guided the occupational safety management program over the last 44 years. No one event stands out as more important than any other. But, the overall effect has been maintaining the quality of the program (MS-OSM graduates) even though the demands on entry level safety professionals is much higher than it was in the early to mid-1970s. 
For survey question $22,75 \%$ of the respondents rated the quality of their education as "above average" or "high". For six of the skill sets, $77.6 \%$ or more of the respondents rated their education as "above average" or "high". The overall satisfaction with preparation for a career in safety based on the seven skill sets was very consistent over all four time periods. The majority of alumni believe their preparation was very good. Only twenty four $(2.7 \%)$ responses ranked skill sets in the low category of which all of those responses preceded 1990. For question 23, sixteen of the 19 categories for skills and knowledge were rated "above average" or "high" by approximately $40 \%$ or more of the alumni. Seven of the 19 categorical areas, all of which are considered practitioner skills (technical knowledge $-59.0 \%$, engineering controls $-52.9 \%$, administrative controls $-61.3 \%$, personal protective equipment $-54.8 \%$, physical hazards (noise/vibration/radiation) $-51.7 \%$, industrial hygiene $-49.6 \%$, and occupational hazard management $-55.3 \%$ ) received $50 \%$ or greater for either "above average" or "high". This research also points out word of mouth activities have been very important and effective for recruiting purposes for the Department of Safety Sciences. A critical aspect of this issue is keeping constituents informed of departmental activities. Almost $64.3 \%$ (81 of 126) of those alumni who reported a specific avenue for information about the occupational safety management program selected a category involving talking with another individual. Friend, colleague and relative were selected by 52 alumni $(41.3 \%)$ and the College Advisor was selected by 16 alumni (12.7), the Air Force was selected by 12 alumni (9.5\%) while the General Studies course was selected by 11 respondents $(8.7 \%)$. Other sources were low, indicating that advertisements were not how most alumni learned of the program (Figure 11). Twenty-five "other" answers were given for 
this question. The other responses were evaluated still finding word of mouth was the best source of information (Figure 12). With increasing budget constraints, and a past history of cyclic increases and decreases in student numbers, careful utilization of money and time will be even more important in the future.

This research also suggests that the general studies course may have had a tremendous impact on the student numbers in the occupational safety management program. It is the researcher's belief that the impact of the general studies course at UCM has been indirect but still very dramatic. The impact is not direct but eleven respondents indicated learning of the occupational safety management program via the general studies course. The researcher believes Safe 2010 helps increase student numbers in the undergraduate programs in the department, which subsequently favorably impacts the numbers of students in the graduate programs. It is noteworthy that the original approval for a general studies course in the early 1970s and the re-approval of the general studies course in 2005 were followed within a few years by rapid expansions in the student numbers in all academic programs in the Department of Safety Sciences. In both instances the number of occupational safety management students increased along with the number of students in the other department programs. The high percentage of MS-OSM alumni who earned a BS degree at UCM before beginning their MS-OSM program supports the possibility that awareness of the academic program offered by Safety Sciences programs is a key component to student recruitment for the occupational safety management program.

This research also lays the foundation for the Department of Safety Sciences to continue assessing their academic programs using online surveys. Plans are already 
underway for similar assessments of one other academic program in the Department of Safety Sciences. University administrators are looking for validation of the quality of academic programs they offer. Such assessments are valuable for both internal and external reviews. In the current state of financial difficulties and constant reviews by internal and external constituents, such research is not only useful but vital.

\section{Suggestions for Future Research}

Many potential avenues of research are suggested by the results of this research project. Other OSHE academic departments can use the assessment instruments and the processes as a guide for similar assessments of their in-house academic programs. They will be able to improve upon the process for their own needs. There are some pronounced advantages of online surveys for OSHE academic programs. One advantage of online surveys is the relatively low financial cost for investigating critically important issues for academic programs.

Online surveys allow academic programs with severely limited research budgets to produce research studies of excellent quality. For this research, there were no direct financial costs involved. The alumni office already had their database and the researcher provided an additional 150 email addresses to them following research to add to their information to send out the survey and for their future use in fundraising for the university.

As a larger percentage of the public becomes aware of program accreditation for OSHE program, the pressure will increase for similar assessments. An additional factor in considering this research track is the limited number of previous publications that discuss these issues. The only academic program that has reported on studies such as this 
one, is with the University of Minnesota (Brosseau \& Frederickson, 2009; Brosseau, Raynor, \& Lungu, 2005). It is advisable that this research track should be explored by other academic departments and programs.

Another avenue for future assessments is the issue of rapid turnover in the Department Chair position. Assessments specifically evaluating the impact of frequent personnel changes in the department chair position on student numbers would be both interesting and valuable. Programs that offer unique degrees may be more heavily impacted by rapid turnover in the Chair position than more standard academic disciplines. For departments with atypical academic programs, having stability in the Chair position may be vital to maintaining healthy student numbers.

A third area for exploration is the best way to keep alumni and other constituents informed of department activities. Technology offers a multitude of possibilities including a departmental website, a departmental newsletter, or periodic email updates of important activities. Another area of research is the potential impact of general studies courses on student numbers in academic departments such as the Department of Safety Sciences at UCM. For highly specialized departments that are rare and in fact not found at most academic institutions, a general studies course similar to Safe 2010 could be extremely important to future and long term viability of the department. Such research could be invaluable to academic programs similar to the occupational safety management program at UCM. 


\section{Conclusion}

Occupational safety management academic programs have played a prominent role in efforts to improve working conditions for the nation's employees. If the discipline of occupational safety and health not developed, the nation would have experienced much higher rates of injuries, illnesses and diseases from the workplace. In order for occupational safety management programs to become the best that they can be, assessment by external organizations is important. Program assessment of academic programs is becoming more common as administrators and constituents look for validation of program offerings. Educational academic programs have a long history of program assessment. Academic programs in occupational safety and health are now under increasing pressure to participate in assessment activities. ABET began accrediting safety and health programs in the 1980s. Today there are still less than 30 accredited industrial hygiene programs in the United States. The UCM industrial hygiene graduate program first achieved accreditation in 1998 and has gone through one re-accreditation cycle so far. A second ABET reaccreditation process is imminent. The attainment of accreditation provides visibility and validation for the Department of Safety Sciences industrial hygiene program. It is hoped that the MS-OSM program can become ABET accredited in the future. Efforts are in progress to change the curriculum for the undergraduate program in safety with separate specialty options for safety management, occupational health and safety, as well as environmental to apply for one accreditation under ABET in the near future. It is hoped this will lead to curriculum changes in the MS-OSM program which would allow achievement of ABET accreditation. 
The Occupational Safety Management graduate program at the University of Central Missouri produced approximately 969 alumni between 1970 and 2014. This study is the first comprehensive assessment of the occupational safety management graduate program. This assessment evaluated how the satisfaction of alumni with the education they received from the Department of Safety Sciences had changed over the years, what skills and knowledge alumni viewed as important for entry level safety professionals, and what courses and topics alumni believed should be included in a graduate degree program.

The results of this research show that alumni are pleased with the quality of the training they received from the Department of Safety Sciences. Changes in the curriculum were timely, as those changes enabled the program to continue producing graduates who successfully gained employment in the discipline and for the most part remained within the OSHE field. In addition, the alumni, as a group, are overwhelmingly in favor of practitioner skills being the focus of the occupational safety management program. This research sets the ground work for the Department of Safety Sciences to assess other programs within the department. The methods used to assess the occupational safety management graduate program can be used by other researchers at other universities to assess other academic programs. 


\section{References}

ABET. (2014). History: More than 75 years of quality assurance in technical education. Retrieved from http://www.abet.org/history

ABET. (2013a). Criteria for accrediting applied science programs: Effective for reviews during the 2013-2014 accreditation cycle. ABET, Inc. Retrieved from http://www.abet.org/uploadedFiles/Accreditation/Accreditation_Step_by_Step/Ac creditation_Documents/Current/2013 - 2014/asac-criteria-2013-2014.pdf

ABET. (2013b). Accredited applied science programs. Accreditation Board of Engineering and Technology. Retrieved from http://main.abet.org/aps/Accreditedprogramsearch

Alkin, M. C. (1991). Evaluation theory development II. In M. McLaughlin \& D. Phillips (Eds.), Evaluation and education at quarter century (pp. 91-112). Chicago, IL: University of Chicago Press.

Al-Nashash, H., Khaliq, A., Qaddoumi, N., Al-Assaf, Y., Assaleh, K., Dhaouadi, R. et al. (2009). Improving electrical engineering education at the American University of Sharjah, Sharjah, UAE. European Journal of Engineering Education, 34(1), 13-28.

American Board of Industrial Hygiene. (2007). Industrial hygiene ethics. Retrieved from http://www.abih.org/ethics

American Board of Industrial Hygiene. (2013). Industrial hygiene certification (ABIH Brochure). Retrieved from http://www.abih.org/general/brochure

American Conference of Governmental Industrial Hygienists. (2013). History of ACGIH. Retrieved from http://www.acgih.org/about/history

American Conference of Governmental Industrial Hygienists®. (2001). 2014 TLVs® and BEIs®: Based on the documentation of the Threshold Limit Values and Biological Exposure Indices for Chemical Substances and physical agents \& biological exposure indices (7th ed.). Cincinnati, OH: ACGIH.

American Industrial Hygiene Association. (2013). What is AIHA? Retrieved from http://www.aiha.org/aboutaiha/Pages/default.aspx

American Society of Safety Engineers. (2014). Homepage retrieved from http://www.asse.org/about

Archibald, R. B., \& Feldman, D. H. (2008). Explaining increases in higher education costs. The Journal of Higher Education, 79(3), 268-295. 
Babbie, E.R. (1990). Survey research methods (2nd ed.). Independence, KY: Wadsworth.

Baron, S. L., \& Brown, T. M. (2009). Lead poisoning in the United States. American Journal of Public Health, 99(53), 547-549.

Best, J. W. (1959). Research in Education. Englewood Cliffs, New Jersey: Prentice Hall.

Board of Certified Safety Professionals (BCSP). (2014). Certified safety professional Certification (BCSP Brochure). Retrieved from http://www.bcsp.org/certifications

Board of Certified Safety Professionals (BCSP). (2014). What is BCSP? Retrieved from http://www.bcsp.org/about_BCSP

Boraiko, C., Zey, J.N., \& Greife, A.L. (2010). Academic Program Assessment - A value-added activity for Industrial Hygiene and Safety Programs? Professional Safety. 55(8), 35-40.

Borg, W. R., \& Gall, M. D. (1989). Educational research: An introduction (5th ed.). New York: Longman.

BLS-United States Bureau of Labor Statistics. (April 2014). Retrieved from http://www.bls.gov/iif/oshwc/cfoi/cfoi_revised12.pdf

Brauer, R. L. (2002). Standards of conduct. In R. Lack (Ed.) Safety, health and asset protection: Management essentials ( $2^{\text {nd }}$ ed.). Boca Raton: Lewis Publishers.

Breakwell, G. M., Hammond, S., \& Fife-Schaw, C. (2000). Research methods in psychology (2nd ed.). Thousand Oaks, CA: Sage Publications.

Brosseau, L. M., \& Frederickson, M. (2009). Assessing outcomes of industrial hygiene graduate education. Journal of Occupational and Environmental Hygiene, 6, 257266.

Brosseau, L. M., Raynor, P. C., \& Lungu, C. (2005). Employers' expectations of knowledge and skills of master's-trained industrial hygienists. Journal of Occupational and Environmental Hygiene, 55(2), 1-7.

Bryson, N. (2011). Grass-roots appeal-employers frequently declare their people to be their most valued asset, yet a huge proportion fail in their legal duty to consult their workforce on health and safety matters. The Safety \& Health Practitioner, 29(7), 42-44. 
Bureau of Labor Statistics (BLS). (2014). Homepage - 2012 Injury Statistics. Retrieved from http://www.bls.gov

Caffarella, R. S. (2002). Planning programs for adult learners - a practical guide for educators, trainers, and staff developers (2nd ed.). San Francisco, CA: JosseyBass.

Campbell, D. T. (1969). Reforms as Experiments. American Psychologist, 24 (April), 409-429.

Canfield, R. (2007). Very small amounts of lead can affect IQ. UPI NewsTrack. Retrieved from http://search.proquest.com/docview/467623227?accountid=6143

Centers for Disease Control. (CDC). (2014). Homepage retrieved from http://www.cdc.gov/DataStatistics

Centers for Disease Control and Prevention. (2013). About CDC organization. Retrieved from http://www.cdc.gov/about/organization/cio.html

Central Missouri State University. (1975- 2006). 1975 - 2006 Graduate Catalog. Occupational Safety Management program, 50-87.

Cervero, R. M. (1988). Book Reviews. Donald A. Schon, Educating the reflective practitioner - toward a new design for teaching and learning in the professions. San Francisco: Jossey-Bass. Adult Education Quarterly, 38(3), 182-186.

Christie, C. A. (2003). What guides evaluation? A study of how evaluation practice maps onto evaluation theory. In C. A. Christie (Ed.), The practice-theory relationship in evaluation. New directions for evaluation, 97, 7-35. San Francisco, CA: Jossey-Bass.

Christie, C. A., \& Alkin, M. C. (2003). The user-oriented evaluator's role in formulating a program theory: Using a theory-driven approach. American Journal of Evaluation 2003, 24, 373-385.

Columbia Southern University. (2014). M. S. Occupational Safety and Health. Retrieved from http://www.columbiasouthern.edu/Degree/Safety/MS-OSH.

Creswell, J. W. (2009). Research design, qualitative, quantitative, and mixed methods approaches (3rd ed.). Thousand Oaks, CA: Sage Publications, Inc.

Cronbach, L. J. (1980). Toward reform of program evaluation. San Francisco, CA: Jossey-Bass Publishers.

Cronbach, L. J. (1982). Designing evaluations of educational and social programs. San Francisco, CA: Jossey-Bass Publishers. 
DiNardi, S. R. (2007). The occupational environment: Its evaluation and control. Fairfax, VA: American Industrial Hygiene Association.

Drennan, F. S., \& Richey, D. (2012). Skills-based leadership. Professional Safety, 57(2), 59-63.

Dunlap, E. S. (2011). Safety leadership. Professional Safety, 56(9), 42-49.

Field, A. (2009). Discovering statistics using SPSS (3rd ed.). Thousand Oaks, CA: Sage Publications, Inc.

Fink, A. (2009). How to conduct surveys: a step-by-step guide (4th ed.). Thousand Oaks, CA: Sage Publications, Inc.

Finney, P., Snell, S. Jr., \& Sebby, R. (1989). Assessment of academic personal, and career development of alumni from Southeast Missouri State University. Teaching of Psychology, 16(4), 173-177.

Fitzroy, H. (2003). Just a number-a personal account of grief. Osborne Park, WA: Optima Press.

Fraenkel, J. R., Wallen, N. E., \& Hyun, H. (2011). How to design and evaluate research in education. New York, NY: McGraw-Hill.

Gay, L. (1981). Educational research. Columbus, Ohio: Charles Merrill.

Gladwell, M. (2002). The tipping point: How little things can make a big difference. Brock Education, 10/2002, 12 (1), 101.

Grasso, P. G. (2003). What makes an evaluation useful? Reflections from experience in large organizations. American Journal of Evaluation, 24(4), 507-514.

Greife, A. L. (2007). Academic program assessment: The view from university administration. Roundtable \#233. Presentation at the AIHCE, June 2007.

Grimaldi, J. V., \& Simonds, R. H. (1989). Safety Management (5th ed.). Boston, MA: Irwin Press.

Greene, J. C. (1988). Stakeholder participation and utilization in program evaluation. Evaluation Review, 12(2), 91-116.

Greer, M. E. (2001). 90 years of progress in safety. Professional Safety, 46(10), 20-25.

Grob, G. F. (2003). A truly useful bat is one found in the hands of a slugger. American Journal of Evaluation, 24(4), 499-505. 
Guskey, T. R. (2000). Evaluating professional development. Thousand Oaks, CA: Corwin Press.

Hagan, P., Montgomery, J. F., \& O’Reilly, J. T. (2009a). Accident prevention manual: Administration and programs (13th ed.). National Safety Council.

Hagan, P., Montgomery, J. F., \& O’Reilly, J. T. (2009b). Accident prevention manual: Engineering and technology (13th ed.). National Safety Council.

Harris, L., Kirsten, B., \& Walker, R. (2012). Role typology for health and safety representatives. Employee Relations, 34(5), 481-500.

Hatch, J. A. (2002). Doing qualitative research in education settings. Albany, NY: State University of New York Press.

Heppner, P. P., \& Heppner, M. J. (2004). Writing and publishing your thesis, dissertation \& research: A guide for students in the helping professions. Belmont, CA: Brooks/Cole Thomson.

Higher Learning Commission. (2014). Institutional accreditation: An overview. The Higher Learning Commission of the North Central Association of Colleges and Schools. Chicago, IL.

Hinkle, D. E., Wiersman, W., \& Jurs, S. G. (1998). Applied statistics for the behavioral sciences (4th ed.). Boston: Houghton Mifflin Company.

History Channel. (2014). Timeline of U.S. School Shootings. Retrieved from http://www.history.com

Hoyt, J. E., \& Allred, E. (2008). Educational and employment outcomes of a degree completion program. The Journal of Continuing Higher Education, 56(2), 26-33.

Indiana State University (ISU). (2014). M. S. \& M. A. Occupational Safety Management. Retrieved from http://www.indstate.edu/academics/graduate/osm

Institute of Medicine (U.S.). Committee to Assess Training Needs for Occupational Safety and Health Personnel in the United States, Committee to Assess Training Needs for Occupational Safety and Health Personnel in the United States. (2000). Safe work in the 21st century: Education and training needs for the next decade's occupational safety and health personnel. Washington, D. C.: National Academy Press.

Isaac, S., \& Michael, W. (1997). Handbook in research and evaluation (3rd ed.). San Diego: Edits. 
Keene State College. (2014). M. S. Safety and Occupational Health Applied Science. Retrieved from http://www.keene.edu/catalog/programs/detail/448/ms/safety_and_occ_health_ap plied_sciences

Keller, H. (1957). The open door. Garden City, N.Y.: Doubleday, 17.

Kerlinger, F. N., \& Lee, H. B. (2000). Foundations of behavioral research (4th ed.). New York: Harcourt College Publishers.

Kraemer, D. G. (1992). An assessment of perceptions of the internship experience of Murray State University occupational safety and health graduates. (Order No. 9230754, Southern Illinois University at Carbondale). ProQuest Dissertations and Theses, 243. Retrieved from http://search.proquest.com/docview/304015203?accountid=6143. (304015203)

Lasfer, K. (2012). The open academic model for the systems engineering graduate program at Stevens Institute of Technology. (Order No. 9781267496553, Stevens Institute of Technology). ProQuest Dissertations and Theses, 230. Retrieved from http://search.proquest.com/docview/3518382? accountid=6143. (3518382)

Life Safety Code. (2012). NFPA 101: Life Safety Code. Retrieved from http://www.nfpa.org

Long, R. (2013). What is safety? Health and Safety Risk Management. Retrieved from http://www.safetyrisk.net/what-is-safety/

Manuele, F. A. (1999). Concepts, principles and methods for safety through design. In W. C. Christensen \& F. A. Manuele (Eds.), Safety through design, 9-21. Itasca, IL: National Safety Council Press.

Markowitz, G., \& Rosner, D. (2011). From the triangle fire to the BP explosion: A short history of the century-long movement for safety and health. New Labor Forum, 20(1), 26-32.

Mathur, A., \& Pater, R. (2014). 7 Safety Leadership Mind-Sets. Professional Safety, 59(4), 22-24.

Mauerman, L. A. (2009). How to enlist the real world of occupational safety, health and environment to enhance academic preparation. Journal of SH\&E Research, 6(1), $42-46$.

Merriam, S. B. (1998). Qualitative research and case study applications in education. San Francisco: Jossey-Bass. 
Meyer, C. (2012). Revising a process of program review of ensure continuous quality improvement in a human resource major. (Order No. 1098947990, Capella University). ProQuest Dissertations and Theses, 136. Retrieved from http://search.proquest.com/docview/3540457? accountid=6143. (3540457)

Missouri Department of Higher Education. (2013). Academic Program Listing. Retrieved from http://www.dhe.mo.gov

Murray State University. (2014). M. S. Occupational Safety and Health. Retrieved from http://www.murraystate.edu/Degree/Safety/MS-OSH

Myers, M. L., Durborrow, R. M., \& Cole, H. P. (2012). Inherently safer - hierarchical hazard controls. Professional Safety, 57(7), 44-51.

National Fire Protection Association (NFPA). (2014). 2012 Fire Statistics. Retrieved from http://www.nfpa.org

National Institute of Occupational Safety and Health (NIOSH). (2014). Centers for Disease Control homepage. Retrieved from http://www.cdc.gov/niosh

National Safety Council. (2014). National safety council homepage, Injury Facts 2012. Retrieved from http://www.nsc.org/news_resources/injury_and_death_statistics/Pages/InjuryDeat hStatistics.aspx

National Institute for Occupational Safety and Health. (2010). Pocket Guide to Chemical Hazards. Cincinnati, OH.: NIOSH Pub. 2010-149.

National Institute for Occupational Safety and Health. (2014). NIOSH Homepage. Retrieved from http://www.cdc.gov/niosh/about.html

National Institute for Occupational Safety and Health. (2013). Prevention through design: Green, safe and health jobs. Retrieved from http://www.cdc.gov/niosh/topics/PtD/greenjobs

Northern Illinois University (NIU). (2012). Academic programs - assessment information packet. NIU: Office of Assessment Services.

Northouse, P. G. (2010). Leadership, theory and practice (5th ed.). Thousand Oaks, CA: Sage Publications, Inc.

Oakland University. (2014). M. S. Safety Management. Retrieved from http://www.oakland.edu/shs/osh

Occupational Safety and Health Administration. (2014). Occupational safety and health administration homepage. Retrieved from http://www.osha.gov 
Occupational Safety and Health Administration. (2013). All about OSHA.

Retrieved from http://www.osha.gov

Occupational Safety and Health Administration. (2013). Occupational safety and health administration homepage. Retrieved from http://www.osha.gov

Palmer, L. R. (1926). History of the safety movement. Annals of the American Academy of Political and Social Science, 123, 9-19.

Patterson, N. E. W. (1974). A history of the Missouri safety center and the school of public service. Central Missouri State University. Warrensburg, MO. Thesis.

Patton, M. Q. (1997). Utilization-focused evaluation: The new century text. Thousand Oaks, CA: Sage Publications, Inc., 18.

Patton, M. Q. (2008). Utilization-focused evaluation (4th ed.). Los Angeles, CA: Sage Publications, Inc., 59-95.

Petersen, G.D. (1998). A bold new change agent. In. How do you measure success? Designing effective processes for assessing engineering education. Washington. American Society for Engineering Education.

Quinlan, P. J., \& Plog, B. A. (2012). Fundamentals of industrial hygiene (6th ed.). Itasca, Ill: National Safety Council.

Roddis, P. (2012). Let's face the music. The Safety \& Health Practitioner, 10/2012, 30(10), 36-38.

Rodgers, E. (2007). Using graduate student research to assess academic programs. Presentation in Roundtable 233. American Industrial Hygiene Conference \& Exposition. Philadelphia, PA. June 2007.

Roosevelt, T., \& O'Toole, P. (2012). In the words of Theodore Roosevelt: Quotations from the man in the arena. Ithaca: Cornell University Press.

Rossi, P. H., Lipsey, M. W., \& Freeman, H. E. (2004). Evaluation-a systematic approach (7th ed.). Thousand Oaks, CA: Sage Publications, Inc.

Rothwell, W. J., \& Cookson, P. S. (1997). Beyond instruction: Comprehensive program planning for business and education. San Francisco, CA: Jossey-Bass.

Schon, D. A. (1983). Educating the reflective practitioner-Toward a new design for teaching and learning in the professions. San Francisco, CA: Jossey-Bass.

Scriven, M. (1991). Evaluation thesaurus (4th ed.). Newbury Park, CA: Sage. 
Silverstein, M. (2008). Getting home safe and sound: Occupational safety and health administration at 38. American Journal of Public Health, 98(3), 416-423.

Sinclair, U. (1946). The jungle: With the author's 1946 introduction. Cambridge, Mass: R. Bentley.

Smitha, M. W. (1998). Bottomline improvement for business, enhanced safety for employees. Professional Safety, 43(11), 28-33.

Sork, T. (2000). Planning educational programs. In A. Wilson and E. Hayes (Eds.), Handbook of adult and continuing education. San Francisco, CA: Jossey-Bass.

Soule, R. D. (1993). Perceptions of an occupational safety curriculum by graduates, their employers and their faculty. (Order No. 9333108, University of Pittsburgh). ProQuest Dissertations and Theses, 148. Retrieved from http://search.proquest.com/docview/304097198?accountid=6143. (304097198)

Stalnaker, C. K. (2006). Hawk's nest tunnel - a forgotten tragedy in safety's history. Professional Safety, 51(10), 27-33.

Statistical Package for Social Sciences (Version 24) [IBM SPSS Statistics for Windows]. Released 2014. Armonk, NY: IBM Corp.

Stout, N. A. (2008). The public health approach to occupational injury research: From surveillance to prevention. Safety Science, 46, 230-233.

Thomas, J. (2001). Where are we going? - An educator's perspective. In R. Lack (Ed.) Safety, Health and Asset Protection: Management Essentials. (2nd ed., 805-810). Boca Raton, FL: Lewis Publishers.

Travis, M. (2002). Workplace safety-health and safety is an integral part of the occupational health remit. This feature explores the role of the safety representative in the workplace. Occupational Health, 54(8), 24-25.

Tulane University. (2014). M.P.H. Occupational Health and Safety Management. Retrieved from http://www.tulane.edu/publichealth/caeph/dl/ohsm

Twain, M. (1957). The complete short stories of Mark Twain now collected for the first time. Garden City, N.Y: Hanover House, 492.

United States (U.S.) Bureau of Labor Statistics, U.S. Department of Labor. (2014). Census of fatal occupational injuries charts, 1992-2012 (revised data). Retrieved from http://www.bls.gov/iff/oshwc/cfoi

United States Department of Labor. (2013). All About OSHA. OSHA 3302 06N. 2006. Retrieved from https://www.osha.gov/Publications/all_about_OSHA.pdf 
University of Alabama - Birmingham. (2014). Advanced Safety Engineering and Management. Retrieved from http://www.uab.edu/engineering/asem

University of Central Missouri (UCM). (2014). UCM Home Page, Safety Science Page. Retrieved from http://www.ucmo.edu/safety

University of Central Missouri. (2007). 2007 Graduate Catalog. Occupational Safety Management program, 72-73.

University of Central Missouri. (2008). 2008 Graduate Catalog. Occupational Safety Management program, 73.

University of Central Missouri. (2008b). 2008 Graduate Catalog. Industrial Hygiene Program, 74-75.

University of Central Missouri. (2009). 2009 Graduate Catalog. Occupational Safety Management program, 74.

University of Central Missouri. (2010). 2010 Graduate Catalog. Occupational Safety Management program, 74.

University of Central Missouri. (2011a). 2011 Graduate Catalog. Occupational Safety Management program, 52.

University of Central Missouri. (2011). Fact Book 2011. Retrieved from http://www.ucmo.edu/factbook.

University of Central Missouri. (2012). 2012 Graduate Catalog. Occupational Safety Management program, 53-54.

University of Central Missouri. (2013). 2013 Graduate Catalog. Occupational Safety Management program, 58.

Van Dalen, D. B. (1973). Understanding educational research. (3rd ed.). New York: McGraw-Hill.

Vassar, M., Wheeler, D., Davison, M., \& Franklin, J. (2010). Program evaluation in medical education: an overview of the utilization-focused approach. Journal of Educational Evaluation for Health Professions, 7(1), 101-103.

Wachter, J. K. (2011). Ethics: The absurd yet preferred approach to safety management. Professional Safety, 56(6), 50-57.

Walter, L. (2011). New ANSI/ASSE standard focuses on prevention through design. EHS Today. Retrieved from http://ehstoday.com/standards/nonsensus/PreventionThrough-Design-Standard 
Warburton, N. (2014). Beyond health and safety expectations. The Safety and Health Practitioner, 32(3), 31-34.

Wilson, A. L., \& Hayes, E. R. (Eds.).(2000). Handbook of adult and continuing education. San Francisco, CA: Jossey-Bass.

Zanko, M., \& Dawson, P. (2012). Occupational health and safety management in organizations: A review. International Journal of Management Reviews, 14(3), 328-344. doi:10.1111/j.1468-2370.2011.00319

Zey, J. (2010). Program assessment: Industrial hygiene and safety science (Doctoral dissertation). University of Missouri, Columbia, MO. 


\section{APPENDIX A}

June 5, 2014

Dear Valued Occupational Safety Management Alumni:

I am conducting a study of our valuable graduates via a survey to obtain information concerning the effectiveness of our Occupational Safety Management program here at the University of Central Missouri. I am a doctoral student and chose this study to identify opportunities within our program to improve our curriculum and course requirements. The ultimate goal is for continuous improvement by striving to be the best program in the country. Our student numbers continue to increase and as a faculty member in the department, my passion is to assure we are providing the best education needed to prepare each of our graduates for the challenging work environments they are entering during these difficult economic times.

Please take approximately $10-15$ minutes of your valuable time to complete this survey to provide information to ultimately improve the Occupational Safety Management program here at UCM. We desire for our graduates to hit the ground running in their work environments and want to make sure we are providing what is needed to prepare them for this challenge.

Your participation in this survey as an alum is irreplaceable and will be greatly appreciated.

Respectfully submitted,

Tammy J. Allen

Assistant Professor, Environ., Physical \& Applied Sciences University of Central Missouri 


\section{APPENDIX B \\ ALLENTJ-QUANTITATIVE-ALUMNIS \\ INFORMED CONSENT FORM}

Identification of Researchers: This research project is being done by Tammy J. Allen, a doctoral student, supervised by Dr. Sandy Hutchinson and a doctoral committee with the Cooperative Doctorate Program at the University of Central Missouri.

Purpose of the Study: The purpose of this study will be to evaluate the M.S.

Occupational Safety Management program in the School of Environmental, Physical and Applied Sciences.

Request for Participation: We are inviting you as an alumni of the M. S. Occupational Safety Management program of the school to participate in the study of the degree program. It is up to you whether you would like to participate. If you decide not to participate, you will not be penalized in any way. You can also decide to stop at any time without penalty. If you do not wish to answer any of the questions, you may simply skip them. You may withdraw your data at the end of the study.

Exclusions: You must be at least 18 years of age to participate in this study.

Description of Research Method: This study involves possibility of participating in a Google forms electronic survey. During the electronic survey, questions will be asked about what is important in the degree program, your personal insights, how the program has benefited you, and other historical information to potentially be used to improve the curriculum and program for future students. The survey will take about 15 minutes to complete.

Privacy: All of the information to be collected will be confidential and stored in a secure location. No personally identifying information will be revealed within the report.

Explanation of Risks: The risks associated with participating in this study are similar to the risks of everyday life. There will be no compensation or incentives for participation.

Explanation of Benefits: You will benefit from participating in this study by gaining firsthand experience as a participant in educational research.

Questions: If you have any questions about this study, please contact Dr. Sandy Hutchinson. She can be reached at (660) 543-4720. If you have any questions about your rights as a research participant, please contact the University of Missouri - Columbia Human Subjects Protection Program (Campus IRB) at (573) 882-9585.

If you would like to participate, please sign a copy of this letter and return it. The other copy is for you to keep.

I have read this letter and agree to participate. 


\section{APPENDIX C \\ Online Survey Questionnaire \\ Safety Alumni \\ (WILL BE ADMINISTERED VIA EMAIL WITH LINK TO GOOGLE FORM)}

1. What year did you graduate from the safety program?

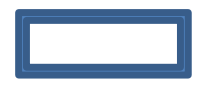

2. What is your age?
○ 22-30
○ $31-40$
○ $41-50$
○ 51-60
- 61 or over

3. Did you obtain your undergraduate degree from Central?
- Yes, in a Safety discipline
- Yes, in other than a Safety discipline; what degree program?
○ No

4. If you completed your undergraduate degree in a Safety discipline from Central, what year did you graduate?

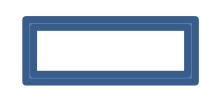

- Not Applicable

5. What percentage of your coursework for your graduate degree was done:
O Online: (WILL BE PULL DOWN BOXES TO PICK \%)
○ Hybrid:
○ Face-to-Face (Live):
o ITV: 
6. How long after graduation did it take for you to get a job in the safety and health profession?

- Not Applicable - Already working in the profession

- 0-3 months

○ 4-6 months

o 7-9 months

- 10 months -1 year

- Greater than 1 year

7. When you graduated, which best describes your level of preparedness to enter the safety and health field?

- I felt inadequately prepared.

- I felt somewhat prepared but wished I had more knowledge.

- I felt adequately prepared.

- I felt very well prepared with technical knowledge to address issues in the field.

8. How many years of professional experience in safety do/did you have?
○ 0 -5 years
○ 6-10 years
○ 11-15 years
○ 16-20 years
○ 21-25 years
○ 26-30 years
○ 31 or more

9. Which of the following certifications do you possess (please check all that apply)?
- CSP
○ $\mathrm{ClH}$
- CHMM
○ QEP
○ ARM
○ REM or Equivalent
- Other (please list the certifications):
- None of the above 
10. If you do not currently possess one of the certifications listed in the previous question, please indicate the reason. Please check all that apply.

- Company did not support certifications.

- Took the test to become certified, but did not obtain the required passing score.

- Was certified but I dropped it when my job duties changed.

- I never viewed certification as worth the time and money involved.

- I am eligible to sit for the exam but I have not taken the exam yet.

- I am currently certified.

O Other:

11. Regarding the Occupational, Safety and Health field, are you currently ?

- Employed full time

- Employed part time

- Not employed in an Occupational, Safety and Health field

- Fully retired

12. Which of the following best describes the business sector in which you currently work?
- General industry
- Construction
○ Government
- Loss control/Insurance
○ Consulting
- Academia
- Retired
- None of the above
o Other:

13. How large is the company or site you are working for at this time (If retired, your last employer)?

- 0-50 employees

- 51-100 employees

- $101-250$ employees

- 251-500 employees

○ $501-750$ employees

- 751- 1000 employees

- Greater than 1000 employees 
14. During your occupational safety management professional career, which of the following has been your primary area of practice?

- General industry safety

- Construction safety

- Mining safety

- Process safety

- Loss control/Insurance

- Industrial hygiene

- Environmental

- Ergonomics

- Academia

- Research

- Regulatory Compliance Agencies

- None of the Above

o Other:

15. In your current or most recent position, what percentage of time do/did you perform safety related functions (i.e. audits, investigations, safety training, etc.)?

- Less than $25 \%$

○ $26-50 \%$

○ $51-75 \%$

○ $76-90 \%$

○ Over $90 \%$

16. What is your approximate current annual salary?
○ Less than $\$ 30,999$
○ $\$ 31,000$ to $\$ 40,999$
○ $\$ 41,000$ to $\$ 50,999$
○ $\$ 51,000$ to $\$ 60,999$
- $\$ 61,000$ to $\$ 70,999$
- $\$ 71,000$ to $\$ 80,999$
- $\$ 81,000$ to $\$ 90,999$
- $\$ 91,000$ to $\$ 100,999$
- $\$ 101,000$ to $\$ 110,999$
- $\$ 111,000$ to $\$ 120,999$
○ $\$ 121,000$ to $\$ 130,999$
- $\$ 131,000$ to $\$ 140,999$
- $\$ 141,000$ to $\$ 150,999$
○ $\$ 151,000+$

17. In your current or most recent safety position, how many other safety and health professionals do or did you work with?
- None
○ $1-4$ 

○ $5-8$
○ $9-12$
○ $13-16$
○ $17-20$
○ $21-24$
○ $25+$

18. In your current or most recent safety position, how many other safety and health professionals do or did you supervise?
○ None
○ $1-4$
○ $5-8$
○ $9-12$
○ $12+$

19. How did you hear about the safety program at Central? Please check all that apply.
- Friend/relative
- College advisor or high school advisor
- Central/UCM/CMSU general studies course
- Central/UCM/CMSU website
- Radio/newspaper advertisement
- Conference exhibition hall
o Other, please specify:

20. Which of the following is/was the most common approach in resolving and handling your occupational safety issues in your current or most recent safety position?

- Conduct all assessments/work myself

- Direct others in specific work assignments

- Hire consultants

- Utilize state or federal OSHA consultants

- Utilize loss control consultants from our insurance company

O Other resources (please specify): 
21. How important are the following skill sets as they relate to your current or most recent safety related job (select one category for each skill)?

\begin{tabular}{|l|c|c|c|c|}
\hline \multicolumn{1}{|c|}{ Skill } & $\begin{array}{c}\text { Not } \\
\text { Necessary }\end{array}$ & Useful & Important & Essential \\
\hline $\begin{array}{l}\text { The ability to communicate } \\
\text { professionally both verbally and in } \\
\text { writing. }\end{array}$ & $\mathrm{O}$ & $\mathrm{O}$ & $\mathrm{O}$ & $\mathrm{O}$ \\
\hline $\begin{array}{l}\text { Knowledge of professional integrity } \\
\text { and ethics. }\end{array}$ & $\mathrm{O}$ & $\mathrm{O}$ & $\mathrm{O}$ & $\mathrm{O}$ \\
\hline $\begin{array}{l}\text { Awareness of contemporary, global } \\
\text { and societal issues as they relate to } \\
\text { the practice of occupational safety } \\
\text { and health. }\end{array}$ & $\mathrm{O}$ & $\mathrm{O}$ & $\mathrm{O}$ & $\mathrm{O}$ \\
\hline $\begin{array}{l}\text { The ability to develop, coordinate } \\
\text { and participate in multi-disciplinary } \\
\text { teams to protect people, property } \\
\text { and the environment. }\end{array}$ & $\mathrm{O}$ & $\mathrm{O}$ & $\mathrm{O}$ & $\mathrm{O}$ \\
\hline $\begin{array}{l}\text { The ability to analyze injury, illness } \\
\text { and liability trends to help establish } \\
\text { priority and direction. }\end{array}$ & $\mathrm{O}$ & $\mathrm{O}$ & $\mathrm{O}$ & $\mathrm{O}$ \\
\hline $\begin{array}{l}\text { The ability to organize limited } \\
\text { resources to optimize risk control. }\end{array}$ & $\mathrm{O}$ & $\mathrm{O}$ & $\mathrm{O}$ & $\mathrm{O}$ \\
\hline $\begin{array}{l}\text { The ability to develop, implement } \\
\text { and evaluate hazard control } \\
\text { processes for a performance safety } \\
\text { program. }\end{array}$ & $\mathrm{O}$ & $\mathrm{O}$ & $\mathrm{O}$ & $\mathrm{O}$ \\
\hline $\begin{array}{l}\text { Ability to develop, implement and } \\
\text { assess a comprehensive safety and } \\
\text { health program in a variety of } \\
\text { occupational settings. }\end{array}$ & $\mathrm{O}$ & $\mathrm{O}$ & $\mathrm{O}$ & $\mathrm{O}$ \\
\hline
\end{tabular}


22. Considering your graduate degree from Central, please rate the quality of your education in each of the following skill sets.

\begin{tabular}{|l|c|c|c|c|}
\hline \multicolumn{1}{|c|}{ Skill } & Low & $\begin{array}{c}\text { Below } \\
\text { Average }\end{array}$ & $\begin{array}{c}\text { Above } \\
\text { Average }\end{array}$ & High \\
\hline $\begin{array}{l}\text { The ability to communicate } \\
\text { professionally both verbally and in } \\
\text { writing. }\end{array}$ & $\mathrm{O}$ & $\mathrm{O}$ & $\mathrm{O}$ & $\mathrm{O}$ \\
\hline $\begin{array}{l}\text { Knowledge of professional } \\
\text { integrity and ethics. }\end{array}$ & $\mathrm{O}$ & $\mathrm{O}$ & $\mathrm{O}$ & $\mathrm{O}$ \\
\hline $\begin{array}{l}\text { Awareness of contemporary, } \\
\text { global and societal issues as they } \\
\text { relate to the practice of } \\
\text { occupational safety and health. }\end{array}$ & $\mathrm{O}$ & $\mathrm{O}$ & $\mathrm{O}$ & $\mathrm{O}$ \\
\hline $\begin{array}{l}\text { The ability to develop, coordinate } \\
\text { and participate in multi- } \\
\text { disciplinary teams to protect } \\
\text { people, property and the } \\
\text { environment. }\end{array}$ & $\mathrm{O}$ & $\mathrm{O}$ & $\mathrm{O}$ & $\mathrm{O}$ \\
\hline $\begin{array}{l}\text { The ability to analyze injury, } \\
\text { illness and liability trends to help } \\
\text { establish priority and direction. }\end{array}$ & $\mathrm{O}$ & $\mathrm{O}$ & $\mathrm{O}$ & $\mathrm{O}$ \\
\hline $\begin{array}{l}\text { The ability to organize limited } \\
\text { resources to optimize risk control. }\end{array}$ & $\mathrm{O}$ & $\mathrm{O}$ & $\mathrm{O}$ & $\mathrm{O}$ \\
\hline $\begin{array}{l}\text { Ability to develop, implement and } \\
\text { assess a comprehensive safety and } \\
\text { health program in a variety of } \\
\text { occupational settings. }\end{array}$ & $\mathrm{O}$ & $\mathrm{O}$ & $\mathrm{O}$ & $\mathrm{O}$ \\
\hline
\end{tabular}


23. Please rate the quality of the education you received from Central in each of the following areas during your academic program.

\begin{tabular}{|c|c|c|c|c|c|}
\hline Area of Study & $\begin{array}{c}\text { Not } \\
\text { Applicable }\end{array}$ & Low & $\begin{array}{c}\text { Below } \\
\text { Average }\end{array}$ & $\begin{array}{c}\text { Above } \\
\text { Average }\end{array}$ & High \\
\hline Technical Knowledge & $\mathrm{O}$ & $\mathrm{O}$ & $\mathrm{O}$ & $\mathrm{O}$ & $\mathrm{O}$ \\
\hline Biohazards & $\mathrm{O}$ & $\mathrm{O}$ & $\mathrm{O}$ & $\mathrm{O}$ & $\mathrm{O}$ \\
\hline Engineering Controls & $\mathrm{O}$ & $\mathrm{O}$ & $\mathrm{O}$ & $\mathrm{O}$ & $\mathrm{O}$ \\
\hline Administrative Controls & $\mathrm{O}$ & $\mathrm{O}$ & $\mathrm{O}$ & $\mathrm{O}$ & $\mathrm{O}$ \\
\hline $\begin{array}{l}\text { Personal Protective } \\
\text { Equipment }\end{array}$ & $\mathrm{O}$ & $\mathrm{O}$ & $\mathrm{O}$ & $\mathrm{O}$ & $\mathrm{O}$ \\
\hline Ergonomics & $\mathrm{O}$ & $\mathrm{O}$ & $\mathrm{O}$ & $\mathrm{O}$ & $\mathrm{O}$ \\
\hline Ethics & $\mathrm{O}$ & $\mathrm{O}$ & $\mathrm{O}$ & $\mathrm{O}$ & $\mathrm{O}$ \\
\hline Management & $\mathrm{O}$ & $\mathrm{O}$ & $\mathrm{O}$ & $\mathrm{O}$ & $\mathrm{O}$ \\
\hline Business & $\mathrm{O}$ & $\mathrm{O}$ & $\mathrm{O}$ & $\mathrm{O}$ & $\mathrm{O}$ \\
\hline $\begin{array}{l}\text { Monitoring and } \\
\text { Instrumentation }\end{array}$ & $\mathrm{O}$ & $\mathrm{O}$ & $\mathrm{O}$ & $\mathrm{O}$ & $\mathrm{O}$ \\
\hline $\begin{array}{l}\text { Physical Hazards } \\
\text { (Noise/Vibration/Radiation) }\end{array}$ & $\mathrm{O}$ & $\mathrm{O}$ & $\mathrm{O}$ & $\mathrm{O}$ & $\mathrm{O}$ \\
\hline Legislation and Standards & $\mathrm{O}$ & $\mathrm{O}$ & $\mathrm{O}$ & $\mathrm{O}$ & $\mathrm{O}$ \\
\hline Research Methods & $\mathrm{O}$ & $\mathrm{O}$ & $\mathrm{O}$ & $\mathrm{O}$ & $\mathrm{O}$ \\
\hline Safety Leadership & $\mathrm{O}$ & $\mathrm{O}$ & $\mathrm{O}$ & $\mathrm{O}$ & $\mathrm{O}$ \\
\hline Industrial Hygiene & $\mathrm{O}$ & $\mathrm{O}$ & $\mathrm{O}$ & $\mathrm{O}$ & $\mathrm{O}$ \\
\hline $\begin{array}{l}\text { Occupational Hazard } \\
\text { Management }\end{array}$ & $\mathrm{O}$ & $\mathrm{O}$ & $\mathrm{O}$ & $\mathrm{O}$ & $\mathrm{O}$ \\
\hline Managing Fire Risk & $\mathrm{O}$ & $\mathrm{O}$ & $\mathrm{O}$ & $\mathrm{O}$ & $\mathrm{O}$ \\
\hline System Safety & $\mathrm{O}$ & $\mathrm{O}$ & $\mathrm{O}$ & $\mathrm{O}$ & $\mathrm{O}$ \\
\hline $\begin{array}{l}\text { Safety Program } \\
\text { Management }\end{array}$ & $\mathrm{O}$ & $\mathrm{O}$ & $\mathrm{O}$ & $\mathrm{O}$ & $\mathrm{O}$ \\
\hline
\end{tabular}


24. How important are the following courses and subjects for safety students to take during their program?

\begin{tabular}{|l|c|c|c|c|c|}
\hline \multicolumn{1}{|c|}{ Area of Study } & $\begin{array}{c}\text { Not } \\
\text { Applicable }\end{array}$ & Low & $\begin{array}{c}\text { Below } \\
\text { Average }\end{array}$ & $\begin{array}{c}\text { Above } \\
\text { Average }\end{array}$ & High \\
\hline Biohazards & $\mathrm{O}$ & $\mathrm{O}$ & $\mathrm{O}$ & $\mathrm{O}$ & $\mathrm{O}$ \\
\hline Engineering Controls & $\mathrm{O}$ & $\mathrm{O}$ & $\mathrm{O}$ & $\mathrm{O}$ & $\mathrm{O}$ \\
\hline Administrative Controls & $\mathrm{O}$ & $\mathrm{O}$ & $\mathrm{O}$ & $\mathrm{O}$ & $\mathrm{O}$ \\
\hline $\begin{array}{l}\text { Personal Protective } \\
\text { Equipment }\end{array}$ & $\mathrm{O}$ & $\mathrm{O}$ & $\mathrm{O}$ & $\mathrm{O}$ & $\mathrm{O}$ \\
\hline Ergonomics & $\mathrm{O}$ & $\mathrm{O}$ & $\mathrm{O}$ & $\mathrm{O}$ & $\mathrm{O}$ \\
\hline Ethics & $\mathrm{O}$ & $\mathrm{O}$ & $\mathrm{O}$ & $\mathrm{O}$ & $\mathrm{O}$ \\
\hline Management & $\mathrm{O}$ & $\mathrm{O}$ & $\mathrm{O}$ & $\mathrm{O}$ & $\mathrm{O}$ \\
\hline Business & $\mathrm{O}$ & $\mathrm{O}$ & $\mathrm{O}$ & $\mathrm{O}$ & $\mathrm{O}$ \\
\hline Monitoring and & $\mathrm{O}$ & $\mathrm{O}$ & $\mathrm{O}$ & $\mathrm{O}$ & $\mathrm{O}$ \\
Instrumentation & & & & & \\
\hline Physical Hazards \\
(Noise/Vibration/Radiation)
\end{tabular}


25. In your current or most recent job in safety, how essential are the following analytical, management, and communication skills/knowledge?

\begin{tabular}{|l|c|c|c|c|}
\hline \multicolumn{1}{|c|}{ Skill/Knowledge } & $\begin{array}{c}\text { Not } \\
\text { Necessary }\end{array}$ & Useful & Important & Essential \\
\hline $\begin{array}{l}\text { Hazard anticipation and } \\
\text { recognition }\end{array}$ & $\mathrm{O}$ & $\mathrm{O}$ & $\mathrm{O}$ & $\mathrm{O}$ \\
\hline Data analysis & $\mathrm{O}$ & $\mathrm{O}$ & $\mathrm{O}$ & $\mathrm{O}$ \\
\hline $\begin{array}{l}\text { Exposure control (Hierarchy of } \\
\text { controls) }\end{array}$ & $\mathrm{O}$ & $\mathrm{O}$ & $\mathrm{O}$ & $\mathrm{O}$ \\
\hline $\begin{array}{l}\text { Operation of field testing } \\
\text { equipment }\end{array}$ & $\mathrm{O}$ & $\mathrm{O}$ & $\mathrm{O}$ & $\mathrm{O}$ \\
\hline Critical and analytical thinking & $\mathrm{O}$ & $\mathrm{O}$ & $\mathrm{O}$ & $\mathrm{O}$ \\
\hline Organizational skills & $\mathrm{O}$ & $\mathrm{O}$ & $\mathrm{O}$ & $\mathrm{O}$ \\
\hline Detail-oriented & $\mathrm{O}$ & $\mathrm{O}$ & $\mathrm{O}$ & $\mathrm{O}$ \\
\hline Financial planning/budgeting & $\mathrm{O}$ & $\mathrm{O}$ & $\mathrm{O}$ & $\mathrm{O}$ \\
\hline Effective team building & $\mathrm{O}$ & $\mathrm{O}$ & $\mathrm{O}$ & $\mathrm{O}$ \\
\hline Problem solving & $\mathrm{O}$ & $\mathrm{O}$ & $\mathrm{O}$ & $\mathrm{O}$ \\
\hline Objectivity & $\mathrm{O}$ & $\mathrm{O}$ & $\mathrm{O}$ & $\mathrm{O}$ \\
\hline Self-motivation & $\mathrm{O}$ & $\mathrm{O}$ & $\mathrm{O}$ & $\mathrm{O}$ \\
\hline $\begin{array}{l}\text { Ability to demonstrate value-added } \\
\text { services to your organization }\end{array}$ & $\mathrm{O}$ & $\mathrm{O}$ & $\mathrm{O}$ & $\mathrm{O}$ \\
\hline Time management & $\mathrm{O}$ & $\mathrm{O}$ & $\mathrm{O}$ & $\mathrm{O}$ \\
\hline Public speaking & $\mathrm{O}$ & $\mathrm{O}$ & $\mathrm{O}$ & $\mathrm{O}$ \\
\hline Interpersonal skills & $\mathrm{O}$ & $\mathrm{O}$ & $\mathrm{O}$ & $\mathrm{O}$ \\
\hline Risk communication & $\mathrm{O}$ & $\mathrm{O}$ & $\mathrm{O}$ \\
\hline Crisis management & $\mathrm{O}$ & $\mathrm{O}$ \\
\hline Written communication & $\mathrm{O}$ & $\mathrm{O}$ \\
\hline Research methodology & $\mathrm{O}$ & $\mathrm{O}$ & \\
\hline
\end{tabular}


26. Please indicate how often you use the following instruments in your current or your most recent safety job.

\begin{tabular}{|c|c|c|c|c|}
\hline Instrumentation & Never & Infrequently & Periodically & Frequently \\
\hline Photoionization Detector & $\mathrm{O}$ & $\mathrm{O}$ & $\mathrm{O}$ & $\mathrm{O}$ \\
\hline $\begin{array}{l}\text { Colorimetric Tubes - } \\
\text { Chemical Specific }\end{array}$ & $\mathrm{O}$ & $\mathrm{O}$ & $\mathrm{O}$ & $\mathrm{O}$ \\
\hline Sound Level Meter & $\mathrm{O}$ & $\mathrm{O}$ & $\mathrm{O}$ & $\mathrm{O}$ \\
\hline Noise Dosimeter & $\mathrm{O}$ & $\mathrm{O}$ & $\mathrm{O}$ & $\mathrm{O}$ \\
\hline $\begin{array}{l}\text { Heat Stress Monitor } \\
\text { (WBGT) }\end{array}$ & $\mathrm{O}$ & $\mathrm{O}$ & $\mathrm{O}$ & $\mathrm{O}$ \\
\hline $\begin{array}{l}\text { Radiation Monitor (Non- } \\
\text { Ionizing) }\end{array}$ & $\mathrm{O}$ & $\mathrm{O}$ & $\mathrm{O}$ & $\mathrm{O}$ \\
\hline $\begin{array}{l}\text { Radiation Monitor } \\
\text { (Ionizing) }\end{array}$ & $\mathrm{O}$ & $\mathrm{O}$ & $\mathrm{O}$ & $\mathrm{O}$ \\
\hline $\begin{array}{l}\text { Ventilation Monitor } \\
\text { (Anemometer) }\end{array}$ & $\mathrm{O}$ & $\mathrm{O}$ & $\mathrm{O}$ & $\mathrm{O}$ \\
\hline $\begin{array}{l}\text { Active-flow IH Sampling } \\
\text { Pumps }\end{array}$ & $\mathrm{O}$ & $\mathrm{O}$ & $\mathrm{O}$ & $\mathrm{O}$ \\
\hline $\begin{array}{l}\text { Setting up IH Sampling } \\
\text { Train and using calibration } \\
\text { equipment }\end{array}$ & $\mathrm{O}$ & $\mathrm{O}$ & $\mathrm{O}$ & $\mathrm{O}$ \\
\hline $\begin{array}{l}\text { Passive IH Sampling } \\
\text { Badges }\end{array}$ & $\mathrm{O}$ & $\mathrm{O}$ & $\mathrm{O}$ & $\mathrm{O}$ \\
\hline $\begin{array}{l}\text { 4-5 Gas Direct Reading } \\
\text { Instrument }\end{array}$ & $\mathrm{O}$ & $\mathrm{O}$ & $\mathrm{O}$ & $\mathrm{O}$ \\
\hline $\begin{array}{l}\text { Ergonomic Assessment } \\
\text { Instruments and Tools }\end{array}$ & $\mathrm{O}$ & $\mathrm{O}$ & $\mathrm{O}$ & $\mathrm{O}$ \\
\hline Illumination Meters & $\mathrm{O}$ & $\mathrm{O}$ & $\mathrm{O}$ & $\mathrm{O}$ \\
\hline $\begin{array}{l}\text { Quantitative Respiratory } \\
\text { Fit Test Equipment }\end{array}$ & $\mathrm{O}$ & $\mathrm{O}$ & $\mathrm{O}$ & $\mathrm{O}$ \\
\hline Flame Ionization Detector & $\mathrm{O}$ & $\mathrm{O}$ & $\mathrm{O}$ & $\mathrm{O}$ \\
\hline Infrared Analyzer & $\mathrm{O}$ & $\mathrm{O}$ & $\mathrm{O}$ & $\mathrm{O}$ \\
\hline Thermal Imaging Camera & $\mathrm{O}$ & $\mathrm{O}$ & $\mathrm{O}$ & $\mathrm{O}$ \\
\hline $\begin{array}{l}\text { Particle/Dust Sampler } \\
\text { (Direct Reading) }\end{array}$ & $\mathrm{O}$ & $\mathrm{O}$ & $\mathrm{O}$ & $\mathrm{O}$ \\
\hline
\end{tabular}


27. Please add any other comments you have about the Central safety graduate degree program below:

Thank your for your time and efforts in completing this survey. You will be able to view results of this study in the future via the UCM Safety Sciences web-page, the program's newsletter, The Safety Net, in journal articles, and through the UCM and University of Missouri Database of Dissertations through their respective libraries.

Tammy J. Allen 


\section{APPENDIX D}

\section{Campus Institutional Revi ew Board University of Missouri-Columbia}

485 McReynolds Hall Columbia, MO 65211-1150 PHONE: (573) 882-9585

FAX: (573) 884-0663

July 25, 2014

Principal Investigator: Allen, Tammy J

Department: Education

Your Application to project entitled Utilization focused program evaluation of graduate safety program at Lniversity of Central Missouri was reviewed and approved by the MU Campus Institutional Review Board according to terms and conditions described below:

\begin{tabular}{|l|l|}
\hline IRB Project Number & 1212329 \\
\hline Initial Application Approval Date & July 25, 2014 \\
\hline IRB Expiration Date & July 25, 2015 \\
\hline Level of Review & Exempt \\
\hline Project Status & Active - Open to Enrollment \\
\hline Regulation & 45 CFR 46.101b(2) \\
\hline Risk Level & Minimal Risk \\
\hline
\end{tabular}

The principal investigator (PI) is responsible for all aspects and conduct of this study. The PI must comply with the following conditions of the approval:

1. No subjects may be involved in any study procedure prior to the IRB approval date or after the expiration date.

2. All unanticipated problems, serious adverse events, and deviations must be reported to the IRB within 5 days.

3. All modifications must be IRB approved by submitting the Exempt Amendment prior to implementation unless they are intended to reduce risk.

4. All recruitment materials and methods must be approved by the IRB prior to being used.

5. The Annual Exempt Form must be submitted to the IRB for review and approval at least 30 days prior to the project expiration date.

6. Maintain all research records for a period of seven years from the project completion date.

7. Utilize the IRB stamped document informing subjects of the research and other approved research documents located within the document storage section of elRB.

If you have any questions, please contact the Campus IRB at 573-882-9585 or umcresearchcirb@missouri.edu.

Thank you,

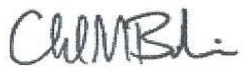

Charles Borduin, PhD

Campus IRB Chair 


\section{VITA}

Tammy J. Allen was born on September 6, 1958, in Camden, Arkansas, the daughter of Richard Daniel and Patsy Ruth Pate Savacool. She attended public schools in Harmony Grove, a rural community outside of Camden, graduating from Harmony Grove High School in 1976. She received a B.S. in Industrial Technology from Southern Illinois University (1989), an M.S. Environmental and Occupational Health (1999) from Saint Louis University. She is part of the University of Missouri-Columbia statewide cohort program trusting to complete the Ed.D. Educational Leadership and Policy Analysis (Dec. 2014). She has been employed by the University of Central Missouri, Warrensburg, Missouri, since August 2010, and is currently an Assistant Professor in the Department of Safety Sciences. She and her husband, Pat, have two sons, Andrew and Will. 